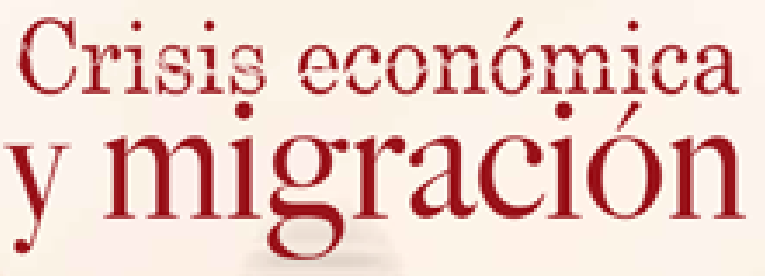
¿Impactos temporales o estructurales?

8

8
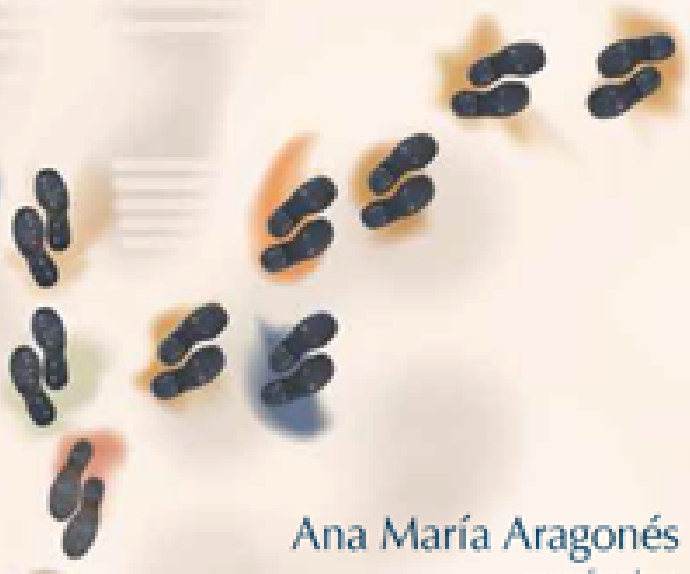

coordinadona

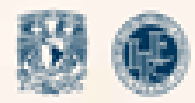




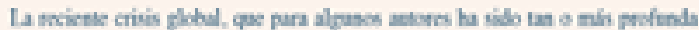

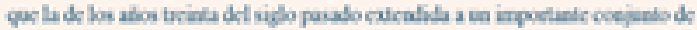

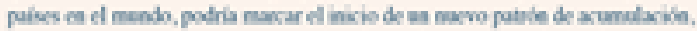

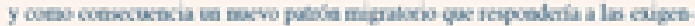

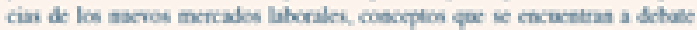

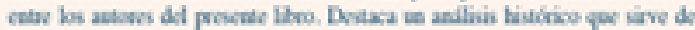

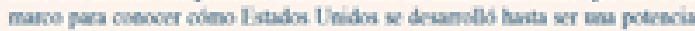

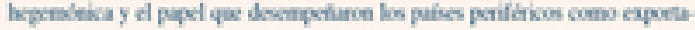

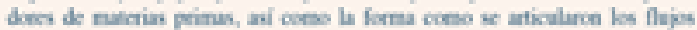

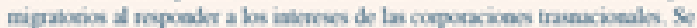

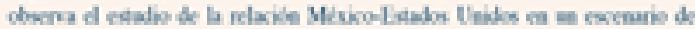

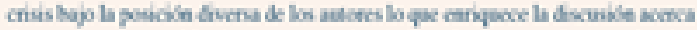

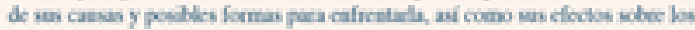

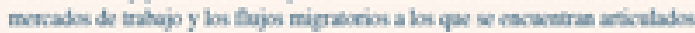

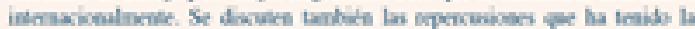

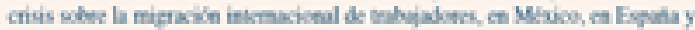

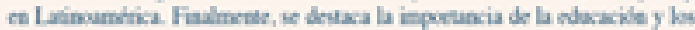

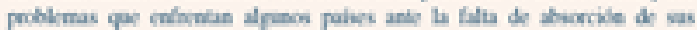

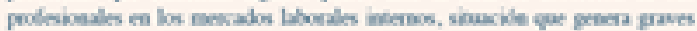

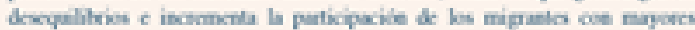

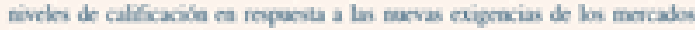
Ihorals introsainoules.

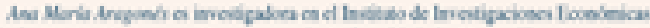

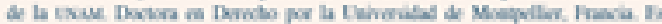

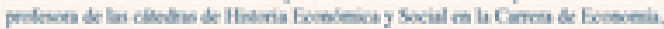

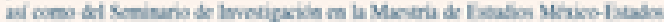

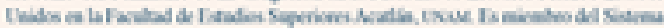

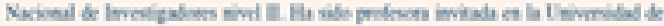

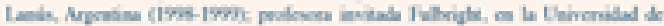

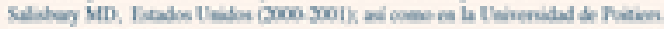

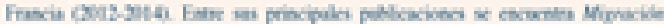

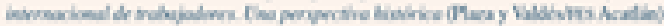

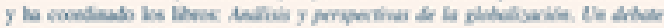

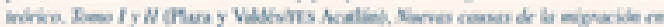

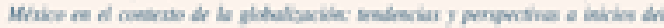

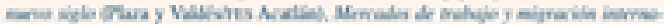

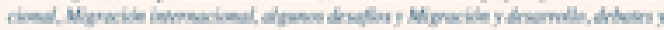

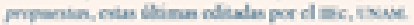


Crisis económica y migración ¿Impactos temporales o estructurales? 


\section{UNIVERSIDAD NACIONAL AUTÓNOMA DE MÉXICO}

José Narro Robles

Rector

Eduardo Bárzana García

Secretario General

Leopoldo Silva Gutiérrez

Secretario Administrativo

Estela Morales Campos

Coordinadora de Humanidades

\section{INSTITUTO DE INVESTIGACIONES ECONÓMICAS}

Verónica Villarespe Reyes

Directora

Gustavo López Pardo

Secretario Académico

Aristeo Tovías García

Secretario Técnico

Roberto Guerra M.

Jefe del Departamento de Ediciones 


\title{
Crisis económica y migración ¿Impactos temporales o estructurales?
}

\author{
Ana María Aragonés \\ (coordinadora)
}


Esta investigación, arbitrada por pares académicos, se privilegia con el aval de la institución editora.

Crisis económica y migración: ¿impactos temporales o estructurales? / coordinadora Ana María Aragonés. - Primera edición. - México: UNAM, Instituto de Investigaciones Económicas, 2014.

276 páginas, mapas; $21 \mathrm{~cm}$.

Incluye bibliografías

ISBN: 978-607-02-5194-8

1. Crisis financiera mundial, 2008-2009. 2. Trabajo migratorio - Aspectos económicos - México. 3. Trabajadores extranjeros mexicanos - Estados Unidos Condiciones sociales. 4. Trabajo migratorio - España. I. Aragonés, Ana María. I. Universidad Nacional Autónoma de México. Instituto de Investigaciones Económicas.

$331.6272073-$ scdd 21

Biblioteca Nacional de México

Primera edición, 17 de marzo de 2014

D.R. (C) Universidad Nacional Autónoma de México

Ciudad Universitaria, Coyoacán, 04510, México, D.F.

INSTITUTO DE INVESTIGACIONES ECONÓMICAS

Circuito Mario de la Cueva s/n

Ciudad de la Investigación en Humanidades

04510, México, D.F.

ISBN: 978-607-02-5194-8

Diseño de portada: Victoria Jiménez

Cuidado de la edición: Hélida De Sales Y.

Prohibida la reproducción total o parcial por cualquier medio sin la autorización escrita del titular de los derechos patrimoniales.

Impreso y hecho en México/Printed in Mexico 


\section{AgRAdeCIMIENTOS}

Agradecemos a la Dirección General del Personal Académico (DGAPA) de la Universidad Nacional Autónoma de México el apoyo prestado para el desarrollo del proyecto PAPIIT IN304010, cuyo resultado final es el libro que aquí presentamos. Agradecemos también al Instituto de Investigaciones Económicas por las facilidades prestadas para la buena realización del proyecto y a los becarios Josué Zavaleta González, Ameyali Altamirano Fernández, Uberto Salgado Nieto y a José Rafael Valencia González, cuya colaboración fue destacada. 


\section{ÍNDICE}

Introducción ................................................................ 10

\section{Capítulo 1}

Migración forzada en México y diseño económico/

geopolítico de posguerra..........................................................

John Saxe-Fernández

\section{Capítulo 2}

El derecho de quedarse

Armando Bartra

\section{Capítulo 3}

México 2013-2014. Recesión a la vista

Eduardo Loría, Emmanuel Salas, Alejandro García y Alejandro Gómez

\section{Capítulo 4}

Problemática económica de Estados Unidos

y su impacto en la economía nacional

92 Arturo Huerta González

\section{Capítulo 5}

Desempleo, precarización, crisis y migración 


\section{Capítulo 6}

¿Por qué se ha reducido la migración mexicana

hacia Estados Unidos?

Juan Luis Ordaz Diaz y Juan José Li $\mathrm{Ng}$

\section{CAPítulo 7}

Nuevos patrones migratorios en el contexto

de la crisis económica. El caso de España

Joaquín Arango

\section{Capítulo 8}

Nuevas dinámicas de los mercados laborales

y educativos de profesionales con la masificación de la cobertura y la expansión del egreso

Claudio Rama

\section{Capítulo 9}

Nuevo patrón migratorio bajo el contexto de la crisis

Ana María Aragonés y Uberto Salgado

Sobre los autores 


\section{INTRODUCCIÓN}

Debido a su profundidad y extensión la crisis de 2007-2009, iniciada en Estados Unidos y extendida en un importante conjunto de países en el mundo, puede considerarse como una crisis estructural. Asimismo, podría marcar el inicio de un nuevo patrón de acumulación y, como consecuencia, un nuevo patrón migratorio que respondería a las exigencias de los nuevos mercados laborales internacionales. Conceptos que se encuentran en debate dado que la crisis de 2007-2009 es reciente y sus tendencias aún son poco claras. Sin embargo, si hacemos un breve recorrido histórico de lo sucedido en las crisis del siglo pasado (las de 1929 y 1970) podemos observar que fueron crisis estructurales que iniciaron nuevos patrones de acumulación e surgieron diversos patrones migratorios.

La propuesta de solución de la crisis en los años treinta planteó la puesta en marcha del Estado de bienestar lo que requirió nuevos flujos migratorios que respondieran a esos nuevos mercados de trabajo. En este sentido, se puede afirmar que el patrón migratorio se conformó por flujos de trabajadores de baja calificación incorporados en diversos mercados laborales. Estos fueron: el sector agrícola y las manufacturas, que estaban en su apogeo y cuya industria más importante fue la automotriz. Los beneficios para los obreros les permitieron obtener un conjunto de bienes, entre los cuales se encontraban, por supuesto, los automóviles. Los migrantes ocuparían los puestos más bajos de la escala laboral, tanto en la agricultura como en la industria. 
Lo interesante en este periodo fue que los países industrializados de ese momento, firmaron diversos programas de trabajadores temporales debido a que los países expulsores de fuerza de trabajo vivían lo que se ha denominado sustitución de importaciones y llevaban a cabo importantes proyectos, no sólo de reforma agrícola sino de industrialización. La sustitución de importaciones fue la respuesta de los países subdesarrollados ante la escasez de productos manufacturados provenientes de los países industrializados por la participación de estos últimos en las diversas conflagraciones. Por lo tanto, ante la escasez interna de trabajadores, los países industrializados requerían de mano de obra extranjera para reconstruir sus devastadas sociedades como resultado de la Segunda Guerra Mundial. Por lo tanto, podría decirse que las necesidades laborales del nuevo patrón de acumulación originaron un nuevo patrón migratorio distinto al producido en las llamadas migraciones clásicas de final del siglo XIX y principios del xx. Lo interesante en ese momento histórico es que la firma entre gobiernos de los programas de trabajadores temporales mostró beneficios mutuos, entre los que se destaca la posibilidad de la reunificación familiar. Recordemos que el Programa Bracero firmado entre México y Estados Unidos, quebrantado en forma continua, finalmente señaló una responsabilidad por parte de ambos gobiernos para resolver los problemas. Si bien es cierto que las soluciones siempre estuvieron por debajo de los conflictos que se presentaban. La última vez que se ratificó el Programa Bracero fue en 1964 y otros países, sobre todo europeos, también cancelaron esos programas y dejaron sin efecto los beneficios otorgados a los trabajadores migrantes.

La crisis de 1970 fue de tal profundidad y extensión que, nuevamente, involucró a la mayoría de los países del mundo. Un poco más tarde también afectaría a los países del llamado socialismo real, transformando por completo las circunstancias de bipolaridad que hasta ese momento caracterizaron las condiciones en las que el mundo vivió en la segunda posguerra y que se manifestó en la tensión de la llamada guerra fría. ¿Se cambió la bipolaridad por un mundo unipolar o, más bien, se debería hablar 
de una multipolaridad? Los países iniciaron una interrelación extraordinaria, como no se había producido en ningún momento histórico anterior. Esta afirmación también tiene sus detractores, en la medida en que algunos autores plantean que esta interrelación no es nueva pues señalan su origen en los siglos XV y XVI con los descubrimientos geográficos. La realidad es que se presentó un nuevo patrón de acumulación, cuya política económica fue el neoliberalismo. Algunos de los argumentos esgrimidos era que la crisis se debía a los beneficios que gozaban los trabajadores y a los aún más grandes de los sindicatos que dieron lugar a una enorme rigidez en el mercado laboral. Era necesario transformar esas condiciones y se impuso la flexibilidad de los mercados laborales así como la desregulación. Por lo tanto, las propuestas se dirigieron contra los obreros y los sindicatos, dando inicio a una verdadera ofensiva. Se buscaría privatizar sectores como: educación, salud, transporte, etc., que hasta ese momento habían sido responsabilidad de un Estado rector de la economía, y se insistía en reducir a un Estado obeso.

A la par de este nuevo modelo de acumulación surgiría un nuevo patrón migratorio formado por flujos de trabajadores con distintos niveles de calificación. Aquellos con alta calificación fueron sumamente importantes pues se relacionaban con el desarrollo de la economía del conocimiento, proyecto del cual Estados Unidos ha sido líder hasta la siguiente crisis.

Aunque podemos caracterizar la crisis 2007-2009 como estructural, es muy reciente para conocer todos sus alcances y estrategias concretas para la superación de sus graves contradicciones. Sin embargo, nos encontramos ante el inicio de un nuevo patrón de acumulación, con nuevas exigencias para los mercados de trabajo, por lo cual vendrá articulado con un nuevo patrón migratorio.

El objetivo de este libro es abordar el fenómeno de la crisis de 2007-2009, sus posibles causas y las diversas formas en las que se articulan los flujos y patrones migratorios bajo este nuevo escenario. ¿Debemos aceptar que estamos ante un nuevo patrón de acumulación y como consecuencia se generará un nuevo patrón 
migratorio? De ser así, ¿se puede vislumbrar cuáles características tendrán ambos?

A continuación presentamos los ejes principales de los ensayos de los investigadores que participan en esta obra reunidos en cuatro secciones.

En la primera se presenta un estudio histórico sobre la forma en la que, a partir de la Segunda Guerra Mundial se marcaron las pautas de desarrollo que sirvieron a Estados Unidos para convertirse en potencia dominante, y el importante papel de los países periféricos hasta la crisis del 2007 como exportadores de materias primas estratégicas, todo ello articulado con una importante migración forzada. Esta situación ha tenido enormes consecuencias en el mundo rural, sector fundamental para cualquier país. En el caso de México se observa un importante éxodo de campesinos cuyas consecuencias serán muy graves de no tomarse las medidas necesarias para revertirlo, sin que ello suponga eliminar su libertad para decidir.

John Saxe-Fernández en el capítulo titulado "Migración forzada en México y diseño económico/geopolítico de posguerra", muestra una investigación en la que el contexto económico y geopolítico de la economía mexicana brinda una herramienta muy eficiente para comprender los fenómenos sociales de gran trascendencia en el país. Uno de los más importantes es la migración de carácter forzada. En este sentido, el desmantelamiento de la industria petroquímica y el enrolamiento del sector agrícola mexicano en una competencia desigual por medio del Tratado de Libre Comercio, elementos centrales en la compresión de la pérdida de fuentes de trabajo e ingresos de un importante sector de la población que, al verse desfavorecida, buscó en la migración un modo de sobrevivir. Es importante demostrar que al favorecer los intereses de las corporaciones privadas trasnacionales mediante las privatizaciones realizadas en las décadas pasadas, indirectamente se provocó la expulsión de una gran número de trabajadores hacia Estados Unidos, por tanto este no es el camino a seguir para el quehacer de las políticas económica y social del Estado mexicano. 
Armando Bartra por su parte presenta el capítulo "El derecho de quedarse", donde plantea que presenciamos una erosión generalizada del campo, un curso prolongado y multidimensional de deterioro; corrosión en marcha que, de no revertirse a tiempo, nos llevará a una crisis general provocada por la combinación de múltiples conflagraciones puntuales. El resultado de esto es un éxodo masivo de mexicanos que buscan en el norte un futuro del que carecen en sus lugares de origen, saldo de un modelo que nos llevó de la explotación hacia la exclusión. El autor señala que es necesario tratar de amortiguar el dolor social que causa la diáspora apoyando a los migrantes organizados que reivindican su dignidad y defienden sus derechos. También es necesario defender el derecho de no migrar. Hoy más que nunca es urgente reivindicar el derecho de los mexicanos al trabajo, exigiendo programas de fomento y defensa del empleo que garanticen la seguridad laboral del país. Entonces y solo entonces, la migración dejará de ser fatalidad y condena para devenir en un intercambio enriquecedor.

En la segunda sección se presenta el fenómeno de la crisis, su explicación y consecuencias desde perspectivas e interpretaciones distintas. El hecho de confrontar esta diversidad de posiciones enriquece la lectura y, sobre todo, el debate acerca de lo que podría hacerse para enfrentar esta crisis, lo cual abre la pauta para comprender las posibles transformaciones en los mercados de trabajo y su efecto sobre los flujos migratorios.

En el texto "México 2013-2014. Recesión a la vista", Eduardo Loría, Emmanuel Salas, Alejandro García y Alejandro Gómez afirman que mucho se ha hablado del buen papel económico que desempeñará México en el ámbito internacional durante los próximos años. Sin embargo, el diferencial de tasas de interés y el fenómeno de acarreo de capitales han provocado un gran influjo de capitales de corto plazo que aprecian sensiblemente el tipo de cambio y vulneran la estabilidad macroeconómica. A pesar de este mexican momentum, hay múltiples factores que nos permiten argumentar que México ha entrado a una fase importante de desaceleración económica que corresponde con la parte 
descendente del ciclo. De los dieciséis indicadores compuestos adelantados y coincidentes, así como de confianza publicados por el INEGI (2013) y al emplear técnicas estadísticas realizan una simulación histórica de dichas variables encontrando evidencia de que México experimenta un cambio negativo en su tendencia desde mayo de 2012, mismo que es muy probable se extienda hasta finales de 2014.

Arturo Huerta González en "Problemática económica de Estados Unidos y su impacto en la economía nacional", señala que es importante analizar el llamado abismo fiscal en Estados Unidos, mismo que determinará el acontecer económico en la economía mundial, ya que el sector privado depende del desempeño de las finanzas públicas y del sector externo. Si el sector externo es deficitario, como en Estados Unidos y México, implica que las importaciones desplazan a la producción nacional y se merma la acumulación del sector privado productivo. Para contrarrestar esto, el gobierno debe gastar más allá de sus ingresos de recaudación para impulsar el mercado interno, la demanda y mejorar las condiciones financieras del sector privado. Si el gobierno opta por reducir el déficit fiscal, se contrae la demanda y tiende a frenarse la recuperación económica en ambos países y, por lo tanto, los flujos de migración disminuyen y se incrementa el descontento social. Por lo tanto, se requiere de una participación activa, organizada y concientizada de la población para cambiar las políticas actuales por otras que generen empleos.

En el capítulo "Desempleo, precarización, crisis y migración", Alejandro Valle Baeza plantea que en las últimas décadas se ha virado hacia una forma de empleo cada vez más funcional para las necesidades de la acumulación del capital, ocasionando peores condiciones para los trabajadores de los países desarrollados y siendo aún más severas en los países de ingresos medio y bajo. La migración ha sido una solución ante los problemas de empleo. Mexicanos y centroamericanos emigran hacia Estados Unidos porque no hay oportunidades de empleo decente en sus lugares de origen. Sin embargo, la migración no puede ser una solución duradera, puesto que el problema de empleo no es 
específico en un solo país, es un problema estructural y universal. A los problemas estructurales se suman los ocasionados por las crisis y las recesiones. Normalmente una crisis resuelve algunas contradicciones del sistema o al menos las atempera; la cuestión del empleo no es una de esas contradicciones que se atenúe con la presente crisis.

En la tercera sección se presentan investigaciones que abordan directamente el fenómeno de la crisis y sus repercusiones sobre la migración de trabajadores. El lector podrá conocer la particular situación de la migración tanto en México como en España ante la crisis y las condiciones que viven sus migrantes.

Juan Luis Ordaz Díaz y Juan José Li Ng, presentan el capítulo: "¿Por qué se ha reducido la migración mexicana hacia Estados Unidos?”. En este plantean el hecho de que la migración mexicana hacia el vecino país del norte ha sido sobre todo laboral y justamente este factor que generó una importante oleada de mexicanos emigrantes durante parte de la década pasada, también explica, en gran medida, la desaceleración de los flujos netos migratorios de México hacia Estados Unidos en los años recientes. Los autores señalan que tras la última recesión económica en Estados Unidos, la cantidad de los flujos de migrantes mexicanos hacia ese país mostró una importante disminución. No se dio un retorno masivo de mexicanos como temía la opinión pública, sin embargo, los autores afirman que a la fecha tampoco se ha observado una tendencia hacia la recuperación de los flujos migratorios de connacionales hacia Estados Unidos. Esta situación parece tener un carácter particular en México, pues los flujos migratorios de otros países que también se dirigen hacia Estados Unidos se han recuperado y recién han alcanzado su mayor nivel histórico. ¿Qué está ocurriendo? ¿Por qué la migración de México se ha estancado y la de otras regiones continúa creciendo? En este trabajo, los autores contribuyen con explicaciones que permitan comprender cuál puede ser el futuro de la migración mexicana.

En el capítulo "Nuevos patrones migratorios en el contexto de la crisis económica. El caso de España”, Joaquín Arango seña- 
la que entre los años del cambio de siglo y el que siguió al comienzo de la crisis, España conoció una auténtica explosión inmigratoria. En ese corto tiempo, el número de los inmigrantes establecidos en España prácticamente se sextuplicó, al pasar de un millón a más de seis millones. El texto se concentra en el agudo contraste entre el gran crecimiento de la población inmigrada en los años que precedieron a la crisis y su contracción posterior, así como de la llamativa ausencia de movimientos de rechazo hacia la inmigración antes y después. El modelo de crecimiento económico que propició la bonanza anterior a 2007 y que ha contribuido a agravar las consecuencias de la crisis constituye un nexo de unión entre una y otra. Por primera vez en décadas se registra emigración de españoles de origen, aunque más en términos de movilidad trasnacional que de emigración en sentido clásico y es probable que la tendencia persista en el futuro próximo.

En la cuarta sección se discute acerca de la importancia que tiene la educación y, al mismo tiempo, los problemas que enfrentan los países latinoamericanos, en particular México, ante la falta de integración de sus profesionales por problemas de sus propios mercados laborales lo que crea graves desequilibrios y una de sus consecuencias será la emigración.

Claudio Rama en su investigación "Nuevas dinámicas de los mercados laborales y educativos de profesionales con la masificación de la cobertura y la expansión del egreso", manifiesta que la expansión de la matrícula universitaria y de su egreso ha sido un proceso continuo en la región incrementado por cambios productivos, feminización, expansión privada y aumento de la eficiencia pública que han contrarrestado los niveles de deserción por integración temprana del mercado laboral, deficiencias previas de capital humano y carencias económicas. Este aumento del egreso ha contribuido para cambiar los mercados de trabajo y tiende a ser superior que las demandas al aumentar los desequilibrios entre los mercados educativo y laboral. Ello se expresa tanto en un cambio del ingreso profesional en el trabajo, incluyendo un aumento de la emigración y del desempleo, así como en nuevas dinámicas de articulación de educación-empleo 
profesional. El presente ensayo propone el análisis de la situación en América Latina y profundiza en el efecto de los crecientes egresos sobre las variables de los sistemas de formación y trabajo al mostrar nuevas formas de absorción profesional.

Ana María Aragonés y Uberto Salgado presentan el capítulo "El nuevo patrón migratorio bajo el contexto de la crisis", donde se reseña la posición de algunos autores acerca de que la crisis ha dado lugar a una importante transformación del comportamiento migratorio, basados en la disminución de los flujos de migrantes mexicanos hacia Estados Unidos, hecho que consideran como parte de un nuevo patrón migratorio. Sin embargo, los autores profundizan en el concepto de patrón migratorio buscando encontrar las diferencias con lo que se ha denominado flujos migratorios. La propuesta de los autores es que el patrón migratorio se explica por los vínculos con el patrón de acumulación, es decir, se trata de articulaciones estructurales y no simplemente coyunturales como la disminución de los flujos migratorios en el marco de la reciente crisis. Opinan que una crisis estructural conformará un nuevo patrón de acumulación y, a partir de ello, se deben identificar las tendencias del nuevo patrón migratorio. Si bien la salida de la crisis pasa por un conjunto de estrategias económicas distintas, la economía del conocimiento como elemento tiene un peso importante que aportar en la superación de la crisis. Por lo tanto, en este marco la propuesta de los autores es que una característica del nuevo patrón es el mayor peso que tienen los trabajadores migrantes altamente calificados. 


\section{Capítulo 1 \\ MigRACIÓN FORZADA EN MÉXICO \\ Y DISEÑO ECONÓMICO/GEOPOLÍTICO}

DE POSGUERRA

John Saxe-Fernández**

El contexto económico y geopolítico de la economía mexicana brinda una eficiente herramienta para la compresión de fenómenos sociales de gran trascendencia en el país. Uno de los más importantes es la migración de carácter forzada, que se vincula con el régimen acreedor instaurado en las líneas de condicionalidad macro y "por rama" atadas a todas las líneas de crédito manejadas por el Fondo Monetario Internacional (FMI), el Banco Mundial (Bм) y el Banco Internacional de Desarrollo (BID), que debilitan el aparato productivo y su capacidad para generar empleo. En este sentido, el desmantelamiento de la industria petroquímica y el ajuste estructural aplicado en el sector agrícola mexicano en una ya de por sí desigual competencia mediante el Tratado de Libre Comercio de América del Norte (TLCAN), son elementos clave en la compresión de la pérdida de fuentes de

* Doctor en Estudios Latinoamericanos de la Facultad de Filosofía y Letras de la UNAM. Es miembro SNI III. Investigador Adlai Stevenson en el United Nations Institute for Training and Research (UnITAR). Recibió el Premio Anual de Investigación Económica Maestro Jesús Silva Herzog 1993 y el Premio Universidad Nacional en el Área de Docencia en Ciencias Sociales en el año 2000, ambos otorgados por la UNAM. Correo electrónico: < jsaxef@gmail.com>. 
trabajo e ingresos para un importante sector de la población que recurre a la emigración para sobrevivir. Al retirarse los subsidios al campo y favorecer los intereses de corporaciones extranjeras afectando (en el caso de la petroquímica) a miles de pequeña y mediana empresas (pyme) se agudizó la expulsión de una gran cantidad de trabajadores hacia Estados Unidos, por lo que es deseable y a la vez urgente un abandono del "recetario" fondomonetarista.

\section{Preámbulo}

La Segunda Guerra Mundial fungió no sólo como el ariete con suficiente potencia para sacar a Estados Unidos y a la economía mundial de la Gran Depresión. Fue, como diría Giovanni Arrighi, el "árbitro último" de una sucesión hegemónica de la pax britannica a la pax americana, en curso desde principios del siglo XIX, que dejó los principales polos capitalistas (y a la Unión Soviética) devastados pero a la economía estadounidense intacta, "revitalizada" y en estado de movilización bélico-industrial permanente, como en tiempos de guerra, pero sin "enemigo aparente" y con un gran consumo de recursos naturales estratégicos, empezando con el carbón, petróleo, gas y una amplia gama de metales y minerales. Además ese fue el fundamento que permitió crear y lanzar, con gran éxito, una mixtura de "liderato intelectual y moral" propia a las "hegemonías", en sentido gramsciano, junto a formidables instrumentos de coerción, ${ }^{1}$ toda una estructura económica, política y militar analizada y articulada por el alto mando bancario/empresarial de Estados Unidos en la segunda parte de la década de los años

${ }^{1}$ En relación con la proyección de fuerza, me refiero a la mayor marina de guerra desde la del Imperio británico, a un amplio despliegue de fuerzas convencionales terrestres y aéreas, así como, en esos momentos, el monopolio del armamento atómico. Sobre el punto de vista gramsciano aplicado a las relaciones internacionales, veáse Cox [1981] y Guillén [2007]. 
treinta, durante el gobierno de Franklin D. Roosevelt² (1933-1945), que adoptó la forma de un "internacionalismo colectivo" bajo la batuta de Washington, el sucesor hegemónico de Londres. Además de Bretton Woods (ver más adelante) se incluyeron la Organización de las Naciones Unidas (ONU), la Organización de los Estados Americanos (OEA) y la Organización (OEA) y la Organización del Tratado del Atlántico Norte (OTAN) e instrumentos $a d$ hoc de alto impacto, entre los que resalta el Plan Marshall.

En el nuevo orden mundial planteado por el alto capital estadounidense, se impulsaría la reconstrucción industrial, con grandes transferencias monetarias vía grants para fomentar el comercio, la industria y las compras de equipo militar a Estados Unidos por parte de los principales polos de desarrollo capitalista devastados por la guerra, incluyendo a los dos enemigos derrotados: Japón y Alemania. En todos ellos, Washington consideró necesario instalar bases militares para una continua "vigilancia", un despliegue que primero se articuló bajo las premisas de la vasta campaña anticomunista de la guerra fría y que permanece hasta el año 2013 bajo otras "regionalizaciones" (contra el crimen organizado, el narco, el terrorismo, etc.) poco más de veinte años después del derrumbe de la Unión Soviética. Cabe aclarar que los grants para Europa permanecían estrictamente controlados y condicionados por Washington, que determinaba los rubros y su orientación. En verdad, el Plan Marshall fue un instrumento dirigido a la incautación del proceso de toma de decisiones europeas en materias económica y de seguridad interna y, en particular, hacia sus excolonias, en parte para a alentar la producción de materia prima en esas "dependencias", cuyas metrópolis, Italia, Francia, Alemania e Inglaterra, habían sido devastadas por la Segunda Guerra Mundial.

El Plan Marshall fue un instrumento idóneo para que las empresas extractivas de Estados Unidos, mineras y las petroleras,

${ }^{2}$ Para un análisis sólido y documentado del papel determinante del alto empresariado industrial y bancario de Estados Unidos en el delineamiento del diseño económico y de política exterior, pre y posbélico del gobierno de Franklin D. Roosevelt, consultar Shoup y Minter [1977]. 
en particular, tuvieran acceso "libre y equitativo" a todas las materias primas de esas colonias [Tanzer y Zorn, 1985]. Parte importante del diseño se encaminó a orientar las compras europeas de petróleo del Oriente Medio: Washington autorizó los grants para las compras europeas de crudo a "sus" firmas petroleras, abriéndoles espacios y más control sobre los yacimientos del Golfo Pérsico. Los primeros pasos en esa dirección se habían tomado desde 1933 cuando la Standard Oil, de California, obtuvo una concesión de sesenta años para la explotación de petróleo de Arabia Saudita, parte de un arreglo especial entre Franklin D. Roosevelt y el rey Abdalá bin Abdelaziz al-Saud. Mantener el control empresarial y militar del grifo petrolero del cual dependían sus "aliados" fue crucial (y sigue siendo) en la proyección global de poder de Estados Unidos. Aunque de manera contemporánea los principales abastecedores de petróleo no están en el Oriente Medio (OM) sino en localizaciones “cercanas” (México, Canadá, Venezuela), es en el OM en especial en torno de los grandes yacimientos del Golfo Pérsico, donde se detecta el mayor despliegue de fuerzas naval, aérea y del ejército de Estados Unidos.

A la periferia capitalista (América Latina, África, Asia, Oriente Medio) no se le asignaron funciones de industrialización, sino de proveedora de materia prima estratégica. En esas zonas se realizó un breve programa de empréstitos, condicionados y con oneroso servicio, para dar espacio y abrir oportunidades a la inversión extranjera directa de firmas estadounidenses con atención especial en el área extractiva de exportación. En América Latina el BM y otras agencias estadounidenses, entre ellas el Eximbank y luego el BID, presionaban a los gobiernos mantenerse alejados o de plano revertir las expresiones del nacionalismo económico industrializador en general y del "nacionalismo sobre los recursos naturales” (resource nationalism) en particular, como las puestas en marcha en México tras la nacionalización petrolera de 1938 [Saxe-Fernández, 2002]. Aunque Estados Unidos era (y es) un gran exponente del "nacionalismo económico", combatió de manera enérgica toda expresión de nacionalismo económico en la periferia considerándolo, en el caso mexicano un "mal ejemplo" 
de "socialismo" o de "capitalismo de Estado" y en otros (Guatemala, Irán, Brasil, Chile, Argentina, Uruguay, Nicaragua, ad nauseam) parte de la gran conspiración del Kremlin contra el "mundo libre". La diplomacia económica y de fuerza de Estados Unidos "enfrentó" esta situación bajo las premisas ideológicas, y los instrumentos abiertos y clandestinos de corte económicomilitar y de inteligencia, de la guerra fría.

La desestabilización y los golpes de Estado, por ejemplo los realizados contra los gobiernos de Jacobo Árbenz Guzmán en Guatemala, Mohammad Mossadegh en Irán, hasta los de João Goulart en Brasil y Salvador Allende en Chile, se dieron bajo “justificaciones” y membretes de la confrontación Este-Oeste lanzada por la Doctrina Truman, parte y parcela de los programas de desestabilización y de regime change para revertir, por ejemplo, la nacionalización del petróleo de Irán. En ese caso, los servicios británicos de inteligencia bajo coordinación y financiamiento de Estados Unidos, "restauran" su forma específica de colonialismo sobre la vasta riqueza petrolera de Irán por medio del golpe de Estado de 1953, imponiendo un régimen de terrorismo de Estado y de colonialismo bajo la bandera del "anticomunismo" [Kinzer, 2003].

Privilegiar economías periféricas orientadas hacia la exportación de materias primas o desalentar y revertir aquellas expresiones de nacionalismo económico industrializador en países como México, Brasil, Chile, Bolivia y Argentina conllevaba la profundización de tensiones sociales y precipitar guerras internas por los altos índices de frustración relativa, de descomposición y desorganización social y personal, salarial, informalidad económica, secuelas del desempleo, subempleo, precarización del trabajo y creciente oleada de expulsión poblacional, derivada de los programas de ajustes estructurales (PAE) contenidos en los lineamientos macroeconómicos y por rama del FMI, el BM y el BID concretados en líneas de condicionalidad en las que ni el desarrollo ni la generación de empleo eran prioritarios a pesar del dinámico incremento poblacional y de las aspiraciones de movilidad social ascendente. Al contrario, por su atención en la desregulación financiera, la 
apertura comercial y la inversión extranjera directa (IED), el desempleo, la precarización del trabajo y una sistemática ofensiva a la economía popular y campesina, se acentuaron las vulnerabilidades, los costos sociales y el uso de la represión policial-militar en lo interno como lo había previsto Leo Pavlovsky al exponer en los años treinta la necesidad de "militarizar" a las repúblicas americanas (América Latina) en las sesiones de planeación posbélica del gobierno de Roosevelt con el Council on Foreign Relations (CFR). Es en este contexto donde la migración en general y la forzada en particular, fungieron como válvula de escape ante la contención del dinamismo económico requerido por la expansión demográfica y el aumento del consumismo y las aspiraciones alentadas por los medios de comunicación, como indican Márquez y Delgado [2011a: 21]:

las migraciones adquieren un nuevo papel dentro de la división del trabajo. Los mecanismos del desarrollo desigual generan condiciones estructurales, como el desempleo y la pobreza, que catapultan las migraciones masivas de conjuntos poblacionales despojados y excluidos. Compelidos por la necesidad de acceder a medios de subsistencia u oportunidades de movilidad social, vastos sectores de la población son literalmente expulsados de sus territorios para desplazarse dentro del propio país o hacia el extranjero.

El fenómeno es amplio. Su tipología incluye además, desplazados o expulsados por $a$ ) catástrofes o cambios ambientales, $b$ ) conflictos sociopolíticos y culturales, c) criminalidad y narcotráfico, d) tráfico y trata de personas, e) despojo de medios de producción y subsistencia, $f$ ) exclusión social, desempleo estructural, pobreza, y g) sobrecalificación laboral relativa, refugiados, solicitantes de asilo, desplazados internos por conflicto armado [Márquez y Delgado, 2011a]. ${ }^{3}$

${ }^{3}$ En materia climática James Hansen, connotado especialista exdirector del NASA Goddard Institute for Space Studies (GIss) en la Universidad Columbia de Nueva York, advirtió con respecto del ascenso en curso del nivel del océano que: “...si las emisiones siguen dependiendo de la lógica habitual del beneficio económico, es probable que el 
La "migración forzada" es un fenómeno que, tras la guerra, fue intensificándose, década tras década, afectó a la región latinoamericana en general pero, de manera directa y abrumadora a México, como resultado de la forma en que se negoció la crisis deudora de 1982 y en paralelo con la aplicación intensificada del recetario fondomonetarista o "neoliberal" es decir, aquel contenido en esa condicionalidad acreedora.

\section{Bretton Woods, el Plan Marshall $y$ los recursos naturales}

Ni la transformación de los recursos naturales, el desarrollo, la generación de empleo y el bienestar de la población estaban previstos en la agenda imperial de posguerra para la periferia capitalista. Desde los instrumentos creados en Bretton Woods, durante la posguerra se desalentó una industrialización periférica que desviara los recursos naturales de su destino hacia las economías centrales, alentándose la reprimarización de aquellas naciones donde el nacionalismo económico se había manifestado en modestos despliegues industriales como en el caso de México, Brasil y Argentina, que se observaron cuando Washington estaba ocupado en las tareas y misiones de la Segunda Guerra Mundial. El fenómeno de la industrialización de importaciones, ciertamente vinculada con los procesos históricos de largo alcance que afectaron a la periferia capitalista latinoamericana, la Primera Guerra Mundial, la Gran Depresión y la concentración de recursos y atención por parte de Estados Unidos hacia los teatros militares de la Segunda Guerra Mundial, se analizó primero en las aportaciones de Raúl Prebisch y después desde el punto de vista crítico de la teoría de la dependencia en el marco del imperialismo

nivel del mar suba al menos dos metros en este siglo. Cientos de millones de personas se convertirán en refugiados. No se restablecerá una costa estable en un tiempo concebible para la humanidad", planteamiento de James Hansen ante el Congreso de Estados Unidos, 23 de junio de 2008, <http://www.circuloastronomico.cl/secciones/calentamiento2.html>. 
fue una temática muy discutida en la obra de Celso Furtado, Theotonio dos Santos, Vania Bambirra, Andre Gunther Frank, Agustín Cueva, Ruy Mauro Marini y Fernando Fanjzylber, entre otros. ${ }^{4}$

El trauma de la Gran Depresión y la devastación/holocausto que le acompañó pende, como espada de Damocles, en toda la fundamentación explicativa sobre el capitalismo y sus crisis elaboradas desde finales del siglo XIX. La propensión del capitalismo monopólico hacia el estancamiento, la recesión/depresión, se vincula de manera directa con fenómenos que son externos para su superación, al menos de manera coyuntural, con la movilización bélico-industrial como aspecto primordial. $\mathrm{Al}$ respecto cabe observar que para estudiosos como John Kenneth Galbraith y Paul Sweezy en realidad "la Gran Depresión nunca acabó, se fusionó con la economía de guerra" [Sweezy, 1994]..$^{5}$ Entre 1939 y 1944, recuerda Sweezy, el producto nacional bruto de Estados Unidos creció $75 \%$ y el desempleo (que en Estados Unidos alcanzó 25\%) llegó a cero. El Departamento de Estado por su parte, en la argumentación pública dirigida al empresariado para promover el nuevo "internacionalismo colectivo", hizo mención a:

[...] 64 millones de trabajadores, 20 mil millones de dólares (mmd) sólo en proyectos gubernamentales bélicos... los $200 \mathrm{mmd}$ del producto nacional anual [...] las exportaciones en 1944 por 14 mil 240 millones de dólares; importaciones de 3 mil 900 millones [...] más barcos que el total de las marinas mercantes de preguerra del mundo juntas [...] $21 \mathrm{mmd}$ en oro, dos terceras partes del oro monetario del mundo [...] una planta de maquinarias y de producción agrícola sin paralelo [...] un prestigio militar y un potencial naval y aéreo sin rival [...] [citado por Kofas, 1996: 20].

Sweezy, después de notar que "eso" no fue parte de la lógica interna del capitalismo, "una lógica que, en su forma más pura es

${ }^{4}$ En general, la obra de Raúl Prebisch requiere nueva atención a la luz de tres décadas de desindustrialización neoliberal, así como la actuación latinoamericana en la UNCTAD Y CEPAL.

${ }^{5}$ Este trabajo es parte del examen que hizo el autor décadas después de publicado "Monopoly Capital”, en Monthly Review Press de 1966 (edición en español de Siglo XXI Editores, México, 1968). 
la Gran Depresión", plantea que "la condición normal del sistema capitalista maduro es el estancamiento y, en tanto esto no se observe en el estado actual del capitalismo avanzado, la explicación se encuentra en elementos externos, en fuerzas no-económicas". Con el transcurso de las décadas, las sucesivas crisis y el funcionamiento mismo de la permanente movilización bélico-industrial mostró creciente incapacidad para mantener en niveles adecuados la dimensión de bienestar, del empleo y de la equidad así como de la competitividad ante la recuperación industrial de los otros polos capitalistas y sobre todo de la fuerza con que se materializó la condición normal del capitalismo maduro. La interacción positiva entre militarismo y prosperidad general se deterioró y se expresó en una paulatina y luego acelerada polarización de clase en Estados Unidos, proceso que incluye, como apunta Jorge Beinstein [2013]: una cada vez más cara carrera armamentista, que terminaría teniendo efectos nulos o incluso negativos sobre el nivel general de ocupación.

La expansión de posguerra en Estados Unidos empezó a sentir los efectos de la competencia europea y japonesa. En los años setenta el daño acumulado de la economía permanente de guerra se intensificó. Sus efectos negativos fueron analizados y calibrados por Seymour Melman [1975, 1987] tanto en la generación de empleo como en la capacidad productiva general y sobre el funcionamiento y competitividad de las firmas contratistas. Téngase presente que entre esos contratistas están las principales industrias militares y también las firmas estadounidenses de la lista Fortune 500 las cuales, además de su rama civil, cuentan con una división militar (General Motors, General Electric, Chrysler, entre otras).

En la industria de bienes de capital, entre otros rubros, el freno a la competitividad de las firmas estadounidenses, cuyas divisiones militares operaban bajo mecanismos de cost-plus ${ }^{6}$

${ }^{6}$ Se trata de procedimientos administrativos de los contratos donde la maximización y no la minimización de costos es relevante a las empresas contratistas para obtener mayores ganancias [Melman, 1987]. 
instaurados en el vasto contratismo del Departamento de Defensa de Estados Unidos por Robert McNamara, de cara a la calidad y precios de las máquinas y herramientas japonesas y alemanas fue notable y se hizo evidente, entre otros factores, en la declinación del empleo en la rama industrial. Los estudios más recientes de la Organización Internacional del Trabajo (OIT) indican que esta tendencia y la polarización socio-económica en Estados Unidos derivada de aquella, se acentuó desde 2007 y se intensifica desde entones. La clase media de Estados Unidos (y en el resto del mundo) experimenta el desempleo de largo plazo, el deterioro de la calidad del empleo y el retiro de sus integrantes del mercado de trabajo. En este tenor Joyce y Gabriel Kolko [1972] ilustran el alto grado como los arquitectos del edificio Bretton Woods estaban al tanto de esa inclinación depresiva inherente al capital monopólico. En ese contexto se utilizó al FMI, el BM y el BID para mantener la explotación y flujo de los vitales recursos naturales de la periferia capitalista, incorporando esos mercados en una dinámica de acelerado dinamismo bélico-industrial en el centro para evitar otra Gran Depresión. Esas metas fueron esenciales, máxime cuando al año de los ataques atómicos contra Hiroshima y Nagasaki, con los que Harry S. Truman quiso mostrar ante Stalin y el mundo que Estados Unidos gozaba de la primacía militar global en la posguerra, ante los primeros atisbos de desmovilización militar y de reducción presupuestal del entonces Departamento de Guerra, aparecieron fulminantes expresiones recesivas en la economía de Estados Unidos y del mundo (excepto en la Unión Soviética) que literalmente aterrorizaron a la cúpula empresarial y a la Reserva Federal (Fed).

Recordemos que el fin de la belle époque llevó después de la Primera Guerra Mundial el persistente resquebrajamiento de los instrumentos coloniales propios al librecambismo inglés, imposibilitando el mantenimiento de la política colonial, por lo que el FMI y el BM, a los que luego se agregó por algunos años el Plan Marshall y luego el GATT (General Agreement on Tariffs and Trade) y una institución interamericana, el BID (otra multilateral, como las otras dos, bajo la batuta de la política exterior y de seguridad 
de Washington hacia América Latina), en realidad fueron instrumentos sustitutos para mantener la extracción y explotación de los recursos vitales, seguir con la expansión de los mercados y, al mismo tiempo, evitar otra Gran Depresión [Saxe-Fernández, 2002; Saxe-Fernández y Delgado, 2003]. Según Edward Goldsmith [1999: 21], "la única solución fue ampliar nuestros mercados al Tercer Mundo, incorporándolos al sistema industrial dentro de la órbita de nuestro comercio. Y eso fue el meollo de lo que fue la conferencia de Bretton Woods de 1944".

Por el alto consumo de combustibles, minerales y metales claves en tiempos guerra, desde 1945-1946 el gobierno de Truman se preocupó por su acelerada disminución en bodegas y depósitos bajo resguardo federal. En marzo de 1947 el discurso cuya intención fue, en palabras de Truman, "espantar" al Congreso (scare the hell out of Congress) para obtener fondos de emergencia, presionando a los legisladores para aprobar grandes partidas con el fin de "evitar que Grecia y Turquía cayeran en manos de la subversión" comunista, fue transformado en la Doctrina Truman, dirigida a "espantar al mundo" definiendo a la exaliada Unión Soviética como un nuevo enemigo externo, ${ }^{7}$ una categoría en la que se incluirá a China a partir de 1949.

En junio de 1947 el general George Marshall, nuevo secretario de Estado, en un discurso realizado en la Universidad de Harvard, lanza el plan para la recuperación de Europa (ERP) conocido como el Plan Marshall. Más que "una expresión de generosidad sin precedente de una nación poderosa para rescatar a potenciales competidores de la devastación de la guerra", fue en verdad, "la respuesta ante la real alarma con que se percibía en Washington la dirección que tomaba la economía mundial" [Goldsmith, 1999]. La retórica del Plan Marshall, todavía repetida por muchos analistas y políticos que a la menor provocación hablan de la necesidad de un Plan Marshall para América Latina, daba la impresión de que en el ERP prevalecían las iniciativas y necesidades

${ }^{7}$ Palabras textuales de Truman citadas por el historiador oficial del Departamento de Estado, <http://history.state.gov/departmenthistory/short-history/truma>. 
de una Europa devastada y sin dólares omitiendo la sustancia: la intención de Washington de "reestructurar" al capitalismo europeo en función de sus intereses y necesidades comerciales así como de sus recursos naturales, incidiendo en las políticas de las metrópolis europeas con sus colonias con el fin de acceder e intensificar la producción de materia prima en el tercer mundo. Este renglón tanto como el de seguridad eran vitales al capitalismo estadounidense que emergió de la Segunda Guerra Mundial:

[...] inmensamente enriquecido pero más vulnerable y dependiente por su tamaño y riqueza $[\ldots]$ incapaz de alterar sus prioridades económicas internas, el capitalismo estadounidense solo podía recurrir al exterior, no con diseños desinteresados, sino con lo que percibió necesario para su sobrevivencia [Kolko y Kolko, 1972: 383].

Bajo la Ley de Seguridad Nacional de 1947 creada por la Agencia Central de Inteligencia (CIA) y un mando militar unificado en el recién establecido Departamento de Defensa (DdD) Estados Unidos desplegó, bajo las premisas de la Doctrina Truman, una sombrilla de seguridad global para proteger las inversiones, el comercio y el acceso del nuevo hegemón y sus aliados a los recursos naturales de la periferia africana, latinoamericana y asiática. Bajo las banderas de la amenaza comunista se encapsularon las políticas para combatir el nacionalismo económico y las pretensiones de algunos gobiernos y movimientos sindicales, en lo particular de América Latina, de agregar valor a las materias primas al adoptar políticas de industrialización que, en criterio de la cúpula político-empresarial estadounidense desviaban o interrumpían el flujo de exportaciones de materiales vitales para los fabricantes en Estados Unidos y a sus "aliados". La postura empresarial estadounidense fue articulada en el Plan Clayton, un esquema de promoción de los intereses de Estados Unidos, según la interpretación del algodonero William Clayton, uno de los principales promotores del Plan Marshall. Como se ilustró anteriormente, desde entonces el Departamento de Estado había planteado que la economía de guerra había sido fundamental para lanzar a Estados Unidos hacia la primacía global en 
lo militar, político y económico, sin embargo, quedaba el problema de cómo traducir este poderío económico, político y militar sin paralelo, en un esquema internacional que garantizara la prosperidad permanente de la nación estadounidense en un mundo de naciones prósperas.

Después de la Segunda Guerra Mundial la dependencia latinoamericana hacia Estados Unidos se intensificó y no había poderío económico o político-militar extra hemisférico capaz de competir, quedó claro que aunque la solidaridad hemisférica permaneció como criterio estratégico (usado para promover bajo el anticomunismo un regionalismo que Washington le negaba de manera terminante a europeos y soviéticos) la utilidad real de las naciones latinoamericanas se centró en garantizar la continuidad de su papel como fuentes estables y seguras de materias primas e importadores de manufacturas de Estados Unidos y siempre abiertas a una desregulada IED. Era un diseño que colocaba a Latinoamérica en desventaja frente a Estados Unidos y Europa. La subordinación de la región a las necesidades de reconstrucción para el desarrollo económico europeo planteado por Washington como directriz a "sus" instrumentos financieros "multilaterales" (Import-Export Bank, FMI, BM) por medio de miles de millones de dólares en grants (aunque condicionados) a Europa y Japón y muy pocos empréstitos, con alto servicio, con el fin de abrir espacios a la IED de Estados Unidos en América Latina, en el sector exportador especialmente de petróleo, cobre y otros materiales estratégicos, fue rechazado por México y un amplio grupo de las naciones latinoamericanas y caribeñas en la Conferencia de Chapultepec de 1945, con respaldo en defensa de la industrialización nacional generadora de empleo, por el principal movimiento sindical de la región. Kofas [1996] sintetiza el asunto al señalar que "la política hemisférica de Washington chocaba con las aspiraciones de los gobiernos latinoamericanos a favor de continuar con el desarrollo industrial y una mayor autosuficiencia económica".

A mediados de 1952, durante el apogeo de la Guerra de Corea y se pusieron en evidencia las fuertes limitaciones en los 
abastecimientos de materia prima estratégica, circularon los cinco volúmenes del Informe de la Comisión Presidencial establecida por Truman para determinar el estado en que se hallaban "los materiales que son el fundamento de la civilización estadounidense" [Paley, 1952]. Conocido como Informe Paley, presentó datos y advertencias veinte años antes de que se manifestaran las evidencias del agotamiento de los estratos de fácil acceso y por tanto baratos de los recursos naturales:

[...] La naturaleza del problema quizá puede aclararse de manera exitosa y breve, aunque muy simplificada, aseverando que el consumo de casi todos los recursos (materiales) se amplía a una tasa exponencial, presionando con fuerza recursos que, sea lo que sea que ocurra con ellos, no expanden su disponibilidad de manera similar. Este Problema de los Recursos (con mayúsculas en el original) no es entonces del tipo de escasez, local y transitoria, que en el pasado halló solución en cambios en los precios que restablecían el equilibrio entre el suministro y la demanda. Los términos del problema de recursos que enfrentamos hoy es de una mayor profundidad y de otro orden [Paley, 1952].

El Informe Paley apuntó que no solo durante los siguientes 20 a 25 años Estados Unidos requeriría aumentar entre tres y cuatro veces el volumen de sus importaciones netas de metales, minerales y combustibles esenciales, también alertó sobre tres procesos que afectan negativamente la creciente y preocupante dependencia de la industria civil y militar estadounidense de esas importaciones: a) la competencia por esos recursos derivada de la reconstrucción industrial de Europa y Japón; b) las necesidades de la movilización bélica ante la "amenaza soviética" y c) los intentos de naciones menos desarrolladas pero ricas en esos recursos por utilizarlos en su industrialización en lugar de destinarlos a la exportación [Paley, 1952]. Para Averrell Harriman, director de Seguridad Mutua (Estados Unidos-Europa) pieza clave y parte de los organismos vinculados con el Plan Marshall, las implicaciones del Informe Paley eran claras y de importancia mayor. Los elementos económicos que están en la base del 
fenómeno (el aumento de la demanda mundial de recursos naturales estratégicos) y el hecho de que, como expresó alarmado Harriman [Kofas, 1948], "sin el Plan Marshall, Estados Unidos sólo obtendría $20 \%$ de sus necesidades de recursos estratégicos", se mezclaron convenientemente con las justificaciones para la intervención abierta o clandestina, la ideología Este-Oeste y los elementos de seguridad de la guerra fría, la CIA (Agencia Central de Inteligencia) y el Pentágono (Departamento de Defensa de Estados Unidos). Harriman personificó la adhesión a una retórica librecambista y la desconfianza crónica en los hechos de la clase dominante de Estados Unidos ante la mano invisible. Se inclinó por soluciones expeditas de corte policial, militar o de subversión de regímenes nacionalistas por medio de instrumentos de inteligencia, con una imagen no de controles colonialistas, sino de cruzadas anticomunistas salvadoras del mundo libre: [...] si vamos a acceder a la materia prima que estaremos necesitando tan desesperadamente en los próximos veinte años, las naciones productoras deben mantenerse libres del dominio soviético y amistosas con el resto de las naciones del mundo libre [...] [Kofas, 1996: 29].

\section{Ajuste estructural en México. \\ MigRACIÓN FORZADA COMO PROBLEMA \\ DE SEGURIDAD NACIONAL}

Mantener una relación amistosa con Estados Unidos y el resto de las naciones del mundo libre, significaba renunciar al fortalecimiento del mercado interno y a la industrialización en las que se había avanzado durante el periodo de sustitución de importaciones, algo limitado en el caso latinoamericano por la presencia y actividad de las grandes trasnacionales y una creciente ofensiva, presente ya desde 1945, en los compromisos derivados de la Conferencia Interamericana sobre Problemas de la Guerra y de la Paz, también conocida como Conferencia de Chapultepec, dirigida al desmantelamiento o debilitamiento de las empresas del 
sector público de la Unión Panamericana. ${ }^{8}$ La reversión del proceso industrializador del petróleo mexicano en 1938, recuperado formalmente de manera operativa por el Decreto de expropiación y nacionalización con fundamento en el párrafo segundo de la fracción VI del art. 27 de la Constitución Política de los Estados Unidos Mexicanos (Constitución de 1917) y en los artículos 1 (fracciones V, VII y X), 4, 8, 10 y 20 de la Ley de Expropiación del 23 de noviembre de 1936, tuvo efectos de largo alcance en lo social, económico y estratégico.

México encabezó la vanguardia en la generación de beneficios sociales derivados de las actividades de Petróleos Mexicanos (Pemex) en exploración, extracción, transformación y comercialización del crudo. A finales de los años sesenta, el desarrollo estabilizador se relacionaba, entre otros de sus pivotes, con la expansión horizontal y la integración vertical de Pemex, cuyos efectos positivos se observaron desde años antes. Más que eso, Pemex había sentado un precedente de éxitos en una economía mexicana que crecía a un ritmo de 5 a $6 \%$ anual que preocupó a la poderosa cúpula petrolera de Estados Unidos y a los asesores del вм como Walter Levy. Era un proceso de industrialización nacional que amenazaba, como lo documenta Saxe-Fernández [2002], con transformarse en un paradigma exitoso que podría reproducirse en otros países de la periferia.

Desde los primeros éxitos de la paraestatal el ejemplo de la industrialización petrolera en Pemex al tercer mundo, en especial a los otros productores de petróleo de América Latina, fue un tema recurrente en los altos círculos petroleros (big oil) de Estados Unidos. En 1969 Michael Tanzer, presidente de Tanzer Economic Associates, consultora especializada en asuntos petroleros

${ }^{8}$ Fue y es una condicionalidad parcial, sin reciprocidad, ya que nunca incluyó las estrechas ligas, vínculos, subsidios y apoyos del sector público de Estados Unidos a sus firmas. Las restricciones abordadas en la Conferencia de Chapultepec, no incluían los recursos canalizados a las altamente subsidiadas petroleras ni a las principales firmas estadounidenses que ya contaban en su estructura organizativa con divisiones militares para acceder a los jugosos contratos (altamente subsidiados y repletos de sobrecostos), del inmenso sector bélico-industrial de Estados Unidos. 
y mineros, realizó un estudio que examinó al detalle los efectos de usar a Pemex como palanca para el desarrollo, es decir, como un canal estratégico para la inversión pública midiendo las ganancias sociales de la inversión y, en segundo lugar, contabilizando el efecto más amplio sobre la economía mexicana como un todo [Tanzer, 1969; Saxe-Fernández [1994]. Con datos en mano, Tanzer cuestionó y refutó las críticas que, desde entonces, el BM hacía a Pemex. La publicación de esa investigación generó un gran impacto en los ámbitos político y petrolero mexicanos por ser un estudio independiente realizado desde Estados Unidos, que otorgaba sustentación objetiva a los planteamientos así como a los programas de trabajo diseñados y puestos en operación por Antonio J. Bermúdez y Jesús Reyes Heroles (padre, desde luego), quienes como directores de Pemex alentaron la transformación del crudo y la creación de instancias de investigación y desarrollo. Reyes Heroles revisó un informe de Walter Levy para el BM en donde se enjuicia la actividad realizada por Pemex de los años 1938 a 1959, mismo que concluía: "en el pasado (Pemex) ha sido incapaz de lograr un nivel adecuado de ganancias sobre el capital invertido y, en consecuencia, fue incapaz de acumular recursos para su expansión futura" [Tanzer, 1969: 179].

Para Tanzer resultaba inadmisible adoptar los criterios propios de una empresa privada para evaluar una de naturaleza pública. Los éxitos de las privadas son para sus inversionistas, por lo que las premisas en las que se sustentó Levy y los informes posteriores del BM, resultaban inadecuados para evaluar a una corporación pública pues se desatiende el hecho de que las ganancias fueron mantenidas en un nivel intencionalmente bajo para subsidiar al resto de la economía mexicana por la vía de bajos precios en los combustibles y petroquímicos, y altos gastos sociales, sin detener el ritmo de inversión en mantenimiento y expansión requeridos por Pemex.

Si, por otra parte, se trata de estimar en qué forma la inversión pública realizada por medio de Pemex afecta a la economía como un todo, una de las maneras más conservadoras es medir los resultados de la inversión de la paraestatal en un sector crucial 
para evaluar el fracaso o el éxito de la industria petrolera: la exploración. En este punto, Tanzer, Bermúdez y Reyes Heroles, coincidían y, naturalmente, rechazaron con determinación los criterios y premisas usados por el BM en sus estudios sobre la empresa, en particular porque Tanzer demostró que, en términos de la economía mexicana, la tasa de ganancias para el interés público nacional y social de las inversiones de Pemex era muy alta, es decir, entre 25 y $35 \%$ anual. En los años sesenta el aporte de Pemex en el presupuesto federal rondaba poco más de $30 \%$ : en términos contables y antes de proceder bajo la condicionalidad del FMI-BM de desviar masivamente los ingresos de Pemex al servicio de la deuda y gastos masivos no productivos, gasto corriente, etc., Pemex contribuía con 30\% del costo de cuanta escuela, salario educativo, hospitalario, carretera, puente o servicio público se ofreciera. Además, de manera independiente a los prejuicios de los estudios de BM y de la conservadora Fundación Heritage que los promovía, en los hechos fue, precisamente el éxito de Pemex en la industrialización del petróleo y el aliento de importantes encadenamientos productivos desde la petroquímica (gran generadora de empleos), lo que más preocupó al big oil hoy con fusiones corporativas tipo Exxon-Mobil, ConocoPhillips y Chevron-Texaco, importante hecho histórico que registró Tanzer. Recuerda, por ejemplo, cómo a finales de los años sesenta y en medio de descubrimientos hechos durante la gestión de Reyes Heroles (padre), el Wall Street Journal informaba con destacados encabezados, que: "el monopolio petrolero nacionalizado de México es tan exitoso que preocupa a las firmas de la industria, las cuales temen que otros países sigan el ejemplo de Pemex" [Tanzer, 1969: 178]. La nota del Wall Street Journal agregaba que los altos cargos de las petroleras mostraban preocupación por el efecto de una empresa estatal como Pemex, que aumenta su eficiencia y puede dañar las operaciones petroleras privadas en el resto de América Latina y en el Oriente Medio. Un alto ejecutivo de una petrolera estadounidense expresó su preocupación porque "una empresa gubernamental tan exitosa como Pemex es un modelo para los otros países que se inclinan por nacionalizar su 
petróleo". Mientras el вм informaba a los gobiernos latinoamericanos y a todo el tercer mundo, que Pemex era un fracaso, Tanzer [1969] aclaraba: "la prensa del sector empresarial en los países desarrollados advertía a sus lectores que ¡Pemex era un éxito peligroso!”. Aún más relevante es que esto ocurrió antes de que Pemex aumentara diez veces sus reservas petroleras históricas a raíz de los grandes descubrimientos en los años setenta en Reforma y Campeche, y de que en 1970 Estados Unidos, además de haber llegado al techo de su reserva de petróleo convencional (peak oil) fuera sometido a un embargo petrolero por la OPEP (Organización de Países Exportadores de Petróleo) en 1972. A pesar de todo el abuso sistemático contra la empresa alentado por el вм desde 1982 como parte de su endoso histórico a los intereses privados nacionales de Estados Unidos, el Journal of Commerce comentaba el hecho de que Pemex realiza una contribución impositiva al gobierno mexicano "mayor que la de todas las empresas (públicas y privadas) del país, juntas" [Crawford, 1997].

La negociación de la crisis de la deuda, que a partir de 1982 conllevó la paulatina instauración de los programas de ajuste estructural (PAE), desde el área de la integración de los recursos energéticos de América del Norte, por la vía de esquemas de libre comercio se realizó mediante dos empréstitos llamados trade policy loans del BM por 500 millones de dólares cada uno, destinados a agilizar el proceso de toma de decisiones dentro y fuera del gobierno que años después desembocaría en la incorporación de México en el TLCAN, a los PAE de la agricultura (ver adelante) y el PAE diseñado para Pemex e implementado por McKinsey y Cambridge Energy Research Associates (CERA), que conllevó las siguientes metas, expuestas según orden de importancia en las Cartas de Política por Rama del вм:

1) Permitir contratos de riesgo para la exploración y el desarrollo petrolero.

2) Permitir una inversión extranjera mayoritaria en la petroquímica.

3) Dividir a Pemex en empresas separadas y en competencia. 
4) Permitir la competencia interna e internacional frente a Pemex.

5) Privatizar Pemex.

En el libro La compra-venta de México: una interpretación histórica y estratégica de las relaciones México-Estados Unidos discutí este programa (que continúa hasta nuestros días, como lo muestran los PAE) en el cual se sustenta el programa de gobierno de Enrique Peña Nieto presentado en 2013, por lo que centraré la atención en lo referido a la petroquímica y la división de Pemex en empresas separadas y en competencia, es decir, incluyendo un esquema diferenciado de precios entre las filiales, un diseño inexistente en el mundo empresarial y petrolero cuyo objetivo desarticulador (para inducir la privatización) es difícil de ocultar: garantizar y profundizar la incoherencia corporativa, en especial entre la filial dedicada a la producción del recurso y la encargada de su transformación (petroquímica). Este proceso encaminado a generar la transferencia de las actividades sustantivas de Pemex hacia firmas privadas, hasta dejar un cascarón dedicado al trámite de contratos ya en marcha en el principal eje de acumulación del país, se aplica en un México donde el gobierno formaliza, por medio del TLCAN el ahogo en materia comercial y de inversión en la economía estadounidense, y prevalecen las directrices de privatización/extranjerización de la potencia del norte, que afectan la economía, la sociedad y el empleo como un todo, y que están en la base estructural de la migración forzada, parte y parcela de la descomposición social inherente al llamado Consenso de Washington: un amplio y persistente mecanismo de corte colonial para la incautación de la riqueza nacional basada en el establecimiento y fortaleza de coaliciones de clase bien descritos por Faux [2008], entre los altos círculos de la finanza, la especulación y el monopolio de Estados Unidos y México.

Robert Kuttner, en una discusión acerca del TLCAN, comentaba que el Tratado evocaba una época anterior, cuando madres patria como Inglaterra ofrecían ventajas comerciales o preferencias a sus excolonias para asegurar su continua dependencia 
económica, financiera y política... Ciertamente las motivaciones del gobierno (de Estados Unidos) en relación con el de México nos recuerdan a los del Imperio británico.

Como se ha indicado, ese fue el cemento de tales alianzas oligárquico-imperiales, alimentadas por procesos de incautación y privatización de las grandes corporaciones públicas de México y que permitieron inusitadas ganancias que, durante el gobierno de Carlos Salinas de Gortari, colocaron veinticuatro megamillonarios en la lista dorada Forbes. Los PAE acentuaron la explotación/emigración de la fuerza de trabajo, acotando ramas con importantes encadenamientos productivos, como la petroquímica (gran generadora de empleo), promovieron el uso de mano de obra barata para las grandes trasnacionales vía las maquilas, alentaron la reprimarización de la economía y el desmantelamiento de la petroquímica estatal. Los PAE también persisten en impulsar el retiro de la protección del Estado de sectores estratégicos, en contraste con lo que ocurre en Estados Unidos, y empresas codiciadas por las grandes empresas extranjeras, sobre todo en transporte, energía y la banca, creando vacíos históricamente ocupados por la banca y las grandes empresas de los centros del capitalismo [Saxe-Fernández, 1995].

Entre los elementos del programa PAE de 1982 a 1995 y vigentes en lo fundamental en el año 2013, Ortiz [1994] destaca: a) la reducción del gasto público; $b$ ) la eliminación del déficit presupuestal al liquidar todo tipo de subsidios, incluyendo alimentos y transporte baratos para los sectores de bajos ingresos; c) la reducción del tamaño del Estado, el despido masivo de burócratas y la privatización de empresas paraestatales; d) la mayor desregulación económica en beneficio de los banqueros y los comerciantes; al estimular e) la eliminación de los controles de precios, no limitar las ganancias ni que se grave el capital especulativo y que los salarios se fijen según las "leyes del mercado"; f) desde el ángulo del sector externo se recomienda la apertura total e indiscriminada a la inversión extranjera y a las mercancías provenientes del exterior; para ello se hace necesario que el gobierno acate sin mayores titubeos las exigencias de los inversionistas extranjeros, 
es decir, la promulgación de leyes que abran las puertas a la inversión y que,además, permitan el libre movimiento de capitales y mercancías del exterior con el fin de atraer a los inversionistas foráneos quienes se transforman en la piedra angular del "modelo"; siguen en consecuencia, g) la instauración de una política cambiaria altamente flexible que permita que entren y salgan libremente los capitales nacionales y extranjeros, sin intervención por parte del Estado, es decir que se de la libertad para saquear a un país si en otro hay mayor seguridad o mayores tasas de ganancias; por esta razón, insiste Ortiz, en los ajustes fondomonetaristas, lo primero que se exige al país endeudado es que elimine todo tipo de controles cambiarios; por último, $h$ ) se considera fundamental la libre oportunidad para especular en las bolsas de valores globalizadas donde se bursatilizan y rematan muchos de los activos nacionales estratégicos.

En este contexto, el esquema de desmantelamiento de Pemex articulado por McKiney \& Co., entre otras consultoras, tuvo como piedra angular la virtual anulación de la integración vertical de Pemex, vital a toda empresa petrolera. A la paraestatal se le aplicó el esquema antimonopólico, usado en el pasado en Estados Unidos, conocido como proceso de divestiture (desmantelamiento de monopolios), que el Senado de Estados Unidos contempló para las grandes petroleras estadounidenses como respuesta a su presunta complicidad con la OPEP en la elevación de los precios del crudo del primer shock petrolero de los años setenta. Realizada una evaluación por expertos, se advirtió al Senado el peligro que presentaba para el interés nacional cualquier debilitamiento de la integración vertical de las actividades de las petroleras (corriente arriba: upstream) del pozo a los diversos encadenamientos petroquímicos y (corriente abajo: downstream) hacia la distribución y comercialización de los derivados del crudo. La integridad de las actividades upstream y downstream eran vitales a su fortalecimiento y competitividad internacional: de otra forma, el divestiture haría inevitable su eventual absorción por la competencia extranjera, representando para Estados Unidos un grave riesgo para la seguridad nacional por lo vital 
del petróleo para sus economías civil y militar. "Eso" fue lo que la quinta columna imperial y sus socios de fuera, le recetaron a Petróleos Mexicanos. Como era de esperarse, los efectos fueron profundos y negativos para Pemex, su personal técnico y trabajadores.

La economía en su conjunto y el empleo en particular fueron afectados por los PAE y por la política de exportar crudo impulsada por el FMI desde la Secretaría de Hacienda, a raíz de la crisis de 1982 para el pago del servicio de la deuda, rubro privilegiado por los tecnócratas por encima del "desarrollo nacional" (con enorme costo de oportunidad para la generación de riqueza y empleo en el país). Heberto Castillo advirtió que, cuando se tiene petróleo y fuerza de trabajo, se deben usar los energéticos en casa para crear empleos y riqueza.

Vender crudo a naciones ricas implica hacer de los trabajadores de las naciones pobres, cuando más, asalariados medio muertos de hambre al servicio de grandes capitales transnacionales [cada barril que se exporta] son miles de oportunidades de trabajo que quitan a los nativos y miles de oportunidades que brindan a las naciones poderosas para mantener su hegemonía económica en el mundo [Castillo, citado en Saxe-Fernández, 2012: 31].

La observación adquiere un tono mucho más profundo por las consecuencias para el proyecto nacional formalizado en la Constitución vigente (escribo a mediados de junio, 2013) para la estabilidad interna y la integridad de la Federación Mexicana por el desmantelamiento, privatización y extranjerización (en curso), de áreas tan vitales a la estabilidad social y política como la generación de empleo de los encadenamientos productivos de la petroquímica que afectó y quebró a miles de pequeñas y medianas empresas. La industria petroquímica de manera irresponsable y desleal ha sido llevada a un punto crítico. Esta industria:

[...] desarrollada en forma extraordinaria en México y que obtuvo en su sector estatal producciones de cerca de 20 millones de toneladas anuales fue desmantelada y actualmente (2005) produce 
cerca de 6 millones de toneladas aproximadamente 30\%. Con las modificaciones a las leyes secundarias del artículo 27 constitucional, que permitieron la inversión privada en campos anteriormente reservados al Estado, se derrumbó su producción [...] [Ocampo, 2008: 120].

En el Anuario 2012 de la Asociación Nacional de la Industria Química (ANIQ), en el rubro de ventas 2011 se indica que el volumen en toneladas de la petroquímica estatal fue de 5848196 toneladas, y el de la privada fue de 2062678.

El abatimiento de la producción nacional de petroquímicos se dio paso a paso en un proceso detectado en el gobierno de Miguel de la Madrid con una "reclasificación" por decreto, de petroquímicos básicos (constitucionalmente reservados al Estado) a "secundarios". En el siguiente sexenio el mecanismo se extendió al resto de los petroquímicos básicos. De manera simultánea se propició la desarticulación entre las filiales por medio de la instauración de los precios de transferencia.

En gran parte la estrategia gubernamental para desmantelar esta rama industrial y transferirla al capital privado [...] se basó en inventar un concepto que llamaron precios de transferencia y que los igualaron a una entelequia llamada precios internacionales. Estos últimos son precios publicados de operaciones, generalmente spot (eventuales) entre dos compañías diferentes, Pemex los aplicó a operaciones dentro de la propia empresa, o entre dos filiales, para determinar la rentabilidad de cada planta. Obviamente, con este procedimiento que nadie utiliza en el mundo con estos fines, ninguna operación petroquímica resulta rentable [...] [Ocampo, 2008: 123].

Sin embargo y a pesar de abrir las puertas de la petroquímica a la IED para invertir en cien por ciento, la avalancha de inversiones nunca se dio tal como lo indica la información de la ANIQ, sin embargo, el daño al país fue profundo. El costo de oportunidad inmenso. En 1982 se importaban 157 barriles diarios de gasolina. En 2005 la importación ascendió a 192 mil barriles diarios. En 
1982 se importaban 5 millones de pies cúbicos diarios de gas natural, en 2004 la cifra ascendió a 1285 millones de pies cúbicos al día [Ocampo, 2008]. En una síntesis sobre el desarrollo de Pemex durante los años 1995 a 2005, petroquímica vs. importaciones de derivados del etano, aromáticos y derivados, derivados del metano, propileno y derivados, así como de las importaciones en la rama petroquímica en miles de millones de dólares y las importaciones petroquímicas en miles de toneladas, Pemex ofrece un retrato bien logrado de un desastre para México, fríamente calculado y de gran beneficio para las refinerías y la generación de empleo en Estados Unidos.

Rafael Decelis Contreras muestra en un estudio que los costos de oportunidad para el país son inmensos sobre el número de empleos generados por barril de petróleo en distintas etapas de la transformación del crudo. La extracción de petróleo genera un empleo; la refinación nueve empleos; la petroquímica básica (etileno, aromáticos, propileno, metano y derivados) 16 empleos; la petroquímica secundaria (polietileno, amoniaco, benceno, glicoles, cloruro de vinilo, etc.) 22 empleos; y el producto terminado (bolsas, pinturas, gasolina, resinas, envases, hule, fertilizantes, anticongelantes, etc.) 48 empleos [Decelis, 2008]. En total un barril, en esas etapas, genera 96 empleos. Decelis estima que en los veinte años entre 1988 y 2008 se perdieron 75 mil empleos en las áreas de química y petroquímica.

\section{La modernización agraria del Banco Mundial}

La devastación salarial, el desempleo y el subempleo se manifestaron de manera profunda sobre la población campesina, en especial la indígena, propiciando un enorme proceso de privatización ejidal junto con la expulsión de varios millones de familias campesinas de sus tierras bajo el lema "drenando al campo" de Luis Manuel Enrique Téllez Kuenzler, subsecretario de agricultura 
durante el sexenio de Carlos Salinas de Gortari' con respecto de la necesidad de modernizar la agricultura y al país. Hay que tener presente que el gobierno de Salinas (y sucesores priistas y panistas) según los lineamientos marcados por el BM-BID, promovió por medio de modificaciones a la Constitución, la desaparición de la propiedad social (ejido) y además, implantó una traumática reducción de la inversión pública en el sector agropecuario de casi $80 \%$, luego entre 1985 y 2007 canalizó los recursos con el rubro de transferencias directas en un nivel alto, en la dirección privatizadora/extranjerizadora, mantuvo un nivel moderado de los bienes públicos en infraestructura y disminuyó el fomento productivo en bienes privado al mantener en nivel bajo los llamados bienes públicos en beneficio social.

Se trata de medidas diseñadas por el BM-FMI a favor de propietarios e inversionistas extranjeros agribusiness y acaparadores de tierras, y que como lo ha percibido el Estado Mayor junto con el Pentágono actúan como precipitantes de una guerra interna al sur del Río Bravo, por haber generado la mayor crisis observada en la agricultura mexicana desde la Revolución de 1910 con una multimillonaria expulsión de "brazos", sin otra dirección que la frontera en lo que las autoridades estadounidenses propensas a la criminalización migratoria llegaron a calificar de "ilegales" y, pocos años después, fueron incorporados por la burocracia de seguridad del vecino país, como "amenazas" a la seguridad nacional de Estados Unidos. ${ }^{10}$ Con la apertura comercial del TLCAN el problema se agudizó.

Los pequeños productores de todo México enfrentan la competencia de importaciones baratas de granos desde Estados Unidos como el maíz, mientras el subsidio gubernamental a los precios de los granos (siguiendo lineamientos previamente pactados con el BM-BID) fue interrumpido de manera fulminante. La inversión pública en el sector agropecuario en 1982 por la vía

${ }^{9}$ Luis Manuel Enrique Téllez Kuenzler fue secretario de Energía durante el gobierno de Ernesto Zedillo.

${ }^{10}$ Sobre inmigración "ilegal”, seguridad nacional y deportaciones en aumento veáse $<$ http://www.c-spanvideo.org/program/298700-1>. 
de créditos, transferencias fiscales y otras inversiones públicas, representaba 2.5\% del PNB. En 1991 cayó a 0.7 por ciento.

Como consecuencia de esta contrarreforma agraria, calificada por algunas revistas estadounidenses como "la revancha de don Porfirio", se observa un aumento sustancial de los latifundios y de una agresiva ofensiva de los agribusiness extranjeros. ${ }^{11}$ Los efectos sociales y políticos que han resultado del colapso de la inversión pública en el sector agrícola llevó al BM a diseñar (y al gobierno de Salinas y sucesores a aplicar) el Procampo (Programa de apoyos directos al campo), un programa de emergencia que ha variado de nombre diseñado, en parte, para enfrentar el predicamento de los campesinos pero que realmente operó con la intención de neutralizar los costos electorales de las regresivas políticas implantadas en el sector agropecuario. Un documento confidencial preparado por los asesores económicos de la Embajada de Estados Unidos dice al respecto que dicho programa (textual):

[...] nace como un instrumento creado a la luz del TLC para opacar el dolor del campesinado hacia la transición de un mercado abierto [...] la transformación económica del campo hacia el sector privado ha tenido consecuencias abruptas y catastróficas para la población rural mexicana que pocas posibilidades tiene de modernizarse para competir en el marco del TLC [...] [Domville, 1994].

Mientras el gobierno de Estados Unidos y el binomio FMI-BM impulsaron por medio del TLCAN el programa salinista de privatización rural con su respectiva contrarreforma constitucional, en ese documento privado los asesores del embajador de Estados Unidos reconocían que tal política agropecuaria representaría, a su vez, un "problema" de seguridad ya que, "[...] ha contribuido a fomentar la inestabilidad social y por lo tanto a impulsar el

${ }^{11}$ La descripción que sigue fue presentada en "Neoliberalismo y TLC: ¿Hacia ciclos de guerra civil?”, en Asociación Latinoamericana de Sociología Rural, globalización, crisis y desarrollo rural en América Latina, México, Universidad Autónoma Chapingo, 1998, y en "Banco Mundial y agricultura: el caso mexicano", en John Saxe-Fernández y Gian Carlo Delgado, Imperialismo y Banco Mundial, La Habana, Centro de Investigación y Desarrollo de la Cultura Cubana Juan Marinello, 2004, pp. 27-33. 
movimiento guerrillero zapatista" [Ibíd.]. Lo que, además, tuvo expresiones directas en el plano presupuestal con crecientes aumentos en las partidas destinadas a la Secretaría de la Defensa Nacional que dieron pie a un paulatino incremento de los programas de "asistencia militar" de Estados Unidos con el ADN de la counterinsurgency. Aquí entran en juego los procesos de centripetación capitalista, con su desenfreno privatizador en el campo, profundamente desestabilizante de los equilibrios sociopolíticos, junto con la centripetación de fuerza policial-militar desplegada desde el Departamento de Defensa de Estados Unidos y otros organismos de seguridad.

Como además, la privatización y contrarreforma agraria salinista ocurrieron casi al mismo tiempo que las elecciones presidenciales, esos mismos analistas puntualizan que el Procampo coincidió: "[...] con un año electoral [pues] el gobierno tiene la obligación de, al menos temporalmente, aliviar los problemas rurales para mantener la ventaja electoral que tradicionalmente ha disfrutado en las áreas rurales [...] [Ibíd.].

La dinámica centrifuga-centrípeta de la presidencia imperial, conoce en este caso una de sus ilustraciones (documentadas) más descarnadas. El documento reconoce, en privado, que Estados Unidos:

[...] será el mayor beneficiario de la instrumentación del Procampo pues el giro en los cultivos de las tierras mexicanas favorecerá una mayor importación de maíz y frijoles en el corto plazo [...] El giro en los cultivos mexicanos hacia otros productos básicos como trigo, sorgo, soya, arroz y algodón, hará que para el mediano y largo plazos se dé una mayor demanda de estos bienes sobrepasando la capacidad productiva nacional e incrementando las importaciones de Estados Unidos [...] [Ibíd.].

Precisamente, estos han sido los intereses cortoplacistas que desde su creación el BM ha impulsado, con respecto de los productores de granos de Estados Unidos. En el caso de México, por medio del préstamo No. 2918-ME, parte del programa de ajuste estructural agrario (Agricultural Sector Adjustment Loan: 
Agasl I) que estableció los lineamientos para impulsar lo que oficialmente se denominan reformas cuyos objetivos fueron: eliminar los subsidios globales a los alimentos; reducir la intervención gubernamental en los mercados agrícolas por la vía de eliminar los precios de garantía de los granos, exceptuando en una primera fase, al maíz y frijoles. La intención en este caso fue dejar que el mercado determinara los precios. Como resultado de la eliminación de los mecanismos de regulación se entregó un cheque en blanco a la especulación con los granos, los cuales son el cimiento de la dieta popular que funge bajo los "topes" salariales fondomonetaristas. Además, se abolieron los controles de exportación y las restricciones cuantitativas en productos claves, se redujo la participación de las paraestatales agrícolas, se liberalizó el comercio agrícola, se retiraron los subsidios a los insumos, se redujo el gasto público y se siguieron las indicaciones del BM para recortar el personal de la Secretaría de Agricultura.

En el Agsal II, de 1991-1993 con el que se profundizó más en la "reforma estructural" intervienen el BM y el BID con 400 millones de dólares, 200 son para la implementación del primer tramo (1991) y los otros 200 para el segundo (en 1993), más un cofinanciamiento con el BID por 200 millones más. Sus objetivos fueron:

a) Impulsar el intercambio y otras reformas políticas para reducir la participación gubernamental en producir, planear, comercializar, almacenar y procesar productos agrícolas e insumos; así como promover la entrada del sector privado.

b) Identificar a los consumidores de los subsidios alimentarios.

c) Modificar la participación de la Secretaría de Agricultura, alejarla de las funciones de regulación, control y formulación de la producción agropecuaria.

d) Eliminar el monopolio de la leche en polvo por parte de la Conasupo (Compañía Nacional de Subsistemas Populares), a las restricciones de importación de leche; 
restricciones que prevenían la competencia con la Productora Nacional de Semillas, el monopolio gubernamental del germoplasma y del cultivo de las plantas [Banco Mundial, 1996].

El programa orientado al desmantelamiento de las estructuras y funciones estatales a favor del sector privado (nacional y extranjero) representa una modificación a la base de la estructura y dinámica, en este caso del sector agrícola, pero que se repite a lo largo y ancho de los sectores de la industria, los servicios, el sector financiero y las actividades extractivas también de gran interés de las grandes firmas de Estados Unidos, Canadá, Europa y Japón. La incorporación de empresarios mexicanos en el reparto del botín a lo largo desde los años ochenta se hizo bajo las premisas del capitalismo de "amiguetes", de manera reminiscente a cómo se procedió con las valiosas empresas y sectores estatales de la ex Unión Soviética. En esto Washington, por medio de las "multilaterales" bajo el Departamento del Tesoro de Estados Unidos parece haber utilizado a México como experimento piloto. Uno de los objetivos centrales de los empréstitos fue "orientar" y "agilizar" el proceso de toma de decisiones intragubernamental, conllevando además un enorme y todavía no bien cuantificado cálculo de sus costos humanos y "de oportunidad". Sólo en el renglón agrícola el programa desalojó a varios millones de familias campesinas mexicanas, obligadas a dejarlo todo, a vender o rematar sus graneros y migrar a las ciudades y/o a la frontera norte.

Los empréstitos conllevan jugosas comisiones legales a favor de los operadores estatales, en particular cuando se aplican los Programas de Ajuste Estructural (PAE) a empresas ferrocarrileras, mineras o de energía, por lo que Joseph Stiglitz, exprimer economista del Banco Mundial, denominó en su oportunidad a esos instrumentos bajo el término de "empréstitos de sobornización”. Según indicó al periodista Greg Palast, para los más altos cargos, las comisiones se depositan en cuentas suizas. Lo vejatorio 
es, además, el mutismo de esas "autoridades" ante los crecientes aumentos en los subsidios, por todas las vías posibles, otorgado por el presupuesto federal, estatal y de condados a la agricultura de Estados Unidos; la ampliación de los créditos para su mayor mecanización y tecnificación por medio de la aplicación de técnicas de manipulación biogenética. Además, la Casa Blanca no sólo mantuvo (y lo sigue haciendo), sino que incrementó los precios de garantía para los granos de empresas agrícolas y farmers de Estados Unidos, especialmente el trigo y el maíz, en detrimento de los productores, desde Argentina y Brasil, hasta México.

\section{Violencia estructural y contrainsurgencia: más migración forzada}

Luego del deterioro de las condiciones estructurales en la base de la rebelión zapatista y bajo un programa castrense, Plan de Campaña Chiapas 94, se agudiza la militarización, aumentan los presupuestos de la Secretaría de la Defensa Nacional, se incrementan las "asesorías" militares de Estados Unidos y sus esquemas de contrainsurgencia, y se crea una unidad llamada la Fuerza de Ataque Arco Iris diseñada para combatir a los zapatistas. Dos meses antes de las elecciones de 1994, con Bill Clinton en la Casa Blanca, Estados Unidos ofrece 64 millones de dólares para fuerzas aéreas, incluyendo cuatro helicópteros UH-60 Backhawk, por un total de 78 millones de dólares.

Como ocurrió en un grado mucho mayor con Felipe Calderón, en Estados Unidos se pensaba que Ernesto Zedillo era política y militarmente débil. Por ello deciden "apoyarlo". Hay documentos declasificados donde se indica que Estados Unidos de manera directa y encubierta por la guerra contra las drogas, continuaría aumentando los armamentos y adiestramientos de las fuerzas militares en México para que pudieran llevar a cabo una guerra de guerrillas en las montañas por periodos prolongados. Eso se revela en documentos del Departamento de Estado y 
del Pentágono. ${ }^{12}$ Uno de los programas más importantes, es el de adiestramiento realizado por las fuerzas especiales de Estados Unidos (Green Berets) en Fort Bragg, Carolina del Norte. Ahí se desarrollan programas de capacitación en contrainsurgencia y se crean unidades especializadas de movilidad aérea para la contrainsurgencia, los Grupos Aéreos de Fuerzas Especiales (GAFE). Son programas de 12 semanas, que incluyen cursos en tácticas de asalto desde helicópteros, explosivos, guerra urbana y rural, espionaje, entre otros. Son grupos de reacción rápida de cerca de 100 hombres cada uno. En febrero de 1998 los graduados habían adiestrado a 42 equipos de 100 integrantes, asignados a las 12 regiones y 40 zonas militares que componen la estructura logística de comando.

El plan de contrainsurgencia conlleva todo tipo de operaciones especiales y de desestabilización desde fuerzas creadas, adiestradas y armadas de corte paramilitar, algo que aparentemente inició desde enero o febrero de 1995, cuando se da el reclutamiento del primer grupo paramilitar en el norte de Chiapas. Esto coincide con la mencionada ofensiva militar sorpresiva realizada por Ernesto Zedillo el 9 de febrero de 1995, para no aparecer débil. Algo similar ocurre con el gobierno de Felipe Calderón, pero en una escala mayor, más "integrada" y "coordinada" con programas de "seguridad" auspiciados por la Alianza para la Seguridad y Prosperidad de América del Norte (ASPAN) y el Comando Norte de Estados Unidos (Usnorthcom).

${ }^{12}$ Esos documentos fueron publicados el 22 de enero de 1998 por El Financiero. Entre 1950 y 1978 sólo 906 militares mexicanos participaron en los programas de adiestramiento de Estados Unidos, alrededor de 31 al año. Entre 1984-1992, Estados Unidos adiestró al menos a 512, un promedio de 57 al año, casi el doble. En 1984 se informa que la Escuela de las Américas había entrenado 600 oficiales mexicanos entre 1946 y 1994. Sólo entre 1995 y 1996, en la campaña de "antidroga", se adiestraron 500 militares y policías. Desde 1994 la presencia de mexicanos en los programas de adiestramiento es la mayor de América Latina, parejo o a la par de Colombia. Algunos cursos son operaciones de jungla, cuerpos de mando, guerra irregular, operaciones conjuntas, operaciones de patrulla, etc., y desde luego, operaciones de contrainsurgencia. También se reconoce en 1996, que en esos cursos se incluyen prácticas como la ejecución de sospechosos de insurgencia, extorsión, abuso físico, coerción y aprisionamiento bajo falsas acusaciones. 
Estados Unidos, durante el sexenio zedillista que entrega ferrocarriles, bancos y gas natural a intereses extranjeros (predominantemente estadounidenses), aumenta su influencia ideológica, financiera, militar, de contrainsurgencia y de lucha contra el narcotráfico, en la dirección y apoyo del aparato de espionaje.

Un informe del inspector del Pentágono, revela que los militares de Estados Unidos han gastado millones de dólares aumentando las labores de vigilancia e interdicción en México, sin que se observara reducción alguna del flujo de drogas hacia Estados Unidos y, mucho menos, algún esfuerzo por controlar las exportaciones de armamento de todo tipo incluyendo el de alta potencia para los carteles o los apoyos y operaciones del aparato bancario estadounidense, imprescindible en ese negocio. Aún más, hay un documento confidencial de la Oficina Federal de Investigaciones (FBI) en el cual se argumenta con datos, cómo "el libre comercio" auspiciado por el TLCAN facilita el tráfico de drogas. El informe indica cuales porciones del presupuesto federal en drogas se usa para vigilancia militar, y que éste se cuadruplicó entre 1995 y 1998.

\section{Campaña antidrogas: pantalla de la contrainsurgencia}

La relación entre la lucha contra las drogas (que es la pantalla) y la contrainsurgencia, es estrecha. Así lo reconoce, Warren Hall, coronel en el grupo del general Barry McCaffrey, entonces comandante del Comando Sur de Estados Unidos (Ussouthcom). Al respecto afirma que:

[...] es poco realista esperar que los militares restrinjan el uso de equipo a las operaciones contra los narcotraficantes [...] las técnicas que las fuerzas especiales de Estados Unidos transmiten para los despliegues antinarcóticos a las fuerzas de "infantería ligera" pueden también ser utilizadas por las fuerzas armadas en sus esfuerzos contrainsurgentes $\left[\ldots . .{ }^{13}\right.$

${ }^{13}$ Citado en informe Willson, op. cit. (textual: "It is unrealistic to expect the military to limit use of the equipment to operations against narcotraffickers $[\ldots]$ the light infrantry 
Un informe de la Oficina de la Contaduría Gubernamental (Government Accounting Office, GAO) de Estados Unidos, ofrece evidencia de que el gobierno mexicano dio mal uso al equipo militar de Estados Unidos asignado para la interdicción de drogas. En lugar de eso se usó en las zonas de levantamientos sociales populares y muchos campesinos e indígenas murieron. Para 1996, el gobierno mexicano acepta que por primera vez, permitió a las agencias de seguridad estadounidenses sobrevolar territorio mexicano. De nuevo, se hace al amparo de la campaña antinarcóticos.

Se traen, para los operativos de contrainsurgencia, a mercenarios argentinos como apoyo para el trabajo de adiestramiento de grupos paramilitares en Chiapas. Los comandantes zapatistas informan haber visto hombres usando insignias estadounidenses junto con grupos militares y paramilitares. En septiembre 1996, El Financiero, obtiene 264 documentos secretos del Pentágono bajo la Ley de libertad de información (FOIA, por sus siglas en inglés), que muestran que el gobierno de Ernesto Zedillo recibía apoyo de consejeros militares de Estados Unidos, de Guatemala, de Argentina e Israel, para reprimir a las organizaciones indígenas así como a sus redes de apoyo solidario.

En 1996, al calor de la campaña del tercer vínculo (el vínculo militar, es decir, el que se agrega al político y al económico) se da un acuerdo militar entre el general Enrique Cervantes Aguirre, encargado de la Sedena, con William Perry, del Pentágono. Willson indica que el paquete incluyó cuatro aviones C-26 de reconocimiento, 500 transportes blindados (que se agregan a los 7000 ya existentes), equipo electrónico de comando y control, equipo de posicionamiento global, más unidades de radar, rifles semiautomáticos, granadas, municiones, lanzadores de llamas, máscaras de gas, etc. Además se autoriza el adiestramiento de soldados mexicanos en Fort Bragg.

skills US Special Operations forces teach during counter drug deployment [...] can be used by armed forces in their counterinsurgency as well”.) 
James Jones, entonces el embajador de Estados Unidos y expresidente del New York Stock Exchange (NYSE), perfectamente enterado de los efectos desestabilizadores e inductores de guerra civil en el paquete económico, como ya se mencionó, afirma que: "Estados Unidos está preparado para ofrecer más, para combatir a los terroristas. Todo lo que el gobierno mexicano tiene que hacer es pedir. Lo que requieran, nosotros ciertamentelo apoyaremos". ${ }^{14}$

\section{Coda: Geopolítica del desalojo ${ }^{15}$}

"Imperialización" y no "globalización" es la categoría adecuada para explicar lo que ocurre en la economía y la política del país. La privatización y extranjerización sigilosa e inconstitucional de Pemex, el desmantelamiento de la petroquímica estatal y la apertura total a la producción subsidiada de maíz, frijol, caña de azúcar y leche en polvo de Estados Unidos al entrar en vigor el capítulo agropecuario del TLCAN en 2008, son ejemplos como se ha reseñado, de un fenómeno de larga data, cuya intensidad y ritmo se acelera. Es además, un diseño demográfico que expulsa anualmente a 600 mil connacionales, centrado en una guerra de clase desplegada en nombre de la tasa de ganancias desde los PAE, con las desleales complicidades empresarial-gubernamentales de México. Con el aumento del desempleo crónico en Estados Unidos por la crisis de 2007, la represión y expulsión de los migrantes mexicanos se intensificó, cerrándose una válvula de escape a la presión/expulsión poblacional forzada generada por el diseño desindustrializador vigente y por la violencia generalizada, especialmente en el norte del país, desatada por el esquema impulsado por el BM-BID en lo económico y por un diseño de guerra irregular con asesorías militares y policiales de Estados Unidos, bajo el título de guerra contra el crimen organizado o contra el narcotráfico.

${ }^{14}$ Textual: All the Mexican government has to do is ask. Whatever they need, we will certainly support.

${ }^{15}$ Una versión preliminar fue publicada en La Jornada, 3/I/2008. 
Al tiempo que durante el gobierno de Calderón se abrieron las puertas a personal militar (formalmente retirado, pero en funciones) y de unas seis agencias de inteligencia de Estados Unidos, la potencia del norte mantiene desde 2004 la desregulación instaurada del enorme flujo de armas de alto poder hacia el sur (que abastece a los carteles y al crimen organizado) junto con el astronómico lavado de dinero en bancos y empresas: parte central de la madeja causal del desenfreno de la violencia que padece México, en especial en Nuevo León, Tamaulipas y Chihuahua, donde miles de connacionales, empresarios y profesionales altamente calificados se refugian en el sur de Texas generando lo que economistas y prensa perciben como un boom por el éxodo norteño.

En la frontera norte, se constata la implicación de Estados Unidos en un proceso de violento desalojo, de migración forzada de mexicanos y centroamericanos, por la guerra antinarco, que incluye, desde tiempos de Bush/Cheney, operativos tipo "rápido y furioso", bajo el auspicio oficial. Se promueve el binomio violencia-desalojo (migración forzada) que, en los hechos, contribuye a que las ciudades fronterizas como El Paso y Mission tengan "un acelerado desarrollo". El boom en Mission, la ha llevado a ubicarse como la cuarta en crecimiento sostenido en Estados Unidos, lo que contrasta con los problemas económicos e inmobiliarios que padece actualmente ese país por la "gran recesión" que se desató a finales de 2007 [Foster y Magdoff, 2009]. En este auge, se destaca que $70 \%$ de las nuevas casas son propiedad de mexicanos. De la red de empresarios mexicanos radicados en El Paso, se advierte que Juárez es territorio de nadie, mientras el Comando Norte $(\mathrm{CN})$ realiza un monitoreo sociológico del gran desalojo, gestado por su guerra irregular que como dice el $\mathrm{CN}$, al igual que en Afganistán, combate a un enemigo que está entre los civiles. Así, a los millones de expulsados por los efectos estructurales del diseño económico vigente desde 1983, se agrega la llamada migración dorada, de la clase empresarial localizada en el norte del país que huye de la violencia desatada desde 2007. La violencia e inseguridad en México han provocado que los estados 
del norte registren caídas de 78\% en IED, según la Secretaría de Economía. El fenómeno, a ser incluido bajo el rubro de migración forzada, fue sintetizado en la prensa nacional así:

La violencia e inseguridad en México ha provocado que los empresarios del norte del país (gente que crea negocios, empresas, que invierten, consumen y rentan viviendas) se trasladen a vivir a Estados Unidos. A este fenómeno se le conoce como migración dorada, la cual beneficia económicamente a la Unión Americana y, por el contrario, deja una estela de casas abandonadas, crisis financiera y éxodo de estudiantes aquí en México [...] [Foster y Magdoff, 2009].

El proceso, con nombres y apellidos, se desprende de una red de complicidades, intereses y transas de clase acentuadas desde la crisis de 1982 y del sometimiento neoliberal a las ambiciones y lucros del capital monopolista de dentro y de fuera, consignados en Forbes y en la cartera de negocios de Pemex [Faux, 2008]. Ello con su caudal de despidos, cientos de miles de ferrocarrileros, trabajadores y técnicos de Pemex y de la Comisión Federal de Electricidad (CFE), quienes sufrieron los costos del desmantelamiento petroquímico y de los millones desalojados de sus puestos de trabajo, de brutal agresión policial-militar a los mineros y a miembros del Sindicato Mexicano de Electricistas (SME), del desarme de sus contratos colectivos y de la expulsión de varios millones de familias campesinas como resultado de la "modernización agraria".

Felipe Calderón, exsecretario de energía de Vicente Fox que encabezó una brutal guerra irregular en funciones de "presidente" (con más de 120 mil bajas y decenas de miles de desaparecidos), continuó el diseño de reprimarización y privatización de facto de las actividades sustantivas de Pemex [Ángeles, 2011]. Cabe recordar que el diseño energético estuvo a cargo de expertos vinculados con Enron, a favor de grandes petroleras/gaseras y una agenda energética en la que, entre otros mecanismos desnacionalizadores, destacó el uso de contratos internacionales "llave en mano" para obra pública, "que privilegia a los extranjeros y crea fuentes 
de trabajo fuera de México" [Ángeles, 2011]. Llevando la dinámica de la migración forzada a trabajadores, cuadros profesionales y técnicos en Pemex y más allá. La industria de ingeniería de plantas de proceso, que se estima llegó a ocupar 20 millones de horas-hombre, ha sido desmantelada y hoy representa menos de 5 millones. Ocampo [2008] agrega que:

Las repercusiones de este desmantelamiento son graves. Al realizarse la ingeniería de las plantas industriales en el extranjero, no solamente se deja sin trabajo a mexicanos especializados en este ramo, sino que se impide el fortalecimiento de las capacidades tecnológicas del país, al realizarse la ingeniería en el extranjero se propicia la compra de equipos y materiales en los países de origen. Los proyectistas que realizan estos trabajos no conocen, ni les importan, los proveedores nacionales de bienes de capital, equipo y materiales $[\ldots]$.

De manera simultánea, Felipe Calderón al mando de la Secretaría de Energía abrió aún más los yacimientos a firmas foráneas de servicios (Halliburton, Schlumberger, etc.) cuando ya se registraban ataques, secuestros de trabajadores de Pemex y saqueo de ductos con apoyo de "entes armados", todo atribuido al crimen organizado. La conjunción del entreguismo energético, con la guerra irregular, persiste en el gobierno de Enrique Peña Nieto y es explosivo. En especial, cuando fuentes periodísticas de Estados Unidos revelan despliegues de fuerzas especiales estadounidenses en 120 países, 19 de ellos latinoamericanos.

La violencia, la descomposición social, el desempleo crónico y la criminalidad que conlleva el diseño instaurado desde hace treinta años se dejan ver de manera dramática en el siguiente retrato estadístico del gran desalojo (véase la gráfica 1 ).

Se deja expresión gráfica de un fenómeno complejo, como lo plantean Márquez y Delgado [2011b], de los:

sujetos sociales que se ven obligados a emigrar para acceder a recursos económicos suficientes que permitan su subsistencia. Por ejemplo: campesinos despojados de la tierra, obreros desempleados o 
en condición de explotación, jóvenes desempleados, profesionistas sin posibilidad de ascenso social, mujeres víctimas de la violencia estructural, trabajadores calificados con pocas posibilidades de trabajo $[\ldots]$.

\section{Gráfi ca 1. Migración de mexicanos hacia Estados Unidos, 1850-2010}

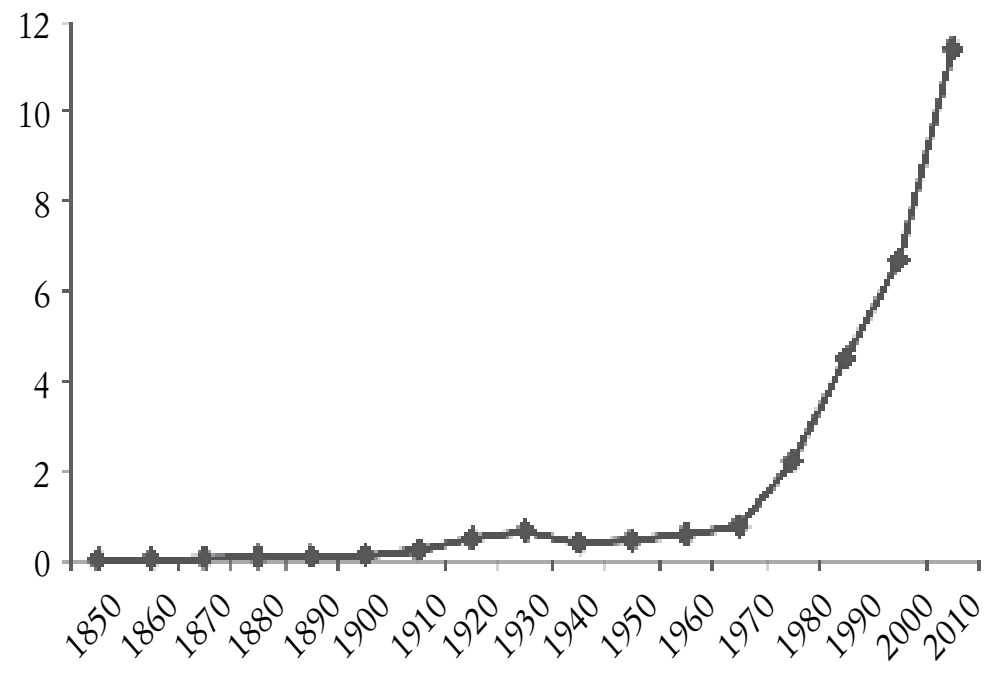

Fuente:Decennial Censuses, 1850-1990; Pew Hispanic Center, 1994-2010.

En este trabajo se abordaron los antecedentes históricos más relevantes en la estructuración de la política económica que está en la base de este tipo de procesos migratorios, parte y parcela de los enormes costos, de la descomposición del tejido social (desempleo, subempleo, hambre e informalidad económica) que acarrea el "esquema" vigente desde principios de la década de los años ochenta, contenido en la condicionalidad "cruzada" de las instituciones financieras creadas en Bretton Woods por Estados Unidos, atada a todas las líneas de crédito. Se ejemplifican los diseños regresivos en materia agraria y los de desindustrialización, en el sector energético con atención en la petroquímica y otras ramas cruciales afectadas por la ineficiencia, el clientelismo 
y los impactos del diseño económico impulsado desde las "instituciones multilaterales", que en realidad operan bajo la batuta del Departamento del Tesoro de Estados Unidos, sobre todo el FMI y el BM. Los efectos cumulativos de treinta años del recetario desde el inicio del siglo XXI adquieren expresiones de alta militarización, paramilitarización y violencia estructural. Con el gobierno de Enrique Peña Nieto, la intención se centra en torno de más de lo mismo, conllevando un PAE multidimensional (laboral, educativo, fiscal, energético) de profunda desestabilización. En este contexto la organización ciudadana de la resistencia civil pacífica debe proyectarse a la población mexicana como un todo, incluyendo aquella afectada por la "migración forzada" y que hoy radica en Estados Unidos.

\section{BiBLIOGRAFÍA}

Ángeles, Sarahí [2011], Reforma energética: anticonstitucional, privatizadora y desnacionalizante, vols. 1 y 2, México, Cosmos Editorial.

Banco Mundial [1996], Informe de Evaluación del Proyecto.

Beinstein, Jorge [2013], "La ilusión del metacontrol imperial del caos: la mutación del sistema de intervención militar de Estados Unidos y sus consecuencias para América Latina”, Mundo Siglo XXI, CIECAS-IPN, 8(30): 27-35.

Cox, Robet W. [1981], "Social forces, states and world orders: beyond international relations theory", Millennium Journal of International Studies, 10(2): 126-155.

Crawford, Leslie [1997], "Pemex Proves Mexico's godsend", Journal of Commerce, 2/III/1997: 1.

Decelis, Rael [2008], Diagnóstico de las reservas y la situación financiera de Pemex, México, UNAM.

Domville, Lucía [1994], "Procampo, instrumento del TLC. EU el principal beneficiario", El Financiero, 28, abril, 1994: 20.

Faux, Jeff [2008], Guerra global de clases. Cómo nos robaron el futuro las elites de Estados Unidos, Canadá y México y qué hacer para recuperarlo, México, UACM, 528 pp. 
Foster, Bellamy y Fred Magdoff [2009], La gran recesión, México, FCE.

Goldsmith, Edward [1999], Interview, Government Technology, Washington DC, $21 \mathrm{pp}$.

Guillén, Arturo [2007], Mito y realidad de la globalización neoliberal, México, UAm/Porrúa, cap. 3 y 4.

Kinzer, Stephen [2003], All the Shah's Men: An American Coup and the Roots of Middle East Terror, Nueva York, John Wiley \& Sons.

Klare, Michael [2004], Blood and Oil, Nueva York, Metropolitan Books, pp 23-55.

Kofas, John [1948], Papers of Averell Harriman, Estados Unidos, Library of Congress, 206 pp.

Kofas, John [1996], Foreign Debt and Underdevelopment, Maryland, University Press of America, 246 pp.

Kolko, Joyce y Gabriel Kolko [1972], The Limits of Power, The World and the United States, 1945-1954, Nueva York, Harper \& Row.

Márquez, Humberto y Raúl Delgado Wise [2011a] "Una perspectiva del Sur sobre capital global, migración forzosa y desarrollo alternativo", Migración y desarrollo, vol. 9, núm. 16: 3-42.

Márquez, Humberto y Raúl Delgado [2011b], "Signos vitales del capitalismo neoliberal: Imperialismo, crisis y transformación social”, Estudios críticos del desarrollo, julio-diciembre, 1(1): $11-50$.

Melman, Seymour [1975], Capitalismo del Pentágono, México, Siglo XXI.

Melman, Seymour [1987], Profits without Productivity, Filadelfia, University of Pennsylvania Press.

Ocampo, José F. [2008], "Sector energético industrial: análisis y propuestas", publicado en John Saxe-Fernández (coord.), La energía en México: situación y alternativas, México, CEIICH/UNAM.

Ortiz, Arturo [1994], Política económica de México, 1982-1995, México, Editorial Nuestro Tiempo, 176 pp.

Paley, William S. [1952], The Report of the President's Materials Policy Commission, Washington DC, Government Printing Office, vols. 1, 2, 3, 4 y 5. 
Saxe-Fernández, John y G. Carlo Delgado [2003], Banco Mundial y Desnacionalización integral en México, México, Ceiich/ UNAM, pp. 12 y ss.

Saxe-Fernández, John [1994], "Pemex: No Privatizarlo”, Excelsior, 28/VI/1994, p.7A y 8A.

Saxe-Fernández, John [2012], "Trabajo, petróleo y despojo”, La Jornada, 15 de noviembre, pp 31.

Saxe-Fernández, John [2002], La compra-venta de México: una interpretación histórica y estratégica de las relaciones MéxicoEstados Unidos, México, Plaza \& Janés.

Saxe-Fernández, John [1995], "Plan de Choque y la dialéctica entre macrorregionalización y microrregionalización”, Problemas del Desarrollo, México, IIEc-UnAm, 26(102):7-28, julioseptiembre.

Shoup, Laurence y William H. Minter [1985], Imperial Brain Trust, Nueva York, Monthly Review Press.

Sweezy, Paul [1994], "The Triumph of financial capital", Monthly Review, 46(2): 1-11, junio, disponible en $<$ http://monthlyreview.org/1994/06/01/the-triumph-of-financial-capital $>$.

Szmrecsá, Tamás [2005], "The contributions of Celso Furtado (1920-2004)", European Journal of History of Economic Thought, 12(4): 689-700, diciembre, disponible en <http:// www.corecon-rj.org.br/pdf/celsofurtado_tamas_european_ journal_of_the_history_of_economic_thought_.pdf $>$.

Tanzer, Michael y Stephen Zorn [1985], Energy Update, Nueva York, Monthly Review Press, pp 51-75.

Tanzer, Michael [1969], The Political Economy of International Oil and the Underdeveloped Countries, Boston, Beacon Press. 


\title{
Capítulo 2 \\ EL DERECHO DE QUEDARSE
}

\author{
Armando Bartra*
}

Sería desastroso para nuestra economía nacional el reconocimiento como sistema aceptado del precedente de facilitar la salida de nuestros mejores elementos de trabajo cuando encuentran demanda en el extranjero y, a la inversa, recibir forzadamente tales contingentes de trabajo cuando ya no son necesarios en el extranjero y nosotros tampoco estamos económicamente en condiciones de recibirlos.

Manuel Téllez, secretario de Relaciones Exteriores durante el gobierno de Plutarco Elías Calles, 1928 [Bartra, 2003].

Presenciamos una erosión generalizada del campo, un curso prolongado y multidimensional de deterioro; corrosión en marcha que de no revertirse a tiempo nos llevará a una crisis general provocada por la combinación de múltiples conflagraciones puntuales; el resultado de esto es un éxodo masivo de mexicanos que buscan en el norte un futuro del que carecen aquí, es el saldo de un modelo que nos llevó de la explotación a la exclusión. Por

* Licenciado en Economía, tiene estudios en Filosofía en la Facultad de Filosofía y Letras de la UNAM. Ha sido profesor en la Facultad de Economía, en la Escuela Nacional de Antropología e Historia, director del Instituto de Estudios para el Desarrollo Rural Maya, A.C. Actualmente es profesor-investigador, titular C, en la UAM-Xochimilco, imparte cátedras en la Licenciatura en Sociología y el Posgrado en Desarrollo Rural. <abartra@correo.xoc.uam.mx>. 
lo tanto, es necesario tratar de amortiguar el dolor social que causa la diáspora apoyando a los migrantes organizados que reivindican su dignidad y defienden sus derechos. Pero es necesario también defender el derecho de no migrar, hoy más que nunca es necesario reivindicar el derecho de los mexicanos al trabajo, exigiendo programas de fomento y defensa del empleo que garanticen la seguridad laboral del país. Entonces, y solo entonces, la migración dejará de ser fatalidad y condena para devenir intercambio enriquecedor.

Si hacemos abstracción del resto de la sociedad mexicana el campo se nos muestra como espejo trizado del desastre nacional. Es frecuente llamar crisis a esta calamidad, pero dado que crisis designa la fase álgida de un proceso, prefiero reservar la palabra para un futuro y por desgracia previsible colapso.

En sentido estricto lo que presenciamos es una erosión generalizada del mundo rural, un curso prolongado y multidimensional de deterioro, degradación y desarticulación con momentos agudos delimitados en el tiempo y el espacio. Corrosión en marcha que, de no revertirse a tiempo, nos lleva a una crisis general provocada por la combinación de múltiples conflagraciones puntuales estallando de manera simultánea y retroalimentándose.

\section{CAMPO EROSIONADO}

Pese a que componen un descalabro sistémico integral describiré por separado algunas de estas dimensiones:

Erosión económica, manifiesta en el peso decreciente del sector agropecuario en el PIB, que en 2012 fue de 4\%, además de incertidumbre, baja rentabilidad y lento crecimiento. Un sector de la producción que entre 1945 y 1976 se expandía a una tasa promedio anual de 3.8\%, entre 1982 y 2008 bajó su tasa de crecimiento a $2 \%$ y en los años del TLCAN, de 1994 a la fecha, la expansión anual fue de sólo 1.8\%. En particular las 
cosechas de granos y oleaginosas se estancaron desde 1980 en alrededor de 30 millones de toneladas y paralelamente en los últimos 15 años se perdieron 2.5 millones de empleos rurales.

Erosión de la seguridad alimentaria, manifiesta en creciente necesidad de importar comida, pues mientras que en 1980 la dependencia del país en alimentos era de $15 \%$, en 2011 fue de casi 50\%: 36\% en maíz, 61 en trigo, 85 en arroz, 94 en soya, $21 \%$ en frijol... México, dice la Cepal, "se convirtió en el principal importador de alimentos básicos en América Latina”, y la FAO precisa: "México es el principal importador de granos en America Latina y el Caribe" [Fernández-Vega, 2012].

Erosión ecológica, manifiesta en reducción de los bosques: entre 2000 y 2010 México perdió en promedio 200 mil hectáreas arboladas por año [Toledo, 2012: 31]; agotamiento de acuíferos, de los que más de 100 están sobreexplotados [Toledo, 2012: 33]; contaminación de aguas, que hoy afecta a 700 cuencas hidrográficas; además de degradación de suelos, desaparición de especies y desarticulación de ecosistemas. De acuerdo con las Cuentas Económicas y Ecológicas de México, que publica el INEGI, entre 2005 y 2009, último periodo reportado, el agotamiento de los recursos naturales y la degradación del ambiente le costaron al país cada año cerca de $8 \%$ del PIB, monto que equivale a la suma de 150 salarios mínimos por habitante [San Vicente, 2012: 140].

Erosión social, manifiesta en debilitamiento, descomposición y aun necrosis del tejido comunitario, derivados del deterioro de la economía y los servicios, de la imparable migración, de la expansiva narcoeconomía y de la inseguridad generalizada. La llamada "guerra" al narcotráfico dejó, entre 2006 y 2012, más de 60 mil muertos y cerca de 300 mil desplazados, la mayor parte en el campo. Y si se añaden las víctimas de homicidios dolosos, la cifra aumenta a cerca de 90 mil, lo que significa que en algo más de un lustro los afectados indirectos de este tipo de violencia son del orden de 360 mil, entre ellos unas 24 mil viudas y cerca de 50 mil huérfanos [Díaz, 2012: 18-20]. 
Erosión demográfica, manifiesta en la desproporción que en los porcentajes de población por género y edad, ocasiona un éxodo en el que aun predominan los varones jóvenes de modo que el campo se feminiza y envejece; así, por ejemplo, $50 \%$ de los ejidatarios tiene más de 55 años y $20 \%$ son mujeres.

Erosión política, manifiesta en que cada vez más mexicanos desconfían del Estado de Derecho y consecuentan el delito o se hacen justicia por propia mano, en una ingobernabilidad hormiga que asociada a la militarización de muchas regiones pone al campo en un virtual y no declarado Estado de excepción. Estudios recientes sostienen que "regiones enteras de México están controladas por actores no estatales, como son las organizaciones multicriminales (que) han mutado de $[\ldots]$ carteles de la droga a [...] motor de sociedades y economías alternativas" [Campbell citado en Appel, 2012: 38].

Erosión moral, manifiesta en que se perdió la esperanza de que la vida en el campo algún día mejore, con el consiguiente desaliento de los viejos y la deserción casi unánime de los jóvenes que no vislumbran ningún futuro rural deseable.

Todas las facetas del desbarajuste son alarmantes, pero más que todas, la erosión de las estrategias productivas de solidaridad intergeneracional con que ancestralmente los campesinos han buscado asegurar el futuro de familias y comunidades.

Sometidos por definición a la incertidumbre climática y económica, los rústicos han tomado siempre muy en cuenta el largo plazo mediante emprendimientos productivos que tanto en las buenas como en las malas garanticen la preservación de la colectividad. Lo que incluye una permanente preocupación por incrementar el patrimonio productivo: tanto natural, como técnico, económico y humano.

Esta percepción de futuro, que no rechaza la innovación pero es básicamente conservadora por cuanto pretende evitar riesgos que pongan en peligro la continuidad de los núcleos familiar y comunitario, está hoy en serio predicamento por la 
deserción física y espiritual de los jóvenes rurales. Ominosa fractura generacional manifiesta en la tendencia creciente a destinar las remesas que envían los migrados, no al patrimonio productivo sino a bienes de consumo duraderos como la vivienda. Por primera vez de manera generalizada las familias rurales mexicanas están reduciendo el horizonte de sus previsiones a una generación, lo que pone en severo riesgo el siguiente eslabón de la milenaria historia campesina.

Algunos piensan que esta debacle es un mal menor pues el campo cuenta poco en el México del tercer milenio. Y es que en años recientes la aportación del sector agropecuario al valor de la producción nacional ha sido de alrededor de $4 \%$ ¿Por qué alarmarse, dicen, ante el desfondamiento de un ámbito que genera apenas cuatro de cada cien pesos del PIB?

Pero sucede que, si bien sólo 4\% del PIB es agropecuario, el agro aun emplea $16 \%$ de la población económicamente activa, además de que $23 \%$ de los mexicanos vive en el medio rural. Es decir que la importancia del campo en el empleo es cuatro veces mayor que su peso en el valor de la producción y es el ámbito de residencia de uno de cada cuatro compatriotas.

Aun esta ponderación es injusta, si tomamos en cuenta que la producción económica nacional (en la que el agro es tan poco relevante) incluye ganancias financieras especulativas, comida chatarra, publicidad chatarra, diversión chatarra y miles de millones de pesos en productos suntuarios que consumen unos pocos. En cambio, $4 \%$ agropecuario del PIB contiene los alimentos: bienes fundamentales cuando la escasez y carestía de los básicos provocan hambrunas en el ámbito planetario. Además de que sí bien menos de dos de cada diez puestos de trabajo son agropecuarios, estos se ubican en labores directamente vinculadas con la reproducción social de la naturaleza.

El trabajo agrícola es el eslabón decisivo en la cadena que articula a la sociedad con el medioambiente, nexo fundamental en tiempos de deterioro ecológico y crisis climática. Porque el campo nos aporta alimentos pero también aire fresco, tierra fértil, agua pura, clima benigno, diversidad de especies, paisajes 
amables... Dones impagables que algunos han querido transformar en "servicios ambientales" para que coticen en el mercado cuando son las premisas de la vida.

\section{EL DERECHO DE NO EMIGRAR EN DIEZ TESIS}

Hace algo más de diez años, cuando estrenábamos siglo y la estampida de mexicanos rumbo al gabacho estaba en su apogeo, yo participaba con regularidad en un seminario sobre migrantes mexicanos y centroamericanos en Estados Unidos, patrocinado por el Human Rights Program de la Universidad de Chicago y coordinado por Susan Gzesh. Los debates se ocupaban sobre todo de los derechos del que migra, y fue ahí donde hable por primera vez del derecho a no migrar. La fórmula fue recogida por estudiosos como la propia Susan, Jonathan Fox y Ana María Aragonés, así como en programas de organizaciones transfronterizas como el Frente Indígena de Organizaciones Binacionales (FIOB), y convergencias como el Movimiento Indígena y Campesino Mesoamericano (Moicam), el movimiento El campo no aguanta más, y los firmantes del Plan de Ayala del siglo xxI.

Hoy el flujo migratorio ha disminuido, no porque haya bonanza en México sino porque hay recesión en Estados Unidos. Pero la compulsión al peregrinaje no disminuye y muchos jóvenes solo esperan que mejore la economía del país vecino para emprender el viaje. El derecho a no migrar sigue, pues, siendo asignatura pendiente y puede ser oportuno recordar lo que entonces escribí y transcribo a continuación:

El éxodo masivo de mexicanos que buscan en el norte un futuro del que carecen aquí es el saldo más lacerante de la vía de desarrollo adoptada desde los ochenta. Un modelo que nos llevó de la explotación a la exclusión; de un sistema injusto de fortunas ofensivas y trabajadores empobrecidos, a un sistema inicuo de fortunas ofensivas, trabajadores empobrecidos y ejércitos de desempleados; de un país donde 
los pequeños y medianos productores del campo y la ciudad estaban en desventaja frente a los grandes empresarios, a un país de pequeños empresarios quebrados y campesinos arruinados.

La diáspora que nos aqueja no se inscribe en una presunta mundialización racional de los mercados de trabajo, sino en la globalización excluyente [...] no es una migración que pueda contenerse con métodos represivos, que pueda atajarse neocolonizando el sur o que pueda atenuarse capitalizando las remesas. Y no la hará remitir el TLCAN, pues la liberación asimétrica del comercio es parte de la enfermedad y no el remedio.

Entonces es necesario tratar de amortiguar el dolor social que causa la diáspora apoyando a los migrantes organizados que reivindican su dignidad y defienden sus derechos. Pero es necesario también defender el derecho de no migrar, el derecho de los hombres del sur a permanecer en su tierra si así lo desean.

Hoy más que nunca es necesario reivindicar el derecho de los mexicanos al trabajo, exigiendo programas de fomento y defensa del empleo que garanticen la seguridad laboral del país $[\ldots]$.

Necesitamos políticas industriales y agrícolas orientadas a la defensa y ampliación de la planta productiva y de los cultivos de interés nacional. Debemos restablecer la seguridad alimentaria respaldando a la pequeña y mediana producción campesina y fortaleciendo el mercado interno, tanto nacional como regional y local. Nos hace falta restaurar la seguridad laboral defendiendo y ampliando la planta fabril y la actividad agropecuaria, mediante la integración de cadenas que potencien nuestras complementariedades productivas.

Entonces y solo entonces, las remesas que sigan llegando podrán incorporarse productivamente al desarrollo. Entonces y solo entonces, la migración dejará de ser fatalidad y condena para devenir intercambio enriquecedor [Bartra, 2003: 62 - 64]. 
Como el dinosaurio, el "problema" migratorio sigue ahí, y a casi tres lustros de distancia puede ser pertinente ratificar las ideas fundamentales de mi argumentación. En busca de claridad y brevedad lo haré en forma de tesis.

1. La emigración de la periferia al centro, del sur al norte, del campo a las ciudades no es virtuoso ajuste en los mercados laborales sino expulsión social resultante de la degradación ambiental, económica, política y moral de los países y regiones de origen.

2. En tanto que expulsión, la migración multitudinaria y compulsiva es en sí misma indeseable, con independencia de si el flujo es terso o accidentado, de modo que si es importante reivindicar los derechos de que migra, lo es más defender el derecho a no tener que migrar.

3. El derecho de irse no es tal si no existe el derecho de quedarse, pues la opción de migrar solo es un acto de libertad si tenemos también la opción simétrica, la de quedarnos, lo que supone oportunidades de trabajo digno y de vida con calidad en las regiones de origen.

4. Compulsiva, multitudinaria y casi siempre indocumentada, la presente implosión demográfica global que tiene a cerca de 300 millones de personas fuera de sus países de origen, es repudiable por el dolor humano que ocasiona, sobre todo cuando se la criminaliza, como hoy sucede, pero es también indeseable por razones estructurales.

5. Cuando el flujo humano se origina en países de jóvenes, el hecho de que emigren al extranjero significa dilapidar el "bono demográfico", consistente en que por un tiempo la población en edad de trabajar es un porcentaje muy alto de la total. Lo que es una ventaja si la capacidad laboral extraordinaria se emplea en crear patrimonio productivo que permita más tarde enfrentar con solvencia las necesidades propias de sociedades envejecidas. Pero si las únicas opciones de quienes llegan a la edad laboral son la migración, el desempleo, la economía subterránea 
y la delincuencia, el premio poblacional se desperdicia y, en el mejor de los casos, se transfiere a los países de destino, que capitalizan la transfusión de sangre joven. El retorno que representan las remesas parece cuantioso, pero es una porción ínfima del valor agregado que creó la esforzada labor de quienes las envían: la parte del salario susceptible de ser ahorrada, mientras que la tajada de león se queda en el país anfitrión en forma de salarios, utilidades e impuestos.

6. Cuando el flujo humano se origina en zonas rurales, además de la transferencia del bono poblacional, cuyos efectos lesivos son de mediano plazo, tiene lugar una pérdida aun más profunda y cuyas implicaciones son seculares. La migración prolongada o definitiva de las generaciones campesinas jóvenes, desarticula las estrategias productivas de solidaridad transgeneracional que han hecho posible la milenaria permanencia de las comunidades agrarias. En el ámbito interno y comunitario lo habitual era que el premio demográfico que representa la presencia de muchos jóvenes se empleara en la creación de patrimonio familiar y comunal, que a su vez permitiría enfrenar con éxito tanto el envejecimiento de la familia como las eventualidades socioambientales: es decir que en tiempo de vacas gordas los campesinos se preparaban para los tiempos de vacas flacas. Pero cuando la mayor parte de los jóvenes se separa física y espiritualmente de una actividad agropecuaria siempre frustrante, se rompe el eslabón generacional y tanto familias como comunidades pierden la perspectiva rural de mediano y largo plazo, acortando sus planes al lapso de vida de una generación, lo que explica que las remesas se empleen casi exclusivamente en bienes de consumo, momentáneo o duradero. Esta pérdida civilizatoria de saberes y valores es preocupante, y más hoy cuando está quedando claro que una de las salidas a las dimensiones ambiental, alimentaria y energética de la gran crisis consiste en restaurar la pequeña y mediana 
producción campesina. Economía doméstica rural que la migración está desfondando en sus aspectos medulares.

7. Dimensión fundamental del derecho a no emigrar (aunque no la única pues también importa la calidad de los servicios en las zonas de origen) es el derecho a un trabajo digno. Un derecho que está en la Constitución, pero en la práctica no es exigible, pues el Estado, que proporciona seguridad, salud, educación y otros servicios, no proporciona empleo, lo que asemeja este derecho al de la alimentación, pues tampoco produce alimentos. Pero lo que sí es obligación constitucional del Estado es la rectoría de la economía mediante una planeación democrática, y es ahí donde los derechos al trabajo y a la alimentación se deben materializar en forma de políticas, programas y presupuestos públicos comprometidos con el fomento a la producción de alimentos y a la creación de empleos.

8. El problema es que la exigibilidad de derechos constitucionales carece de sustento práctico si no existen las correspondientes leyes reglamentarias. En este caso hace falta una Ley de Planeación para Seguridad y Soberanía Laboral con Empleos de Calidad, del todo semejante a la Ley de Planeación para la Seguridad y la Soberanía Alimentaria y Nutricional, que está perdida en los laberintos del Congreso. Es verdad que por sí solas las leyes no resuelven los problemas, pero son el marco adecuado para demandar al poder legislativo que en su atribución de revisar y en su caso modificar la Ley de Ingresos y el Presupuesto de Egresos, la desempeñe asumiendo como prioridades la generación de alimentos sanos y de empleos de calidad.

9. En el caso del campo, es claro que el actual gasto público no tiene como prioridades ni la producción de alimentos sanos ni la creación de empleos rurales de calidad, de modo que, así sea por omisión, propicia tanto la dependencia alimentaria como la desbandada migratoria. Y es que a los campesinos se les trata como pobres y no como productores en desventaja, de modo que son destinatarios 
del gasto social rural pero no de la inversión pública productiva, que es fuertemente regresiva pues se concentra en las regiones desarrolladas y los productores capitalizados. Así pues, en lo respectivo al campo, reconocer en serio el derecho de no emigrar haciendo efectivo el derecho constitucional a trabajos rurales dignos, supone invertir las prioridades en las políticas, programas y presupuestos públicos.

10. Hacer valer el derecho a no emigrar y el derecho a la alimentación, demanda reasumir la soberanía laboral y alimentaria, pues estos derechos sólo serán efectivos si se toma la decisión estratégica de impulsar las pequeña y mediana economías campesinas productoras de alimentos y generadoras de empleos. Economías que, debidamente palanqueadas, pueden ser eficientes y competitivas. Sobre todo si en el balance beneficio/costo se consideran, además del producto estrictamente económico, las aportaciones sociales, ambientales y culturales que acompañarían a la revitalización de la comunidad agraria.

\section{BiBLIOGRAFÍA}

Appel, M. [2012], “Ante el Estado fallido, narcoestado sustituto", Proceso, 6/5/12, núm. 1853: 38.

Bartra, A. [2003], Cosechas de ira. Economía política de la contrarreforma agraria, Itaca, México, pp. 131.

Díaz, G. L. [2012], "Las víctimas visibles e invisibles del sexenio”, Proceso, 3/6/12, núm. 1857: 18-20.

Fernández-Vega, C. [2012], "México S.A.”, La Jornada, 27/11/12, Opinión, México.

San Vicente, A. [2012], "Campo y soberanía alimentaria”, en Bartra, A., Los grandes problemas nacionales, Itaca, México, pp. 397.

Toledo, V. [2012], "Medio ambiente”, en Bartra, A., Los grandes problemas nacionales: Diálogos por la regeneración de México, Itaca, México, pp. 397. 


\title{
Capítulo 3 \\ MÉXICO 2013-2014. RECESIÓN A LA VISTA ${ }^{1}$
}

\author{
Eduardo Loría", Emmanuel Salas** \\ Alejandro García ${ }^{* \cdots *}$ y Alejandro Gómez:*****
}

No bay mayor dolor que recordar los tiempos felices desde la miseria.

Dante Alighieri

Mucho se ha hablado del buen papel económico que desempeñará México a nivel internacional en los próximos años. Ello, junto con el diferencial de tasas de interés y el fenómeno de acarreo de capitales provocó hasta mediados del 2013, un gran influjo de capitales de corto plazo que apreció sensiblemente al tipo de cambio

* Doctor y maestro en Economía. Para más datos visite <http://www.economia.unam. $\mathrm{mx} /$ profesores/eloria/>.

** Técnico Académico Titular B adscrito al Centro de Modelística y Pronósticos Económicos (Cempe) de la unam. Doctorante en el área de econometría aplicada, profesor de la especialidad en econometría aplicada, árbitro de la revista Economía teoría y práctica de la UAM y miembro del comité editorial de Journal of Economics E Finance.

**** Pasante en la Facultad de Economía de la UNAM y becario del proyecto PAPIIT "Recesión y mercados laborales en México. Un análisis estructural, 1985-2020". Asistente de investigación en el Cempe, UNAM.

**** Pasante en la Facultad de Economía de la UNAM y becario del proyecto PAPIIT "Recesión y mercados laborales en México. Un análisis estructural, 1985-2020". Asistente de investigación en el Cempe, UNAM.

1 Agradecemos el financiamiento del proyecto "Recesión y mercados laborales en México. Un análisis estructural, 1985-2020”. PAPIIT IN-305711, DGAPA, UNAM. Los autores son los únicos responsables de lo que aquí se dice o se omite. Autor principal: <eduardol@unam.mx>, coautor: <salas.emmanuel@gmail.com>. 
vulnerando la estabilidad macroeconómica. Poco después ocurrió el fenómeno opuesto, por lo que la economía mexicana ha estado expuesta a gran volatilidad cambiaria este año.

A pesar de este mexican momentum, hay múltiples factores que deben considerarse para argumentar que México ha entrado en una fase importante de desaceleración económica que corresponde a la parte descendente del ciclo económico. De los 16 indicadores compuestos adelantados y coincidentes y los de confianza que publica el INEGI [2013], utilizamos la técnica de componentes principales para seleccionar a los dos que están más asociados con la actividad económica mensual y, por tanto, son los más eficientes para aproximar al indicador de producción de México. Esto se corrobora al estimar un VAR(6) y hacer la simulación histórica de las variables. Se encuentra evidencia que México está experimentando un cambio negativo en su tendencia desde mayo de 2012 y que muy probablemente se extienda hasta fines de 2014.

\section{ADÉNDUM}

Este capítulo es producto de la investigación sistemática realizada en el Centro de Modelística y Pronósticos de la Facultad de Economía de la Universidad Nacional Autónoma de México (Cempe). Una actividad principal de este centro consiste en seguir y pronosticar la dinámica de la economía mexicana. Es por ello que la predicción de un escenario recesivo no fue un resultado fortuito. Ya lo habíamos anticipado desde fines del año 2012, ${ }^{2}$ cuando prevalecía gran confianza en las perspectivas de crecimiento económico del país por analistas nacionales y extranjeros. ${ }^{3}$

${ }^{2}<$ http://www.economia.unam.mx/cempe/pronosticos/13-1_pp_loria.pdf $>$.

${ }^{3}$ Los fenómenos meteorológicos Ingrid y Manuel terminaron con una larga sequía, sin embargo, produjeron precipitaciones pluviales históricas que causaron graves estragos sobre todo en algunos de los estados más atrasados, situación que junto con los problemas de inestabilidad internacional precipitaron la aparición de pronósticos cada vez menos alentadores, hasta que la presencia del escenario recesivo fue inobjetable. 
Hemos actualizamos las estimaciones del modelo con los datos disponibles al 18 de octubre de 2013, con el objetivo de corroborar que la selección eficiente de variables logró reproducir la dinámica macroeconómica de una manera adecuada, lo que reveló aspectos estructurales de la economía mexicana que pueden ser de gran utilidad para la comprensión de los ciclos y por ende del desarrollo de país.

\section{INTRODUCCIÓN}

Desde fines de 2012 se han publicado muchos artículos en diversos medios internacionales de gran prestigio sobre el buen papel que ha desempeñado el gobierno mexicano en turno (desde el 1 de diciembre de 2012) y sobre el futuro prometedor que tiene México en los ámbitos económico y político. ${ }^{4} \mathrm{~A}$ esto se le ha llamado mexican momentum.

Friedman [2013] ha llegado a mencionar que México será el país más dominante en materia económica del siglo desplazando a China. De igual forma, a principios de 2013, las proyecciones de la Encuesta sobre las Expectativas [Banxico, 2013] señalaban que la economía mexicana crecería a tasas mayores a tres puntos, e incluso, algunos consideraron que en los próximos años podría acelerarse y acercarse a 5\%; cifras altas para el contexto internacional de bajo crecimiento que se está viviendo. De hecho no solo es bajo, sino de reducción en todas las regiones del mundo.

Loría y Salas [2013] encuentran alta sincronización (96\%) del ciclo económico de México con el ciclo industrial de Estados Unidos desde 1995. De acuerdo con este análisis de ciclos de crecimiento, observan que el ciclo industrial de Estados Unidos llegó a la cresta en 2012.04 y a partir de 2013.01 hay un claro cambio de tendencia, con lo cual se inicia la fase recesiva del ciclo actual. En virtud de que en ese artículo se identifica que

4 The Economist [2012], Thomson [2013], Anderson [2013], Friedman [2013], Oppenheimer [2013] y Rogoff \{2013]. 
el ciclo económico de México se determina en $96 \%$ por el ciclo industrial de Estados Unidos, es altamente probable que este solo factor haga que la economía mexicana siga la misma dinámica. De hecho, varios de los indicadores aquí analizados sugieren una fuerte desaceleración productiva de México desde mayo de 2012 y otros, incluso con anterioridad.

Otro elemento que fortalece nuestra hipótesis de la fase de desaceleración del ciclo económico es el análisis de los indicadores compuestos coincidentes y adelantados, que sirven para mostrar la evolución del ciclo, así como para prever los posibles cambios de tendencia. De acuerdo con el INEGI [2013], la gran mayoría de indicadores sugiere una desaceleración de la economía mexicana por lo menos desde mayo del 2012 que se acentúa de acuerdo con los datos más recientes, particularmente con el crecimiento del PIB de los primeros trimestres del año, que muestra el menor crecimiento anual desde 2009.04 cuando se registró una caída de $2.03 \%$. Es decir, los datos del primer semestre de 2013 muestran el peor desempeño de los últimos 15 o 16 trimestres, con una medición anual de trimestre a trimestre como se aprecia en la gráfica $1 .{ }^{5}$ Estos resultados, combinados con el análisis econométrico del ciclo de crecimiento que hacen Loría y Salas [2013] reforzarían, por otra vía, la hipótesis de que la economía mexicana ha entrado en la fase recesiva del ciclo económico.

El texto se estructura de la siguiente forma. En la primera sección, se describe la metodología de indicadores de coyuntura del INEGI. En la segunda, presentamos el criterio para filtrar y seleccionar las variables que utilizamos para nuestro análisis. En la tercera sección, presentamos un análisis econométrico de estimación y simulación que fortalece nuestra hipótesis de recesión. Por último, se hacen los comentarios finales y se incluye un apéndice estadístico y conceptual que explica los indicadores compuestos y de confianza.

${ }^{5}$ Con el fin de simplificar la lectura, ésta y todas las demás gráficas se presentan en el anexo. 


\section{MetOdOLOGÍA DEL INEGI}

\section{Los indicadores compuestos}

La actividad de cualquier economía tiende a expandirse en el tiempo, pero no lo hace de una manera constante o lineal, sino a partir de oscilaciones periódicas que generan fases de expansión y retracción. A estos altibajos que experimenta la actividad económica se les conoce como ciclos económicos. Si bien hay muchas metodologías estadísticas y aproximaciones teóricas, instituciones de muchos países publican periódicamente indicadores de coyuntura que permiten hacer un seguimiento de su ciclo económico.

En México ${ }^{6}$ el INEGI publica desde hace algunos años series de indicadores económicos, financieros y de confianza que denomina indicadores compuestos adelantados y coincidentes e indicadores de confianza para hacer el seguimiento del ciclo de la economía mexicana, que comienzan en 1980.01. Como su nombre lo indica, tienen la propiedad de adelantarse o de sugerir la tendencia del ciclo económico. Su fin último consiste en anticipar por algunos meses los puntos de inflexión de la actividad económica.

El INEGI no provee información oficial (ni pretende hacerlo) sobre cuántos meses su indicador es capaz de anticipar al ciclo económico. Sarabia [2011] encontró que si se comparan los puntos de giro de los indicadores compuestos coincidente y adelantado para el periodo 1980.01-2009.12, el indicador adelantado se ha anticipado en promedio cuatro meses en la detección de puntos de inflexión de la actividad económica. De igual forma, la OCDE [1999] señala que su indicador está construido de tal forma que permite anticipar en, aproximadamente, seis meses los cambios en el ciclo económico.

${ }^{6}$ Además del INEGI [2013a], la OCDE [1999] es otra fuente pública de información sobre indicadores compuestos adelantados para México. 
El primer grupo de indicadores, el indicador compuesto adelantado, está conformado por las siguientes seis variables: tipo de cambio real; exportaciones no petroleras; indice BMV (Bolsa Mexicana de Valores); tendencia del empleo en las manufacturas; tasa de interés interbancaria de equilibrio y el indice Standard E Poor's 500 (veáse el anexo).

Por su parte, el segundo indicador importante, indicador compuesto coincidente, está formado por las siguientes variables: indicador de la actividad económica mensual; indicador de la actividad industrial; numero de asegurados permanentes del IMSS; indice de ventas al por menor de establecimientos comerciales; tasa de desocupación urbana y las importaciones. ${ }^{7}$

Todas estas series se presentan en términos de su ciclo y se calculan por el método estadístico X12-ARIMA [INEGI, 2010]. ${ }^{8}$ De esta manera, el punto de referencia del análisis de cada serie es el índice 100. Cualquier colección de datos por arriba de este valor indica que la economía se encuentra en la fase ascendente del ciclo y, por debajo que está en la fase recesiva. No obstante, puede ocurrir que se encuentre por encima de 100 pero que muestre una tendencia negativa, lo cual significaría desaceleración. En caso que el indicador estuviera por debajo de 100 y con tendencia negativa, daría cuenta de recesión, o peor aún, de una depresión.

Por otro lado, para indicar que hay un cambio de tendencia, el indicador adelantado debe presentar durante varios meses variaciones negativas que también van acompañadas de variaciones negativas en el indicador coincidente. Si esto persiste durante muchos meses, indica una etapa recesiva en la economía. Esto es lo que ha ocurrido en la economía mexicana desde hace varios meses.

\footnotetext{
${ }^{7}$ Ver anexo.

${ }^{8}$ Para mayores referencias veáse Findley et al. [1998], Makridakis et al. [2008] y U.S. Census Bureau [2002].
} 


\section{SELECCIÓN DE VARIABLES}

Como punto de inicio conviene ver la evolución mensual de la actividad económica a través del indicador global de la actividad económica (IGAE) y del indicador de la actividad económica mensual. Llama la atención que posterior a la gran recesión de 2009, en 2010.05 se observa que alcanza el punto más alto de crecimiento $(6.94 \%)$ y en adelante hay una clara tendencia decreciente que se detiene entre 2011.04 y 2012.05. Desde entonces la caída es constante y vertiginosa (veáse la gráfica 2). Lo mismo ocurre si analizamos la evolución del indicador compuesto coincidente, del indicador de la actividad económica mensual y de la actividad económica industrial (veánse las gráficas 3, 4 y 5).

Como ya se mencionó, el INEGI utiliza una batería de 16 indicadores para tratar de hacer un seguimiento (desde distintas perspectivas) de la dinámica del ciclo económico de México. Conviene mencionar que algunos autores les atribuyen mayor capacidad de seguimiento y predicción a otros indicadores. Por ejemplo, Heath [2012] lo hace con los indicadores de confianza del consumidor. ${ }^{9}$ Sin embargo, si analizamos la evolución de este indicador, sólo a partir de 2013.01 se observa un cambio de tendencia. Sin embargo, el Índice de Confianza del Productor ${ }^{10}$ los muestra de forma contundente desde 2010.11 (véanse las gráficas 6 y 7$)$.

${ }^{9} \mathrm{La}$ información se expresa en forma de índice con base en enero de 2003=100, que resulta del promedio de cinco índices parciales, de los cuales dos hacen referencia a la situación económica actual y esperada del hogar entrevistado, otros dos atienden a la situación económica actual y esperada del país y el quinto índice refleja qué tan propicio es el momento actual para la compra de bienes de consumo durable [INEGI, 2010].

${ }^{10} \mathrm{La}$ Encuesta Mensual de Opinión Empresarial tiene una cobertura de 1553 empresas, mismas que se encuentran registradas en el directorio del Censo Económico 2009 del sector manufacturero. El indicador de confianza del productor está constituido por la opinión de los directivos empresariales en cuanto a la situación económica que se presenta tanto en el país como en su empresa. Esta información permite dar seguimiento a las opiniones acerca de la situación actual y las expectativas que los directivos tienen con respecto de sus empresas en particular y de la actividad económica en general. Las cifras se refieren al mes de la entrevista. 
Consideramos que, si bien todos los indicadores aportan elementos de análisis, es conveniente hacer una selección de variables, de modo que utilicemos solo las que reflejen con mayor profundidad la dinámica del Indicador de la actividad económica mensual que, como se muestra en el anexo, es una combinación estadística del IGAE y del PIB mensual.

Para tal efecto, seleccionamos solo a las que presentan mayor correlación con esta variable. Si bien existen las series para 1980.01-2013.07, cerramos la muestra para 1997.01-2013.07. ${ }^{11}$ De tomarse el periodo completo las correlaciones cambian y no reflejan con fidelidad la estructura actual de la economía mexicana. El cuadro 1 presenta la correlación parcial de 14 indicadores con el índice de actividad económica mensual y el punto de quiebre más reciente.

De este primer análisis resulta que las variables más asociadas con el indicador de actividad mensual ${ }^{12}$ son: el indicador coincidente, el de la actividad industrial, el de importaciones y el de exportaciones no petroleras. De hecho, podríamos decir que debido al grado de apertura comercial y a la vinculación internacional, estas variables reflejan de manera importante la nueva estructura de la economía mexicana desde que se integró dinámicamente en la economía mundial, convirtiéndose en una economía exportadora de bienes manufactureros con un alto contenido de componentes importados.

Con la finalidad de tener una selección aún más precisa, hicimos una discriminación adicional por la técnica de componentes principales [Pearson, 1901; Hotelling, 1993], de la que resulta una selección aún menor, pero estadísticamente más eficiente de variables que mejor explican la varianza de este grupo. De ello resulta la elección final para aproximar el comportamiento del indicador la actividad económica mensual por medio de los indicadores de importaciones y de la actividad industrial.

${ }^{11}$ A partir de 1997.01 es cuando Loría y Salas [2013] encuentran que se logra la mayor sincronización del ciclo económico de México con el ciclo industrial de Estados Unidos.

${ }^{12}$ Con coeficientes de correlación parcial superiores a 90 por ciento. 


\section{ESTIMACIÓN}

A partir de esta selección estimamos un VAR(6) correctamente especificado ${ }^{13}$ que permite simular fielmente las tres variables (véase la gráfica 8). Llama la atención la gran capacidad de simulación histórica de las tres variables en cuestión y, por lo tanto, puede considerarse una buena aproximación al proceso generador de información.

\section{CONCLUSIONES Y COMENTARIOS FINALES}

A diferencia de lo que se ha escrito y especulado en el ámbito internacional, los indicadores de producción de coyuntura de la economía mexicana sugieren una fuerte caída del dinamismo productivo desde mediados de 2012, aunque algunos otros desde 2011.

La sincronización con el ciclo industrial de Estados Unidos hace que la economía mexicana sea altamente vulnerable a cambios en su tendencia. Loría y Salas [2013] con series trimestrales del PIB han identificado los ciclos de crecimiento desde 1980.01 y han encontrado que a partir de 2013.01 se inicia la desaceleración del producto industrial de Estados Unidos y, por lo tanto, también de la economía mexicana.

En este artículo hemos utilizado el análisis de indicadores compuestos adelantados y coincidentes, y los de confianza para analizar la evolución del ciclo económico mexicano. Lo que se puede apreciar es que, desde hace varios meses, se ha perdido dinamismo y es probable que estemos en una fase de desaceleración que eventualmente será de recesión. El dato del crecimiento del PIB del primer semestre del año, así lo indica, y es uno de los más bajos en los últimos años. Por último, el sector

13 Raíz Máxima = 0.9808; Urzúa $=21.70(0.65) ; \mathrm{LM}(7)=13.14(0.156)$; W(nc) = 223.23(0.774); W(tc) = 395.122(0.261). Es decir, el VAR no presenta ningún problema de especificación. 
privado (mediante el indicador de confianza del productor) ha percibido un panorama pesimista desde 2010.11. Con todo esto es difícil aceptar que México tenga altas tasas de crecimiento como se ha sugerido en la literatura internacional y que se refiere al mexican momentum.

Todos estos resultados los hemos corroborado al sintetizar la información en un modelo de vectores autorregresivos (VAR) a partir de una selección eficiente de los indicadores propuestos por el INEGI [2013]. El resultado es plausible en términos económicos ya que propone que la actividad industrial orientada hacia el exterior desde 1995 y la dinámica de las importaciones necesarias para la producción industrial del país alertan sobre el escenario recesivo al que hacemos mención desde el título de este artículo.

Las variables que más información aportan para la explicación del ciclo productivo son los ciclos de la actividad industrial, seguida por el de las importaciones (véase el cuadro 2). Esto tiene que ver con la fuerte influencia del sector industrial sobre el conjunto de la actividad económica y la importancia de las importaciones en la producción total y en la producción de exportaciones.

\section{ANeXo}

$\mathrm{El}$ indicador compuesto adelantado se construye con las variables siguientes:

1. Tipo de cambio real: cociente del índice de precios al consumidor de 111 países, dividido por el índice nacional de precios al consumidor multiplicado por el tipo de cambio nominal.

2. Exportaciones no petroleras: ventas al exterior de las actividades agropecuarias, extractivas y manufactureras.

3. Índice BMV (Bolsa Mexicana de Valores): se refiere al índice de precios y cotizaciones (IPC) de la Bolsa Mexicana de 
Valores, indicador de la evolución del mercado accionario en su conjunto de México, deflactado por el índice nacional de precios al consumidor.

3. Tendencia del empleo en las manufacturas: se construye a partir de los resultados de la Encuesta mensual de coyuntura, inventarios, empleo y días laborados en el sector manufacturero (Banco de México). ${ }^{14}$

4. Tasa de interés interbancaria de equilibrio: es una tasa representativa de las operaciones de crédito a 28 días de los bancos. La TIIE es calculada diariamente por el Banco de México con base en cotizaciones presentadas por las instituciones de banca múltiple.

5. Índice Standard E Poor's 500: es un indicador del mercado de valores de Estados Unidos, que incluye a las 500 empresas líderes en diferentes sectores de la economía de Estados Unidos.

El indicador compuesto coincidente se construye con las siguientes variables:

1. Indicador de la actividad económica mensual: es una estimación del producto interno bruto mensual y se obtiene mediante métodos de desagregación de series temporales, utilizando para ello al PIB y al IGAE.

2. Indicador de la actividad industrial: refleja el volumen físico de la producción de las actividades industriales (minería, electricidad, agua y suministro de gas por ductos al consumidor final), construcción e industrias manufactureras.

${ }^{14}$ Este índice se construye sobre la siguiente pregunta: "Con respecto al mes anterior el número de empleados: aumentó, permaneció igual o disminuyó. La tendencia del empleo manufacturero se calcula como la diferencia entre el porcentaje de los que opinaron que el número de trabajadores aumentó y de los que opinaron que el número de trabajadores disminuyó. 
3. El número de asegurados permanentes del IMSS: son las personas que en el ámbito urbano están contratadas e inscritas en el IMSs.

4. El indice de ventas al por menor de establecimientos comerciales: son las mercancías vendidas propiedad de minoristas, que se dedican principalmente a la venta de bienes de consumo final.

5. Tasa de desocupación urbana: porcentaje de la población económicamente activa que se encuentra sin trabajar, pero que está buscando trabajo.

6. Importaciones: es el total de mercancías expresadas en valor monetario que entra de manera definitiva o temporal, mediante un pedimento aduanero.

ANEXO

\section{Gráfi ca 1. Tasa de crecimiento trimestral anualizada del PIB en México \\ 1981.01- 2012.04}

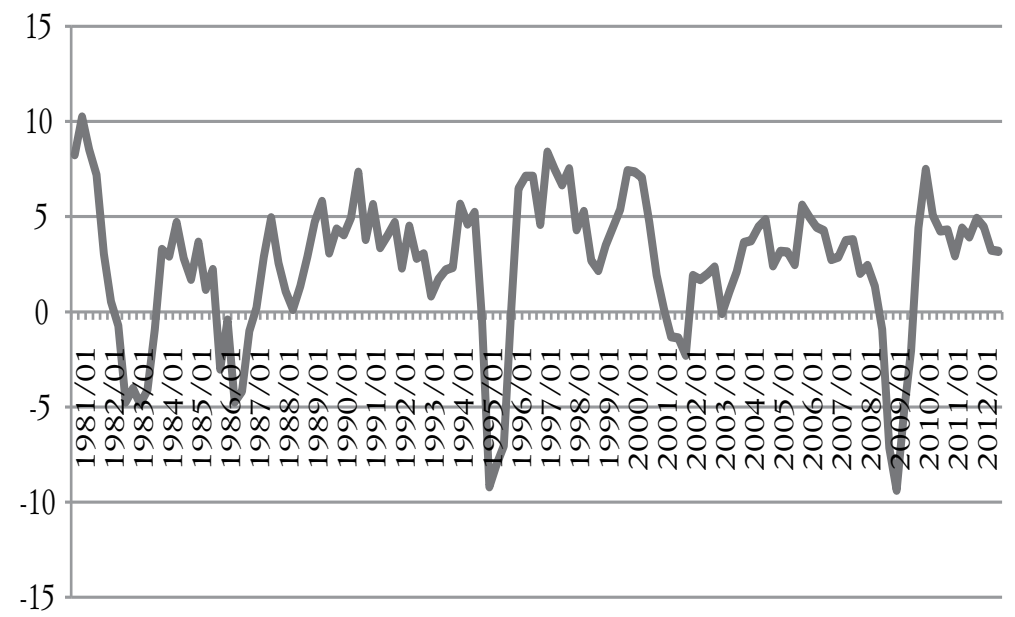

Fuente: elaboración propia con datos del INEGI [2012b]. 
Gráfi ca 2. Indicador global de la actividad económica. Crecimiento mensual anualizado, 1997.01-2013.02

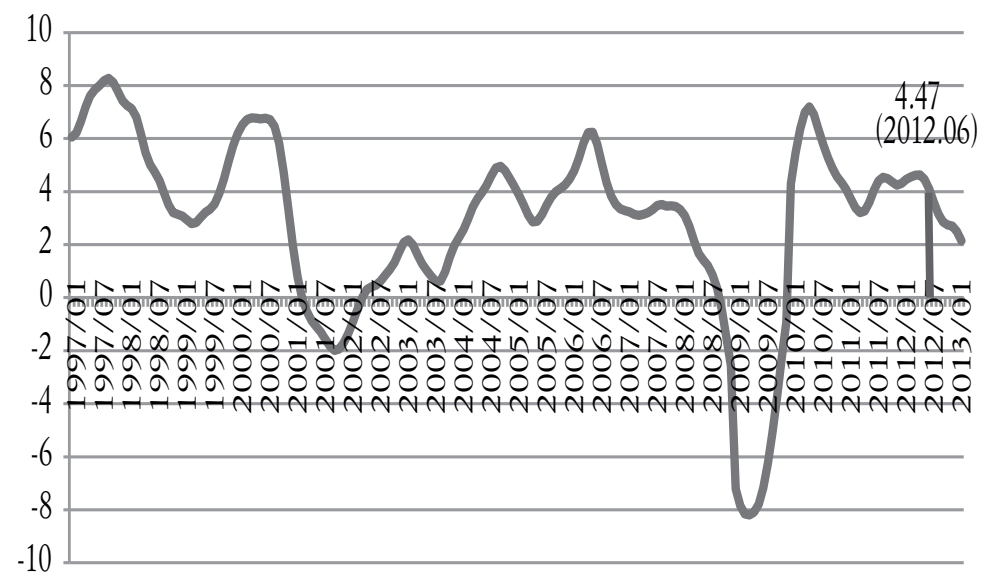

Fuente:INEGI [2013b].

Gráfica 3. Indicador compuesto coincidente, 1980.01-2013.02

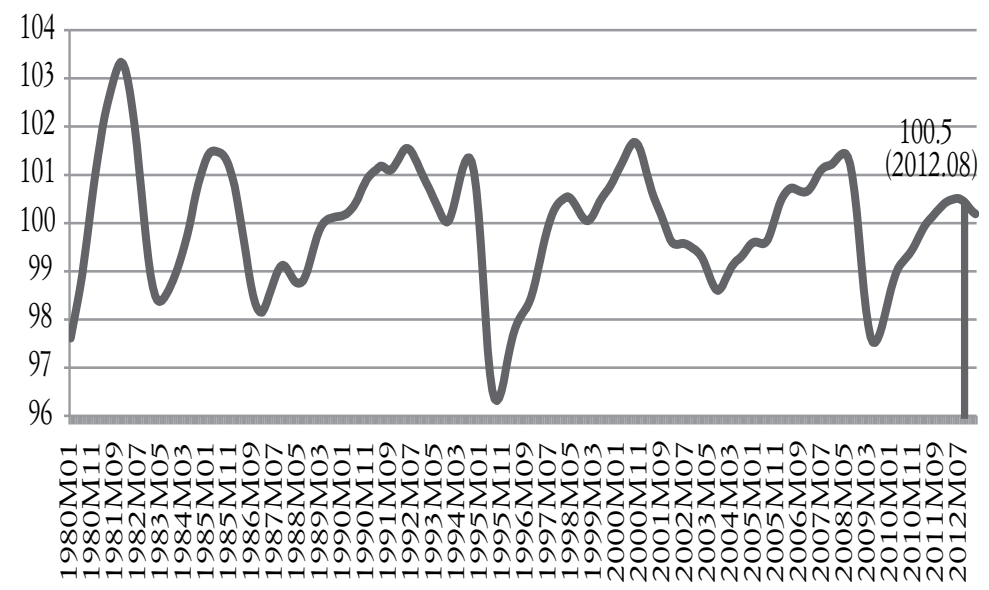

Fuente: INEGI [2013a]. 
Gráfi ca 4. Indicador de la actividad económica mensual, 1980.01-2013.02

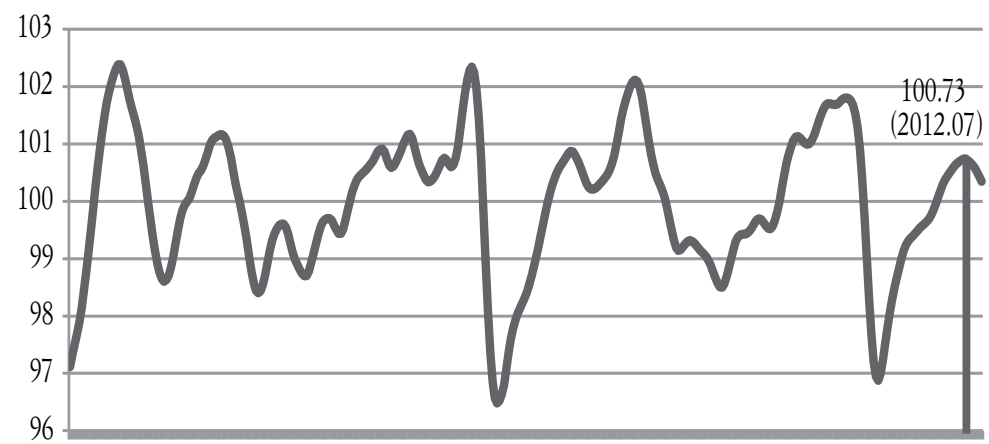

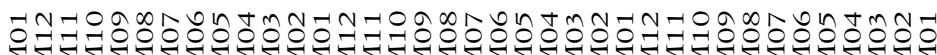

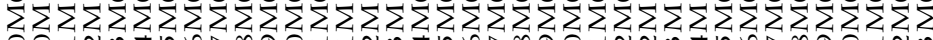
o o $1 m$ m n

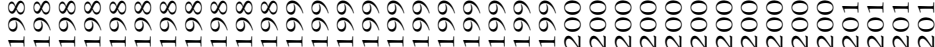

Fuente: INEGI [2013a].

Gráfi ca 5. Indicador de la actividad industrial, 1980.01-2013.02

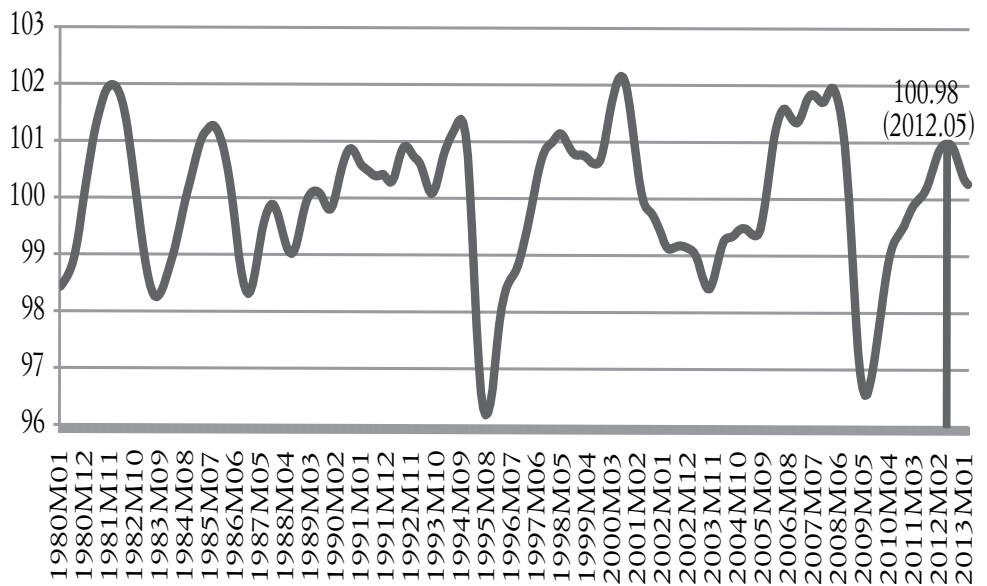

Fuente: INEGI [2013a]. 
Gráfi ca 6. Índice de confianza del consumidor, 2004.1-2013.04

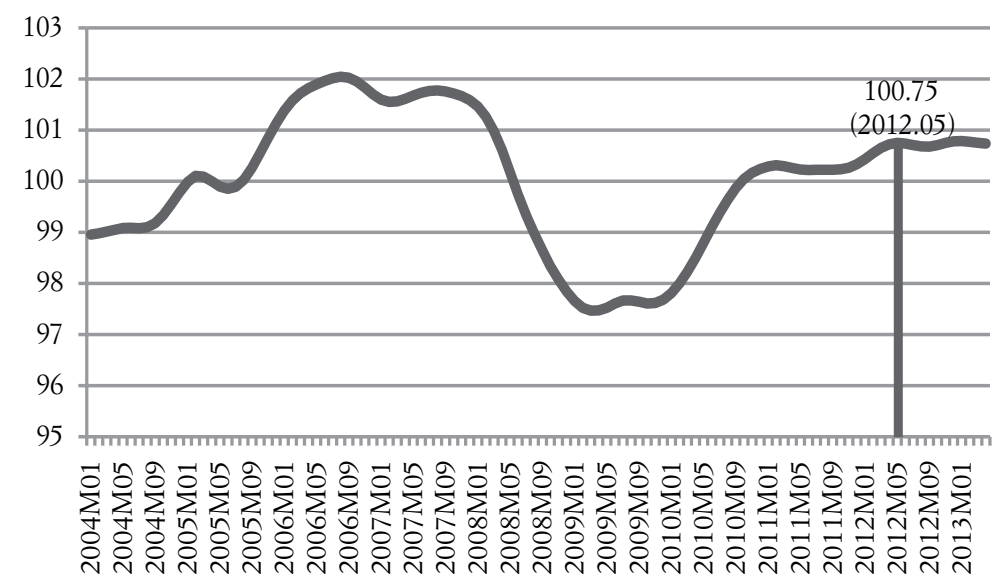

Fuente: INEGI [2013a].

\section{Gráfica 7. Índice de confianza del productor, 2004.01-2013.04}

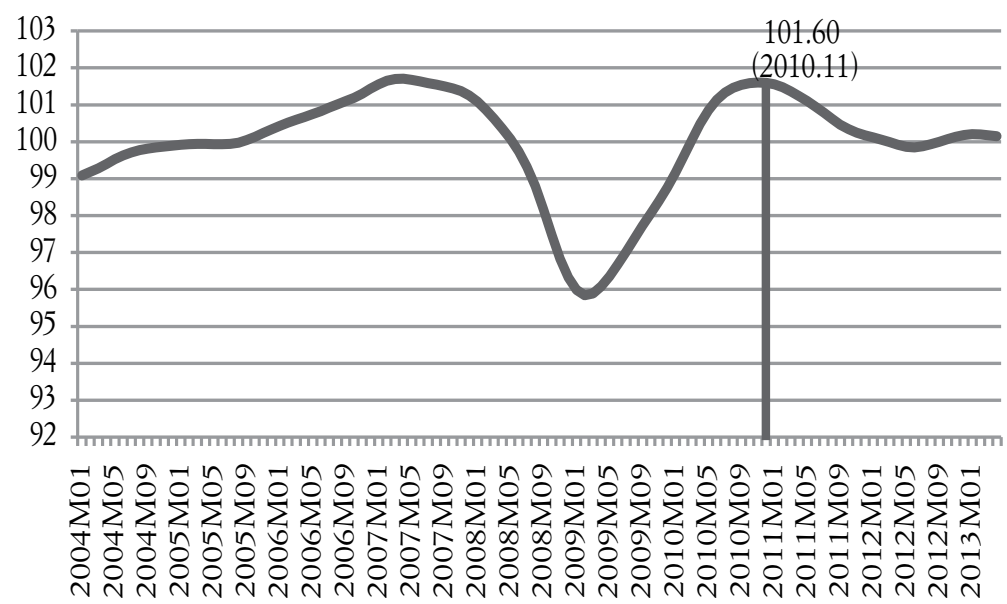

Fuente: INEGI [2013a]. 


\section{Gráfica 8. Simulación histórica del VAR(6), 1997.01-2013.09}
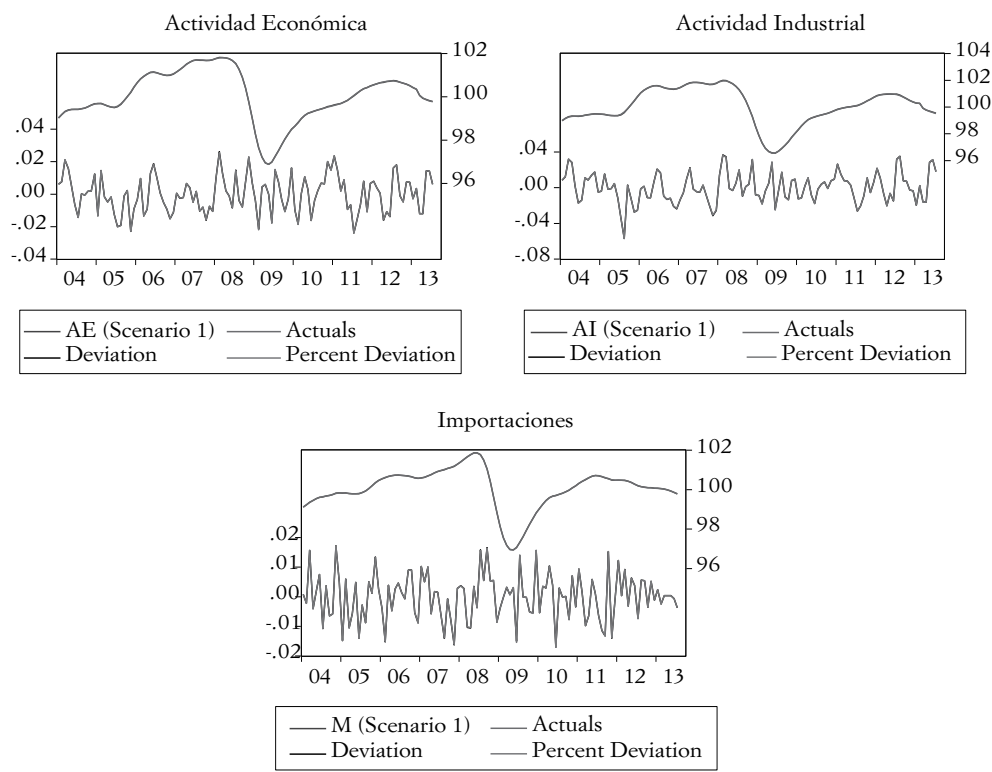

Cuadro 1. Análisis de correlación de variables con respecto al índice de la actividad económica mensual. 1997.01-2013.04

\begin{tabular}{c|l|c}
\hline Indicador & Correlación & $\begin{array}{c}\text { Punto de } \\
\text { quiebre }\end{array}$ \\
\hline Indicador coincidente & 0.98291 & 2012.06 \\
\hline Actividad industrial & 0.980679 & 2012.05 \\
\hline Importaciones & 0.948913 & 2011.06 \\
\hline Exportaciones no petroleras & 0.92212 & 2012.03 \\
\hline SP500 de asegurados permanentes del Imss & 0.89422 & 2012.12 \\
\hline Índice de confianza del productor & 0.856115 & - \\
\hline Indicador adelantado & 0.84088 & 2010.11 \\
\hline
\end{tabular}




\begin{tabular}{c|c|c}
\hline Ventas al por menor & 0.744136 & 2012.07 \\
\hline Índice de precios y cotizaciones & 0.716449 & - \\
\hline Índice de confianza del consumidor & 0.687488 & 2013.01 \\
\hline Tendencia del empleo manufacturero & 0.450167 & 2012.01 \\
\hline Tasa de interés interbancaria de equilibrio & 0.416082 & - \\
\hline Tipo de cambio real & -0.391939 & 2011.11 \\
\hline Desempleo urbano & -0.77534 & 2012.07 \\
\hline
\end{tabular}

Fuente: elaboración propia con datos del INEGI [2013].

Nota: negativo en las series que aún no muestran punto de quiebre.

1. El Análisis de componentes principales es una técnica estadística de análisis multivariado propuesta por Hotelling [1933] basada en Pearson [1901] que permite seleccionar la información contenida en un conjunto de $p$ variables de interés en $m$ nuevas variables independientes, mediante la combinación lineal de las variables que resume el conjunto de información.

En el cuadro 2 se reportan los resultados del eigenvalor, la varianza explicada y los valores del primer y segundo componentes. Al considerar ocho variables debido a la correlación que tienen con la actividad económica mensual, el resultado será la obtención de ocho componentes principales. Sin embargo, centramos la atención en el primer y segundo componente ya que explican $94 \%$ de la varianza total del conjunto; a partir del tercer componente la varianza explicada comienza a disminuir de manera drástica. 


\section{Cuadro 2. Eigenvalores y varianza explicada por los componentes principales}

\begin{tabular}{l|c|c}
\hline \multicolumn{1}{c|}{ Variable } & Componente 1 & Componente 2 \\
\hline Importaciones & 0.504742 & -0.384178 \\
\hline Indicador coincidente & 0.499922 & 0.443924 \\
\hline Actividad industrial & 0.496856 & 0.544541 \\
\hline Exportaciones no petroleras & 0.498446 & -0.599011 \\
\hline
\end{tabular}

Fuente: elaboración propia con datos del INEGI [2013].

Nota: eigenvalor $=3.81$ y 0.12 , respectivamente. Proporción de la varianza $=0.95$ y 0.03 , respectivamente.

BIBLIOGRAFÍA

Anderson, C. [2013], “Mexico: The New China”, The New York Times, 26 de enero: S7.

Banxico [2013], Encuesta sobre las expectativas de los especialistas del sector privado, abril.

Cantú, F., A. Acevedo y O. Bello [2010], Indicadores adelantados. CEPAL. Serie Macroeconomía del Desarrollo, núm. 101.

Findley, D., B. Monsell, W. Bell, M. Otto y B. Chen [1998], "New capabilities and methods of the X-12-ARIMA Seasonal-Adjustment Program", Journal of Business E Economic Statistics, 16(2): 127-152.

Friedman, L. [2013], "How Mexico got back in the game", The New York Times, 23 de febrero : S11. Disponible en $<$ http:// www.nytimes.com/2013/02/24/opinion/sunday/friedmanhow-mexico-got-back-in-the-game.html?_r=0>.

Heath, J. [2012], "La confianza del consumidor en la coyuntura”, disponible en <http://www.economia.unam.mx/cempe/ reuniones/12-2_pp_heath.pdf $>$.

Hotelling, H. [1933], "Analysis of a complex of statistical variables into principal components", Journal of Educational Psychology, 24(6): 417. 
INEGI [2010], Sistema de indicadores compuestos: cíclico y adelantado. Disponible en $<$ http://www.inegi.org.mx/prod_ serv/contenidos/espanol/bvinegi/productos/derivada/coyuntura/sicca/sicca.pdf $>$.

[2013a], Reloj de los ciclos económicos. Disponible en $<$ http://www.inegi.org.mx/sistemas/reloj_cicloseco/>.

[2013b], Banco de información económica. Disponible en $<$ http://www.inegi.org.mx/sistemas/bie/>.

Loría, E. y E. Salas [2013], "Mexico and the United States: Cycle synchronization, 1980.1-2012.4. A Forecast”, Journal of Economic Integration, en dictamen.

Makridakis, S., S. C. Wheelwright y R.J. Hyndman [2008], Forecasting methods and applications, 3 era ed., John Wiley \& Sons.

Oppenheimer, A. [2013], "Everybody is upbeat on Mexico, except mexicans", The Miami Herald, 2 de marzo. Disponible en <http://www.miamiherald.com/2013/03/02/3262162/ everybody-is-upbeat-on-mexico.html .

Organización para la Cooperación y el Desarrollo Económico (OCDE) [1999], "Composite leading indicators a tool for shortterm analysis", OECD Statistics, Leading Indicators. Disponible en <http://www.oecd.org/fr/std/clits/15994428.pdf>.

Pearson, K. [1901], "LIII. On lines and planes of closest fit to systems of points in space", The London, Edinburgh, and Dublin Philosophical Magazine and Journal of Science, 2(11): 559-572.

Reddy, S. [2013], La desaceleración global amenaza la recuperación de Estados Unidos, 22 de abril. Disponible en <http:// www.lanacion.com.ar/1575005-la-desaceleracion-globalamenaza-la-recuperacion-de-estados-unidos $>$.

Rogoff, K. [2013], Mexico breaking good?, 14 de abril. Disponible en <http://www.project-syndicate.org/commentary/ mexico-s-coming-growth-surge-by-kenneth-rogoff $>$.

Sarabia, A. [2011], "El ciclo económico en México", Revista Internacional de Estadística y Geografía, 2(2): 32-49.

The Economist [2012], "The rise of Mexico", 23 de noviembre.

Disponible en <http://www.economist.com/news/leaders/ 
21567081-america-needs-look-again-its-increasingly-important-neighbour-rise-mexico $>$.

Thomson, A. [2013], Mexico: Aztec Tiger. 30 de enero, Financial Times. Disponible en $<\mathrm{http}: / / \mathrm{www} . \mathrm{ft} . \mathrm{com} / \mathrm{cms} / \mathrm{s} / 2 / \mathrm{dc}-$ 545d0a-696a-11e2-8d07-00144feab49a.html>.

U.S. Census Bureau [2002], "X-12-ARIMA", Reference Manual, Final Version 0.2, Washington DC, US Census Bureau. 


\section{Capítulo 4 \\ Problemática eCONÓMica de ESTADOS UNIDOS Y SU IMPACTO EN LA ECONOMÍA NACIONAL}

Arturo Huerta González*

Es importante analizar el llamado abismo fiscal en Estados Unidos que determinará el acontecer económico en el mundo, ya que el sector privado depende del desempeño de las finanzas públicas y del sector externo. Si es deficitario, como en Estados Unidos y México, implica que las importaciones desplazan a la producción nacional y se merma la acumulación del sector privado productivo. Para contrarrestar esto, el gobierno debe gastar más allá de sus ingresos de recaudación, para impulsar el mercado interno, la demanda y mejorar las condiciones financieras del sector privado. Si el gobierno opta por reducir el déficit fiscal se contrae la demanda y tiende a frenarse la recuperación económica en ambos países y, por lo tanto, los flujos de migración disminuyen y se incrementa el descontento social, se requiere de una participación activa, organizada y concientizada de la población para cambiar las políticas actuales por unas que generen empleos.

* Es jefe de la División de Estudios de Posgrado de la Facultad de Economía. Obtuvo el Premio Anual de Investigación Económica Maestro Jesús Silva Herzog 1985, otorgado por el IIEc, UNAM y el Premio Universidad Nacional 1994, en el área de investigación en ciencias económicas-administrativas. Es miembro del Sistema Nacional de Investigadores nivel III. Correo electrónico: <ahuerta@unam.mx>. 


\section{EL ABISMO FISCAL Y LA TENDENCIA A UNA NUEVA DESACELERACIÓN DE LA ECONOMÍA DE EsTADOS UNIDOS}

Es importante analizar el llamado abismo (recorte) fiscal en Estados Unidos que determinará el acontecer económico, no solo en dicho país, sino en la economía mundial. El Congreso de Estados Unidos aprobó reducir el déficit fiscal mediante fuertes recortes al gasto público, que rompe con la política fiscal contra-cíclica instrumentada en 2008-2009, que permitió poner freno a dicha crisis y que la economía estadounidense retomara su crecimiento en 2010 y 2011 (véase la gráfica 1), así como muchas otras economías que dependen de la dinámica de tal país.

\section{Gráfi ca 1. Estados Unidos. Tasa de crecimiento del PIB , 2006.01-2013.01}

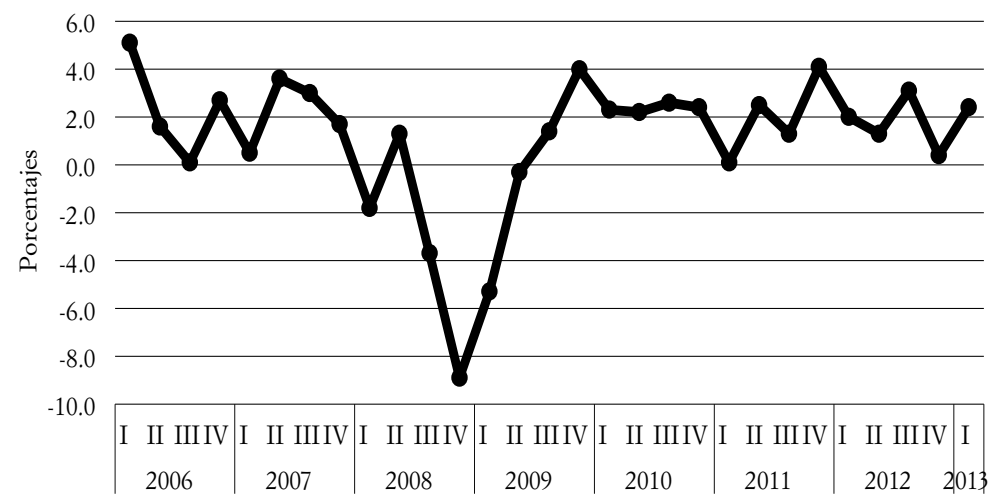

Fuente: Bureau of Economic Analysis, National Economic Accounts, 2013.

Los déficit de comercio exterior crecientes en las últimas décadas en Estados Unidos, afectan la dinámica de acumulación del sector privado, por lo que lo ha sobreendeudado para poder financiar su inversión y consumo. La crisis de 2008-2009 descubrió los problemas de insolvencia, ya que las empresas e individuos vieron disminuidos sus ingresos y las capacidades de pago 
de sus deudas, lo que generó la crisis bancaria. Esta situación rápidamente trastocó el sector productivo y frenó la actividad económica de dicho país así como del resto del mundo, dada la interrelación de los mercados y de las economías. Ante la problemática del sector bancario-financiero, los gobiernos actuaron para apalancar al sector financiero vía rescate bancario, lo que aumentó el déficit fiscal el cual frenó la caída y la desvalorización de activos financieros, así como los problemas de deflación de deuda, que podrían ahondar la crisis. Nos dice Wray [2013] que la crisis fue generada por la deuda privada, no por la deuda soberana, ésta deuda fue resultado del rescate bancario. En igual sentido nos dice Hein [2012] que las deudas privada y del sector externo no fueron ocasionadas por el déficit fiscal, sino por las políticas predominantes.

Las economías trabajan en un contexto de tres sectores. Lo que acontece en el sector privado depende del desempeño de las finanzas públicas y del sector externo. Si el sector externo es deficitario, que es el caso de Estados Unidos, México y la mayoría de los países europeos y muchos otros, implica que las importaciones están desplazando la producción nacional y se merma la dinámica de acumulación del sector privado productivo. Para contrarrestar tal situación, el gobierno debe trabajar con gasto público deficitario, es decir, gastar más allá de sus ingresos de recaudación, justo para impulsar el mercado interno, la demanda y mejorar las condiciones financieras del sector privado. Si el gobierno opta por reducir el déficit fiscal, se contrae la demanda y tiende a frenarse la actividad económica.

En la gráfica 2, podemos observar como en Estados Unidos el gasto público deficitario se dispara en 2008 y 2009, por su parte, se reduce el déficit financiero del sector privado cayendo en superávit para encarar el pago del servicio de su deuda. El gasto público deficitario puso freno a la caída del crecimiento del PIB en 2009 y permite que se recupere la actividad económica desde ese entonces, aunque a baja tasa de crecimiento, debido a las filtraciones de demanda por el déficit de comercio exterior. El déficit público disminuye sobre todo desde 2010, bajo la premisa 
de que el sector privado puede comandar el crecimiento, el cual ha disminuido su superávit financiero, reflejando que hay cierto crecimiento de consumo e inversión, pero sin constituirse en motor de crecimiento [Papadimitriou et al., 2013].

Gráfi ca 2. Estados Unidos. Balances de los sectores principales y evolución del PIB real, 2005-2013

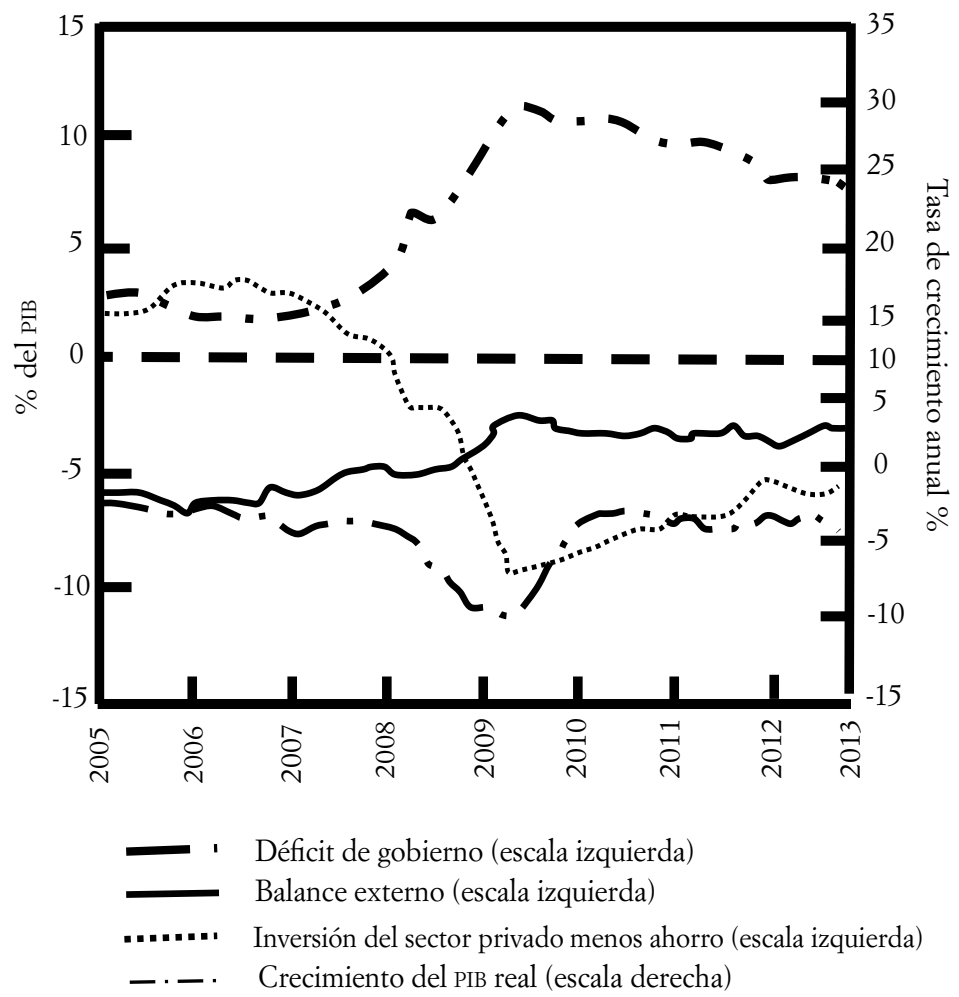

Fuente: Elaboración propia con base en Papadimitrou et al. 2013.

Gran parte del gasto deficitario del gobierno estadounidense fue resultado en parte del rescate bancario. Nos dice Tcherneva [2010] que el sector financiero suspende su fobia contra el gasto público deficitario hasta que mejoren sus hojas de balance. Así es 
como en 2010 crece la actividad económica en Estados Unidos, lo que impulsó el crecimiento de muchas economías en el ámbito mundial. Sin embargo, la recuperación alcanzada duró muy poco. El contexto de globalización origina que la filtración de demanda hacia importaciones, por lo que parte de ese gasto público dirigido a incrementar la demanda, si bien frenó la recesión y generó ciertas condiciones de crecimiento, se frenó rápidamente debido a tales filtraciones de demanda que presionan negativamente el déficit de comercio exterior y, por lo tanto, sobre la dinámica de acumulación del sector privado productivo y mantiene altas tasas de desempleo.

Cuando se recuperaron las condiciones de crecimiento en 2010, se dijo que ya no era necesario trabajar con gasto público deficitario, y que habría que ser "responsables". Se privilegió el término de responsabilidad fiscal, tanto en Estados Unidos como en nuestro país y en el resto del mundo. Los países europeos, como los republicanos en Estados Unidos, consideran irresponsable el déficit fiscal porque puede generar inflación, sobre endeudamiento y desestabilizar a la economía, por lo que viran hacia la disciplina fiscal. Al privilegiar las economías la estabilidad de sus monedas, optan por la sustentabilidad fiscal.

Las políticas encaminadas a reducir el déficit fiscal, contraen el gasto y aumentan impuestos, lo cual merma el poder adquisitivo del sector privado. Cuando el gobierno disminuye el gasto, las empresas venden menos y se reducen sus ingresos. Las familias ven afectados sus ingresos con las políticas de austeridad fiscal. Se contrae el mercado interno y las ventas de las empresas por lo que el sector privado ve incrementado su déficit financiero, como consecuencia de las políticas de "responsabilidad" fiscal.

\section{¿A QUIÉN FAVORECE LA RESPONSABILIDAD FISCAL?}

Las políticas de "responsabilidad" y disciplina fiscal originan irresponsabilidad en el lado del sector privado, ya que éste ve incrementado su déficit financiero, su nivel de endeudamiento y sus problemas de insolvencia. En Estados Unidos ello lleva a la 
banca a no otorgar créditos y, en el caso de los países periféricos de la zona euro, a la mayor inestabilidad y crisis bancaria, lo que mantiene la tendencia de la desaceleración de la actividad económica a nivel mundial.

Entonces surgen varias preguntas, ¿para quién deben responder las finanzas públicas?, ¿para quién deben ser "responsables”?, ¿por qué esas políticas de austeridad fiscal?, ¿cómo se logran esas políticas?, ¿quién se favorece de ellas? Cabe recordar que durante el gobierno de Salinas de Gortari se logró la disciplina fiscal vendiendo Teléfonos de México, la banca, la aviación y se concesionó la minería a la inversión privada, lo obtenido se utilizó para pagar el monto de la deuda pública. Entonces disminuyó la carga del servicio de la deuda y logró reducir el déficit fiscal junto con las políticas de baja inflación, que disminuyeron la tasa de interés. Se vendieron activos para poder pagar pasivos y así reducir las presiones sobre las finanzas públicas. Se logra la austeridad y disciplina fiscal vía disminución de activos públicos, así como la reducción del tamaño del Estado en la actividad económica y, la contraparte, es el mayor poder económico y político de la cúpula empresarial. En Europa, los países altamente endeudados están disminuyendo el gasto, incrementando impuestos y como ello no es suficiente para alcanzar la disciplina fiscal, se están impulsando las reformas estructurales de venta de empresas de sectores estratégicos para pagar la deuda y lograr la disciplina fiscal.

Por otra parte tenemos que en Estados Unidos, los republicanos, que dominan la Cámara de Representantes de Estados Unidos, siempre han estado por la disciplina fiscal, para que el sector público se deshaga de activos y el sector privado los adquiera, de esta forma se reduce la participación del Estado en la economía y se amplía la esfera de influencia del sector privado en la economía. Las políticas de austeridad fiscal y las reformas estructurales responden a intereses de clase que favorecen al gran capital, a costa de que el gobierno desatienda las demandas de la mayoría de la población y ésta pague por la prestación de los servicios públicos. 
La teoría económica que defiende la responsabilidad fiscal indica que el gasto público deficitario es "irresponsable" porque genera inflación. Señala Kregel [2010] que la "sustentabilidad fiscal tiene que estar relacionada a la naturaleza intrínseca del sistema monetario con que está operando el gobierno". Las economías se condenan a políticas de restricción del gasto público para evitar presiones inflacionarias e inestabilidad de la moneda. Sin embargo, no hubo inflación alguna en Estados Unidos en 2008-2009 cuando el déficit público se disparó arriba de 10\% como proporción del PIB. No es un problema de inflación lo que se vive en el ámbito mundial, sino es un problema de recesión económica, de desempleo y deterioro del nivel de vida de la población que demanda de política fiscal expansionista.

Ahora, ¿quién defiende la estabilidad de la moneda? Lo hace el sector financiero que desea la estabilidad de la moneda del país en el cual ellos invierten, de ahí que estemos condenados a políticas monetarias y fiscales restrictivas para evitar presiones de demanda que puedan aumentar precios y desestabilizar la moneda. La teoría económica convencional también nos indica que el déficit fiscal incrementa la deuda pública y, por lo tanto, significa mayor carga a las futuras generaciones en el sentido de que esa deuda va a tener que ser pagada mediante el incremento de impuestos y reducción de gasto público. Por lo tanto, la teoría convencional señala que hay que trabajar con disciplina fiscal para evitar el aumento de la deuda pública y de las cargas tributarias para las futuras generaciones. No toman en cuenta el efecto que el gasto público deficitario tiene sobre la actividad productiva y el empleo y, por lo tanto, sobre el ingreso de empresas e individuos que reactivaría la economía y la capacidad de los agentes económicos para adquirir la deuda del gobierno sin que signifique carga alguna. Por el contrario, éstos ganan, tanto porque venden más como por la tasa de interés que obtienen por la compra de la deuda pública.

En el caso de la economía mexicana, durante el sexenio de Felipe Calderón se trabajó con disciplina fiscal y no obstante la deuda pública externa se incrementó al doble, mientras que la 
deuda pública interna pasó de cerca de dos billones de pesos en el inicio del sexenio a cinco billones al final de su periodo (véanse el cuadro 1 y la gráfica 3).

\section{Cuadro 1. México. Deuda externa e interna (millones de dólares)}

\begin{tabular}{c|c|c}
\hline Año & $\begin{array}{c}\text { Deuda externa } \\
\text { (millones de } \\
\text { dólares) }\end{array}$ & $\begin{array}{c}\text { Deuda interna } \\
\text { (millones de pesos) }\end{array}$ \\
\hline 2006 & 54766 & 1767910 \\
\hline 2007 & 55355 & 2082398 \\
\hline 2008 & 56939 & 2361763 \\
\hline 2009 & 96354 & 2767947 \\
\hline 2010 & 110428 & 3152934 \\
\hline 2011 & 116420 & 3875915 \\
\hline 2012 & 125726 & 4663085 \\
\hline $2013^{*}$ & 127886 & n.d. \\
\hline
\end{tabular}

Notas: n.d. No disponible

*Hasta abril.

Fuente: SHCP, Unidad de Crédito Público y Banco de México.

Gráfi ca 3. México. Deuda externa y deuda interna, 2006-2013

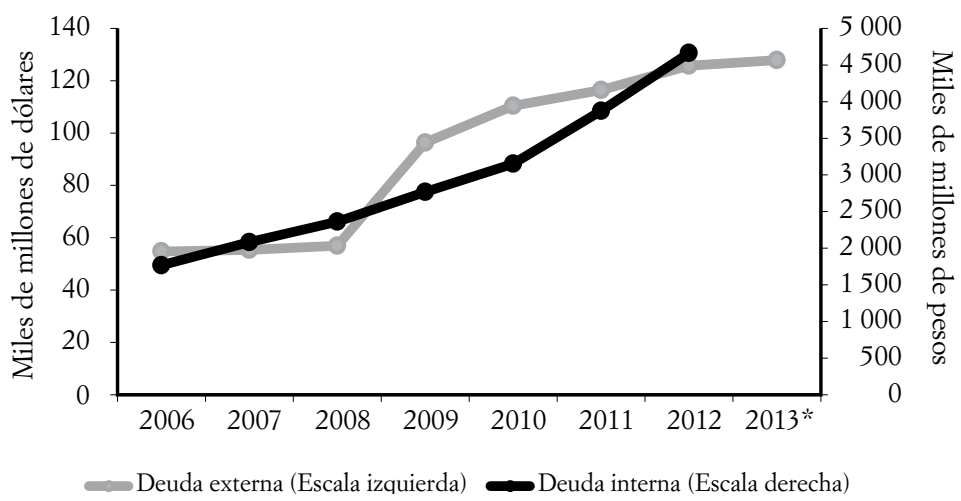

Fuente: SHCP, Unidad de Crédito Público y Banco de México, 2013. 
Así tenemos que las políticas de disciplina fiscal no llevan a disminuir la deuda pública. El aumento de la deuda pública es resultado de los rescates gubernamentales a la banca, el rescate a los fondos de pensión y para apalancar los problemas financieros de diversos sectores privados, así como el proceso de promoción de entrada de capitales que realiza el gobierno, los cuales adquieren deuda pública, dado el diferencial de tasas de interés.

También está el hecho de que la disciplina fiscal reduce la actividad económica, tal como ejemplifican los contextos recesivos que se registran en el ámbito mundial. En los contextos recesivos se reducen los ingresos de empresas e individuos y, por lo tanto, el gobierno recauda menos porque la recaudación es función del ingreso nacional. Al reducirse el ingreso nacional, la recaudación es menor, por lo que continúan las presiones sobre las finanzas públicas, como sobre el monto de la deuda. De lo anterior también da cuenta el caso europeo, en donde no pueden reducir el déficit fiscal en los niveles deseados por más contracción del gasto e incremento de los impuestos que realizan. Además, no pueden reducir la relación de endeudamiento por las consecuencias derivadas de las políticas predominantes y de la recesión económica. Señalan Papadimitriou y Wray [2011] que el aumento de la deuda privada es consecuencia de que las políticas predominantes han actuado en detrimento del sector productivo y a favor del sector financiero. Asimismo, Nersisyan [2010] señala que la causación corre del lento crecimiento a alta deuda y no a la inversa como dicen los ortodoxos.

\section{EN Estados Unidos NO HAY PROBLEMAS DE FINANCIAMIENTO DEL SECTOR PÚBLICO, A DIFERENCIA DE LA ZONA EURO}

En la zona euro hay un solo banco central para 17 países. Éstos perdieron el control de la moneda y al no tener moneda, tampoco tienen política económica. Es decir, carecen de política monetaria, cambiaria, política fiscal a favor del crecimiento y del em- 
pleo. Nos dicen Hannsgen y Papadimitriou [2012: 3] que hay "diferencia entre países cuyas monedas están restringidas, en relación a los países que trabajan con moneda soberana". Sin embargo en Estados Unidos a pesar de tener manejo soberano de su moneda y no tener problemas de financiamiento (dado además que su moneda es aceptada internacionalmente), los republicanos acordaron que se tiene que disminuir drásticamente el déficit fiscal. En 2013 entró en vigor el abismo fiscal, de mayor reducción del gasto público, al tiempo que los organismos financieros internacionales han reconocido que la actividad de Estados Unidos se contraerá al entrar en acción el abismo fiscal.

Con tal política fiscal, se incrementan de manera automática los impuestos y se contrae el gasto público para reducir el déficit fiscal. Lo mismo aconteció en los años 1936 a 1938 en Estados Unidos, donde en los años previos se había salido de la Gran Depresión de 1929-1933, con expansión del gasto público; en 1936 se dijo que ya había mucho gasto deficitario y que se tenía que volver a la disciplina fiscal. Así se dio el abismo fiscal y la actividad económica cayó 6\% en 1937 y gran parte de 1938. Fue durante la Segunda Guerra Mundial (1939-1945), cuando el gobierno de dicho país fue obligado a incrementar el gasto deficitario para incentivar la industria bélica y salir victoriosos de dicha conflagración mundial. Durante la Segunda Guerra Mundial, el gasto público deficitario llego a ser $25 \%$ del PIB en Estados Unidos [Nersisyan y Wray, 2010]. Al resultar funcional la participación del Estado en la economía, decidieron prolongarla.

\section{Mientras el dÓlar SEA ACEPTADO, Estados Unidos NO TIENE PROBLEMAS FINANCIEROS}

Para el caso de Estados Unidos no hay problema en el momento de trabajar con dos desequilibrios macroeconómicos: déficit fiscal y déficit en el sector externo, pues se financia con su moneda y el resto del mundo la acepta. Todos los países ahorran en dólares, todos los tienen en sus reservas internacionales. Las tesorerías de 
las grandes empresas tienen sus fondos en dólares y no en euros, debido a que está cayendo al igual que el yen, por lo que prefieren los dólares. Mientras el resto del mundo acepte dólares, Estados Unidos no tiene problema alguno de financiamiento de sus déficit comercial y fiscal. Entonces, se observa que los republicanos no entienden de economía; pues toman decisiones de austeridad fiscal y de disminuir el déficit fiscal sin justificación económica alguna, ya que dicho gobierno no enfrenta restricciones financieras. Estados Unidos no tiene problema ya que la deuda está en "su" moneda y la puede refinanciar, además con la tasa de interés de $0.17 \%$ no tiene problema de pago de dicha deuda y, por tanto, está en condiciones de incrementar la demanda por venta de bonos del Tesoro estadounidense. La decisión política que toman está encaminada a reducir el tamaño y la participación del gobierno en la economía y avanzar en la privatización de los servicios públicos. El gobierno de Barack Obama y sus congresistas demócratas están presionando para que el abismo fiscal, por las consecuencias que podrían surgir en la actividad económica, no sea tan drástico.

\section{ANTE LA INCAPACIDAD DE QUE EL SECTOR PRIVADO \\ Y EL SECTOR EXTERNO SEAN MOTOR DEL CRECIMIENTO, SE REQUIERE DEL GASTO PÚBLICO DEFICITARIO}

El sector privado estadounidense enfrenta problemas en sus finanzas. Se encuentra altamente endeudado, por lo que restringe consumo e inversión para poder pagar, lo que frena su actividad económica. En muchos países el sector externo no es motor de crecimiento por ser deficitario.

El sector externo fue el motor de crecimiento en Alemania que ha crecido a costa de los demás países en la zona euro. En Japón, el sector externo es superavitario, pero no contrarresta la caída del mercado interno derivado de los altos niveles de ahorro predominantes en dicho país, lo que ha configurado un muy bajo crecimiento en las últimas décadas. 
El déficit de comercio exterior en la mayoría de los países en la zona euro (véase el cuadro 2) ha puesto sus economías en el peor de los mundos posibles. El sector privado está sobreendeudado. Antes de la crisis los déficit de comercio exterior en dicha zona eran financiados por la entrada de capitales [Hein, 2012] y el problema es que no pueden pagar su deuda, no pueden invertir ni generar condiciones de empleo. Se han visto obligados a instrumentar políticas de austeridad fiscal para crear condiciones de confianza de pago y en la nueva moneda [Pisani Ferry, 2012], las cuales contraen más la demanda y el mercado interno, y merman aún más las condiciones de acumulación del sector privado. De ahí los problemas de desempleo, de quiebra de empresas, de insolvencia y de la crisis bancaria.

\section{Cuadro 2. Saldos de balanzas comerciales de países seleccionados de Europa (2000-2012)}

\begin{tabular}{c|c|r|r|r|r|r|r|r}
\hline Año & $\begin{array}{c}\text { Zona euro } \\
(\mathbf{1 7} \text { países })\end{array}$ & Francia & Alemania & Grecia & Irlanda & Italia & Portugal & España \\
\hline 2000 & 38.9 & 13.5 & 6.1 & -17.6 & 12.9 & 10.6 & -13.0 & -18.2 \\
\hline 2001 & 88.6 & 15.4 & 37.7 & -17.6 & 16.3 & 15.5 & -12.3 & -15.4 \\
\hline 2002 & 168.5 & 22.4 & 91.7 & -20.5 & 21.3 & 11.4 & -11.0 & -14.7 \\
\hline 2003 & 166.3 & 15.7 & 96.3 & -24.3 & 25.4 & 8.3 & -11.0 & -21.2 \\
\hline 2004 & 196.3 & 8.8 & 135.2 & -23.6 & 27.8 & 12.1 & -15.5 & -41.8 \\
\hline 2005 & 149.3 & -12.7 & 143.6 & -22.3 & 23.9 & -0.9 & -18.1 & -59.4 \\
\hline 2006 & 124.7 & -23.7 & 164.6 & -28.4 & 21.7 & -15.1 & -17.5 & -78.7 \\
\hline 2007 & 186.7 & -40.6 & 235.8 & -41.2 & 23.5 & -5.3 & -18.6 & -97.3 \\
\hline 2008 & 130.8 & -59.9 & 226.6 & -49.6 & 23.8 & -19.1 & -25.5 & -93.7 \\
\hline 2009 & 165.9 & -48.2 & 165.6 & -36.7 & 34.8 & -11.1 & -17.4 & -27.3 \\
\hline 2010 & 151.6 & -59.3 & 176.7 & -26.8 & 39.6 & -39.8 & -16.4 & -29.5 \\
\hline 2011 & 184.1 & -79.5 & 180.7 & -22.4 & 46.8 & -32.3 & -9.3 & -9.0 \\
\hline 2012 & 243.1 & -76.1 & 162.0 & -12.0 & 50.1 & -21.8 & -2.4 & 29.8 \\
\hline
\end{tabular}

Fuente: Elaboración propia con base en OECD Economic Outlook.

La única salida que tiene el sector privado para mejorar sus finanzas ante la dificultad de que se revierta el déficit de comercio 
exterior, es que el gobierno en vez de contraer el gasto, trabaje con gasto público deficitario, en favor del sector privado productivo y no siga actuando favoreciendo al sector financiero como lo ha hecho los últimos años en Estados Unidos y en todas partes del mundo.

Debemos identificar las virtudes del gasto público deficitario. En el esquema de los tres sectores de la economía, el sector privado decíamos, depende de las finanzas del sector público y del sector externo. El sector externo va a seguir siendo deficitario, tanto en Estados Unidos como en nuestro país, pues se ha perdido competencia frente a los países asiáticos, sobre todo con China, lo que ha derivado en la desindustrialización. En Estados Unidos durante la década de los años ochenta, la industria manufacturera representó $20 \%$ de la actividad económica y, hoy día, es $12 \%$. Se observa el rompimiento de cadenas productivas que frenan su crecimiento y la generación de empleo.

La reversión del déficit de comercio exterior se daría si el resto de los países no aceptara dólares, por lo que el dólar se devaluaría y, por lo tanto, mejoraría la competitividad, así Estados Unidos recuperaría su dinámica de exportaciones, disminuiría su déficit de comercio exterior e impulsaría su crecimiento. Sin embargo, como todo el mundo vive gracias a las importaciones de Estados Unidos, al resto del mundo le conviene que aquel siga con déficit comercial. Así se explica que China compre los bonos del Tesoro estadounidense para que Estados Unidos siga comprando e importando sus productos. Así China sigue exportando y dinamizando su economía.

En el contexto de recesión generalizada, el sector externo deja de ser motor de crecimiento; está cayendo el mercado internacional. En el caso de México, las exportaciones y las remesas están disminuyendo, asimismo, pierden dinamismo las exportaciones de Alemania, China y de todos, eso acentuará la tendencia de recesión económica en el ámbito mundial (véanse el cuadro 3 y la gráfica 4). 
Cuadro 3. Países seleccionados. Exportaciones (miles de dólares)

\begin{tabular}{l|r|c|c}
\hline \multicolumn{1}{c|}{ Año } & Estados Unidos & \multicolumn{1}{c|}{ Alemania } & \multicolumn{1}{c}{ China } \\
\hline 2005 & 904339487 & 977131972 & 761953410 \\
\hline 2006 & 1037029245 & 1121962887 & 968935601 \\
\hline 2007 & 1162538150 & 1328841354 & 1220059668 \\
\hline 2008 & 1299898877 & 1466137413 & 1430693066 \\
\hline 2009 & 1056712078 & 1127839933 & 1201646758 \\
\hline 2010 & 1277109162 & 1271096329 & 1577763751 \\
\hline 2011 & 1479730169 & 1482202274 & 1898388435 \\
\hline
\end{tabular}

Fuente: UNCTAD . Data and statistics.

Gráfica 4. Países seleccionados. Exportaciones totales, 2005-2012 (miles de dólares)

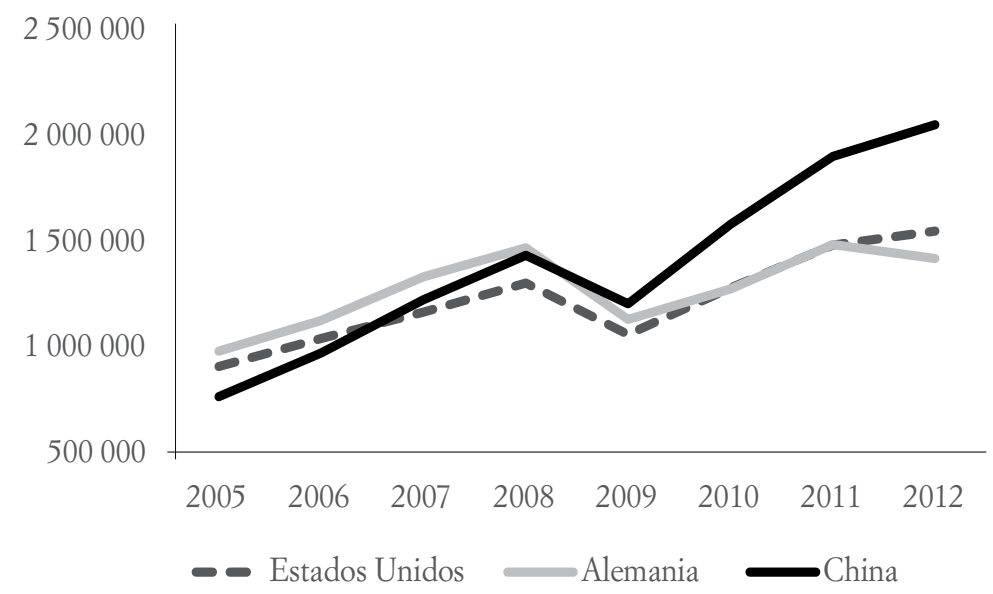

Fuente: UNCTAD . Data and statistics, 2013. 


\section{LA IMPORTANCIA DEL GASTO PÚBLICO}

DEFICITARIO PARA REACTIVAR LA ECONOMÍA, Y LA RESISTENCIA A ELLO

El gasto público deficitario es importante para dinamizar la economía y para mejorar las finanzas del sector privado. Nos dice Dale Pierce [2013: 1] que "para mantener la demanda alta, para emplear a la mayoría que quiere trabajar, el gobierno debe emitir más dinero de lo que colecta”. Ello es funcional para las economías que no tienen motor interno y externo de crecimiento. De retomar Estados Unidos el gasto público deficitario, sería funcional también para aquellas economías que exportan hacia dicho país, por lo que están dispuestos a seguir comprando la deuda pública que emite el gobierno estadounidense. Además, el gasto público deficitario no es inflacionario dados los altos niveles de desempleo y la capacidad ociosa existente y, además todo depende hacia dónde se canaliza la expansión fiscal. Si se dirige hacia incrementar la productividad, la capacidad productiva, la sustitución de importaciones y la oferta para satisfacer el aumento de demanda, dicho gasto público no va a ser inflacionario ni va a presionar sobre el sector externo. Hay que evitar los efectos de filtración de demanda al exterior, pues en un contexto de economía abierta gran parte del incremento del gasto público deficitario se traslada hacia las importaciones, genera déficit de comercio exterior y dicho déficit termina por convertirse en una limitante. De ahí la importancia de un gasto público deficitario dirigido en favor de la esfera productiva y del empleo.

El problema es que no se vislumbran perspectivas de una política fiscal flexible. En la zona euro no es posible porque, como ya se dijo, perdieron el control de la moneda, por lo que no pueden financiarse con ella. La política fiscal fue separada de la moneda [Wray, 2012]. En Estados Unidos, el predominio de la ortodoxia no permite que se incremente el gasto público deficitario, sino al contrario, la tendencia es que siga la política de austeridad fiscal y por lo tanto continuarán los problemas de contracción de la actividad económica. 
Somos testigos de que siempre hay dinero para el sector financiero, pero no hay dinero para la generación de empleo, para el fortalecimiento del mercado interno y para que las empresas vean incrementadas sus ventas e ingresos para así invertir y pagar lo que deben. Ello ocurre porque al sector financiero, es decir, a los acreedores les conviene; debido a que están presionando a los gobiernos y a las empresas para pagar con activos. En la zona euro, Alemania se está apropiando del resto de Europa, ya que como los demás países son deficitarios y tienen alta deuda, están vendiendo activos para pagar sus pasivos, lo que le permite a Alemania, que es el país acreedor, adquirir a bajo costo tales activos. Gana, tanto por las tasas de interés que cobra, como porque adquiere los activos estratégicos de los otros.

La política económica responde a los intereses de grupos hegemónicos que quieren menor participación del Estado en la economía para apropiarse de los activos del sector público. Los acreedores presionan más a los deudores para que paguen su deuda con sus empresas. Ello polariza los niveles de concentración y centralización del capital en manos de los acreedores. Por otro lado, se agudizan las contradicciones, ya que se recrudecen los problemas de insolvencia lo que desestabiliza a la banca. Ésta demanda rescates gubernamentales a su favor, a costa de que se contraiga la actividad económica y se desatiendan las demandas sociales, lo que acentúa la lucha de clases.

Ante la tendencia decreciente de la actividad económica en Estados Unidos, derivada de la política fiscal restrictiva, más se van a contraer los ingresos de los deudores lo que derivará en otra crisis bancaria. Entonces, ¿cómo se rescatará a la banca en un contexto de austeridad fiscal? Para apoyar a la banca se rompe con la austeridad fiscal, como aconteció en 2008 y 2009. Para ellos sí hay dinero, no para impulsar la actividad económica, ni el empleo, mucho menos para aumentar los gastos de bienestar social. 


\section{PerspeCtivas de LA ECONOMÍA NACIONAL}

Y SU EFECTO EN LA MIGRACIÓN

La actividad económica del país creció $0.8 \%$ durante el primer trimestre de 2013 en relación con el mismo periodo del año anterior, esto llevó a la Secretaría de Hacienda y Crédito Público (SHCP) a modificar sus pronósticos de crecimiento para el presente año de $3.5 \%$ a $3.1 \%$. El indicador global de la actividad económica del mes de marzo, registró una disminución anual de $1.8 \%$ y la producción industrial de marzo muestra una caída de $4.9 \%$ anual. Todo ello lo adjudican a la desaceleración de la demanda externa presente desde mediados de 2012. Las exportaciones no petroleras muestran un crecimiento de solo $0.1 \%$ durante el primer trimestre de 2013 en relación con igual periodo de 2012. Adelanta la SHCP que la desaceleración de la economía, se reflejará en menor recaudación tributaria, lo que presionará sobre las finanzas públicas y obligará al gobierno a recortar el gasto para mantener la disciplina fiscal. Si el gobierno nos dice que gastará menos, ello apunta a que no habrá política fiscal contracíclica para contrarrestar el bajo crecimiento de las exportaciones que frena la economía del país, por lo que es difícil que la economía crezca 3.1\% como ellos dicen. El gobierno en acto de fe, afirma que las condiciones económicas serán diferentes en el segundo semestre del año, pero nada respalda dicha afirmación, pues la economía mundial continúa desacelerándose y, con ello, seguirá la caída de las exportaciones aún más por la fuerte apreciación de la moneda nacional, dada la gran entrada de capitales financieros que han incrementado las reservas internacionales y abaratan el dólar mermando más la competitividad de la producción nacional. La economía ha dejado de tener motor externo de crecimiento y carece de motor interno, dado el predominio de las políticas macroeconómicas de estabilidad (disciplina fiscal, alta tasa de interés, apreciación cambiaria), que sacrifican el crecimiento del mercado interno. De ahí la insistencia del gobierno a que se aprueben sus reformas estructurales de privatización y extranjerización para atraer inversión extranjera directa 
para que impulse el crecimiento. El problema de ello, es que dicha inversión solo representa cambio patrimonial y no incrementa la capacidad productiva, ni de la economía, debido a que ellos invierten donde el gobierno deja de hacerlo.

Si comparamos el comportamiento de primer trimestre de 2013, en relación con el cuarto trimestre de 2012, se evidencia más claramente la desaceleración de la economía. Datos del INEGI reportan que el PIB muestra durante el primer trimestre, una caída de $5.8 \%$ en relación con el último trimestre de 2012 . Hay crecimiento negativo en la industria manufacturera de $5.1 \%$, la electricidad de 4.1 y el comercio de $6.2 \%$, por lo que de mantenerse dicha tendencia entraríamos a una recesión este mismo año, la cual se conforma cuando la actividad económica tiene un comportamiento negativo durante dos trimestres consecutivos.

Este comportamiento de la economía real contrasta con el de la Bolsa Mexicana de Valores (BMv), la cual mostró durante el primer trimestre del año un incremento de ganancias de $22 \%$ en relación con igual periodo de 2012. El 20 de mayo La Jornada [Zúñiga y Cardoso, 2013] informó que según estadísticas de las casas de bolsa, 205884 cuentas individuales para fines de marzo (que representan $0.17 \%$ de la población) sus inversiones financieras eran equivalentes a $47 \%$ del PIB, lo que evidencia como este sector es el beneficiado de las políticas macroeconómicas de estabilidad predominantes que tanto defienden los gobiernos y los partidos políticos del Pacto por México.

El sector financiero no genera riqueza, esta se genera y produce en la esfera productiva por lo que, al mostrar que la economía está desacelerándose, dicho sector volverá a caer ya que no hay economía real que sustente y convalide las ganancias que dicho sector ofrece. Lo financiero no puede crecer por sí solo. Se despega su crecimiento cuando los capitales fluyen hacia dicho sector, lo cual acontece cuando el sector productivo no ofrece opciones rentables de inversión. Sin embargo, cuando los inversionistas no ven perspectivas de mantener las ganancias en el mercado de acciones, se retiran de él provocando su caída y, 
ante el escenario de recesión económica, seguirá la vulnerabilidad del mercado de capitales que ahuyentará la entrada de ello y provocará su salida con las consecuentes presiones sobre el tipo de cambio. Aquellos que han aprobado la gestión del nuevo gobierno, terminarán por cambiar su posición.

$\mathrm{Al}$ mantenerse y crecer el problema del desempleo, subempleo y miseria, crecerá cada vez más el deseo de emigrar hacia Estados Unidos en búsqueda de mejores oportunidades. El problema es que cada vez es más difícil cruzar la frontera, tanto por los mayores muros como porque en Estados Unidos el desempleo también repuntará ante el escenario de contracción de la actividad económica. Al carecer de sindicatos fuertes, de un movimiento obrero y partidos políticos que luchen por las reivindicaciones laborales así como por mayores fuentes de empleo, muchos trabajadores y excluidos se sienten desamparados, lo que conlleva a que no se manifiesten para exigir que las políticas económicas respondan a las necesidades de empleo, tal y como se vive en Europa donde vemos huelgas generales y grandes manifestaciones, el problema es que a pesar de ello no hay cambio en la política económica, misma que sigue respondiendo a intereses del sector financiero. Conforme vaya creciendo el descontento, habrá más movilizaciones en el mundo. Ello se traducirá en cambio de gobiernos y de las políticas económicas para que satisfagan las demandas de las mayorías de la población. En nuestro país, predominan las alianzas de los partidos de oposición con el gobierno, mediante el Pacto por México donde participan los partidos políticos PRI, PAN y PRD, para impulsar más reformas estructurales que llevan a mayor privatización y extranjerización, pensando que la cúpula empresarial nacional e internacional van a resolver los problemas existentes en la economía sin tener memoria histórica de que hoy el país está más privatizado y extranjerizado que nunca, lo que nos ha llevado a tener menos bases productivas y financieras para el crecimiento y para la generación de empleos dignos bien remunerados, así como al clima de violencia que se vive en todo el país. 


\section{A MANERA DE CONCLUSIÓN}

Vivimos momentos históricos muy importantes que están definiendo los rumbos, tanto en países desarrollados como en nuestro país, que configuran un escenario nada optimista. De ahí la importancia de seguir con el análisis de coyuntura y la necesidad de tener pronunciamientos en contra de estas políticas económicas causantes de la problemática económica mundial y nacional. Para revertir tal situación, se requiere de una participación activa, organizada y concientizada para cambiar la correlación de fuerzas existente en el ámbito nacional y mundial, lo cual no es nada fácil no obstante el número creciente de excluidos.

\section{BIBLIOGRAFÍA}

Hannsgen, G. y D. Papadimitriou [2012], "Fiscal trap and macro policy alter the Eurozone crisis", Levy Economics Institute of Bard College, PPB, WP 127.

Hein, E. [2012], “The crisis of finance-dominated capitalism in the Euro Area, deficiencies in the economic policy architecture, and deflationary stagnation policies", Levy Economics Institute of Bard College, WP 734.

Kregel, J. [2010], "Fiscal responsability: what exactly does it mean?”, Levy Economics Institute of Bard College, WP 602.

Nersisyan, Y. [2010], "More reasons to doubt rogoff and reinhart", New Economic Perspectives, agosto.

Nersisyan, Y. y R. Wray [2010], "Deficit hysteria redux? why we should stoop worrying about US government deficits”, Levy Economics Institute of Bard College, PPB 111A.

Papadimitriou, D. et al. [2013], "Is the link between output and jobs broken?, Levy Economics Institute of Bard College, Strategic Analysis, marzo.

Papadimitriou, D. y R. Wray [2011], "Confusion in Euroland", Levy Economics Institute of Bard College, WP 20. 
Pierce, D. [2013], "Modern money theory: an introduction: part I", New Economic Perspectives, abril.

Pisani Ferry, J. [2012], "The euro crisis and the new impossible trinity”, Bruegel Policy Contribution, enero.

Tcherneva, P. [2010], "What is responsible fiscal policy?", New Economic Perspectives, abril.

Wray, R. [2012], Modern Money Theory. A Primer on Macroeconomics for Sovereign Monetary Systems, Palgrave Macmillan, $312 \mathrm{pp}$.

Wray, R. [2013], "Why reinhart and rogoff results are crab", disponible en <www.ecomonitor.com/lrwray>, consultado el 20 de abril de 2013.

Zúñiga, J.A. y V. Cardoso [2013], "Ganaron casi \$30 millones al día las 33 casas de bolsa del país", La jornada, México, sección Economía, 20 de mayo. 


\section{Capítulo 5 \\ DESEMPLEO, PRECARIZACIÓN, CRISIS Y MIGRACIÓN}

\section{Alejandro Valle Baeza"}

En las últimas décadas se ha virado hacia una forma de empleo cada vez más funcional a las necesidades de la acumulación del capital, ocasionando peores condiciones para los trabajadores de los países desarrollados y siendo aún más severas para los países de ingresos medios y bajos. La migración ha sido una "solución" ante los problemas de empleo. Mexicanos y centroamericanos emigran hacia Estados Unidos porque no hay oportunidades de empleo decente en sus lugares de origen. Sin embargo, la migración no puede ser una solución duradera, puesto que el problema de empleo no es específico de un solo país sino un problema estructural y universal. A los problemas estructurales se suman los ocasionados por las crisis y las recesiones. Normalmente una crisis resuelve algunas contradicciones del sistema o al menos las atempera; la cuestión del empleo no es una de esas contradicciones que se atenúe con la presente crisis.

* Doctor de Economía y profesor de tiempo completo del Área de Economía Política y del Posgrado de la Facultad de Economía de la UNAm. Correo electrónico: <valle@ servidor.unam. $\mathrm{mx}>$. 


\section{INTRODUCCIÓN}

El tener un empleo estable y bien pagado es cada día más difícil en todo el mundo, eso motiva la emigración y la retroalimenta, pero también la dificulta. En este trabajo argumento que los problemas de empleo son estructurales. Los problemas laborales se han agravado por una seria crisis iniciada en Estados Unidos: "La gran recesión". Aún los defensores incondicionales del capitalismo, como Blanchard [Madár y Kovács, 2012], han perdido su optimismo sobre que la economía estadounidense vuelva a crecer a los ritmos anteriores a la crisis de 2007-2009. Cuando ya parecía bajo control, la crisis mundial ha resurgido en Europa y amenaza otra vez a Estados Unidos. Para los trabajadores mexicanos es relevante entender por qué está resultando tan severa y duradera la crisis estadounidense y en cuáles formas afecta a la economía de nuestro país. Cuando decimos "los trabajadores mexicanos", debemos pensar en los que están aquí y en los que han debido emigrar al tratar de encontrar el empleo decente que no han hallado dentro de sus fronteras. Decenas de millones de trabajadores asentados en Estados Unidos son de origen mexicano, ellos emigraron de un país que ofrece magras oportunidades de trabajo hacia otro donde también se han deteriorado las condiciones laborales en los últimos cuarenta años. En lo que sigue desarrollaré una explicación de la causa de los problemas de empleo basada en algunas ideas de Marx. Posteriormente trataré muy someramente la teoría de la crisis e intentaré explicar con ella la más reciente crisis estadounidense. Exploraré algunos aspectos de la relación entre migración y crisis a lo largo de estas secciones para finalmente formular algunas conclusiones.

\section{DESEMPLEO, PRECARIZACIÓN DEL TRABAJO}

ESTADOUNIDENSE E INMIGRACIÓN INDOCUMENTADA

El desempleo y el trabajo precario se han enseñoreado del mundo. En los inicios de la crisis de 2007 la Organización Internacional 
del Trabajo (Оіт) señalaba que aún en los países ricos los problemas de empleo eran graves y endémicos:

En los países industriales avanzados, el pleno empleo prevaleció hasta mediados de la década de los setenta cuando el primer "shock petrolero" indujo un problema de empleo. El problema persiste aún hoy a pesar de algunas mejoras ocurridas en la década de 1990. La tasa de desempleo supera 5\% en 14 de los 23 países industriales avanzados. Más de $15 \%$ de los empleos son de tiempo parcial en 13 países y el empleo a tiempo parcial parece haberse sustituido por el desempleo de forma significativa.

En la década de los noventa, la mayoría de los países intentaron abordar el problema de empleo esencialmente mediante políticas encaminadas a aumentar la flexibilidad del mercado laboral. Pero estas políticas tuvieron muy poco éxito en reducir el desempleo y en su lugar llevaron al crecimiento de los empleos mal pagados de tiempo parcial y temporales e incluso a los mercados de trabajo de primera y segunda clase. Esto es sorprendente teniendo en cuenta que la década de 1990 fue realmente un periodo de rápido crecimiento económico [Ghose, Majid y Ernst, 2008: 2].

Desde luego que en los países con menor desarrollo esos problemas son aún más graves, tal como se afirma en Valle [2002]. Los trabajadores precarios son una porción muy considerable del empleo en los países de ingresos medios y bajos. Una respuesta de los trabajadores de los países pobres ante sus problemas de empleo ha sido la emigración hacia los países con mejores niveles de vida. Al ser los problemas de empleo universales la emigración no es una solución duradera.

Una gráfica publicada por The New York Times (NYT) del 12 de abril de 2008, mostraba claramente que la cantidad de varones sin empleo aumentó consistentemente desde 1960: en ese lapso el porcentaje de hombres en edad de trabajar sin empleo, pasó de alrededor de 6\% y se acercó a 12\%. De manera que al inicio de la crisis aunque la tasa de desempleo no parecía muy alta ocultaba un problema de empleo mucho mayor. El NYT explicaba que la falta de trabajo hacía de la inmigración un tema electoral obligado. 
La migración no autorizada se combatirá más duramente debido a las dificultades crecientes de obtener empleo empeoradas por la recesión. Con dos gobiernos ultraconservadores en Estados Unidos y en México, con el pretexto del combatir el narcotráfico se han recrudecido las medidas antimigrante, como se esperaba.

La crisis, como ocurre siempre, incrementó el desempleo (véase gráfica 1). En sólo dos años el número de desempleados en Estados Unidos se duplicó, pasó a 14.3 millones en 2009. Sus efectos sobre la inmigración pueden verse en Aragonés et al. [2012].

Gráfi ca 1. Estados Unidos. Desempleo, 1966-2012

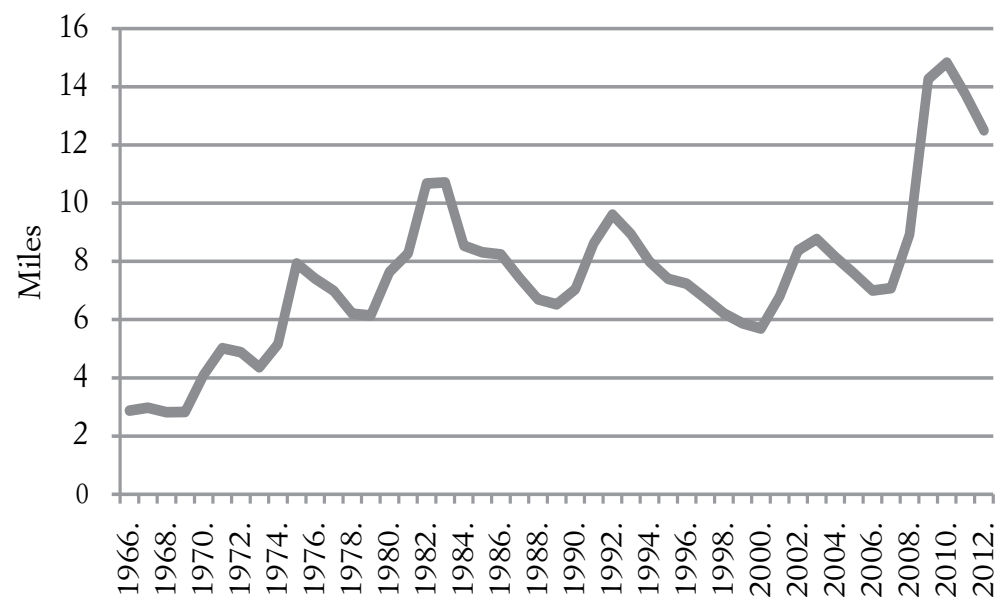

Fuente: Elaboración propia con datos del Economic Report of the President, 2013.

También creció el número de personas que ya no buscan empleo después de no haberlo logrado durante mucho tiempo. Eso se muestra claramente en la tasa de participación (el porcentaje de personas que trabajan obteniendo un ingreso monetario, entre la población en edad de trabajar) que ha descendido desde la crisis de 2001 (véase gráfica 2). Durante mucho tiempo dicha variable aumentó con la incorporación de más mujeres en el trabajo asalariado, pero después de 2001 ha disminuido. 
Gráfi ca 2. Estados Unidos. Tasa de participación

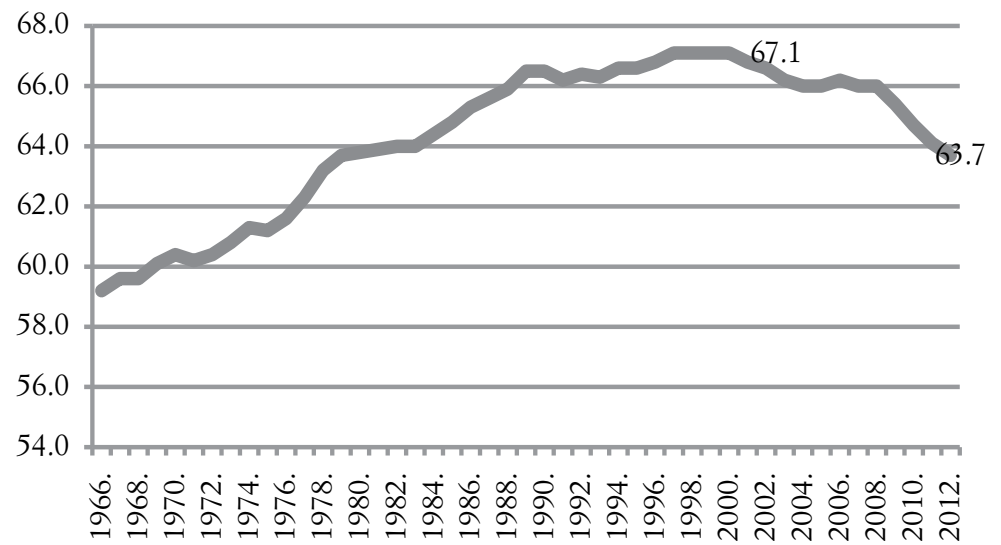

Fuente: Elaboración propia con datos del Economic Report of the President, 2013

Una variable que condensa mucho de lo ocurrido con los trabajadores estadounidenses es el salario medio real por hora, como se muestra en la gráfica 3.

\section{Gráfica 3. Estados Unidos. Salario real por hora}

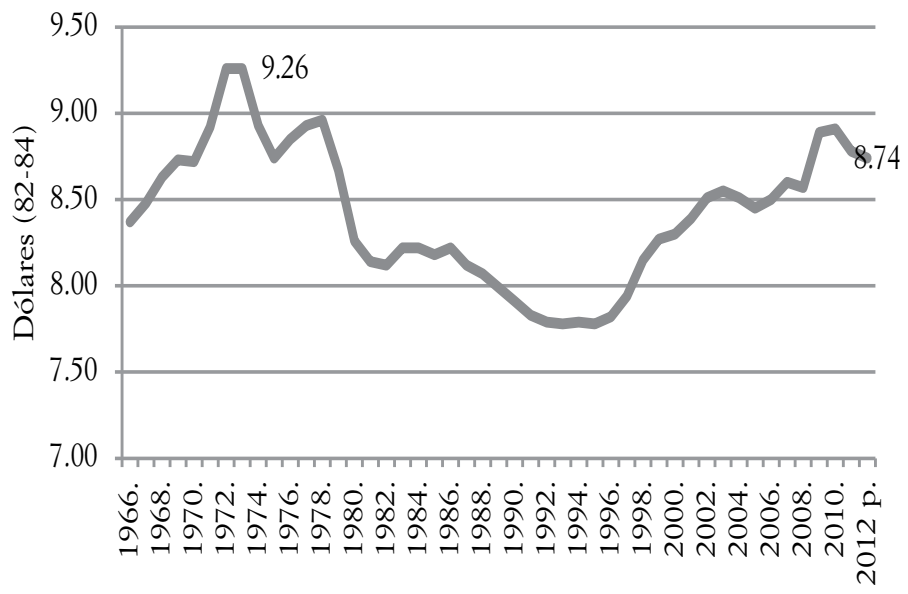

Fuente: Elaboración propia con datos del Economic Report of the President, 2013. 
El salario real promedio por hora es hoy menor que hace 40 años en Estados Unidos. En ese lapso la productividad creció considerablemente por lo que todos sus incrementos fueron a parar a manos de los capitalistas. Los salarios anteriores tienen errores de medición pues incorporan datos de funcionarios del capital: gerentes, supervisores, etcétera. Esta clase de errores oculta que el salario de los trabajadores es menor a lo publicado. Por otro lado, el salario monetario no es todo lo que recibe el trabajador ya que las remuneraciones incluyen ingresos tales como los servicios de salud cubiertos por las empresas o las instituciones gubernamentales.

Volveremos a este asunto de los salarios medios más adelante para relacionarlo con las causas de la crisis; aquí nos importa su relación con la política de migración. Ya destacamos que la falta de trabajo coloca a la inmigración como un asunto político de primer orden. Cuando vemos que además los empleos reciben menor paga en promedio la problemática laboral se vuelve más difícil. La emigración hacia Estados Unidos tiene causas y efectos económicos considerables. Los trabajadores emigran en mayor proporción que antes porque la situación en sus lugares de origen empeora pero esa degradación de las condiciones laborales está ocurriendo también en sus lugares de destino. La inmigración es admitida para presionar a la baja a los salarios en el país de destino, dicha función se intensifica cuando la inmigración es indocumentada. La "ilegalidad" es creada tanto para bajar los salarios del inmigrante como los del residente nacional.

En América del Norte y Europa existe una creciente tendencia hacia la criminalización y la discriminación de la migración indocumentada. Esta criminalización no frena la inmigración, sino que coloca a los migrantes socialmente fuera de la ley con el fin de controlarlos, marginarlos e invisibilizarlos y, de esa manera, hacer que los empleadores obtengan mejores dividendos de su trabajo. La criminalización como mecanismo de (incrementar $)^{1}$

${ }^{1}$ La palabra "incrementar" la inserto yo para aclarar el erróneo concepto de explotación compartido por los no marxistas. De acuerdo a esa idea la autora califica 
la explotación es legitimada por las actitudes discriminatorias, xenófobas y racistas de las sociedades receptoras [Estévez, 2012: 63].

Al disminuir los salarios se crea demanda del trabajo indocumentado. Familias que no podían contratar trabajadores domésticos regulares pueden contratar ilegales con bajos salarios. Como los trabajadores están fuera de la ley no puede haber actos ilegales contra ellos [Estévez, ídem] y el círculo infernal se agranda: trabajadores sin derechos propician la contratación de más trabajadores en esas condiciones.

Según el último censo de 2010 en Estados Unidos, uno de cada seis habitantes de ese país es de origen latino (51 millones de un total de 309 millones en cifras redondeadas) y poco más de la mitad del incremento poblacional de la década 2000-2010 se debió a población de origen latino. Los hispanos como los denominan oficialmente, son en su mayoría mexicanos de acuerdo con una investigación del PEW Center [Motel y Patten, 2012].

Los defectos del capitalismo en general y del estadounidense en particular, se combinan produciendo acciones antinmigratorias. Estados Unidos han instrumentado un abanico que va desde las acciones paramilitares hasta leyes para perseguir, deportar o volver insufrible la vida a los indocumentados.

Un ejemplo de lo primero se observó el 30 mayo de 2009 cuando un grupo de hombres y mujeres armados asesinaron a Brisenia Flores, de 9 años, y a su padre en Arivaca, Arizona. Los asesinos pertenecían a un grupo paramilitar Minutemen, una extensa red de civilian defense corps que patrullan la frontera entre México y Estados Unidos para impedir la inmigración indocumentada. ${ }^{2}$

\footnotetext{
de explocación del trabajo la situación donde ser perciben salarios y prestaciones muy por debajo de lo humanamente aceptable, es decir se trata de una categoría con fuerte carga moral. Para el marxismo en cambio es explotado todo trabajo que produce o que permite apropiarse de excedente capitalista o plusvalía, ya que percibe un salario que le da alcance al trabajador para adquirir mercancías cuyo valor es inferior al tiempo trabajado.

${ }^{2}$ Los asesinos trataban de hacerse de dinero para sus actividades cuando mataron a los migrantes [Kohn, 2009].
} 
Según los líderes del grupo paramilitar Minuteman Project (originador de la red Minutemen) la inmigración: "Es una invasión, no la visita de un vecino pidiendo una taza de azúcar" [Dufort, 2012: 207]. Describen la situación como una guerra y asocian la inmigración indocumentada con el terrorismo y el crimen, especialmente con el tráfico de drogas. Minuteman Project desarrolla además de su labor parapoliciaca una extensa labor de propaganda incendiaria y cabildeo desde su fundación en 2004, por Jim Gilchrist, veterano de la guerra de Vietnam y Chris Simcox, maestro de educación preescolar [Dufort, 2012: 68]. El Minuteman tiene distinguidos ancestros, como el Ku Klux Klan Border Watch en California (1976), además hay otros grupos con similares objetivos y métodos, como Arizona Guard y American Border Patrol, tan sólo en Arizona. Esta clase de grupos facistoides serían considerados ilegales en otros países pero no en Estados Unidos donde son promovidos por los medios de difusión.

El "muro de la muerte" una gran barrera cuya construcción se inició en 1994, está dotada de luces intensísimas, detectores de movimiento, visores infrarrojos y vigilada mediante vehículos todo terreno y helicópteros artillados. Cuando se concluya tendrá miles de kilómetros, desde su inicio tuvo el efecto de obligar a los migrantes para cruzar por los sitios más inhóspitos como montañas y desiertos, lo que ha provocado numerosas muertes.

La legislación federal vigente posibilitó que, durante el primer periodo de gobierno de Barack Obama, Estados Unidos deportaran un millón y medio de indocumentados, ello ha obligado a la ruptura familiar o a la emigración de muchísimas familias. La Corte Suprema de Estados Unidos confirmó gran parte de la criticable Ley S.B. 1070 antimigrante de Arizona, que permite a la policía determinar el estatus migratorio de alguien arrestado o detenido cuando se tiene una sospecha razonable de no estar legalmente en Estados Unidos. La Ley S.B. 1070 impulsó a Alabama, Georgia, Indiana, Carolina del Sur y Utah para promulgar leyes semejantes.

Las desventuras de los migrantes no se limitan a Estados Unidos: 
A principios de 2006 mencionaba el Quinto Visitador General de la Comisión Nacional de Derechos Humanos, más de 300 mil migrantes de otros países, sobre todo centroamericanos, se internaron en México con el propósito de llegar a Estados Unidos, de ellos 240 mil fueron devueltos a su país por la autoridad migratoria. Los estudiosos del fenómeno estiman que en la actualidad la migración asciende de 350 mil a 400 mil personas por año, usualmente de manera irregular [Arámbula y Santos, 2007].

Los problemas para los migrantes no se limitan a los del lugar de destino, el tránsito de la migración es extraordinariamente difícil.

El Programa de Naciones Unidas para el Desarrollo [PNUD, 2007: 78] afirma:

Para los migrantes [...]el cruce fronterizo -representa- condiciones que minan su salud y ponen en peligro sus vidas: calor o frío, falta de alimento y agua, ataque de animales, accidentes, abusos de la policía mexicana, de la Patrulla Fronteriza y de prestadores de servicios, maltrato, agresiones sexuales, abusos de los coyotes (costos más elevados, crueldad o secuestro) y ataques de grupos delictivos organizados, como traficantes de personas y asaltantes.

Estos factores, además de implicar riesgos de daño físico, contribuyen a que el cruce sea vivido como una experiencia traumática que deja secuelas como el síndrome de estrés postraumático, varios años después de haber cruzado la frontera.

\section{El Siglo de Torreón, en Coahuila México, denunció:}

Si no es a garrotazos o con toletes, los migrantes centroamericanos que van de paso rumbo a Estados Unidos son víctimas de policías federales y estatales o agentes del Instituto Nacional de Migración (INM) o vejados con armas de fuego, gases lacrimógenos, piedras, perros y hasta toques eléctricos. Frontera con Justicia, AC y Humanidad sin Fronteras, AC, han documentado desde hace por lo menos tres años con encuestas la situación de los migrantes, a quienes auxilian y quienes acceden a dar su testimonio.

Mediante entrevistas con migrantes centroamericanos que estuvieron en los albergues de mayo de 2006 a abril de 2007, ambas 
asociaciones civiles lograron documentar 2506 casos de violaciones a los derechos humanos. El informe revela que un migrante es vejado hasta en más de una ocasión desde su travesía por Guatemala y a lo largo del territorio mexicano. La mayoría de los entrevistados son hombres según los datos de las Organizaciones no Gubernamentales con sede en Coahuila, cuyo informe considera a quienes cruzan esas tierras y son albergados porque necesitan medicinas, alimentos y hospedaje. "Ha habido un aumento en cuanto al número de mujeres que decide denunciar. No obstante, no todas las que pasan lo hacen, debido a la falta de cultura de denuncia, por miedo y por considerar las violaciones sufridas como un costo por llegar a la frontera" [El Siglo de Torreón, julio 2 de 2007]. Las violaciones superlativas de los derechos de los migrantes son los asesinatos y los secuestros. En un solo año la Comisión Nacional de Derechos Humanos [CNDH, 2011] registró 11 mil secuestros de migrantes en el territorio mexicano.

Mexicanos y centroamericanos emigran hacia Estados Unidos porque no hay oportunidades de empleo decente en sus lugares de origen. Los capitalistas estadounidenses contratan inmigrantes para ampliar sus ganancias las cuales son mermadas por otros capitalistas en otras partes del mundo. Este proceso plagado de cambios contradictorios es el capitalismo y su mercado el cual, según la propaganda, asigna eficientemente los recursos. Los asalariados en dificultades emigran desde países atrasados hacia países ricos cuyos trabajadores también tienen crecientes dificultades y todo se complica con las crisis, especialmente con una seria y más larga de lo habitual. Las crisis son momentos en los cuales el capitalismo resuelve algunas de sus contradicciones, en muchas ocasiones lo racional sólo se lleva a cabo en el irracional escenario de la crisis. Por ejemplo, la irracional tendencia para producir autos más grandes y dispendiosos que recurrentemente mueve a la industria automotriz ha precisado de las crisis para, al menos, pausarse. Así ocurrió en los años setenta del siglo xx y en la actual crisis con los aumentos de precios de los combustibles. Antes de la presente crisis, la industria automotriz, principalmente la estadounidense, impulsaba de manera intensa 
la venta de autos grandes para ganar y acumular. La mayor contaminación producida por esos vehículos debido al mayor uso de combustibles fósiles y que incorporan más cantidad de materiales se explica debido a que los capitales automotrices ganan más y conllevan más capital por unidad vendida. Dicho comportamiento no se vio pausado por los reclamos de los ambientalistas, sino por los aumentos de precios de la gasolina y el desplome del crédito. Es decir, la crisis hace lo que los capitalistas se niegan a realizar; aunque al abatir los gastos en favor del ambiente el resultado neto pueda ser negativo. ${ }^{3}$

¿Esta crisis ha traído o traerá efectos positivos para la migración y el empleo? Buscaremos responder a esta preguntas en la siguiente sección.

\section{TRABAJO PRECARIO Y CRISIS}

El capitalismo de hoy produce pocos empleos decentes. Un ejecutivo de alto nivel lo dice muy descarnadamente: "American business is about maximizing shareholder value. You basically don't want workers. You hire less, and you try to find capital equipment to replace them". ${ }^{4}$ Las dificultades de los trabajadores para encontrar empleo decente han aparecido incluso en los informes neoliberales. Por ejemplo el FMI publicó "Jobs and growth: analytical and operational considerations for the fund", texto donde reconoce la urgencia de atender los problemas del empleo y del incremento de la desigualdad en el mundo. No obstante, como corresponde a una de las instituciones líderes del capitalismo, sus explicaciones y soluciones están sesgadas para defender el sistema.

\footnotetext{
${ }^{3}$ La crisis reorientó parte de la producción automotriz hacia modelos menos contaminantes, al mismo tiempo redujo los gastos gubernamentales y empresariales en conservación ambiental. El resultado neto está por verse.

${ }^{4}$ La afirmación es de Allen Sinai, economista en jefe de la firma Decision Economics [Goodman, 2010].
} 
La precarización del trabajo es un aspecto de la debilidad del capitalismo para absorber la fuerza de trabajo disponible. $\mathrm{Si}$ bien es cierto que el desempleo es indispensable para facilitar la acumulación y disciplinar a los trabajadores empleados, el hecho que deje de explotar grandes porciones de trabajadores contradice uno de los principios capitalistas básicos: acumular y acumular. Como el origen de la riqueza capitalista es el trabajo impago, la continua adición de nuevos trabajadores coexiste con el constante desempleo, sin embargo, lo primero debe predominar mientras el sistema sea dominante.

El tamaño mínimo del ejército industrial de reserva (EIR), término más amplio que el de desempleo, se establece de manera más o menos automática: cuando el conjunto de trabajadores desempleados o en situación precaria dispuestos a trasladarse hacia donde tengan demanda sea insuficiente, los salarios subirán y la tasa de ganancia caerá arrastrando con ella a la acumulación. Los capitalistas harán lo necesario para reestablecer el equilibrio despidiendo trabajadores y sustituyéndolos por medios de producción.

El mecanismo anterior no funciona cuando el EIR es más que suficiente. Los salarios a la baja por el excesivo desempleo no obligan a los capitalistas a acumular de forma más acelerada. Es cierto que los bajos salarios aumentan su tasa de ganancia, pero ello no hace que acumulen lo suficiente para absorber el EIR sobrante. Esta situación describe al capitalismo desde hace muchos años en todo el mundo.

La idea esbozada por Marx en el capítulo XV del tomo III de El capital es que hay un momento cuando el descenso continuo de la tasa de ganancia provoca una caída de la masa de ganancia y todo nuevo capital se ve obstaculizado para funcionar, esa situación se denomina sobreproducción absoluta de capital.

Se trata de un esbozo de explicación de la crisis mediante el comportamiento de la ganancia muy distante de un análisis completo de la relación entre ganancia y crisis. Por ejemplo, es obvio que la crisis es en gran medida la disminución de las ganancias; ${ }^{5}$

5 Tapia [2012] documenta la sincronía de las recesiones y de las crisis con un descenso de la tasa de ganancia, sin embargo, no analiza el comportamiento secular de la 
de manera que el comportamiento de éstas son causa y efecto de la crisis. Es una relación compleja que hasta ahora sólo el marxismo trata de entender sin haber agotado el tema.

El elemento que organiza la producción capitalista es la ganancia. Cuando disminuye la rentabilidad, las empresas realizan ajustes que llevan con frecuencia a recuperarla.

Abaten costos, modifican los precios y/o los volúmenes de producción y modifican los productos mismos. Otras ocasiones ciertas empresas encuentran formas de ganar que elevan su rentabilidad y orientan hacia ellas nuevas inversiones. La producción capitalista está cambiando constantemente, pero las mutaciones están orientadas siempre por la búsqueda de una mayor ganancia o para, cuando hay problemas, recuperar la rentabilidad.

El sistema se mueve de manera más o menos armónica buscando la máxima ganancia aunque hay muchas variables que intervienen en el resultado final. Los capitalistas bien pueden haber planeado todo de forma cuidadosa para incrementar sus ganancias, por ejemplo, la invasión de Estados Unidos en 2003 a Iraq y no lograrlo como resultó por la resistencia del pueblo iraquí. La burguesía puede imponer una ley laboral que les otorga todas las ventajas para doblegar al trabajo y el resultado puede ser otro. Por lo contrario, una lucha obrera que potencialmente podría afectar la ganancia capitalista puede por las circunstancias desembocar en una derrota laboral y con ello a elevar la rentabilidad.

Durante largos periodos, a pesar de las acciones correctivas de los capitales individuales, la tasa media de ganancia disminuye tal como ocurrió entre 1965 y 1982 en Estados Unidos.

No obstante que hubo un descenso prolongado y más o menos continúo de la rentabilidad del capitalismo, que no estuvo en recesión durante todos esos años. Sólo en determinados momentos la búsqueda de la ganancia pierde su eficacia como principio rector de la acumulación. Episódicamente, durante las recesiones o las crisis deja de funcionar la ganancia como el prin-

rentabilidad, ni el asunto de que la caída no secular de la tasa de ganancia puede ser efecto y no causa de la crisis. 
cipio regulador del mercado. En la fase descendente del ciclo las acciones que normalmente corrigen el curso de la acumulación fallan y producen el efecto opuesto al que en los buenos tiempos consiguen: la recuperación de la rentabilidad.

Si abaten costos o volúmenes de producción no restablecen su tasa de ganancia.

Hay tres formas de pérdida de eficacia de la regulación capitalista:

a) El descenso prolongado de la tasa de ganancia.

b) La recuperación insostenible de la rentabilidad.

c) Choques externos bruscos en una economía nacional.

\section{Descenso prolongado de la tasa de ganancia}

Un descenso más o menos continuo de la rentabilidad en un periodo de varios años generalmente se explica por una elevación de la composición orgánica del capital, es decir, por la forma capitalista de elevar la productividad que en el largo plazo debe hacer crecer el valor del capital más rápido que el trabajo. ${ }^{6}$ También puede producirse un comportamiento similar si disminuye la tasa de explotación pero esto es difícilmente permitido por el capitalismo. Un descenso de la rentabilidad continuado por mucho tiempo acumulará problemas que pueden inhabilitar por algún tiempo la eficacia de los mecanismos restablecedores de la tasa de ganancia. El descenso generalizado de la rentabilidad resulta de la pugna de fuerzas que buscan elevar la tasa de ganancia y otras que la abaten. Un gran número de capitales perciben que lo que hacen para elevar su rentabilidad la disminuye y eso paraliza la acumulación.

La disminución sincrónica de la producción en muchas ramas abate la demanda agregada, eleva el desempleo y la capacidad no

${ }^{6}$ La elevación de la composición orgánica del capital es un aspecto polémico aún hoy. La discusión se encuentra en Valle [2006]. 
utilizada de la economía. Con menos empleo se reduce la masa de plusvalía y el menor uso de los medios de producción se suma para provocar una caída adicional de la rentabilidad y, posteriormente, a una nueva ronda de disminución de producción, de demanda, de empleo, etcétera.

En el proceso se destruye capital físico, se desvalorizan deudas y se llega a un punto donde es posible relanzar la acumulación.

La salida de la crisis o la recesión no restablece necesariamente el nivel de la tasa de ganancia que había al inicio de la fase descendente pero si restaura el mecanismo de regulación de la acumulación mediante la búsqueda de la máxima rentabilidad. Ese es el paso esencial para el inicio de la fase expansiva. Son dos cosas distintas la restauración del mecanismo de regulación de la acumulación y la recuperación de la rentabilidad.

Durante mediados de los setenta y principios de los años ochenta la rentabilidad media en los principales países capitalistas cayó con respecto de los niveles de los años cincuenta y sesenta [Weisskopff et al., 1992]. En ese periodo ocurrieron crisis a mediados de los años setenta y a principios de los ochenta. No sabemos si antes de ese periodo hubo en todo el centro del capitalismo una conciencia burguesa clara acerca de haber llegado a una situación de baja rentabilidad. Al menos en Estados Unidos y en Gran Bretaña si hubo dicha conciencia [Llebling, 1980; Martin, 1981]. En ambos países se emprendieron políticas para elevar la rentabilidad abatiendo los costos capitalistas de producción. Muchas de esas medidas incrementaron la tasa de explotación y hubieran restringido el crecimiento del consumo en Estados Unidos de no ser por la expansión del crédito al consumo.

\section{Recuperación insostenible de la rentabilidad}

Hay crisis que ocurren después de un alza de la tasa de ganancia y que resultan de transitoriedad para las medidas que permitieron 
su recuperación. Las crisis cambiarias típicas son un ejemplo de este tipo de vínculo ganancia-crisis y una muestra de la manera que se "resuelven" las propias crisis. Si los precios internos del país se elevan con respecto de los externos, los medios de producción se abaratan y la tasa de ganancia se recupera aunque el déficit comercial se eleva y deberá ser cubierto con deuda. Esta recuperación de la rentabilidad no es sostenible pues afecta a la producción interna de ciertas ramas, las exportadoras y las que producían los medios sustituidos por las importaciones. Conforme el déficit se agranda y los problemas de la deuda externa se incrementan, la situación se vuelve insostenible, la moneda debe devaluarse y, con ello, los precios y la tasa de ganancia deberán ajustarse.

Sobran ejemplos de este tipo de crisis. La mexicana de 19941995 es uno de ellos.

\section{Choques externos bruscos en una economía nacional}

La tercera causa de crisis puede ser un choque externo: la caída de la demanda de un producto exportado o de su precio. Puede ser presentado por la clase dominante como una especie de desgracia semejante a un terremoto o un tsunami, las crisis pueden tener diversas causas inmediatas pero siempre moduladas por búsqueda capitalista de la ganancia, por ejemplo, cuando el caucho artificial sustituyó al natural o cuando el petróleo sustituyó al carbón. La velocidad con la que se instrumenta un cambio en el capitalismo y las consecuencias del mismo no están determinadas por las necesidades humanas sino por la inhumana lógica capitalista. Por eso, los choques externos a una economía nacional no hacen menos capitalista la crisis: se trata de crisis capitalista ocasionada por un choque externo y las habrá mientras hay capitalismo. Si cayera un meteorito, matara a millones de personas y elevara la tasa de ganancia, habría auge y no crisis. Sin embargo, como ese evento afectará la producción y abatirá las ganancias, las empresas reaccionarán tratando de que los costos de la desgracia les 
afecten lo menos posible y de que los paguen los trabajadores: se trataría de una crisis capitalista ocasionada por la caída de un meteorito. La crisis de Estados Unidos de 2008 ha sido la caída de un meteorito para numerosas economías, como ilustra el caso mexicano.

\section{LA CRISIS ESTADOUNIDENSE DE 2008}

De acuerdo con lo planteado con respecto de las explicaciones marxistas acerca de la crisis, ¿cómo se entiende la crisis de 2008? Para esta hay más de una interpretación basada en la teoría marxista de dicha crisis, Roberts [2009] y Shaikh [2011] son dos ejemplos de esto. A continuación expongo mi interpretación.

Estados Unidos es el caso de una crisis de recuperación insostenible de la tasa de ganancia que parcialmente se "resolvió". El déficit comercial de ese país ha aumentado desde hace muchos años (véase gráfica 4):

\section{Gráfi ca 4. Estados Unidos, balanza comercial 1953-2011}

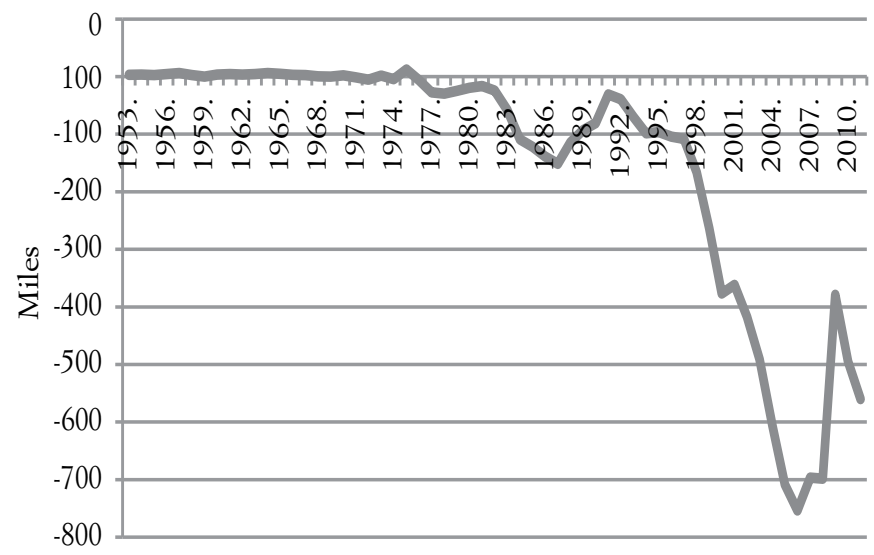

Fuente: Elaboración propia con datos del Economic Report of the President, 2013.

El déficit que aumentó aceleradamente se atemperó en 2007 por una devaluación del dólar con respecto del euro. Después, la caída de la economía estadounidense contribuyó a una mayor 
corrección de la balanza comercial. La complejidad del asunto que discutimos antes, cuando pusimos como ejemplo la recuperación insostenible de la rentabilidad, se muestra ahora: hay enormes dificultades para que Estados Unidos, que son productores de la divisa más importante del mundo por su posición productiva dominante aún, pero en franco declive, devalúen su moneda como los demás países. China y Japón, los mayores acreedores de Estados Unidos, no desean que sus cuantiosas reservas se devalúen y contribuyen fuertemente para mantener el dólar. Por otro lado, el déficit mismo es una transferencia de valor que beneficia a la economía estadounidense en tanto pueda cubrirse con deuda. Este aspecto del vínculo entre ganancia y balanza comercial no se trata así, salvo en pocos trabajos se hace una revisión de este problema [Valle y Mendieta, 2012].

Esta crisis estadounidense se relaciona con la rentabilidad de otra manera: la tasa de ganancia descendió en ese país desde mediados de los años sesenta hasta principios de los ochenta. Después, la ofensiva capitalista contra los trabajadores elevó la tasa de explotación y contribuyó para recuperar la tasa de ganancia (véase gráfica 5).

Gráfi ca 5. Estados Unidos, tasa de ganancia 1929-2011

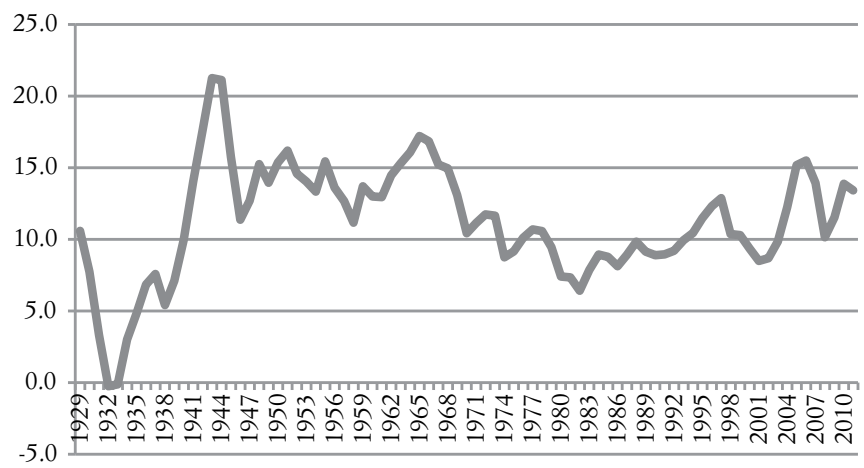

Fuente: Elaboración propia con datos de Bureau of Economic Analysis, Corporate CurrentCost Net Stock of Private Nonresidential Fixed Assets y Corporate Profits with inventory Valuation Adjustment. 
Con salarios medios estancados, el consumo y el PIB hubieran crecido como lo hizo la población trabajadora. La salida transitoria a este límite para la acumulación capitalista fue el endeudamiento, como se ve en la gráfica 6 .

Gráfica 6. Estados Unidos. Deuda total 1964-2004 (\% PIB)

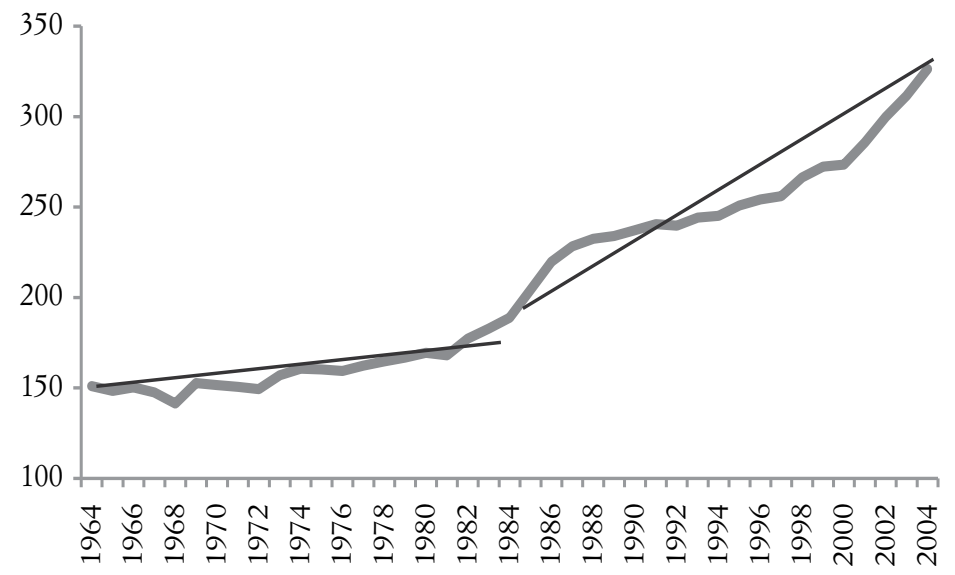

Fuente: Elaboración propia con datos de Federal Reserve, Flow of Funds Accounts of the United States; Bureau of Economic Analysis.

La gráfica muestra que el endeudamiento creció coincidentemente con la recuperación de la ganancia y la caída de los salarios (supra gráfica 3). Es claro ahora que el endeudamiento llegó a un límite en 2007. La forma como recuperó la ganancia en Estados Unidos durante el periodo neoliberal precisó del crédito al consumo y condujo hacia una crisis que duró más de cinco años en ese país, aunque oficialmente se dio por terminada en 2009. Es otro caso de recuperación insostenible de la rentabilidad que condujo a una crisis, mezclado con otro que aún no llega a la fase de ajuste. Si el crédito tuvo que expandirse para así paliar el efecto negativo que la mayor tasa de plusvalía tuvo sobre la acumulación, ¿cómo deberá comportarse la acumulación una vez que esa "solución" deja de serlo? 
Hay dos posibles comportamientos: a) una gran crisis que reduzca los desequilibrios o $b$ ) una disminución del ritmo de la acumulación que postergue los necesarios ajustes. El primer comportamiento traería muy graves efectos porque, además del ajuste requerido por la tasa de plusvalía, se daría seguramente la crisis externa de la economía estadounidense. Por lo tanto lo que estamos viendo es el intento del capitalismo para postergar una gran crisis. El gobierno de Estados Unidos ha elevado su déficit y las deudas externas pública y privada aumentan mientras la economía crece lentamente. No es claro durante cuánto tiempo podrá Estados Unidos evitar una gran crisis. Mientras los keynesianos reclaman un mayor déficit para impulsar la economía, hay numerosas voces también dentro del sistema, que se oponen a mantener el déficit en los niveles actuales por mucho más tiempo.

¿Conducirá cualquiera de los dos posibles derroteros de la crisis a disminuir los problemas de empleo en Estados Unidos? Difícilmente, si dichos problemas no son producto de ella sino estructurales, por tanto el restablecimiento de la acumulación no los elimina; pero como lo más probable parece un lento crecimiento, esto más bien los agravará.

\section{CONCLUSIONES}

Los problemas de empleo en Estados Unidos y en los países de América Latina son estructurales. El capitalismo está absorbiendo mal a la fuerza de trabajo, incluso para sus propios fines, y los de los trabajadores nunca aparecen entre sus prioridades, a menos que éstos los impongan. Los trabajadores de todo el mundo padecen porque hay menos trabajos aceptables a pesar de que los niveles educativos crecen y los medios de producción mejoran. Hijos más capaces que sus padres tiene menor oportunidad para una vida digna. Esto es un hecho crucial que puede exigir a las clases dominadas la superación del capitalismo pues es un síntoma de senilidad en el modo de producción. Limitándonos a lo más mediato, la poca capacidad capitalista para absorber 
trabajadores ha impulsado importantes flujos migratorios desde los países pobres hacia los industrializados, al mismo tiempo que desemplea y precariza en unos y en otros. Los salarios se estancan o retroceden para muchas ocupaciones. Estados Unidos, una de las economías más ricas del mundo, no es diferente en este aspecto. La inmigración indocumentada hacia Estados Unidos es causa y efecto de la precarización del empleo. El capitalismo precisa del desempleo, pero demasiado desempleo no disminuye su rentabilidad directamente y, por lo tanto, no es importante para el sistema.

Sin embargo, es necesaria la emigración desde los países pobres hacia los ricos, al mismo tiempo que faltan los buenos trabajos para los residentes de los países receptores de la fuerza de trabajo.

A los problemas estructurales se suman los ocasionados por las crisis y las recesiones. Normalmente una crisis resuelve algunas contradicciones del sistema o al menos las atempera; la cuestión del empleo no es una de esas contradicciones que se atenúe con la presente crisis. Al contrario, la gravedad de ella las exacerba como sucede en Irlanda que con la crisis ha pasado de país de inmigración a ser país de emigración. ${ }^{7}$ Pocos países mantienen una política expansiva para paliar la crisis y, en ocasiones, los efectos de un mayor gasto público no son suficientes para volver a los niveles de empleo de antes de la crisis. Es el caso de Estados Unidos donde no se prevé una recuperación del empleo en los años venideros. Consecuentemente los migrantes mexicanos seguirán enfrentando una situación de endurecimiento.

${ }^{7}$ Con la crisis de 2008, Irlanda pasó abruptamente de ser país receptor de inmigrantes a ser un país de emigración neta [Gilmartin, 2012]. 


\section{BIBLIOGRAFÍA}

Aragonés, Ana María; Esperanza Rios y Uberto Salgado [2012], Migración internacional: algunos desafíos. México, IIEc-UnAM, México, 21-73 pp.

Arámbula Reyes, Alma y Gabriel Santos Villarreal [2007], “El flujo migratorio centroamericano hacia México", octubre, Cámara de Diputados, México, en <http://www.diputados. gob.mx/cedia/sia/spe/SPE-ISS-19-07.pdf>.

Comisión Nacional de los Derechos Humanos (CNDH) [2011], Informe especial sobre secuestro de migrantes en México, 22 de febrero, en <http://www.cndh.org.mx/sites/all/fuentes/ documentos/informes/especiales/2011_secmigrantes.pdf>.

Dufort, Julie [2012], "Constructing security on the US-Mexico Border: an analysis of the minutemen movement", en Mónica Verea, Anti-Inmigrant: Sentiment, Actions, and Policies, México, UnAm, CISAN, 207-227 pp.

Estévez, A. [2012], "Conflicto social, migración y derechos humanos en Norteamérica y Europa”, en Mónica Verea, AntiInmigrant: Sentiment, Actions, and Policies, México, UNAM, CISAN, 63-81 pp.

Ghose, Ajit K., Normaan Majid y Christoph Ernst [2008], “The global employment challenge: executive Summary", ILO, en <http://www.ilo.org/wcmsp5/groups/public/---dgreports/--dcomm/---publ/documents/article/wcms_092210.pdf > .

Gilmartin, M. [2012], "The changing landscape of Irish migration, 2000-2012", The National Institute for Regional and Spatial Studies, Working paper (69), en <http://www.nuim.ie/ nirsa/research/documents/WP69_The_changing_face_of_ Irish_migration_2000_2012.pdf $>$.

Goodman, Peter [2010], "The new poor: despite signs of recovery, chronic joblessness rises", New York Times, 20 de febrero de 2010.

Kohn, Sally [2009], “Armed radical 'minutemen' kill father and 9-year-old daughter in anti-immigrant hate", 17 de junio de 2009 , en <http://www.alternet.org/story/140745/armed_ 
radical_\%27minutemen \%27_kill_father_and_9-year-old_ daughter_in_anti-immigrant_hate>

Llebling, Herman [1980], U.S. Corporate Profitability and Capital Formation. Pergamon Press, EVA.

Madár, István y Krisztina Kovács [2012], “Blanchard: Eurozone integration needs to go forward or go back, but it can't stay here”, Portafolio.hu, 3 de octubre de 2012, en <http://www. portfolio.hu/en/economy/blanchard_eurozone_integration_needs_to_go_forward_or_go_back_but_it_cant_stay_ here.24931.html>.

Martin, W.E. [1981], “The profit crisis: introduction”, en Martin, W. (ed.), The Economics of the Profits Crisis, Gran Bretaña, Her Majesty's Stationery Office.

Motel, Seth y Eileen Patten [2012], “The 10 largest hispanic origin groups: characteristics, rankings, top countries", $12 \mathrm{de}$ julio de 2012, <http://www.pewhispanic.org/files/2012/06/ The-10-Largest-Hispanic-Origin-Groups.pdf $>$.

PNUD [2007], Informe sobre desarrollo humano México 20062007: migración y desarrollo humano.

Roberts, Michael [2009], “The great recession: profit cycles, economic crisis. a marxist view", en <http://archive.org/download/TheGreatRecession.ProfitCyclesEconomicCrisisAMarxistView/GreatRecessionInside4.pdf $>$.

Shaikh, A. [2011], "The first great depression of the 21 century", The Crisis this Time, en L. Panitch, G. Albo y V. Chibber, Socialist Register, 44-63 pp.

Tapia Granados, José A [2012], "Statistical evidence of falling profits as cause of recession a short note", Review of Radical Political Economics, diciembre 2012, vol. 44(4): 484-493.

Valle Baeza, Alejandro [2006], "Capital o dominio de trabajo muerto sobre el trabajo vivo: el aumento capitalista de la productividad", México, UAm Azcapotzalco, en <http://www. azc.uam.mx/socialesyhumanidades/06/departamentos/economia/PDF/12\%20Alejandro\%20Valle\%20Baeza.pdf>. 
Valle Baeza, Alejandro e Iván Mendieta Muñoz [2012], "Profit and trade deficit in the US economy: a Marxist perspective", Marxism 21, vol. 9 (3): 353-372.

Valle Baeza, Alejandro [2002], "Dos crisis de inicio de siglo: EUA y México", Laberinto 9, 105-114 pp.

Siglo de Torreón [2007] "Víctimas de maltrato de centroamericanos que pasan por México a EU”, 2 de julio, Coahuila, México.

Weisskopff et al. [1992], "A comparative analysis of profitability trends in the advanced capitalist economies", en F. Moseley y E. Edwards (eds.), International Perspectives on Profitability and Accumulation, Edward Elgar, 13-37 pp. 


\title{
Capítulo 6 \\ ¿POR QUÉ SE HA REDUCIDO LA MIGRACIÓN MEXICANA HACIA ESTADOS UNIDOS?
}

\author{
Juan Luis Ordaz Diaz* \\ Juan José $\mathrm{Li} \mathrm{Ng}^{* * *}$
}

\section{INTRODUCCIÓN}

La población de origen mexicano en Estados Unidos es un grupo numeroso, cerca de 34 millones de personas en 2012 si se consideran a los denominados de segunda y tercera generaciones. De este grupo, 11.9 millones nacieron en México y migraron hacia el vecino país del norte por diversos motivos: reunión familiar, estudios, matrimonio, entre otros; la mayoría por razones laborales. Así la migración mexicana hacia el vecino país del norte es predominantemente laboral como lo indican datos de la Encuesta sobre Migración en la Frontera Norte de México (Emif Norte) y de la Encuesta Nacional de Ocupación y Empleo (ENOE)

* Maestro en Economía por El Colegio de México. Desde 2008 es Economista Senior del BBVA, en los temas sobre migración y desarrollo. Es profesor de la Facultad de Economía de la unAm. Ha sido consultor del la CEPAL y del Programa de Desarrollo Humano Oportunidades. E-mail: <juan.ordaz@bbva.com>.

** Maestro en Economía por El Colegio de México. Desde 2011 es Economista Senior del BBVA en los temas sobre migración y evaluación. Ha laborado en la Secretaría de Salud, en el Museo Interactivo de Economía; profesor de la UNAM en temas de microeconomía y economía mexicana; consultor y analista para la UNAM y PNUD de diversos programas públicos de dependencias federales. E-mail: <ljuan99@hotmail.com>. 
de diversos años. Este factor de atracción que generó una importante oleada de mexicanos emigrantes durante parte de la pasada década, explica también en gran medida el estancamiento de los flujos migratorios netos de México hacia Estados Unidos durante los años recientes.

En el periodo comprendido entre los años 2000 y 2007, el saldo migratorio promedio anual de mexicanos hacia Estados Unidos fue de 550 mil personas; es decir, en este lapso de 8 años que puede considerarse como el boom migratorio de mexicanos hacia Estados Unidos, la cantidad de migrantes mexicanos aumentó en 4.4 millones, al pasar de 7.4 millones en 1999 a 11.8 millones en 2007, de acuerdo con cifras de la Current Population Survey (CPS) [Albo et al., 2012].

Tras la última recesión económica en Estados Unidos, el tamaño de los flujos de migrantes mexicanos hacia ese país mostró una fuerte contracción. La pérdida de empleos en Estados Unidos y, en particular, para los migrantes mexicanos que laboran ahí, infundió en la opinión pública de México la idea de un posible regreso masivo de mexicanos. Se dieron a conocer diferentes cantidades estimadas de migrantes mexicanos por regresar que iban desde 350 mil hasta 3 millones [véase Alarcón et al., 2008]. Se creía que era una situación coyuntural y, que tras la recuperación de la economía estadounidense, se reiniciarían los flujos migratorios de mexicanos hacia ese país.

No se dio ese retorno masivo de mexicanos tan temido por la opinión pública [Fundación BBVA Bancomer y BBVA Research, 2012] pero tampoco se ha observado a la fecha una tendencia hacia la recuperación de los flujos migratorios de mexicanos hacia Estados Unidos. Incluso la opinión pública y diversos investigadores del tema migratorio enfatizaron e hicieron evidente que el flujo migratorio neto de mexicanos hacia Estados Unidos ha llegado a cero o menos; es decir, que este flujo migratorio neto se ha estancado desde 2008. Esta situación parece particular de México, ya que los flujos migratorios de otros países ya se han recuperado y algunos han alcanzado su mayor nivel histórico. 
¿Qué está ocurriendo? ¿Por qué la migración de México se ha estancado y la de otras regiones continúa creciendo? Diversas hipótesis se han planteado al respecto, pero poca evidencia se ha ofrecido sobre su sustento y se desconocen los factores más importantes que explican esta situación. Este estudio busca contribuir en ese sentido, lo cual es muy relevante para tener una mejor idea de lo que puede ocurrir hacia el futuro con la migración mexicana.

\section{CUÁLES FACTORES EXPLICAN LA RALENTIZACIÓN \\ DEL FLUJO MIGRATORIO DE MEXICANOS \\ HACIA ESTADOS UNIDOS}

En el estudio de Passel, Cohn y Gonzalez-Barrera [2012] se ha señalado que la migración mexicana neta hacia Estados Unidos se redujo a cero o menos, y que esto obedece a distintos factores, entre ellos el debilitamiento de los mercados laborales y de la construcción de viviendas en Estados Unidos, las políticas y leyes antimigrantes, el reforzamiento de la frontera, un incremento en las deportaciones, los crecientes peligros asociados con el cruce ilegal en la frontera, la disminución a largo plazo en las tasas de natalidad y mejores condiciones económicas en México. Desde luego que no todos los factores que se mencionan tienen la misma relevancia, por es importante contar con mayores elementos de cómo cada uno podría estar afectando y si realmente afectan. En esta sección se analizan dichas hipótesis y se proponen otras alternativas.

\section{La crisis económica en Estados Unidos}

La pasada recesión económica de Estados Unidos que inició por problemas con los créditos para las hipotecas subprimes y que posteriormente se transfirió al sector financiero, llevó a un colapsó en el sector de la construcción y al quebranto de importantes 
entidades financieras. Además de los cierres o contracciones de empresas y de la importante pérdida de empleos en estos sectores, la crisis se propagó al resto de la economía estadounidense mediante la contracción directa e indirecta de la demanda agregada acompañada de una fuerte escasez de liquidez en los mercados, que también afectó a la economía mundial.

La gráfica 1 presenta la evolución del empleo entre enero de 2006 y junio de 2009, siendo este último cuando oficialmente concluye la crisis económica. ${ }^{11}$ Como ahí se observa, en general los migrantes de diferentes regiones vieron disminuir sus puestos de trabajo, aunque no todos fueron afectados por igual.

Los migrantes mexicanos y centroamericanos fueros los más afectados por la crisis económica por su alta concentración entre los sectores que perdieron más empleos en Estados Unidos: la industria de la construcción, las manufacturas y el comercio. En 2007 la proporción de migrantes mexicanos que trabajaba en estos tres sectores era de $51 \%$ y la de centroamericanos era $45 \%$. En conjunto, la disminución de puestos de trabajo derivado de la crisis en estos tres sectores fue de poco más de 6 millones, es decir $75 \%$ de los más de 8 millones perdidos en total entre los años 2007 y 2009.

En tanto que de los otros grupos de migrantes con mayor presencia, su concentración en estos sectores no alcazaba $32 \%$. Es decir, la crisis económica se manifiesta con mayor fuerza donde había mayor concentración de migrantes mexicanos y centroamericanos, cuya participación en estos tres sectores se redujo en 2009 en 6 y 4 puntos porcentuales, respectivamente. Ello generó que, de ser los grupos que mostraron mayor crecimiento en el empleo entre 2006 y 2007 fueran de los que presentaron disminuciones más pronunciadas a lo largo de 2008 y la primera mitad de 2009. Estimamos que más de 500 mil migrantes mexicanos y cerca de 200 mil centroamericanos perdieron su empleo durante ese periodo.

${ }^{1}$ De acuerdo con The National Bureau of Economic Research (véase http://www. nber.org/cycles.html). 


\section{Gráfica 1. Migrantes empleados en Estados Unidos según región/país de procedencia. Enero de 2006-junio de 2009 (enero de 2006=100)}

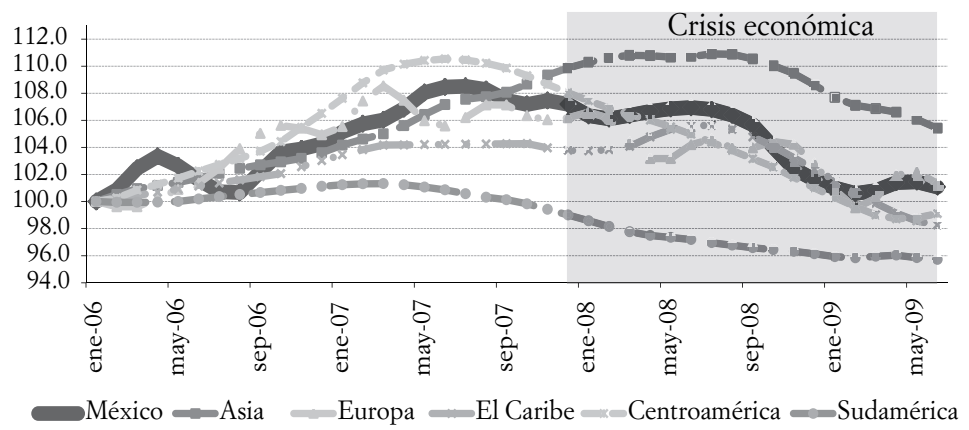

Fuente: Elaboración propia con cifras de la Current Population Survey. Nota: Datos desestacionalizados con TRAMO/SEATS.

Sin duda la crisis económica es un factor que incidió en el empleo de los migrantes mexicanos y, por tanto, en los flujos migratorios, al ser la de los mexicanos principalmente laboral. ¿Qué ocurre al concluir oficialmente la crisis económica? Ello se analiza en la siguiente sección.

\section{La politica, leyes y acciones antimigrantes en Estados Unidos. Efecto Arizona}

Tras concluida la recesión en Estados Unidos, los diferentes grupos de migrantes comienzan a ganar puestos de trabajo. Los centroamericanos y caribeños lo logran con mayor rapidez y en todos los casos comienza una tendencia creciente en el empleo. Los mexicanos también presentan una fase en la que ganan cerca de 150 mil puestos de trabajo, que ocurre entre el último trimestre de 2009 y entre junio y julio de 2010. Posteriormente, se observa en los migrantes mexicanos, a diferencia de los otros grupos de migrantes de gran cantidad, una tendencia de pérdida de empleo que dura cerca de un año y en la que pierden alrededor de 350 mil puestos de trabajo. 
En ese periodo entre el término del primer semestre de 2010 y el del 2011 cuando los migrantes mexicanos pierden empleos, si bien la economía estadounidense se mantiene débil continúa su recuperación económica. Entonces, ¿por qué cae el empleo de los mexicanos? La única explicación posible es lo que se conoce como el Efecto Arizona, es decir, el conjunto de acciones contra los migrantes indocumentados en Estados Unidos, que comienzan con la promulgación de la Ley SB1070 en abril de 2010 en Arizona y que continúa con diferentes acciones contra los migrantes que llevan a la promulgación de diferentes leyes antimigrantes en distintos estados: Tennesse (28 de junio de 2010), Indiana (10 de mayo de 2011), Georgia (13 de mayo de 2011), Alabama (2 de junio de 2011), Carolina del Sur (27 de junio de 2011) y que generan un cierto rechazo hacia los migrantes indocumentados en algunos estados de ese país, lo que llevó al despido de estos y a que algunos decidieran salier. Así este periodo de pérdida de empleos para los mexicanos coincide con el periodo de promulgación de diferentes acciones contra los migrantes.

Que la influencia de las leyes antimigrantes se presentara en el empleo de los mexicanos más que en el de otros países, se debe a que más de la mitad de los migrantes indocumentados en Estados Unidos son mexicanos [Passel y Cohn, 2011; Fundación BBVA Bancomer y BBVA Research, 2013].

De los grupos con mayor presencia de migrantes, en los estados donde se instrumentaron leyes antimigrantes, únicamente se observan disminuciones de población entre 2009 y 2011 del grupo mexicano, lo que indica que fue el más afectado (véase gráfica 2). De los 1.12 millones de migrantes mexicanos en estos estados en 2009 la cifra se redujo en 133 000. Esta situación generó dos efectos en el número de personas que potencialmente emigrarían de México hacia Estados Unidos: un desincentivo hacia estos estados producto de las leyes, pero también una desmotivación por ir hacia otros estados donde los migrantes se trasladaron, ya que pudieron a ocupar puestos que hubieran ocupado los nuevos migrantes. Además, las redes sociales con que cuentan los migrantes mexicanos funcionaron para informar a los potenciales migran- 
tes para no ir a Estados Unidos ante tal situación.

\section{Gráfica 2. Migrantes empleados en Estados Unidos según región/país de procedencia. Julio de 2009-abril de 2012 (enero de 2006=100)}

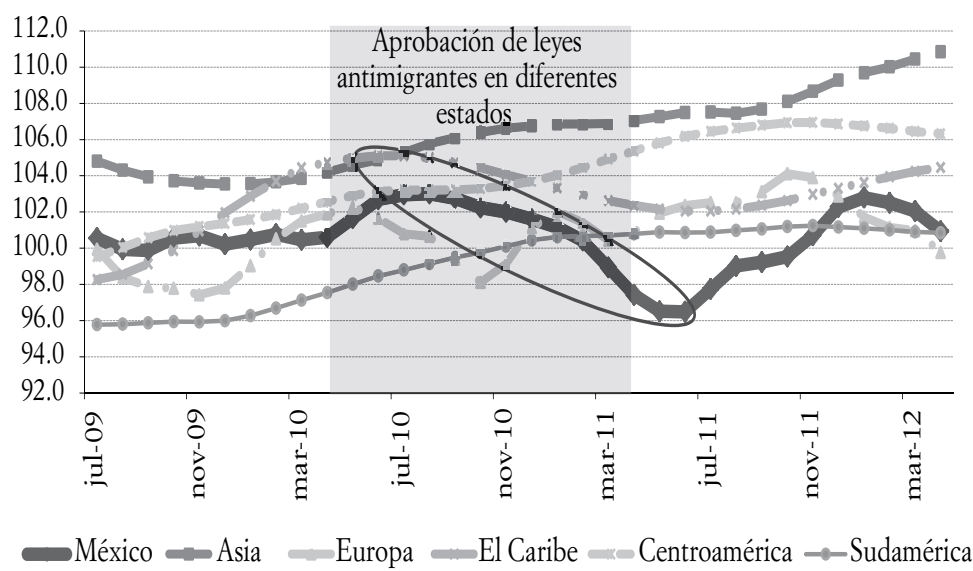

Fuente: Elaboración propia con cifras de la Current Population Survey. Nota: Datos desestacionalizados con TRAMO/SEATS.

EL INCREMENTO DE LAS DEPORTACIONES EN EsTADOS UNIDOS

Para las ejecución de las acciones para el cumplimiento de la ley de control migratorio en Estados Unidos, el Department of Homeland Security (DHS) cuenta principalmente con dos agencias: el Customs and Border Protection (СВP) y el Immigration and Customs Enforcement (ICE). En general, el CBP es responsable de las actividades migratorias en las zonas fronterizas y puntos de acceso, tiene a su cargo a los agentes de la Border Patrol; mientras que el ICE es responsable de las actividades al interior del territorio estadounidense. Esta última agencia consta principalmente de dos componentes: el Homeland Security Investigations (HSI) encargada de investigar y combatir ciertos asuntos relacionados 
con crímenes y temas de seguridad nacional y el Enforcement and Removal Operations (ERO) que cuenta con agentes para identificar, arrestar y deportar a personas que violen la ley de inmigración.

En el cuadro 1, se puede observar la importancia cada vez mayor en la proporción de aprensiones del ICE y del ERO en el total de las realizadas por asuntos de control migratorio, lo cual puede ser un factor que desincentive los flujos migratorios y la obtención de trabajo para los migrantes que ya se encuentran dentro de Estados Unidos. De las estadísticas que reporta el DHS se puede saber el número de aprensiones y de deportaciones por país de origen, sin embargo, no se tiene información desagregada para identificar si el incremento de las aprensiones en el interior de Estados Unidos afecta más a ciertos grupos de migrantes.

Sin embargo con la información disponible se infiere que la proporción de migrantes mexicanos deportados tras ser aprehendidos es menor que el promedio de todos los migrantes. Esto podría sugerir que el efecto de las acciones de búsqueda, arresto y deportación de migrantes en territorio estadounidense afecta más a otros grupos de migrantes, los cuales de forma agregada incrementan su nivel de empleo y su flujo hacia Estados Unidos, si se compara con los migrantes mexicanos. Aunque el último dato disponible del año 2011 muestra que la razón de deportados entre aprehendidos de los migrantes mexicanos es muy cercana al promedio de todos los migrantes.

Así, aunque las acciones de deportación en el interior del país afectan la migración, no explican el comportamiento de los flujos de migración de mexicanos en comparación con los flujos migratorios del resto de los países hacia Estados Unidos. Sería deseable contar con más información y de forma más desagregada que permita comprender más claramente el efecto que tienen estas deportaciones en el interior del territorio estadounidense en la dinámica de los migrantes y, específicamente, sobre los de origen mexicano. 


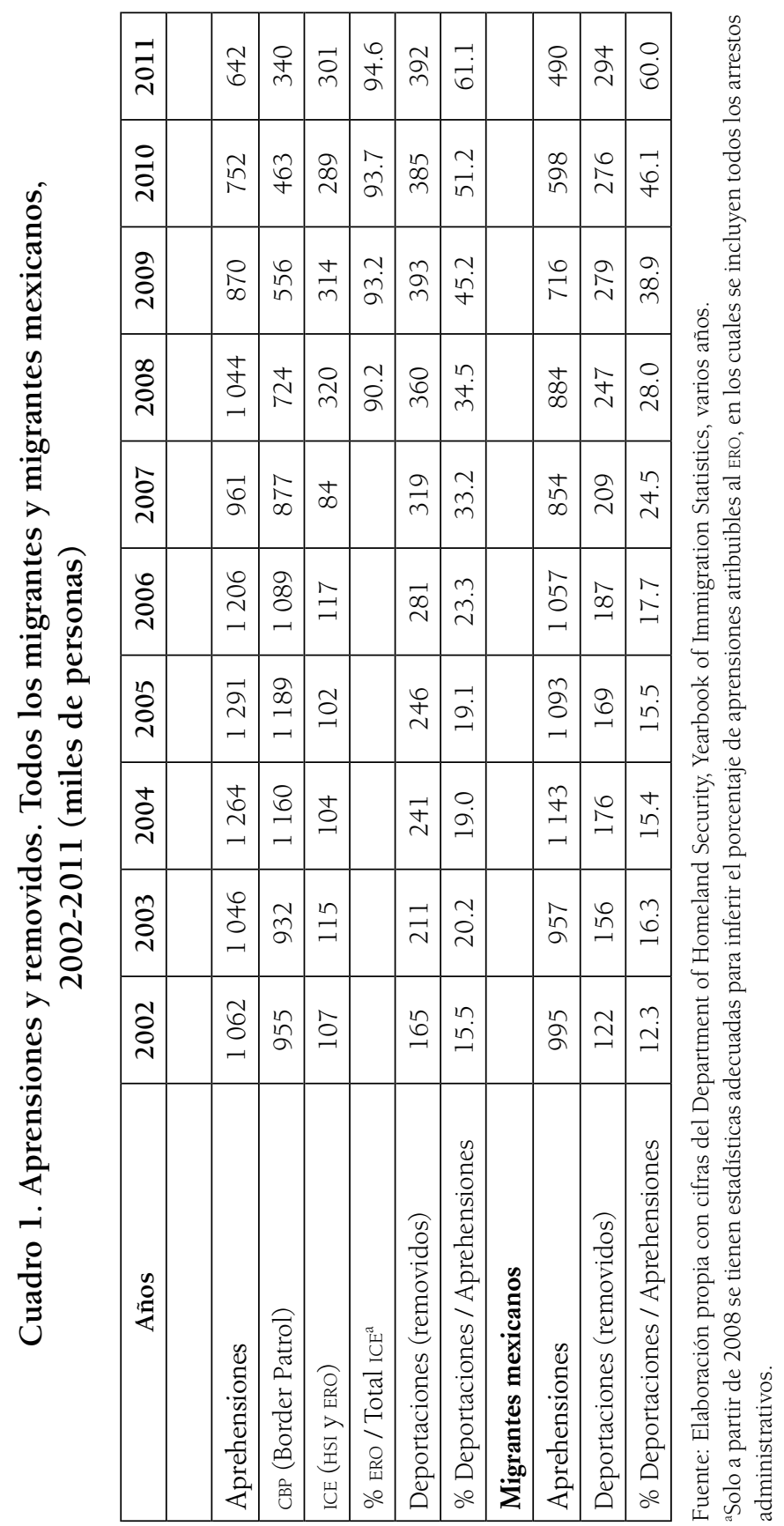




\section{EL REFORZAMIENTO DE LA FRONTERA \\ de México con Estados Unidos}

Estados Unidos ha reforzado continuamente la frontera que comparte con México, hecho que ha sido más evidente tras los incidentes de 2001. Además de la instalación de bardas fronterizas y de la incorporación de equipo de tecnología, también se ha incrementado el personal encargado de la vigilancia en la frontera. En 1995 el número de agentes de la patrulla fronteriza era de cinco mil, para el año 2002 esa cifra se había duplicado y, para 2011, se había multiplicado por cuatro para llegar a 21 mil agentes, de los cuales 18500 (86\%) pertenecen a la frontera sudoeste.

Contraria a la tendencia positiva en el número de agentes, el número de mexicanos aprehendidos ha mostrado una tendencia negativa, principalmente a partir del año 2001 (véase gráfica 3). Este comportamiento puede tener dos explicaciones: 1) Que el incremento en el número de agentes fronterizos desincentive la migración indocumentada desde México y que, por este motivo, también disminuya el número de aprehendidos de origen mexicano; 2) Que la entrada de mexicanos hacia Estados Unidos de forma indocumentada disminuye por otros factores y que, por ello, la patrulla fronteriza detiene a menos mexicanos. Dada la información disponible creemos que es de mayor trascendencia la segunda hipótesis.

Como se observa en la gráfica 4 el número de migrantes mexicanos aprehendidos por la patrulla fronteriza se correlaciona en gran medida con el crecimiento del PIB de Estados Unidos, lo que sugiere que cuando la economía estadounidense crece más mexicanos emigran pasando por la frontera sur y, en consecuencia, más mexicanos pueden ser aprehendidos, lo contrario ocurre cuando la economía se debilita. En la misma gráfica, se observa que en años recientes la fuerte correlación entre ambas variables se ha reducido, lo que parece explicarse por las acciones recientes que se implementan en Estados Unidos contra los migrantes indocumentados. 
Gráfi ca 3. Estados Unidos. Migrantes mexicanos aprehendidos y agentes de la patrulla fronteriza (miles)

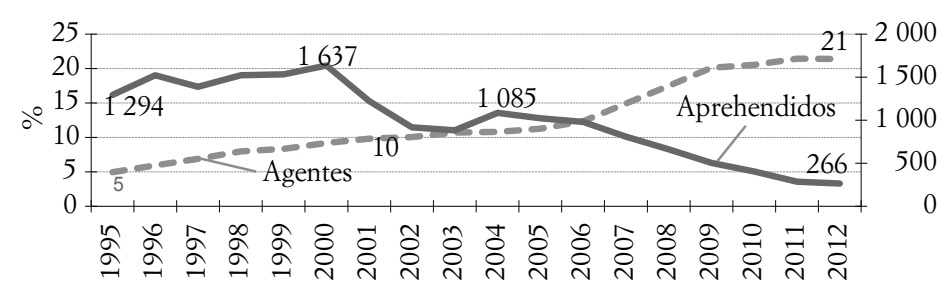

Fuente: Elaboración propia con cifras de Department of Homeland Security.

\section{Gráfi ca 4. Estados Unidos. Mexicanos aprehendidos por la patrulla fronteriza y crecimiento del PIB}

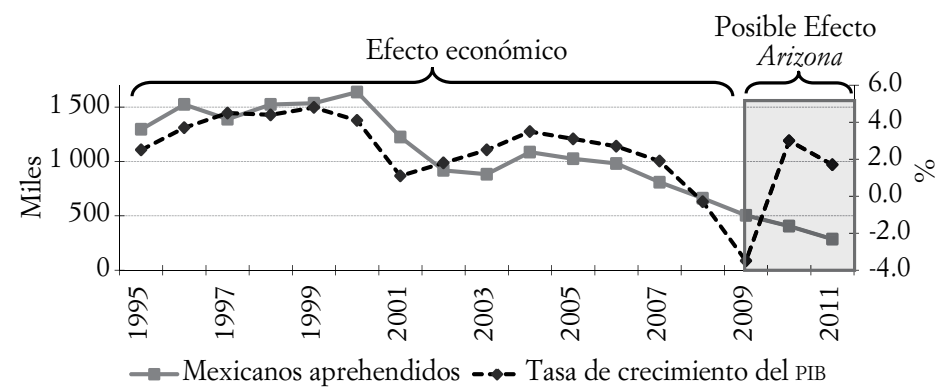

Fuente: Elaboración propia con cifras de Department of Homeland Security y US Bureau of Economic Analysis.

\section{INSEGURIDAD EN MÉXICO}

El Institute for Economics and Peace elabora el índice internacional GPI (Global Peace Index) que incluye variables sobre datos de crímenes violentos, homicidios, percepción de la inseguridad, entre muchas otras. Su rango va de 1 a 5 , donde 5 es la menor escala de paz. Al compararlo con el comportamiento de la migración se podría conjeturar que el incremento en la inseguridad y la violencia desalientan la migración de los mexicanos y centroamericanos 
hacia Estados Unidos, ya que gran parte de la migración en ambas regiones se realiza por la frontera sur de Estados Unidos.

Sin embargo, si se considera la serie de migración neta de centroamericanos hacia Estados Unidos, los cuales son más vulnerables a la violencia e inseguridad en México dada sus condiciones, no se observa relación clara. El flujo de migración neta de centroamericanos hacia Estados Unidos sólo muestra una contracción en los años más severos de la crisis económica del país vecino del norte.

Así, no se tiene evidencia sólida de si la violencia y la inseguridad en México están desalentando los flujos migratorios hacia Estados Unidos ya que pese al incremento de la violencia e inseguridad en el país, sigue incrementándose el número de migrantes centroamericanos en Estados Unidos (véase gráfica 5). Esta situación puede sugerir que, si bien el reforzamiento de la frontera y la violencia en México son factores que influyen en los flujos migratorios de mexicanos hacia Estados Unidos, su efecto parece menor que otros factores como la situación económica o las acciones contra los migrantes en algunos de sus estados.

\section{Gráfica 5. Variación anual del número de migrantes mexicanos y centroamericanos hacia Estados Unidos, 2007-2011 vs. GPI}

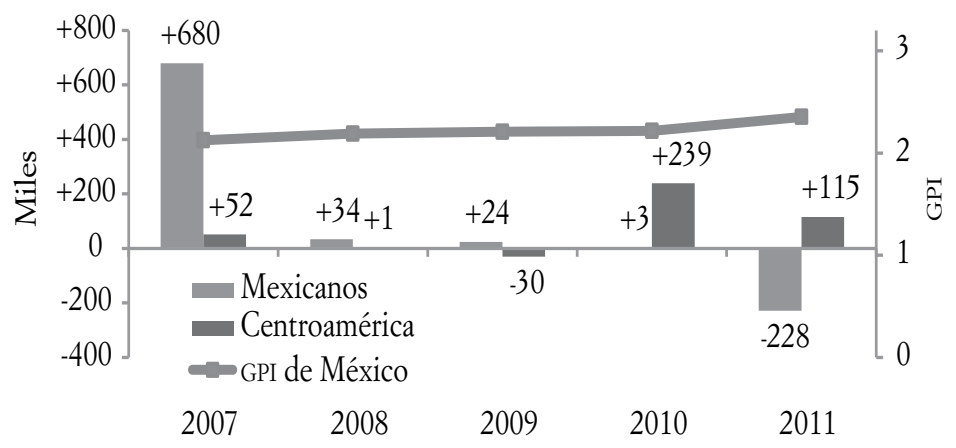

Fuente: Elaboración propia con cifras de la Current Population Survey y del Institute for Economics and Peace. 


\section{LA DISMINUCIÓN EN LA NATALIDAD EN MÉXICO}

Si esta situación se explicara por la tasa de natalidad en México, disminuiría de forma importante y estaría por debajo de la tasa de natalidad de regiones con mayor flujo migratorio. Si bien la tasa de natalidad de México ha disminuido, no ha sido una situación exclusiva de México, incluso, se encuentra por encima de las de países europeos o asiáticos, cuyos flujos migratorios hacia Estados Unidos tienen una mayor tendencia positiva. Además de acuerdo con las proyecciones del Consejo Nacional de Población (Conapo) la población en México entre 15 y 49 años de edad (65\% de los migrantes mexicanos en Estados Unidos) crecerá hasta 2042 y para 2050 habra casi 69 millones de mexicanos en ese rango [Fundación BBVA Bancomer y BBVA Research, 2013]. Por tanto, las tasas de natalidad no explican la disminución reciente del flujo migratorio de México hacia Estados Unidos y, si bien pueden incidir, su efecto es de largo plazo y gradual, por lo que no podrían manifestarse de forma repentina (véase la gráfica 6).

\section{Gráfi ca 6. Tasas de natalidad 1980-2010 (por cada 1000 habitantes)}

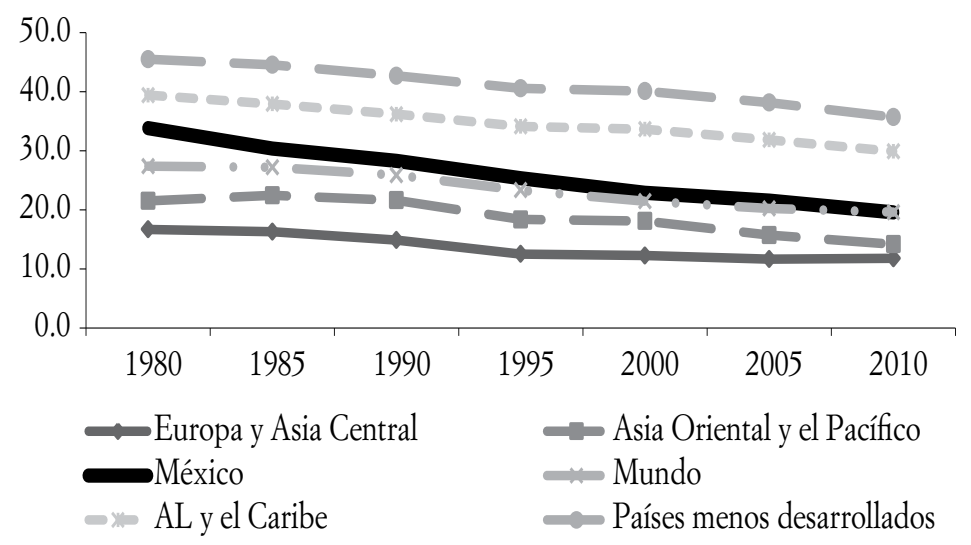

Fuente: Elaboración propia con cifras del Banco Mundial, World Development Indicators. 


\section{Mejores CONDiCiOneS ECONÓMiCAS En MÉXico}

Hay la idea de que las mejoras en las condiciones económicas de México pudieron influir en la reducción del flujo migratorio de connacionales hacia Estados Unidos [e.g. Cave, 2011]. Aunque en México hay condiciones que han mejorado y han permitido a los hogares una mayor posesión de bienes así como mejores oportunidades de educación traducidas en un mayor nivel de escolaridad promedio de la población mexicana (en 1960 era de 2.6 grados, en 2000 de 7.5 y en 2010 aumentó a 8.6 grados), lo cierto es que estas mejoras no han sido suficientes como para reducir la brecha salarial con respecto de Estados Unidos. Cifras de la OCDE muestran que la diferencia en la compensación laboral por empleado entre Estados Unidos y México se ha incrementado (véase la gráfica 7). Así, mientras las mejoras económicas no se traduzcan en una reducción de la brecha salarial con respecto de Estados Unidos, los incentivos para emigrar no se reducirán.

\section{Gráfica 7. Compensaciones laborales por empleado entre Estados Unidos y México, 2000-2009 (dólares ajustados por paridad del poder adquisitivo)}

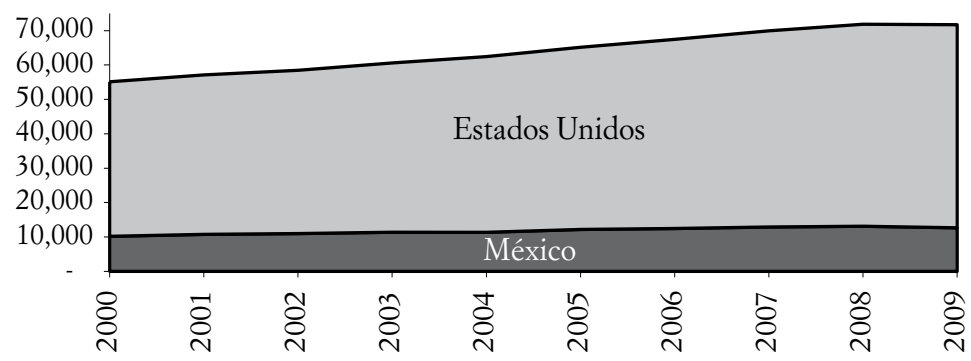

Fuente: Elaboración propia con cifras de la OCDE

\section{Demanda LABORAL EN Estados Unidos}

Y OFERTA LABORAL DE LOS MIGRANTES MEXICANOS

Tras concluir la recesión económica, los hispanos en su conjunto comenzaron a ganar empleos y, poco después, los migrantes 
mexicanos también lo hicieron, esto daba la impresión de que el empleo de ambos grupos seguiría una trayectoria muy similar. Sin embargo, a partir de la segunda mitad de 2010 el empleo de los migrantes mexicanos mostró una trayectoria diferente y, a la fecha, mantiene una tendencia distinta. Mientras los hispanos en su conjunto ya recuperaron todo el empleo perdido con la crisis económica y durante 2012 se encuentra en sus niveles máximos históricos, los migrantes mexicanos aún están muy por debajo de sus niveles máximos en empleo, logrados antes de la recesión económica.

Es posible que el principal motor de los flujos migratorios hacia Estados Unidos, la demanda de empleo, no solicite fuerza de trabajo correspondiente con la estructura de la oferta laboral de migrantes de origen mexicano. A continuación se analizan algunos de los recientes cambios que se suscitan en la estructura laboral de Estados Unidos. Lo anterior con el objetivo de conocer los tipos de trabajadores que en la actualidad demanda la economía estadounidense y si los migrantes mexicanos son trabajadores que, en general, cubren esas características. Si esto último se cumple es posible que el propio mercado minimice los efectos dados por las acciones contra los migrantes; por el contrario si los migrantes mexicanos carecen de las características principales que demanda el mercado, las dificultades para que consigan empleo son mayores.

\section{Bajo nivel de escolaridad de los migrantes mexicanos}

Los migrantes mexicanos satisfacen una gran proporción del total de la demanda de mano de obra con menos de 10 años de escolaridad. Los empleos que cubren se asocian con trabajos de baja calidad, baja remuneración económica y/o de poca calificación. En 2004, había cerca de 7.2 millones de personas empleadas con menos de 10 años de escolaridad en Estados Unidos, de los cuales 4 de cada 10 empleos eran ocupados por migrantes mexicanos. En 2012, esta cifra disminuyó a 6.1 millones, pero la proporción de trabajadores migrantes mexicanos aumentó a $46.6 \%$ 
del total de los empleos con menos de 10 años de escolaridad en ese país (cuadro 2).

\section{Cuadro 2. Distribución de los trabajadores en Estados Unidos con menos de 10 años de escolaridad, 2004-2012 (miles)}

\begin{tabular}{c|c|c|c|c|c|c|c|l}
\hline & \multicolumn{5}{|c|}{ Miles } & \multicolumn{3}{c}{$\%$} \\
\hline Año & $\begin{array}{c}\text { Migrantes } \\
\text { de origen } \\
\text { mexicano }\end{array}$ & $\begin{array}{c}\text { Otro } \\
\text { migrantes }\end{array}$ & Nativos & Total & $\begin{array}{c}\text { Migrantes } \\
\text { de origen } \\
\text { mexicano }\end{array}$ & $\begin{array}{c}\text { Otro } \\
\text { migrantes }\end{array}$ & Nativos & Total \\
\hline 2004 & 2859 & 1513 & 2779 & 7151 & 40.0 & 21.2 & 38.9 & 100.0 \\
\hline 2005 & 3020 & 1570 & 2836 & 7426 & 40.7 & 21.1 & 38.2 & 100.0 \\
\hline 2006 & 3101 & 1647 & 2648 & 7396 & 41.9 & 22.3 & 35.8 & 100.0 \\
\hline 2007 & 3119 & 1643 & 2604 & 7366 & 42.3 & 22.3 & 35.4 & 100.0 \\
\hline 2008 & 3009 & 1345 & 2209 & 6563 & 45.8 & 20.5 & 33.7 & 100.0 \\
\hline 2009 & 2816 & 1357 & 2129 & 6302 & 44.7 & 21.5 & 33.8 & 100.0 \\
\hline 2010 & 2661 & 1321 & 1924 & 5906 & 45.1 & 22.4 & 32.6 & 100.0 \\
\hline 2011 & 2630 & 1376 & 1715 & 5721 & 46.0 & 24.1 & 30.0 & 100.0 \\
\hline 2012 & 2843 & 1470 & 1788 & 6102 & 46.6 & 24.1 & 29.3 & 100.0 \\
\hline
\end{tabular}

Fuente: Elaboración propia con cifras de la Current Population Survey.

Gráfica 8. Proporción de trabajadores con nivel de escolaridad de técnico superior, profesional y posgrado, por origen

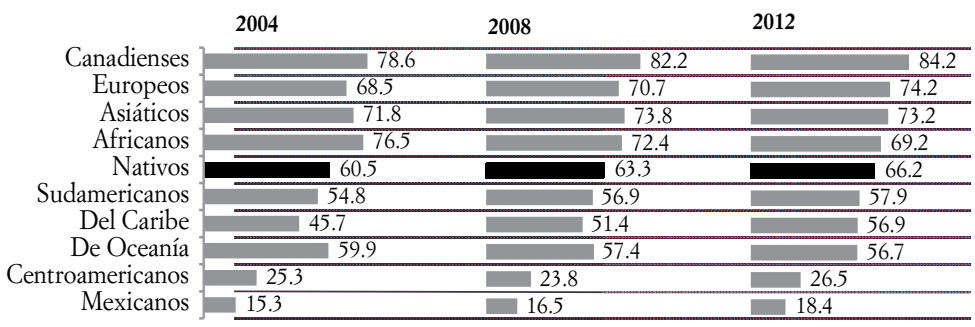

Fuente: Elaboración propia con cifras de la Current Population Survey. 
A diferencia de los mexicanos y centroamericanos, en 2012 más de $50 \%$ de los migrantes de otras regiones que laboran en Estados Unidos cuentan con niveles de escolaridad técnico superior, profesional o posgrado (véase la gráfica 8). Incluso algunos grupos de trabajadores migrantes, como los procedentes de Canadá, Europa, Asia y África, cuentan con un elevado nivel de escolaridad que en promedio es superior al de los nativos. Solo $18.4 \%$ de los migrantes mexicanos que labora en Estados Unidos cuenta con escolaridad de técnico superior, profesional y posgrado, proporción que es superada por los centroamericanos, $26.5 \%$ durante este periodo.

\section{Gráfi ca 9. Empleos en Estados Unidos por nivel de escolaridad, 2004-2012 \\ (índice, 2004=100)}

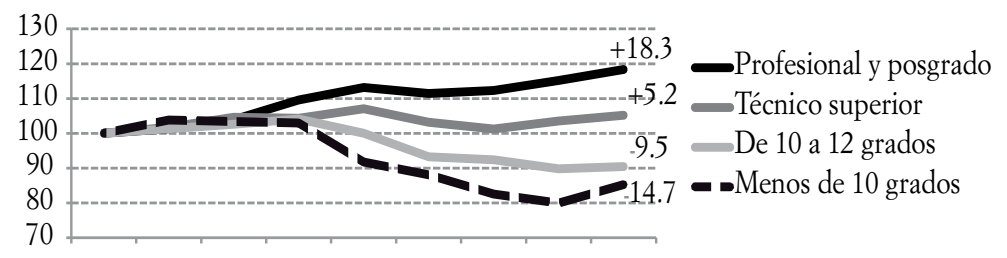

200420052006200720082009201020112012

Fuente: Elaboración propia con cifras de la Current Population Survey.

Datos de la CPS para 2012, indican que 29.4\% de los trabajadores en Estados Unidos contaban con estudios de nivel técnico superior y $34.3 \%$ con estudios profesionales o de posgrado. Pese a los efectos de la crisis, entre 2004 a 2012 los empleos con educación de nivel técnico superior crecieron $5.2 \%$, mientras que para este mismo periodo el número de trabajadores con nivel profesional y posgrado aumentaron $18.3 \%$. La oferta laboral de los otros migrantes en Estados Unidos (excluyendo a los mexicanos) sigue una tendencia similar buscando concentrarse en los niveles de mayor escolaridad (véase la gráfica 9). En contraste, los trabajadores migrantes mexicanos se concentran casi en su totalidad en los niveles de escolaridad más bajos. Esto puede ser 
un motivo que explique la cantidad de migrantes mexicanos y de trabajadores migrantes mexicanos que ha permanecido casi estancado en sus empleos desde hace varios años.

Estos resultados son similares a los señalados en otros estudios donde se indica que "[...] (En Estados Unidos, los extranjeros) con los niveles más bajos de educación son los que sufren en mayor medida el desempleo y ocurre lo contrario con aquellos que presentan niveles de educación superior" [Aragonés y Salgado, 2011].

\section{Alta concentración en pocos estados de Estados Unidos}

Son dos los estados donde se concentra la mayor cantidad de migrantes mexicanos. En California y Texas en 1996 residían 71\% y aunque esta proporción ha mostrado una tendencia decreciente en los años, aun en 2012 la concentración en ambos estados es elevada: $59 \%$, casi 6 de cada 10 migrantes son mexicanos. Si en los datos de estos estados se suman los migrantes mexicanos que viven en Illinois y Arizona (en promedio concentran poco más de $5 \%$ del total cada uno), se observa que en cuatro estados de Estados Unidos reside 70\% de los migrantes mexicanos.

Esta alta concentración en pocos estados que pudo ser favorable para la migración mexicana en periodos de rápido crecimiento económico y laboral en esos estados, actualmente puede desempeñar un papel en el sentido opuesto. De acuerdo con cifras del US Bureau of Labor Statistics, en los años posteriores a la crisis económica, California, Illinois y Arizona registraron tasas de desempleo superiores a las del promedio nacional. Desde 2008 el estado de California, donde residen más de 35\% de los trabajadores mexicanos, se ha ubicado dentro de los cuatro estados con las mayores tasas de desempleo a nivel nacional, en 2011 y 2012 fue el segundo estado con la mayor tasa de desempleo con 11.8 y $10.5 \%$ en promedio, respectivamente (véase cuadro 3$)$. 
Cuadro 3. Tasa de desempleo en estados seleccionados de Estados Unidos, 2006-2012

Promedio anual

\begin{tabular}{l|c|c|c|c|c|c|c}
\hline & 2006 & 2007 & 2008 & 2009 & 2010 & 2011 & 2012 \\
\hline (Nacional) & 4.6 & 4.6 & 5.8 & 9.3 & 9.6 & 8.9 & 8.1 \\
\hline California & 4.9 & 5.4 & 7.2 & 11.3 & 12.4 & 11.8 & 10.5 \\
\hline Texas & 4.9 & 4.4 & 4.9 & 7.5 & 8.2 & 7.9 & 6.8 \\
\hline Illinois & 4.6 & 5.1 & 6.4 & 10 & 10.4 & 9.7 & 8.9 \\
\hline Arizona & 4.1 & 3.7 & 6 & 9.8 & 10.4 & 9.4 & 8.3 \\
\hline
\end{tabular}

Fuente: Elaboración propia con cifras de US Bureau of Labor Statistics.

\section{Alta concentración en sectores}

económicos con poco dinamismo

en los últimos años

Los principales sectores económicos donde se concentran los migrantes mexicanos son: construcción, hostelería y esparcimiento, manufacturas, servicios profesionales y negocios, y comercio. Los que en conjunto emplean $70 \%$ de los migrantes mexicanos. La pérdida de empleo en esos sectores parece obedecer al ciclo que presentan en la nación.

En la gráfica 10 se puede observar la evolución del empleo en estos sectores donde se concentra la fuerza laboral de los migrantes mexicanos. Salvo por los sectores de hostelería y esparcimiento, de servicios profesionales y de negocios, el resto no ha logrado recuperar los niveles de empleo previos a la crisis económica, en donde el sector de la construcción y las manufacturas han sido de los más afectados.

Así, la alta concentración de migrantes mexicanos en sectores de bajo dinamismo ha afectado la recuperación y la creación de nuevos empleos, lo cual afecta el flujo total de migrantes. Además, es posible que el bajo nivel de escolaridad de los migrantes 
mexicanos afecte su inserción en otras industrias más dinámicas en las cuales podrían encontrar más fácilmente empleo y posiblemente mejores condiciones salariales.

Gráfica 10. Estados Unidos. Empleo nacional en los principales sectores de concentración de los migrantes mexicanos (enero de 2007=100)

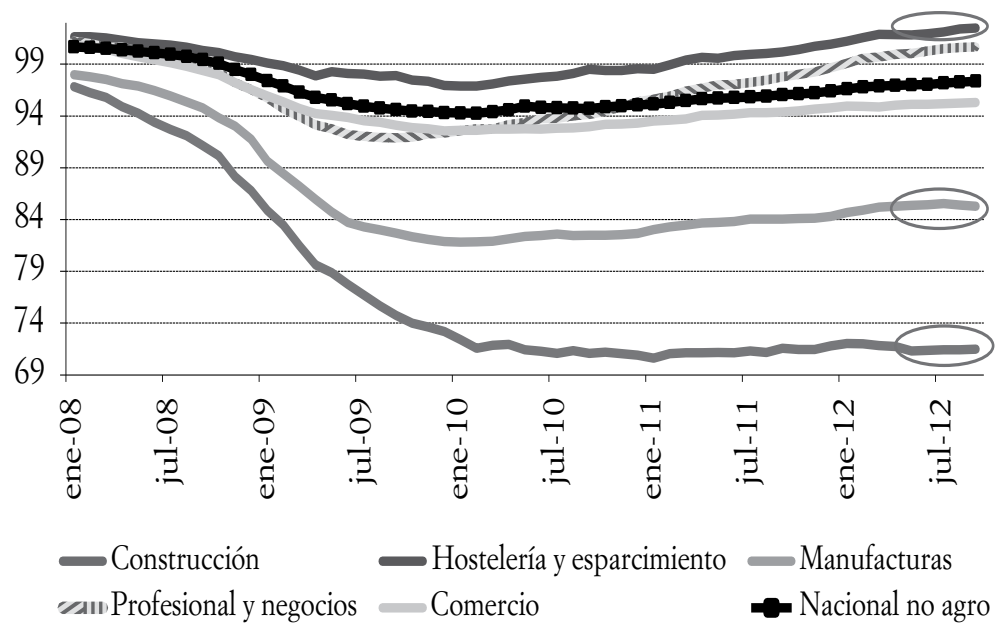

Fuente: Elaboración propia con cifras de la Current Population Survey.

\section{CONCLUSIONES}

Entre 2000 y 2007 fue el boom en la migración México-Estados Unidos. Fue cuando se dio la mayor entrada de migrantes mexicanos generando un aumento de $60 \%$ para llegar casi a $12 \mathrm{mi}-$ llones, sin embargo, a partir de 2008 la historia cambió y tras ese gran dinamismo el número de migrantes no ha mostrado crecimiento en 5 años. Esta situación busca respuestas, sobre todo si se considera que los flujos migratorios de otras regiones ya se recuperaron. Diversas hipótesis se han planteado, desde factores económicos como la crisis económica reciente o las mejoras económicas en México, factores demográficos como la disminución 
de la natalidad en México o factores político-sociales como el endurecimiento de la política migratoria en Estados Unidos o el incremento de la violencia en México. No obstante, quienes han planteado estas hipótesis, han ofrecido poca evidencia acerca de cuales factores son los más relevantes.

El estudio tuvo como objetivo contribuir con esos temas. Se encontró que los factores que explican el "estancamiento" de la migración mexicana son los que inciden en la generación de empleos para los migrantes mexicanos en Estados Unidos puesto que la migración mexicana es sobre todo con fin laboral.

El primer factor que afectó el empleo de los migrantes mexicanos y, por tanto, al flujo migratorio fue la crisis económica que se manifestó en mayor medida en sectores con alta concentración de migrantes mexicanos. Tras el término de la crisis económica durante el segundo semestre de 2009, el empleo en Estados Unidos empezó a recuperarse y los migrantes mexicanos llegaron a una fase de ganancia de empleos, la cual se vio frenada por el Efecto Arizona, es decir, a partir de abril de 2010 se presentan diferentes acciones en distintos estados que llevaron a la promulgación de diversas leyes antimigrantes. Ello generó la pérdida de más empleos para los migrantes mexicanos, siendo los principales afectados pues representan la mayoría de los indocumentados en Estados Unidos.

En la actualidad el empleo en Estados Unidos ha aumentado, situación de la que los mexicanos no han resultado favorecidos como el resto de los trabajadores hispanos, quienes ya recuperaron todo el empleo pérdido tras la crisis económica y se encuentran en sus niveles máximos históricos. Que los mexicanos no aprovecharan la reciente coyuntura de creación de empleos tiene que ver con cuestiones de oferta y demanda laboral. La economía estadounidense demanda en mayor medida puestos de trabajo en niveles de mayor calificación laboral, desafortunadamente para los migrantes mexicanos, su oferta se concentra en niveles de menor nivel de calificación. Así, la limitada calificación laboral de los migrantes mexicanos está ligada con el estancamiento en los últimos años del flujo migratorio neto, que no se ha podido adap- 
tar a los cambios en la demanda laboral del vecino país del norte.

Otro factor por considerar es que los migrantes mexicanos están concentrados en pocos estados y sectores que no necesariamente tienen los mayores niveles de crecimiento económico en los años recientes. Una alta concentración de migrantes mexicanos en pocos estados y pocos sectores genera una dependencia, cuando estos estados y sectores crecen se ve como benéfica, pero cuando se encuentran estancados o en recesión afectan a todo el grupo: la población migrante mexicana en Estados Unidos lleva 5 años de estancamiento laboral.

El crecimiento hacia adelante del flujo migratorio de mexicanos hacia Estados Unidos dependerá, entre otros factores de: 1) una mayor recuperación de la economía de Estados Unidos, 2) que la oferta de mano de obra mexicana se adecue a las necesidades del mercado estadounidense, que actualmente demanda empleos con mayor nivel de calificación, y 3) la flexibilidad y capacidad de los migrantes mexicanos para diversificar su oferta en otros estados y otros sectores económicos no "tradicionales" donde sean más competitivos. Que algunos de estos elementos se cumplan depende en gran medida de la capacitación de la fuerza laboral mexicana y, para ello, es indispensable avanzar cada vez más para elevar los niveles de escolaridad en el país, así como incrementar la calidad educativa.

Dado este panorama, la migración mexicana hacia Estados Unidos pudiera entrar en una nueva fase donde habrá flujos migratorios, pero lo común serían saldos de emigrantes y de migrantes de retorno relativamente bajos que podrían ser de cero.

\section{BiBLIOGRAFÍA}

Alarcón, R., R. Cruz, A. Díaz-Bautista, G. González-König, A. Izquierdo, Yrizar, G., y R. Zenteno [2008], La crisis financiera en Estados Unidos y su impacto en la migración mexicana, El Colegio de la Frontera Norte, México. Albo, Adolfo, Juan Luis Ordaz, Juan José Li Ng, Humberto Ceba- 
llos, Telésforo Ramírez [2012], Anuario de migración y remesas México 2013, en Albo, Adolfo (coord.), BBVA Research-Conapo-Fundación BBVA Bancomer, México.

Aragonés, Ana María y Uberto Salgado [2011], "Mercados de trabajo en la economía del conocimiento y el fenómeno migratorio. El caso de Estados Unidos (1990-2006)", en Aragonés, Ana María (coord.), Mercados de trabajo y migración internacional, Instituto de Investigaciones Económicas, UNAM, México.

Cave, Damien [2011], "Better lives for mexicans cut allure of going North", The New York Times, en <http://www.nytimes. com>, 6 de julio.

Fundación BBVA Bancomer y BBVA Research [2012], "Situación migración México", BBVA, julio.

Fundación BBVA Bancomer y BBVA Research [2013], "Situación migración México", BBVA, julio.

Passel, Jeffrey, D’Vera Cohn y Ana González-Barrera [2012], "Net migration from Mexico falls to zero-and perhaps less", Pew Hispanic Center.

Passel, Jeffrey y D’Vera Cohn [2011] "Unauthorized immigrant population: national and state trends, 2010", Pew Hispanic Center.

US Census Bureau y US Bureau of Labor Statistics [2012], "The Current Population Survey (CPs)", varios años.

US Department of Homeland Security, Yearbook of Immigration Statistics, varios años. 


\section{Capítulo 7 \\ NuEVOS PATRONES MIGRATORIOS \\ EN EL CONTEXTO DE LA CRISIS ECONÓMICA. \\ EL CASO DE ESPAÑA}

Joaquin Arango*

\section{INTRODUCCIÓN}

Cuando han transcurrido seis años desde el inicio, en el verano de 2007, de la crisis económica y financiera, su poderoso influjo sigue dejándose sentir sobre numerosas parcelas de la realidad en no pocos países. Por razones fáciles de comprender, la migración está lejos de contarse entre las excepciones. No es de extrañar, por ello, que buena parte de la atención de los estudiosos de los movimientos migratorios gire en torno de los impactos de la crisis sobre éstos. En efecto, en este tiempo numerosos países han visto alterados sus patrones migratorios [OCDE, 2009; Papademetriou y Terrazas, 2009; Awad, 2009; Martin, 2009; Papademetriou, Sumption y Terrazas, 2010; Cachón,

* Catedrático de Sociología en la Universidad Complutense de Madrid y director del Centro de Estudios sobre Migraciones y Ciudadanía en el Instituto Universitario de Investigación Ortega y Gasset. Fue presidente del Foro para la Integración Social de los Inmigrantes, es co-director del Anuario sobre Inmigración y Políticas de Inmigración en España y miembro de los consejos asesores o científicos de varias instituciones internacionales y nacionales; de los consejos de redacción del Journal of Ethnic and Migration Studies, Migration Studies, Studi di Sociologia, Migraciones y Desarrollo, Mondi Migranti, Demográfia, Revista de Occidente y Pensamiento Iberoamericano. E-mail: < arango@cps.ucm.es>. 
2012]. Sin embargo, la magnitud y el sentido de los cambios inducidos por la recesión varían considerablemente de unos países a otros.

En el caso de Europa, el efecto de la crisis sobre flujos migratorios y stocks de inmigrantes es muy desigual y, en general, más limitado de lo que se piensa. Ciñendo la mirada a variaciones en los stocks de inmigrantes entre 2007 y 2011, y a los principales países receptores, se observan tendencias muy diversas. Entre los países más afectados por la crisis, Irlanda y España registran disminuciones en el volumen de la población inmigrada; Portugal y Grecia, incrementos mínimos; y el Reino Unido, un aumento no desdeñable. Sin embargo, Italia, muy castigada por la crisis, experimenta el mayor aumento. Por su parte, países con economías poco afectadas, como Alemania y Holanda, han visto descender el volumen de la población inmigrada; y en Francia el incremento ha sido mínimo. Otros, como Austria o Bélgica, han tenido incrementos intermedios. En suma, el cuadro es demasiado variopinto como para deducir claras relaciones de causalidad.

No obstante, en algunos países la relación entre los efectos de la crisis y la alteración de las pautas migratorias es tan clara como acusada. Uno de ellos es el caso de España, país golpeado con inusitada dureza por la recesión. La intensidad de los cambios acaecidos le confiere particular interés. Además, tal interés se ve acrecentado por el radical contraste observado entre las tendencias y realidades de los años que precedieron a la crisis y las que han resultado de ésta. Ello es predicable tanto de la economía en general como de la inmigración en particular.

En este último terreno, la experiencia inmigratoria española atraía de manera considerable la atención internacional por el espectacular crecimiento de la cantidad de población inmigrada desde los años del cambio de siglo. También llamaba la atención el hecho de que los caudalosos y sostenidos flujos migratorios que tenían España por destino no dieran lugar a las manifestaciones de rechazo registradas en otros países; y que las políticas de inmigración practicadas no participaran de la acusada deriva europea hacia el endurecimiento y la restricción. En años recientes, esa 
atención se ha extendido al hecho de que la crisis económica y financiera, con efectos particularmente severos y astronómicas tasas de desempleo, no haya acarreado una mutación significativa de las actitudes hacia la inmigración en la sociedad española ni un cambio en las políticas que pretenden gestionarla [Arango, 2012]. Del agudo contraste entre el gran crecimiento de la población inmigrada en los años que precedieron a la crisis y su disminución posterior, de la llamativa ausencia de movimientos de rechazo hacia la inmigración antes y después, se ocupan las páginas que siguen. El modelo de crecimiento económico que propició la bonanza anterior a 2007 y que ha contribuido a agravar las consecuencias de la crisis constituye un nexo de unión entre una y otra.

\section{EL LEGADO DEL PASADO RECIENTE:}

EL BOOM INMIGRATORIO Y SUS MOTORES

Entre los años del cambio de siglo y el que siguió al comienzo de la crisis, España conoció una auténtica explosión inmigratoria. En esa década prodigiosa de la inmigración [Aja, Arango y Oliver, 2009], el número de los inmigrantes establecidos en España prácticamente se sextuplicó, pasando de un millón a más de seis, incluyendo a los cientos de miles que en este tiempo adquirieron la nacionalidad española. La proporción que los venidos de fuera hizo que población total pasara de $2.5 \%$ a $13 \%$. Tan rápido y sostenido incremento situó a España entre los diez primeros países del mundo por la cantidad de población inmigrada de acuerdo con datos de la División de Población de las Naciones Unidas. En esos años, España fue el país de la Unión Europea que más inmigrantes recibía (véase el cuadro 1) y el segundo de la OCDE en números absolutos, sólo superado por Estados Unidos. En 2007, el año de mayor crecimiento de la inmigración, el número de los venidos de fuera aumentó 957000 en un país de 45 millones de habitantes. Es posible que en ello pesara la inscripción en los registros de población municipales de ciudadanos rumanos y búlgaros que ya vivían en España y que obtuvieron el permiso de residencia 
como consecuencia de la incorporación de sus países a la UE en ese año, pero en los años anteriores sin esa circunstancia, el incremento ya había sido de gran magnitud, cercano en promedio al medio millón de personas. En ese año los inmigrantes establecidos en España enviaron a sus países 8135 millones de euros (cerca de 11 mil millones de dólares), lo que situaba a España en el tercer lugar entre los países emisores de remesas en el mundo, tras Estados Unidos y Arabia Saudí [Arango, 2009].

\section{Gráfi ca 1. Evolución del número de extranjeros empadronados en España, 1998-2011}

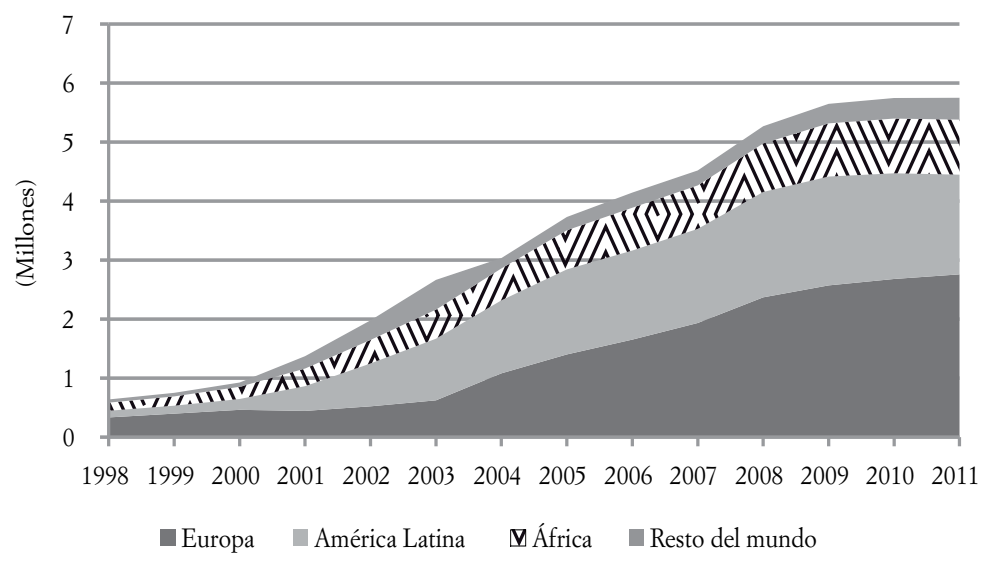

Fuente: INE, Padrón Municipal de Habitantes.

Ningún otro país registró un boom inmigratorio de la magnitud del español en la primera década del siglo XXI, pero otros países también conocieron notables crecimientos, entre ellos: Italia, Reino Unido, Irlanda y Chipre. Con los tres últimos España compartió también la burbuja del sector de la construcción, la burbuja inmobiliaria y la gravedad de la crisis, además de importantes cambios en los patrones migratorios. La comparación con Italia resulta particularmente interesante debido a que a la par de acusadas similitudes ofrece marcados contrastes: con ella España tuvo en común el fuerte crecimiento de la inmigración, junto con 
numerosas facetas del fenómeno, pero no el vigor del crecimiento económico que en Italia fue lánguido y tampoco el boom de la construcción ni la burbuja inmobiliaria. Y resulta llamativo que el cambio de las pautas migratorias haya sido mucho menor en el país transalpino que en España y los otros países mencionados [Pastore, 2009]. Todo ello puede sugerir pistas para la identificación de la etiología del crecimiento y el análisis de los impactos de la crisis.

\section{Cuadro 1. Migración neta, países de la Unión Europea} (1997-2008)

\begin{tabular}{|c|c|}
\hline UE-27 & 14011406 \\
\hline UE-25 & 14819222 \\
\hline Alemania & 1038727 \\
\hline Austria & 333302 \\
\hline Bélgica & 392457 \\
\hline Bulgaria & -215594 \\
\hline Chipre & 74658 \\
\hline Dinamarca & 106011 \\
\hline Eslovaquia & 5005 \\
\hline Eslovenia & 46018 \\
\hline España & 5074846 \\
\hline Estonia & 1413 \\
\hline Finlandia & 75361 \\
\hline Francia & 1370253 \\
\hline Grecia & 336948 \\
\hline Hungría & 133357 \\
\hline Irlanda & 379888 \\
\hline Italia & 3249440 \\
\hline Letonia & -20621 \\
\hline Lituania & -67357 \\
\hline Luxemburgo & 44356 \\
\hline Malta & 16295 \\
\hline Países Bajos & 119596 \\
\hline Polonia & -552121 \\
\hline
\end{tabular}


Cuadro 1. Continuación...

\begin{tabular}{l|c}
\hline Portugal & 386087 \\
\hline Reino Unido & 1703523 \\
\hline República Checa & 246867 \\
\hline Rumanía & -592222 \\
\hline Suecia & 324913 \\
\hline
\end{tabular}

Fuente: Eurostat.

\section{LOS MOTORES DEL BOOM}

La explicación del rápido crecimiento de la población inmigrada en España se puede encontrar en una ecuación cuyo primer factor residía en el crecimiento sostenido de la economía entre 1995 y 2007, a tasas generalmente por encima de la media de la Unión Europea. En los siete primeros años del siglo el PIB español creció a un ritmo de $3.5 \%$ anual, frente a $2.4 \%$ de la UE, según Eurostat. Se trataba de un crecimiento intensivo en trabajo, y sobre todo en trabajo de baja cualificación, que dio lugar a la creación de más de seis millones de puestos de trabajo durante el periodo considerado [Fundación Ideas, 2012; Mahía y Arce, 2010]. La ecuación comprendía también una menguante oferta nativa de fuerza de trabajo, por la muy baja natalidad de la población española durante el último cuarto del siglo $\mathrm{xx}$, y el elevado peso en la economía española de los sectores más proclives al empleo de mano de obra inmigrante: construcción, servicio doméstico, cuidado de personas dependientes, hostelería, comercio, agricultura intensiva, horticultura y recogida de frutas y verduras. El resultado fue una vigorosa y creciente demanda de trabajo foráneo, no obstante la reducción del desempleo nativo y el aumento de la tasa de actividad de las mujeres. No es de extrañar que una considerable y creciente proporción de esos puestos de trabajo fuera cubierta por personas venidas de fuera. Entre 2002 y 2008 , más de la mitad de los nuevos puestos de trabajo fueron ocupados por inmigrantes [Oliver, 2008]. A tan insaciable demanda también pudieron contribuir, finalmente, las rápidamente crecientes expectativas y aspiraciones laborales de jóvenes 
autóctonos con niveles de educación en ascenso que les llevaban a desdeñar puestos de trabajo considerados poco atractivos [Cachón, 2009]. El grueso de los venidos de fuera encontró empleo en sectores de bajas cualificación y remuneración [Cebolla y González, 2008; Garrido, Miyar y Muñoz, 2010; Pérez Infante, 2010; Cachón, 2009].

\section{UNA EXPERIENCIA MIGRATORIA PECULIAR}

Hasta la llegada de la crisis, la experiencia inmigratoria española pudo ser vista como una historia de éxito, por la combinación de un fuerte y sostenido crecimiento con efectos evaluados de modo favorable, una recepción sosegada y políticas relativamente abiertas. En efecto, el acelerado crecimiento de la población inmigrada recibió considerable atención en los medios de comunicación, no exenta de un alto grado de curiosidad ante la novedad que suponía y de un cierto orgullo patriótico, al considerarlo indicativo de un alto grado de prosperidad. Sin embargo, apenas fue objeto de debate en la arena política, más allá de crudas imputaciones al efecto llamada de la regularización de 2005 y a la falsa imputación al gobierno de una política de "papeles para todos" [Arango, 2008].

A ello pudo contribuir el hecho de que, al menos hasta el comienzo de la crisis, los efectos de la inmigración fueran objeto de una valoración predominantemente positiva. La idea de que la economía necesitaba trabajadores inmigrantes y de que éstos contribuían al crecimiento de aquélla, gozaba de muy amplio consenso. Entre economía e inmigración parecía observarse un círculo virtuoso. Diversos estudios calificaban de notable la contribución de los inmigrantes en el crecimiento del PIB [Izquierdo, Jimeno y Rojas, 2007; Oficina Económica del Presidente, 2006; La Caixa, 2006]. Además la inmigración aliviaba las rigideces del mercado de trabajo, proporcionaba mano de obra barata a innumerables empresas y prestaba valiosos servicios a una miríada de familias. El balance fiscal parecía ser favorable a las 
arcas públicas. A todo ello se sumaba una contribución demográfica altamente positiva [Arango, 2004].

Por supuesto, no todos compartían la perspectiva positiva acerca de la inmigración. Las encuestas ponían de manifiesto que algunos segmentos de la población mostraban preocupación acerca del rápido crecimiento del número de inmigrantes, aun aceptando que fueran necesarios. Los picos de tal preocupación se asociaban más con la ocasional presencia de noticias relacionadas con la inmigración en los medios de comunicación que con el crecimiento de ésta. Puede decirse que el boom inmigratorio no generó explosión alguna de rechazo o de xenofobia. Prueba de ello fue la serena y contenida reacción popular que siguió a los atentados terroristas que tuvieron lugar en Madrid en marzo de 2004, no obstante dejar doscientos muertos y miles de heridos. El hecho de que tal matanza no diera lugar a la securitización de la inmigración que tenía lugar en otros países [Arango, 2011] apunta a la influencia de una cultura política renuente a mezclar inmigración con criminalidad y terrorismo. En efecto, las encuestas realizadas tras los trágicos sucesos manifestaron que la mayoría de los ciudadanos no culpaban a los inmigrantes por los atentados: menos de uno de cada cuatro expresaban "menos simpatía" por los marroquíes, una proporción similar a la declarada hacia los rumanos [Martínez i Coma y Duval-Hernández, 2009].

En España no han surgido partidos populistas xenófobos de extrema derecha como los que han proliferado en una docena de países europeos. Las excepciones son minúsculas y prácticamente irrelevantes. Por el contrario, los grupos antirracistas y favorables a la inmigración han pesado mucho más que los xenófobos. El grado de politización de la cuestión migratoria ha sido generalmente reducido, con algunas excepciones menores en algunas campañas electorales recientes que han tenido escasa continuidad [Arango, 2012].

Entre los factores de estructura y de agencia que pueden explicar la serena recepción de grandes números de inmigrantes en España, uno muy influyente puede ser la orientación predominantemente proinmigrante de los poderes públicos, en todos los 
niveles de gobierno (con diferencias entre ellos) y de otros actores políticos en la sociedad, y la influencia que aquélla tendría sobre las percepciones y actitudes sociales, una influencia que en ocasiones funcionó en la dirección inversa.

\section{Políticas Relativamente abierTas}

En el terreno de las políticas de inmigración, el boom no trajo consigo el endurecimiento de las mismas, con la no desdeñable excepción del refuerzo de los controles fronterizos, que incluían una mayor severidad en la exigencia de los requisitos para autorizar la entrada por razones de turismo a ciudadanos de países no pertenecientes a la OCDE. Sin perjuicio de ello, puede decirse que España no participó de la deriva restrictiva dominante en Europa [Arango, 2012]. Por el contrario, las políticas de inmigración han tendido a la apertura más que al cierre, y los esfuerzos en pro de la integración se han hecho más extensos y vigorosos. En 1993 se produjo un primer intento por ensanchar los canales para la inmigración laboral, con la adopción del "contingente", un número de permisos de trabajo aprobado anualmente para que extranjeros cubrieran puestos de vacantes. Un paso más ambicioso fue el constituido por la reforma de la política de inmigración que tuvo lugar en los años 2004-2005. Su objetivo central fue a la vez la reducción de la inmigración irregular, mediante el ensanchamiento de los canales legales para la admisión de trabajadores extranjeros, y una mayor agilidad en la contratación de éstos. Su piedra angular fue el Catálogo de puestos de trabajo de difícil cobertura, un listado trimestral de ocupaciones en las que habitualmente se producían vacantes no cubiertas por trabajadores españoles o comunitarios y para las que las solicitudes de permisos de trabajo formuladas por los empleadores recibían inmediata luz verde. La reforma comprendía también el endurecimiento de las sanciones a los empresarios, un intento de lucha contra el empleo irregular por medio del fortalecimiento de la Inspección de trabajo que se revelaría efímero, una vasta 
regularización y un mayor acento en la integración social. La regularización extraordinaria de 2005 fue la mayor y más exitosa de una serie que contaba con seis procesos anteriores, aunque fue duramente criticada por los representantes de algunos gobiernos europeos [Arango y Jachimovicz, 2005]. Las nuevas políticas tuvieron relativo éxito en el aumento de la inmigración legal en los años 2006 y 2007, aunque no está claro que redujeran significativamente la irregularidad.

En términos generales, se puede decir que, con la excepción de los años 2000-2004, las políticas de inmigración en España, más que por la cantidad de los flujos se han preocupado por hacer legal la inmigración de trabajadores, ampliando los canales para su admisión, reforzando el control de entradas y permanencias y regularizando a irregulares, con independencia del éxito de tales esfuerzos.

A la ausencia de tensiones también contribuyeron los esfuerzos realizados para promover la integración social de los inmigrantes. En ellos participó el gobierno central, los de varias regiones y numerosos municipios. Algo parecido puede decirse de un número considerable de organizaciones de la sociedad civil. Un primer Plan de Integración fue adoptado por el gobierno central en 1994 y, aunque era poco más que un catálogo de principios y buenas intenciones, de éste resultaron valiosos instrumentos como el Observatorio Permanente de la Inmigración y el Foro para la Integración Social de los Inmigrantes. En 2007 vio la luz un Plan Estratégico para la Ciudadanía y la Integración (PECI), mucho más ambicioso y articulado, al igual que su sucesor (PECI II) cuatro años después [Arango, Cebolla, Pinyol y Stanek, 2012]. En el mismo año, el gobierno central estableció un fondo nacional destinado a apoyar programas municipales de integración y a promover la coordinación de los tres niveles de gobierno en la materia, un fondo que reduciría su cuantía a lo largo de la crisis hasta desaparecer en 2012, en medio de múltiples recortes presupuestarios. Las políticas de integración españolas han ocupado lugares destacados en las tres ediciones celebradas hasta la fecha del Migrant Integration Policy Index (MIPEX). En términos 
generales cabe decir que los poderes públicos han mostrado en España un decidido compromiso con la integración de los inmigrantes. Además, no han participado de la creciente concepción condicionalista de la integración que la hace contingente a la superación de exámenes y pruebas.

Hubo, sin embargo, otros rasgos de la realidad migratoria española que merecían una calificación menos positiva a los que no se prestó la debida atención, a pesar de que en el mediano y largo plazos eran susceptibles de deparar efectos preocupantes. Entre ellos destacaba la desfavorecida inserción en el mercado de trabajo del grueso de la población inmigrada. En efecto, la mayor parte de los inmigrantes desempeñaban empleos de baja cualificación y baja remuneración, con tasas de temporalidad, precariedad y estacionalidad superiores a las de los trabajadores españoles [Cebolla y González, 2008; Pérez Infante, 2010; Cachón, 2009; Garrido, Miyar y Muñoz, 2010]. Puede decirse que la caudalosa entrada de inmigrantes en el mercado de trabajo español supuso una vasta importación de trabajo barato, que proporcionó un nuevo peonaje, una nueva clase subalterna a la economía y la sociedad españolas. Tal inserción en el mercado de trabajo derivó, sobre todo, del tipo de demanda derivada de un modelo de crecimiento económico intensivo en trabajo de baja cualificación, difícilmente sostenible en el mediano plazo, como la crisis ha demostrado dramáticamente. Desde un punto de vista sociológico, la desfavorecida inserción de los inmigrantes en los escalones inferiores del mercado de trabajo agravó la desigualdad social y dificultó la movilidad social y, por ende, la integración en la sociedad [Cachón, 2013; Bunge Vivier, 2013]. Esta faceta negativa constituye un importante componente del legado dejado por el boom inmigratorio.

\section{DEL BOOM A LA CRISIS}

A lo largo de este excepcional periodo y sobre todo en su parte final, a medida que pasaban los años y se mantenía el caudal de los 
flujos o incluso aumentaba, las preguntas acerca de qué ocurriría cuando las vacas gordas dieran paso a las flacas y hasta cuándo se prolongaría un crecimiento que parecía irrefrenable se hicieron cada vez más frecuentes. Tales preguntas encontraron respuesta a partir de 2008, meses después de iniciada la gran recesión.

En efecto, aunque la crisis financiera y económica comenzó a mediados de 2007, sus principales efectos sobre la inmigración en España no se hicieron patentes hasta bastantes meses después, con la importante aunque parcial, excepción del aumento del desempleo en el sector de la construcción. No obstante la conciencia de que el cambio era inminente ya se había instalado en la sociedad española a comienzos de 2008, en una atmósfera presidida por la incertidumbre. Varios indicios hacían pensar que 2008 iba a ser un año de cambio y de cambio significativo si no radical, en materia de inmigración. En primer lugar, los pronósticos cada vez más confirmados acerca de la extensión y gravedad de la recesión hacían augurar que entrañaría el fin de un periodo caracterizado por flujos extraordinariamente caudalosos y sostenidos. En segundo, cabía temer que la crisis y, en especial el desempleo, contribuyeran a tensar el clima social que rodea a la inmigración; un clima que, a juzgar por algunos datos de encuesta, podía estar enrareciéndose. En tercer lugar, el destacado papel que el primer partido de la oposición, el conservador Partido Popular, había asignado a la inmigración en la campaña de las elecciones generales del invierno de 2008 y los acerados tonos que presidieron la confrontación en torno a la misma, apuntaban a la posible instalación en la vida política española de dos modelos de relación diametralmente opuestos con la inmigración, lo que amenazaba con conferir a la cuestión migratoria la condición de asunto divisorio, de línea de fractura, que reviste en algunos países europeos [Arango, 2009].

Cabía esperar que la crisis económica, por su indudable efecto sobre el empleo y la demanda de trabajo, redujera las entradas de inmigrantes, seguramente en medida considerable; y que estimulara los retornos en medida incierta aunque probablemente limitada; que las vías legales para el acceso de inmigrantes al mercado de trabajo se estrecharan; que aumentara la politización de la cuestión 
migratoria y se agudizara la confrontación partidaria en torno de ella; y que las actitudes ciudadanas hacia la inmigración se tornaran más hoscas. De confirmarse esas previsiones, la crisis supondría un nítido punto de inflexión en la evolución del fenómeno inmigratorio en España. Conviene examinar hasta qué punto se han cumplido tales previsiones.

\section{UNA CRISIS DE INUSITADA GRAVEDAD}

Lo que nadie pudo prever es que la crisis resultara tan grave y prolongada como lo es en España, sobre todo en términos de desempleo. Su especial gravedad es, en buena medida, tributaria de la explosión de una desmesurada burbuja inmobiliaria, de tamaño proporcional al boom de la construcción que tuvo lugar en los años precedentes, facilitado por bajos tipos de interés. Baste decir que en España se construían más viviendas y edificios que en Alemania, Francia e Italia juntas [Arellano y Bentolila, 2009]. El sector de la construcción fue el primero y más severamente golpeado por la crisis. Ello afectó duramente a los bancos y cajas de ahorro (sobre todo a las últimas) que quedaron fragilizados por su fuerte implicación en el mismo y que, a su vez, recibieron cuantiosos créditos de bancos extranjeros, particularmente alemanes y franceses. A la grave crisis crediticia siguió el estancamiento de la economía.

El espectacular aumento de la tasa de desempleo de los nativos y, más aún, la de los inmigrantes, es el principal efecto de la crisis en España y el que más lo singulariza en el ámbito internacional, mucho más que el volumen del déficit público o de la deuda. Esta ha pasado de $7.5 \%$ a mediados de 2007 a $22.5 \%$ cinco años después; la de los extranjeros, de 12 a $36 \%$ en el mismo periodo. Por sectores, la principal contribución a tan exorbitante deterioro ha procedido del sector de la construcción, en el cual se han perdido casi tres millones de puestos de trabajo de los cuatro que proporcionaba al inicio de la crisis, según datos de la encuesta de población activa (EPA) para el primer trimestre de 2013. 
Gráfi ca 2. Evolución del producto interno bruto, España 2001-2011

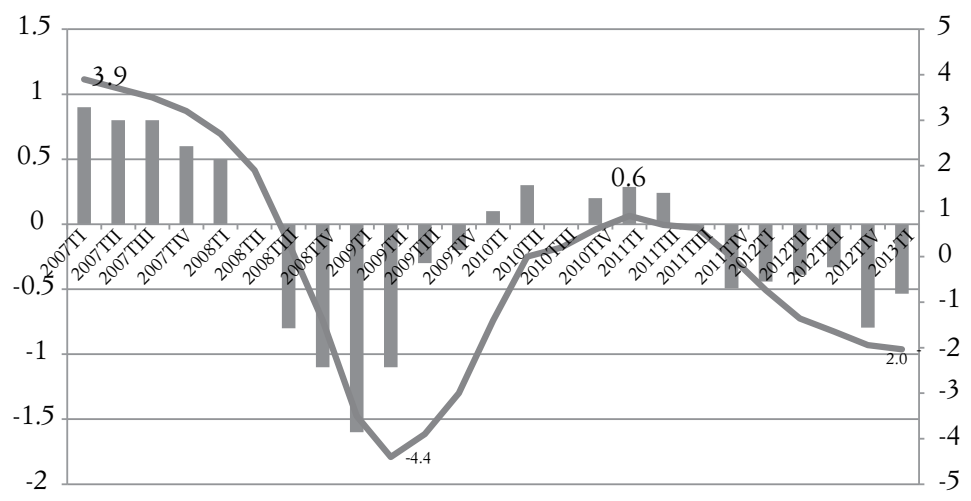

Fuente: INE, Evolución del producto interno bruto.

Gráfi ca 3. Evolución de la tasa de paro en España, 2007-2013.

(\% de la población activa)

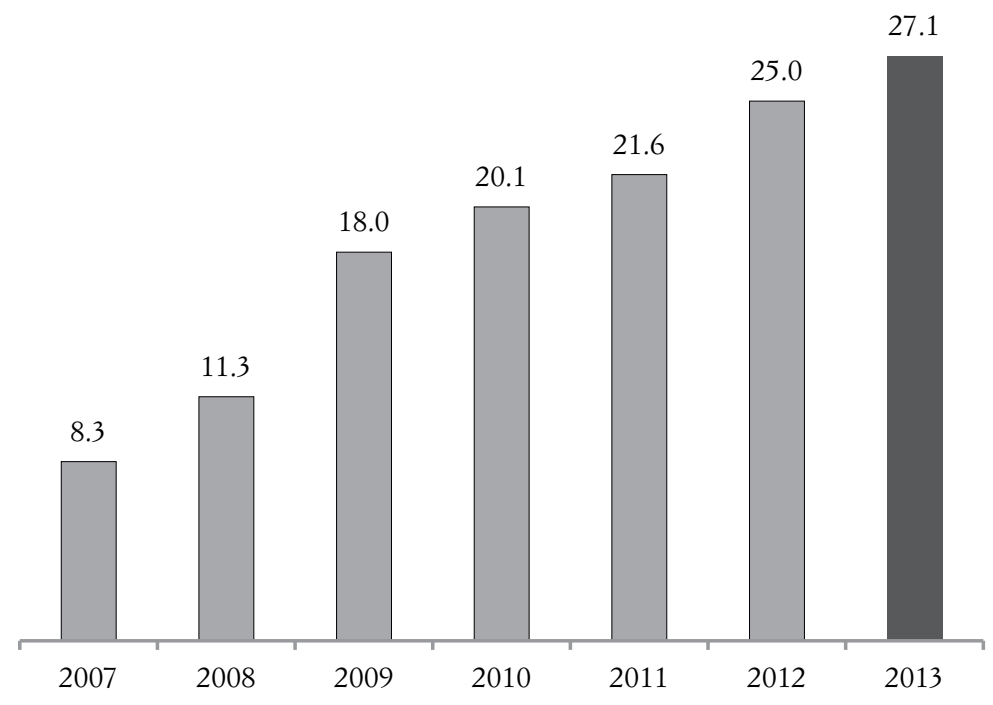

Fuente: INE, Encuesta de población activa. 


\section{LOS EFECTOS SOBRE LA INMIGRACIÓN}

Cabía pensar que los efectos de la crisis sobre la inmigración serían especialmente acusados en España por cuatro razones principales: a) porque en España la inmigración es laboral en mayor medida que en otros países europeos; $b$ ) por la excepcional intensidad de los flujos migratorios recibidos en años recientes y, por consiguiente, la alta proporción de inmigrantes con situaciones escasamente consolidadas y elevados grados de vulnerabilidad; c) por el destacado peso que había tenido el sector de la construcción en el crecimiento de la economía y del empleo, incluido el empleo inmigrante; $d$ ) y por la especial gravedad que recesiones precedentes tuvieron en términos de desempleo.

En una economía tan intensiva en trabajo como la española, la drástica desaceleración del crecimiento debía traducirse inexorablemente en contracción de la demanda de trabajo y en elevación de la tasa de paro. En ambos planos, como la experiencia sugiere, los inmigrantes suelen encontrarse entre los primeros afectados.

El aumento del diferencial de desempleo entre nativos y extranjeros se hizo visible en fecha temprana, en cuanto la crisis golpeó al sector de la construcción, uno de los que más empleo directo e indirecto creaba en España tanto para trabajadores nacionales como para los externos. Al inicio de la crisis, los inmigrantes suponían $21 \%$ de los trabajadores de la construcción, una proporción superior en un tercio a la de Italia y más del doble que la de Francia [OCDE, 2009]. Para el tercer trimestre de 2008, el número de inmigrantes desempleados había aumentado 623 mil, un incremento de $64 \%$ sobre el año anterior, alcanzando la preocupante cota de $17 \%$. Marroquíes y rumanos eran los más afectados por el paro [Arango y González Quiñones, 2009]. En la primera fase de la crisis, el aumento del desempleo resultó más del continuado incremento de la población activa inmigrante que de la destrucción de puestos de trabajo ocupados por trabajadores foráneos. Así, los datos de la EPA para el cuarto trimestre de 2008 ponían de manifiesto que el número de puestos de trabajo ocupados por 
los venidos de fuera se mantenía, en términos agregados, en niveles semejantes al de inicios de ese año. Aún no se había producido destrucción neta de empleo inmigrante, a diferencia de lo ocurrido en el lado de los nacionales. Por supuesto, era cierto sólo en términos netos. Se habían perdido muchos puestos de trabajo, especialmente masculinos y en la construcción, pero el balance se vio compensado por la creación de otros, sobre todo femeninos en los servicios [Oliver, 2009].

El sorprendente resultado de conjunto de 2008 en términos de ocupación fue tributario del aumento en el número de ocupados extranjeros durante la primera parte del mismo. Durante el primer trimestre, el número de extranjeros afiliados a la Seguridad Social aún creció en 70 mil, cifra similar a la de los mismos meses del año anterior, aunque se estuviera ralentizando el empleo de autónomos, quizá por deslizamiento al sector informal. La creación neta de empleo inmigrante aún se mantuvo durante los meses siguientes, si bien corriendo paralela al aumento del desempleo derivada del creciente número de activos. Según los datos de la EPA, los inmigrantes empleados aumentarían $6.8 \%$ durante el primer semestre de 2008. Por su parte, el número de extranjeros afiliados a la Seguridad Social eran para 30 de junio $4.6 \%$ superior al del año anterior. Otros sectores, especialmente la hostelería, debieron compensar la caída del empleo extranjero en la construcción. Al mantenimiento del nivel agregado de empleo inmigrante durante la primera fase de la crisis debió contribuir la mayor movilidad geográfica y la mayor empleabilidad de los trabajadores extranjeros, así como la creación de nuevos puestos de trabajo en el sector informal. En términos agregados, la recesión sólo se tradujo en destrucción de empleo inmigrante a partir del segundo semestre de 2008, cuando se extendió a los servicios. En otros países parece que se produjo un lag temporal entre el inicio de la crisis y el grueso de sus efectos sobre la inmigración [OCDE, 2009]. Desde 2009 el aumento del paro inmigrante resulta cada vez más de la destrucción neta de puestos de trabajo y menos del aumento del número de activos. 
En los años transcurridos desde el inicio de la crisis, se han perdido 650 mil puestos de trabajo ocupados por inmigrantes. Ello se explica, en primer lugar, por la fuerte presencia que tenían en la industria de la construcción y sectores conexos, pero también porque la contracción del crédito y del consumo doméstico, así como la del gasto público, han extendido la recesión hacia otros sectores, en particular de los servicios, donde se centra el empleo de la mayor parte de los inmigrantes. El número de personas desempleadas de origen inmigrante alcanzaba la cifra de 1300000 a inicios de 2013, de acuerdo con la EPA, y una elevada proporción de ellos llevaba más de un año en el paro. La situación de la población inmigrada era peor que la de la población general en todos los indicadores laborales. Finalmente, la crisis está agravando todos los rasgos que definían como desfavorecida la inserción de los inmigrantes en el mercado de trabajo.

\section{CAMBIOS EN LAS DINÁMICAS MIGRATORIAS}

El importante aumento del desempleo y, más en general, el enrarecimiento del clima económico y la reducción de oportunidades y expectativas tienen un formidable efecto sobre los flujos migratorios. Para empezar, la recesión ha puesto fin al largo periodo de crecimiento de la población inmigrada, aunque su principal consecuencia, la incorporación en la sociedad española de millones de personas de otras procedencias forma parte importante del presente y lo hará en el futuro. Sin embargo, aunque la mayoría de los que vinieron permanece y constituyen una importante proporción de la fuerza de trabajo, no cabe duda de que se están instalando nuevos patrones migratorios. Han disminuido mucho las entradas y aumentado las salidas de inmigrantes que retornan a sus países de origen o emigran a terceros, así como de españoles de nacimiento. Contrariamente a lo que se piensa, los flujos de inmigración no han cesado, pero han cedido la primacía a los de emigración. 
Si el signo de las nuevas tendencias es claro, su cuantificación precisa muestra dificultades. Aunque no esté libre de problemas, el registro y consiguiente cómputo de las entradas puede considerarse razonablemente satisfactorio en España. La piedra angular del sistema es el Padrón Municipal de Habitantes, una especie de registro de población que tiene la ventaja comparativa de incluir tanto a los inmigrantes con permiso de residencia como a los que se encuentran en situación irregular. De ella se obtiene la Estadística de Variaciones Residenciales. Los problemas residen ante todo en el cómputo de las bajas, que constituyen un área de penumbra estadística, como ocurre en otros países a pesar de los intensos y sostenidos esfuerzos del Instituto Nacional de Estadística. Contabilizar las salidas resulta difícil, por la escasa huella que deja la mayoría y por lo tardío de su detección dado que entre la partida y la cancelación de la inscripción en el registro municipal puede mediar un tiempo. Una norma legal de 2003 requiere que los extranjeros que no estén en posesión de permisos de residencia de larga duración renueven cada dos años su inscripción padronal. En consecuencia, la cancelación de las inscripciones padronales no renovadas se produce hasta pasados más de dos años desde la última renovación, cuando el ayuntamiento da por concluidos los esfuerzos para localizar a quienes no han renovado. Ello resulta en la subestimación de las salidas por el retraso en la contabilización de las más recientes y ese retraso es especialmente sensible en tiempos de crisis, cuando tienden a aumentar las salidas.

Según el Instituto Nacional de Estadística, la población empadronada en España ha disminuido en 2012, con respecto del año anterior, por primera vez desde que existen datos. La explicación reside en la disminución, 216 mil, del número de extranjeros, mientras el de españoles registraba un mínimo aumento, 10 mil. Pero estas cifras no tienen en cuenta las decenas de miles de naturalizaciones que han tenido lugar durante el año; si lo hicieran, la disminución del número de extranjeros sería menor y el saldo de los españoles resultaría claramente negativo. La población extranjera se redujo por primera vez en 2011, en unas 15 mil 
personas. Si se tiene en cuenta el gap temporal que media entre buena parte de las salidas del país y su contabilización tras la cancelación del registro padronal, hay que pensar que las cifras ofrecidas por el INE subestiman las salidas de inmigrantes.

Las Estadísticas de Variaciones Residenciales y las Estimaciones de la Población Actual, otros índices estadísticos del INE, ofrecen datos que permiten una mejor estimación de la cantidad de las salidas. De acuerdo con ellas, desde mediados de 2008 hasta fines de 2011 se habían contabilizado 1335000 bajas padronales, 91\% de inmigrantes varios naturalizados españoles y el restante $9 \%$ de españoles nacidos en España, si bien algunos de ellos hijos de inmigrantes [Domingo y Sabater, 2013]. La salida de inmigrantes aumentó hasta 2010 y se ralentizó levemente en 2011. Aunque la información acerca de los destinos de quienes se van es muy limitada, no cabe duda que la mayoría retornan a sus países de origen, sobre todo en América Latina [Domingo y Sabater, 2013]. Emigran más hombres que mujeres, reflejando ante todo el mayor impacto de la crisis en sectores altamente masculinizados, como la construcción.

Los cambios inducidos por la persistente crisis económica en las pautas migratorias en España no se limitan a la atenuación de los flujos de entrada y al aumento de los de salida con la consiguiente estabilización primero, y la gradual disminución del tamaño de la población inmigrada después. No menos relevantes son los cambios operados en la composición de ésta, y más en particular, en la población activa de origen inmigrante. En efecto, como manifiestan los datos proporcionados por la Encuesta de Población Activa, en los últimos años tiene lugar un envejecimiento de la población activa inmigrante que causa el diferente efecto que la recesión tiene sobre los distintos grupos de edad. La desaparición de puestos de trabajo ocupados por inmigrantes en los primeros cinco años de crisis, cerca de $16 \%$, similar a la de los nativos, ha ido acompañada de profundas modificaciones en la estructura de la población. Tal tendencia hacia el envejecimiento se observa en todas las magnitudes del mercado de trabajo inmigrante. Mientras disminuyen los efectivos en la mitad más 
joven de la población activa, la comprendida entre 16 y 34 años, aumentan los de la mitad menos joven, de 35 a 64 años. La destrucción de empleo ha golpeado con especial saña a los más jóvenes. Por ello, no es de extrañar, que la reacción de un considerable número de jóvenes de origen inmigrante ante el deterioro del mercado de trabajo sea salir del país [Oliver, 2013].

Junto con la capital transformación que supone el envejecimiento, una segunda tendencia es la creciente feminización. En efecto, ha aumentado el peso de las mujeres en la actividad y especialmente en el empleo, al tiempo que disminuía la proporción que suponen de los "parados". Ambas tendencias están lógicamente asociadas con los profundos cambios operados en la distribución sectorial del empleo, presididos por el inusitado colapso de la construcción que ha reducido su volumen en más de $70 \%$ y rebajado su peso en el empleo total a un exiguo $7.5 \%$, muy alejado de $22 \%$ que suponía en los albores de la crisis. De hecho, la caída del empleo en la construcción explica prácticamente la totalidad de las pérdidas ocupacionales de la población inmigrada, cifradas en 519 mil puestos de trabajo. En cambio, en el sector servicios el empleo ha aumentado ligeramente durante los cinco años de crisis, lo que ha supuesto que su peso haya pasado de $62 \%$ durante el tercer trimestre de 2007 a nada menos que $77 \%$ en septiembre de 2012. Ello supone una creciente terciarización que se afirma como el tercero de los grandes cambios que se operan en el mercado de trabajo de la inmigración [Oliver, 2013].

\section{INCIPIENTE Y CRECIENTE EMIGRACIÓN DE ESPAÑOLES DE ORIGEN}

Aunque la "parte del león" de la nueva emigración se constituye por antiguos inmigrantes, el foco de la atención pública española sobre todo se sitúa en la salida de españoles de origen, no obstante su inferior cantidad. Los medios de comunicación llevados de una cierta fascinación por lo novedoso, hacen frecuente eco 
de la emigración de jóvenes españoles y exageran su número, lo que contribuye a crear una imagen distorsionada en amplios sectores de la opinión pública y magnifican los perjuicios que en términos de pérdida de capital humano pueden resultar de tales salidas. No pocas veces se atribuye a emigración de españoles lo que se explica mejor como retorno de inmigrantes que adquirieron la nacionalidad española o como aumento del número de extranjeros que de manera reciente la adquirieron al amparo de la Ley de memoria histórica sin haber residido en España. En todo caso, la estimación de la magnitud del fenómeno es particularmente difícil porque una considerable proporción de los que se van, no se dan de baja en el registro municipal y tardan en darse de alta en los respectivos consulados de los países de destino, eso cuando lo hacen.

Distintas fuentes estadísticas deparan estimaciones diferentes. Sobre la base de las Estadísticas de variaciones residenciales, Domingo y Sabater calculan en 115 mil el número de los españoles de origen que emigraron desde el inicio de la crisis hasta fines de 2011. Garrido [2013] analizando las variaciones registradas en el padrón de españoles residentes en el extranjero (PERE), hecho público por el INE para 1 de enero de 2013, sugería que la emigración de españoles es más aparente que real, dado que la mayor parte del aumento registrado en el PERE se debe a la salida de naturalizados y a quienes han adquirido la nacionalidad española sin salir de sus países. A ello hay que añadir que los medios de comunicación se hacen eco del aumento de los españoles de nacimiento residentes en otros países, pero no de los que regresan [Garrido, 2013]. Sin embargo, este último análisis ha sido puesto en solfa por no tener en cuenta que el PERE no registra las salidas de españoles "con la misma precisión que registra los retornos a España”, lo que se pone de manifiesto si se comparan sus cifras de, por ejemplo, nuevos registros en el Reino Unido, el principal destino de las salidas recientes, con las cifras de nuevas llegadas de españoles que proporcionan las estadísticas de dicho país [González Ferrer, 2013]. Así, mientras según las estadísticas en 2011 del Reino Unido, 30 mil españoles se dieron de alta por 
primera vez como trabajadores en ese país, el PERE sólo registraba un aumento veinte veces menor. Diversos medios de comunicación se han hecho eco de datos que apuntan a una tendencia similar para Alemania [La Vanguardia, 11 de agosto de 2012 y 8 de mayo de 2013; Público, 16 de noviembre de 2013]. En suma, no parece haber duda acerca de la clara tendencia hacia el aumento que muestra la emigración de españoles de origen, compuesta en forma equilibrada tanto por hombres como por mujeres, sobre todo jóvenes y con niveles de estudios medios y superiores, pero la disparidad de datos ofrecidos por otras fuentes impide cuantificarla con precisión. Europa del Noroeste y Estados Unidos constituyen sus principales destinos, seguidos por algunos países de América Latina [Domingo y Sabater, 2013].

\section{Cuadro 2. Bajas según la nacionalidad y el lugar de nacimiento, España 2007-2011}

\begin{tabular}{l|c|c|c|c}
\hline & \multicolumn{2}{|c|}{ Españoles nacidos en } & & \\
\hline & España & Extranjero & Extranjeros & Total \\
\hline 2007 & 22517 & 5574 & 198974 & 227065 \\
\hline 2008 & 25863 & 8590 & 232007 & 266460 \\
\hline 2009 & 25532 & 9840 & 288269 & 323641 \\
\hline 2010 & 26675 & 10603 & 336676 & 373954 \\
\hline 2011 & 37890 & 14951 & 317699 & 370540 \\
\hline Total 08-11 & 115960 & 43984 & 1174651 & 1334595 \\
\hline
\end{tabular}

Fuente: Domingo y Sabater [2013] a partir del INE, Estadística de variaciones residenciales, 2007-2011.

\section{OTROS IMPACTOS}

Los efectos de la crisis sobre la inmigración no se limitan al aumento del desempleo y al cambio en las pautas migratorias. Algunos otros son cada vez más perceptibles, aunque la insuficiencia de datos impide calibrarlos con precisión. Uno de especial re- 
levancia, que constituye preocupación preferente para muchos inmigrantes derivada de situaciones de desempleo prolongado, es la pérdida del permiso de trabajo y, por consiguiente, de residencia. Cuando se produce, esa pérdida se extiende hacia los hijos. Otro posible, pero no documentado, es el probable paso de muchos inmigrantes a la economía sumergida. La altísima proporción de contratos temporales entre los inmigrantes ha podido facilitar ese trasvase, al que también apuntan indicios impresionistas.

Otro posible efecto, atribuible sobre todo al desempleo, es un gradual cambio en los patrones de distribución de los inmigrantes en el territorio. Un informe de la AGETT (Asociación de grandes empresas de trabajo temporal) documentó en 2009 una tendencia hacia el estancamiento en la cantidad de la población activa de origen extranjero en las principales áreas receptoras, Madrid y Cataluña, para crecer con más intensidad en comunidades autónomas con menor presencia de inmigrantes, como Asturias y Castilla y León, seguidas de Castilla-La Mancha y Extremadura. El censo de 2011 confirmó estas tendencias para años posteriores [INE, 2012].

Un efecto adicional es la reaparición de excedentes de mano de obra en la agricultura. Diversos testimonios apuntan al retorno hacia el campo de antiguos trabajadores de la construcción ahora desempleados, especialmente en Andalucía, en algún caso en un viaje de sentido inverso al que hicieron al iniciarse el boom de la construcción. Esta tendencia se ha confirmado en las campañas para la recogida de la aceituna en provincias del sur: a diferencia de lo que ocurría antes de la crisis, una elevada proporción de los contratados son desempleados españoles que han exigido preferencia para ocupar los puestos de trabajo que, en su día, dejaron vacantes y desde entonces cubrieron los inmigrantes. En 2012 la recolección de un producto emblemático como la fresa en la provincia de Huelva, no ha estado a cargo de trabajadores extranjeros $[A B C, 10$ de marzo de 2012), cuando años atrás empleaba de manera estacional a decenas de miles de ellos y, sobre todo, ellas. 
Aparte del desempleo, los efectos sociales de la crisis sobre la población inmigrada son mal conocidos, a salvo de informaciones de carácter impresionista que aluden a una creciente incidencia de la exclusión social y un marcado aumento de la demanda de asistencia social. Especial gravedad y notoriedad tienen las crecientes dificultades para enfrentar a las hipotecas que cientos de miles de inmigrantes consiguieron para financiar sus viviendas en los años de bajas tasas de interés y mínima exigencia de garantías. Un informe de Raquel Rolnik, relatora especial de las Naciones Unidas por el Derecho a la vivienda, cifraba en nada menos que 180 mil el número de familias en España latinoamericanas con riesgo de perder sus hipotecas [Arango, 2009]. El número de los inmigrantes que las han perdido por procesos de desahucio (cada vez más contestados socialmente) no es bien conocido, sin embargo, es muy probable que constituya una proporción importante de los muy numerosos operados en España durante los años de la crisis, especialmente en 2011 y 2012. A esto se suman indicios impresionistas que apuntan hacia numerosas familias inmigrantes que se han visto obligadas para alquilar sus viviendas a terceros e irse a vivir como subarrendados, o hacerlo en la propia vivienda con otros inquilinos, lo que supone un retroceso en las trayectorias de progreso residencial [Leal y Alguacil, 2011]. Otras estrategias de adaptación a las nuevas circunstancias incluyen el retorno hacia el país de origen de algunos miembros de la familia, generalmente el cónyuge o los hijos, mientras otro u otros permanecen en España. También se narran casos de personas de países relativamente cercanos (Marruecos y Rumania, sobre todo) que van y vienen mientras perciben la prestación por desempleo. Una encuesta sobre condiciones de vida de la población inmigrada llevada a cabo por FEDEA en la región de Madrid revelaba reducciones salariales, un menor uso de cuentas corrientes bancarias y de tarjetas de crédito, una disminución de la proporción de viviendas en propiedad y menos hogares con internet, entre otros efectos derivados de la crisis [El País, 14 de enero de 2010]. 
Aún no es posible un diagnóstico completo de los efectos de la crisis y menos aún de la huella que dejarán para el futuro. Algunas de las expectativas que se formularon en su inicio se han materializado, sobre todo las relativas al desempleo y a la desaceleración de los flujos. A ellas se ha añadido la emigración de españoles; otras han sido desmentidas por la realidad o se han verificado en menor medida de lo pronosticado, en particular las que anunciaban crecientes dosis de rechazo y xenofobia, además de un acusado cambio en el tenor de las políticas de inmigración e integración.

\section{LA PERSISTENCIA DE UNA ATMÓSFERA SOSEGADA EN TORNO A LA INMIGRACIÓN}

En los años que precedieron a la crisis muchos albergaban el temor de que cuando cesase el largo período de bonanza económica, la aceptación sosegada de la inmigración diera paso a actitudes más adversas. Los pronósticos en esa dirección no se han cumplido. La crisis no ha alterado significativamente la atmósfera social en la que se desenvuelve la inmigración, ni ha tenido efectos políticos relevantes. No se han registrado grandes cambios en las políticas de inmigración e integración, con un par de excepciones, más allá de los que resultan de los recortes presupuestarios, ni en las actitudes ciudadanas hacia los inmigrantes. El clima social que rodea a la inmigración ha permanecido sereno, no hay indicios de grandes tensiones sociales, ni se han registrado incidentes de envergadura desde el inicio de la crisis. La politización de la cuestión migratoria tampoco ha aumentado significativamente. Los intentos de explotar el malestar derivado de la crisis y el desempleo por parte de partidos populistas xenófobos como los que florecen en varios países europeos han tenido escaso éxito. Los resultados electorales del más caracterizado de ellos en Cataluña han sido mínimos: crecieron algo en las elecciones municipales de 2011 y han decrecido en las elecciones autonómicas de noviembre de 2012. 
Las actitudes sociales hacia la inmigración no parecen haber empeorado significativamente durante la crisis, aunque tampoco han sido totalmente inmunes a su influencia. Las encuestas cuantitativas, como las que lleva a cabo mensualmente el Centro de Investigaciones Sociológicas (CIS), ponen de manifiesto que la inmigración no ha ascendido en la escala de preocupaciones ciudadanas. Por su parte, las encuestas cualitativas sugieren que las razones funcionales en las que un segmento de la población basa su aceptación de la inmigración (la necesidad de su concurso en el mercado de trabajo o su contribución a la economía) pueden experimentar cierto grado de erosión en un contexto marcado por altísimos niveles de desempleo, lo que podría deparar un deslizamiento de algunos hacia actitudes más negativas [Cea D’Ancona y Valles, 2010; Rinken, 2010]. Si el contraste entre la magnitud del boom inmigratorio y la tranquila recepción que lo acompañó fue llamativo, es mayor el contraste entre la gravedad de la crisis económica y la ausencia de movimientos de rechazo hacia la inmigración. En un continente donde algunos se preguntan si el ascenso de partidos antimigración es inevitable, como un influyente think-tank tituló recientemente (Is the rise of antiimmigration parties inevitable in an open Europe?, Policy Network, 27 de septiembre de 2011), España puede constituir una interesante excepción.

\section{Políticas MigRATORIAS ENTRE LA CONTINUIDAD Y EL CAMBIO}

En los años transcurridos desde el inicio de la recesión, las políticas de admisión relativamente abiertas vigentes desde 20042005 han permanecido básicamente estables. El acusado descenso del número de inmigrantes admitidos anualmente por motivos de empleo no se debe a la aplicación de criterios más restrictivos sino a la naturaleza adaptativa de los mecanismos de admisión en un contexto de fuerte contracción de la demanda de trabajo. El plan de retorno asistido, puesto en marcha por el gobierno en 
2008, fue criticado por entender que suponía una inducción encubierta al retorno, pero también pudo ser visto como un paso adelante en la portabilidad de derechos sociales, dado que ofrecía a inmigrantes desempleados que regresaran la posibilidad de recibir $40 \%$ del monto total acumulado de su subsidio de desempleo en el momento de la partida y $60 \%$ restante dentro del mes siguiente a su retorno [McCabe et al., 2009]. Más significativo es el hecho de que la reforma de la ley de inmigración aprobada por el parlamento en 2009, con el propósito principal de alinear la legislación con sentencias del Tribunal Constitucional y de incorporar recientes directivas de la Unión Europea, dejase prácticamente intacto el marco legal ya existente [Gobierno de España, 2009]. Cabe añadir que la crisis no ha debilitado el fuerte compromiso con la integración en la sociedad española.

Antes de las elecciones municipales de 2011, el gobierno español puso en marcha iniciativas para extender el derecho de voto a nacionales de países fuera de la UE. Para hacerlo posible, España tenía que promover la firma de acuerdos diplomáticos bilaterales con los países de origen, dado que un artículo de la Constitución española establece una desafortunada cláusula de reciprocidad para el reconocimiento del derecho de sufragio a ciudadanos de terceros países. Por iniciativa del gobierno español, una docena de tales acuerdos vio la luz antes de las elecciones, aunque premuras de tiempo y obstáculos burocráticos restaron efectividad al esfuerzo.

No obstante desde 2012 se observan cambios graduales, de magnitud aún limitada. Pero más que a la crisis se le atribuyen a la llegada al poder, para finales de 2011, de un gobierno con orientaciones distintas a las que habían prevalecido desde 2004. En efecto, el color político del gobierno central cambió a fines de 2011, cuando el conservador Partido Popular (PP) obtuvo mayoría absoluta. Tanto la orientación de la política de inmigración del Pp en sus años de gobierno, sobre todo durante la legislatura 2000-2004, como sus posiciones con respecto de la materia en el curso de los años siguientes como principal partido de la oposición hacían pensar en importantes cambios en las políticas de 
inmigración. Sin embargo, en el año y medio transcurrido desde su victoria electoral, los cambios de rumbo en materia de inmigración han sido limitados, con dos principales excepciones.

La primera, de naturaleza administrativa, fue la rebaja del locus institucional de la inmigración en la estructura del gobierno. El rango del principal responsable en la material dejó de ser el de Secretario de Estado y las tres direcciones generales que la gestionaban han sido reducidas a una. El anterior Ministerio de Trabajo e Inmigración ha cambiado su nombre por Ministerio de Empleo y Seguridad Social. Ello apunta a un menor peso político en el área de inmigración e integración. Más allá del mensaje simbólico que estos cambios transmiten están sus implicaciones en términos de cooperación intragubernamental en la gestión de la inmigración, especialmente relevantes en lo que tiene que ver con los habitualmente delicados equilibrios con el Ministerio del Interior. No es menor la implicación de que, la única voz española en los consejos de ministros de la UE en la materia, será la del Ministro del Interior, generalmente más preocupado por la seguridad nacional que por la integración.

La segunda excepción es la eliminación desde septiembre de 2012, del derecho a la asistencia sanitaria gratuita que tenían reconocido los inmigrantes irregulares. Hasta esa fecha, la legislación española extendía los derechos relativos a salud y educación, incluso otros beneficios sociales, a todos los inmigrantes, incluidos los de situación irregular, con el solo requisito de inscribirse en el registro municipal de población, el Padrón Municipal. El empadronamiento, obligatorio para todos los residentes en el municipio con independencia de su estatuto legal, entrañaba la recepción de la tarjeta sanitaria, que daba derecho a la plena cobertura de salud. No cabe duda de que la amplísima aceptación social del empadronamiento de los inmigrantes irregulares y de los derechos sociales conexos se constituía la prueba convincente de la existencia en España de una cultura política amistosa hacia la inmigración. Esta excepcional faceta del sistema español, adoptada en el año 2000, apenas había sido cuestionada. Unos pocos ayuntamientos con gobiernos de orientación conservadora trataron de 
obstaculizarla en 2008, pero cesaron en su empeño cuando el gobierno central les hizo saber que su iniciativa era contraria a la ley. La retirada en 2012 de la tarjeta sanitaria a los inmigrantes irregulares (de la que se exceptúan las situaciones de urgencia, las mujeres embarazadas y los menores de 18 años) ha dado lugar a extendidas protestas, incluyendo las de amplios sectores médicos y sanitarios. Algunos gobiernos regionales e innumerables profesionales médicos y sanitarios, han expresado su decisión de mantener la plena asistencia a los inmigrantes en situación irregular. Ante ello, el gobierno central ha optado por condicionarla al pago de una cuota, fijada inicialmente en algo más de 700 euros anuales. Meses después, la situación creada por la medida en cuestión puede calificarse de confusa.

Más allá de estos dos cambios, no resulta descartable que, presididas por una orientación gubernamental claramente diferente de la que prevaleció entre 2004 y 2011, las políticas españolas de inmigración e integración tiendan a alinearse con el paradigma fuertemente restrictivo prevalente en la mayor parte de Europa.

\section{UN FUTURO INCIERTO}

Vista en perspectiva comparada, la experiencia española en materia de inmigración e integración puede considerarse peculiar por la rapidez y magnitud del crecimiento de la población inmigrada en el decenio que precedió al inicio de la crisis, debido a que tal crecimiento fuera aceptado sin manifestaciones de rechazo ni endurecimiento de las políticas de inmigración, por la extraordinaria profundidad y gravedad de la crisis económica, sobre todo en términos de desempleo y porque ello, no obstante, la inmigración se haya mantenido inmune a la crispación social. Los rasgos de tal experiencia no sólo han diferido de los que se observan en otras regiones del mundo, caracterizadas por patrones migratorios claramente diferentes de los europeos, sino también de los dominantes en la Europa noroccidental. 
La extrema gravedad de la crisis ha supuesto para España la alteración de los patrones migratorios vigentes en el cuarto de siglo que la precedió y, en particular, el fin del gran boom inmigratorio. Las entradas de inmigrantes se han reducido considerablemente y han aumentado notablemente las salidas, en dirección a los países de origen o a terceros destinos. Por primera vez en décadas se registra emigración de españoles de origen, aunque más en términos de movilidad trasnacional que de emigración en sentido clásico y, es probable que la tendencia persista en el próximo futuro. Desde el punto de vista de las migraciones, España ha entrado en un hiato o impasse de duración tan imprevisible como probablemente prolongada.

Cabe pensar que este hiato terminará algún tiempo después del fin de la actual crisis: cuando se restaure el crecimiento económico y muestre el vigor suficiente para reabsorber el gran desempleo que ha generado la crisis. Sólo entonces, España volverá a demandar trabajo foráneo y será de nuevo receptor de flujos netos de inmigración. Sin embargo, ese momento puede estar aún lejano. Prever cuáles caracteres revestirá la realidad inmigratoria en ese tiempo futuro es de todo punto imposible. No sorprendería que en varios sentidos divergieran de los mostrados en las décadas finales del siglo Xx y en la primera del XXI, un tiempo que habrá resultado excepcional en la corta historia de la inmigración en España. Es posible, aunque no probable, que para entonces el modelo de crecimiento intensivo en trabajo haya cambiado. Es harto improbable que el sector de la construcción vuelva a los niveles anteriores a la crisis. Que la inmigración los recupere no es menos improbable como lo es que vuelva a ser tan relevante para América Latina como lo fue en años no lejanos. Pero el futuro, por definición, es imprevisible.

\section{BIBLIOGRAFÍA}

Aja, Eliseo; Joaquín Arango y Josep Oliver [2009], La inmigración en tiempos de crisis. Anuario de la Inmigración en España, Barcelona, СIDOB Edicions, 248 pp. 
Aja, Eliseo; Joaquín Arango y Josep Oliver [2012], La hora de la integración. Anuario de la Inmigración en España, Barcelona, СІDОВ Edicions, $462 \mathrm{pp}$.

Arango, Joaquín [2004], "La inmigración en España a comienzos del siglo xxI", en, Informe sobre la situación demográfica en España 2004, Madrid, Fundación Fernando Abril Martorell, pp. 161-186.

Arango, Joaquín [2008], "La inmigración y la vida política en España", en La estrategia de la crispación. Derrota, pero no fracaso. Informe sobre la democracia en España 2008, Madrid, VVAA: Fundación Alternativas, pp. 65-93.

Arango, Joaquín [2009], "Después del gran boom: la inmigración en la bisagra del cambio", en E. Aja, J. Arango y J. Oliver Alonso (eds.), La inmigración en tiempos de crisis. Anuario de la Inmigración en España, Barcelona, СIDOB Edicions, pp. 52-73.

Arango, Joaquín [2011], "La securitización de las migraciones internacionales, diez años después”, Vanguardia Dossier, 11-S El mundo diez años después, 41: 54-59, Octubre-Diciembre. Arango, Joaquín [2012], "Exceptional in Europe? Spain's Experience with Immigration and Integration", Rethinking $\mathrm{Na}$ tional Identity in the Age of Migration, Berlín, Bertelsmann Stiftung and Migration Policy Institute, pp. 319-341.

Arango, Joaquín y Maia Jachimowicz [2005], "Regularizing Immigrants in Spain: A New Approach", Migration Information Source, Special Issue: The Unauthorized, septiembre, disponible en <www.migrationinformation.org/Feature/display. cfm?id=331 $>$.

Arango, Joaquín y Fernando González [2009], "The impacts of the current financial and economic crisis on Migration in the SpainMorocco Corridor", CARIM Working Papers, 39(09): 1-25.

Arango, Joaquín, Héctor Cebolla, Gemma Pinyol y Mikolaj Stanek [2013], "Spain", en Giuliana Urso y Anke Schuster (eds.), Migration, Employment and Labour Market Integration Policies in the European Union (2011), Brussels, International Organization for Migration, pp. 283-291. 
Arellano, Manuel y Samuel Bentolila [2009], "La burbuja inmobiliaria: causas y responsables", La crisis de la economía española: lecciones y propuestas, Madrid, FEDEA.

Awad, Ibrahim [2009], The global economic crisis and migrant workers. Impact and response, Ginebra, International Labour Office, 64 pp.

Bunge, Vivier [2013], Movilidad ocupacional y migración: trayectorias laborales de los inmigrantes en España, Tesis Doctoral, Instituto Universitario de Investigación Ortega y Gasset, Universidad Complutense de Madrid.

Cachón, Lorenzo [2009], La "España inmigrante": marco discriminatorio, mercado de trabajo y políticas de inmigración, Barcelona, Anthropos.

Cachón, Lorenzo [2012], "La inmigración de mañana en la España de la Gran Recesión y después”, Panorama Social, España, FUNCAS, 16:71-83, julio-diciembre.

Cea d'Ancona, M. Ángeles y Miguel Valles [2010], Evolución del racismo y la xenofobia en España (Informe 2010), Madrid, Ministerio de Trabajo e Inmigración, 423 pp., disponible en $<$ www.oberaxe.es/files/datos/4e20230088dc8/INFORME \%20RACISMO\%202010.pdf>.

Cebolla, Héctor y Amparo González [2008], La inmigración en España (2000-2007): del control de flujos a la integración de los inmigrantes, Madrid, Centro de Estudios Políticos y Constitucionales, $318 \mathrm{pp}$.

Centro de Investigaciones Sociológicas (CIS), varias fechas, Barómetros de Opinión, disponible en <www.cis.es/cis/opencm/ ES/11_barometros/index.jsp>.

Domingo, Andreu y Albert Sabater [2013], "Crisis económica y emigración: una perspectiva demográfica”, en E. Aja, J. Arango y J. Oliver (eds.), Anuario de la Inmigración en España, edición 2012. Barcelona, СIDOB Edicions.

Fundación Ideas [2011], La contribución de la inmigración a la economía española. Evidencias y perspectivas de futuro. Madrid: Fundación Ideas. Disponible en <www.fundacionideas. 
es/sites/default/files/pdf/I-La_contribucion_de_la_inmigracion-Ec_0.pdf>.

Garrido, Luis; María Miyar y Jacobo Muñoz [2010], "La dinámica laboral de los inmigrantes en el cambio de fase del ciclo económico", Presupuesto y Gasto Público, 61(4):201-221.

Garrido, Luis [2013], "Quiénes se van y qué hacemos para que vuelvan”, El País, 2 de abril de 2013.

Gobierno de España [2009], Ley Orgánica 2/2009 (2009), Boletín Oficial del Estado, núm. 299, 12 diciembre 2009, <www. boe.es/boe/dias/2009/12/12/index.php>.

González, Amparo [2013], "La emigración española contada desde fuera", consulta el 25 de abril de 2013, <www.eldiario.es>. Instituto Nacional de Estadística [2012], Cifras oficiales de población: Revisión del Padrón municipal y Estimaciones de la población actual, Madrid, Instituto Nacional de Estadística.

Instituto Nacional de Estadística [2012], Censos de Población y Viviendas 2011, <www.ine.es/censos2011_datos/cen11_datos>, consulta 10 de mayo 2013.

Izquierdo, Mario, Juan Jimeno y Juan Rojas [2007], "On the Aggregate Effects of Immigration in Spain". Documentos de Trabajo 0714, España, Banco de España, 41 pp. Disponible en $<$ www.bde.es/webbde/SES/Secciones/Publicaciones/PublicacionesSeriadas/DocumentosTrabajo/07/Fic/dt0714e.pdf $>$. La Caixa [2006], "Economía española y contexto internacional", Informe Semestral, julio.

Leal, Jesús y Aitana Alguacil [2011], "Vivienda e inmigración: las condiciones y el comportamiento residencial de los inmigrantes en España”, en E. Aja, J. Arango y J. Oliver Alonso (eds.), La hora de la integración. Anuario de la Inmigración en España, edición 2011, Barcelona, СІDOB Edicions, pp. 127-156.

Mahía, Ramon y Rafael Del Arce [2010], "Impacto de la crisis laboral cobre la población inmigrante", <www.realinstitutoelcano.org>, consulta el 24 de febrero de 2010.

Martin, Philip [2009], "Recession and migration: a New Era for Labor Migration", International Migration Review, 43(3): 671-91. 
Martinez, Ferran y Robert Duval-Hernández [2009], Hostility toward Immigration in Spain, Discussion Paper No. 4109, IZA, Bonn: IZA. Disponible en <http://ftp.iza.org/dp4109.pdf > .

McCabe, Kristen, Senrena Lin, Hiroyuki Tanaka y Piotr Plewa [2009], "Pay to Go: Countries Offer Cash to Immigrants Willing to Pack Their Bags", Migration Information Source, 16 de noviembre de 2009.

OCDE (Organización para la Cooperación y el Desarrollo Económico) [2009], International Migration Outlook, 2009 Edition. OCDE, París.

Oficina Económica del Presidente del Gobierno [2006], Inmigración y economía española: 1996-2006.

Oliver, Josep [2008], "Inmigración y mercado de trabajo en 2007: el último impulso de la década prodigiosa”, en E. Aja, J. Arango y J. Oliver Alonso (eds.) La inmigración en la encrucijada. Anuario de la Inmigración en España, Edición 2008. Barcelona, СIDOB Edicions, pp. 16-35.

Oliver, Josep [2011], "El empleo inmigrante ante la nueva fase de la crisis y la integración de la inmigración, en E. Aja, J. Arango y J. Oliver Alonso (eds.), La hora de la integración, Anuario de la Inmigración en España, Barcelona, СІDOB Edicions, pp. 26-66.

Oliver, Josep [2013], "La inmigración y la doble recesión del mercado de trabajo en España, 2011-2012", en E. Aja, J. Arango y J. Oliver (eds.), Anuario de la Inmigración en España, Barcelona, CIDOB Edicions, pp. 30-61.

Papademetriou, Demetrios y Aaron Terrazas [2009], Immigrants and the Current Economic Crisis: Research Evidence, Policy Changes, and Implications, Washington D.C., Migration Policy Institute, $31 \mathrm{pp}$.

Papademetriou, Demetrios; Madeleine Sumption y Aaron Terrazas [2010], Migration and Immigrants Two Years after the Financial Collapse: Where do we stand? Report for the BBC World Service, Washington D.C., Migration Policy Institute, $128 \mathrm{pp}$. 
Pastore, Ferruccio [2009], "The impact of the economic crisis on migrants and migration policy in Italy", en Migration and the Economic Crisis: Implications for Labour Market policies in the European Union and the Post-2010 Lisbon Agenda. Expert Seminar. Bruselas, 10 de diciembre de 2009.

Pérez, J. Ignacio, [2010], "Crecimiento y características del empleo de los inmigrantes en España", Revista del Ministerio de Trabajo e Inmigración, 80: 237-253.

Rinken, Sebastian [2010], "La evolución de las actitudes ante la inmigración en tiempos de crisis económica: un análisis cualitativo", en E. Aja, J. Arango y J. Oliver Alonso, Inmigración y crisis económica: Impactos actuales y perspectivas de futuro, Barcelona, СIDOB Edicions. 


\section{Capítulo 8 \\ NuEVAS DINÁMICAS DE LOS MERCADOS \\ LABORALES Y EDUCATIVOS DE PROFESIONALES \\ CON LA MASIFICACIÓN DE LA COBERTURA \\ Y LA EXPANSIÓN DEL EGRESO}

Claudio Rama*

\section{INTRODUCCIÓN}

Estamos asistiendo a la conformación de un nuevo modelo de acumulación de capitales [Pérez, 2005] que al tiempo implica un nuevo modelo de migraciones [Aragonés, 2011] y un cambio en los procesos de formación del capital humano a escala global. Ello parece expresarse en una nueva división internacional del trabajo con un centro estructurado en torno a la innovación, la investigación y el empleo de mano de obra altamente capacitada,

"Decano de la Facultad de Ciencias Empresariales de la Universidad de la Empresa (UDE) de Uruguay. Economista (UCV), Master en Gerencia de la Educación (UJMV), Doctorado en Educación (UNESR), Doctorado en Derecho (UBA), y tres postdoctorados (UNICAMP; UNESR, UFF). Fue Director del Instituto Internacional de la UNESCO para la Educación Superior en América Latina y el Caribe (IESALC). Dictó cursos y conferencias en más de 170 instituciones y eventos académicas en 30 países. Tiene 21 libros propios, 10 libros como co-editor, 78 artículos publicados en libros y revistas arbitradas y cientos de artículos en diversos diarios. Recibió en dos ocasiones el Premio Nacional de Literatura del Uruguay por sus escritos académicos y 3 distinciones de Doctor Honoris Causa (UNMSM, ULADECH, UIGV). Correo electrónico: <claudiorama@gmail.com>. 
crecientes migraciones selectivas de profesionales así como una masificación y articulación de los sistemas educativos y especialmente de la educación superior en el ámbito mundial. Esta dinámica se soporta en un sistema educativo crecientemente mundial en el cual se produce una sintonía entre los procesos educativos nacionales [Azevedo, 2007] que impulsa una estandarización educativa que a su vez contribuye a viabilizar un escenario en el cual los desequilibrios entre los mercados laborales y educativos se ajustan también mediante la movilidad internacional derivada de una mayor propensión a la emigración profesional. Al tiempo, la expansión educativa permite la creación de capacidades y también la constitución de niveles de subempleo y de desempleo profesional que facilitan la instalación de procesos productivos intensivos en trabajo capacitado con menores estructuras de costos.

La teoría de los sistemas educativos mundiales plantea que las políticas nacionales de educación muestran el predomio creciente de los componentes internacionales más allá de los particularismos nacionales o regionales y que se comienzan a conformar dinámicas educativas y laborales crecientemente articuladas en escala global. La educación se inscribe en una globalización de baja intensidad por su componente social y la dominancia de las resistencias sociales, así como sus dinámicas internacionales son lentas, difusas y ambiguas, y cuyos componentes se articulan en el marco de la conformación como un sistema educativo mundial [Hüfner, 1992]. La teoría de los sistemas globales se sustenta en los estudios de Wallerstein y Braudel que conciben la conformación de un sistema histórico desarrollado alrededor de la expansión del mercado mundial y de las tensiones que se generan en el modelo sociopolítico y de regulación del Estado-nación [Azevedo, 2007].

La región está inserta en estos procesos de dimensión internacional en una de sus dimensiones por medio de la conformación de una creciente masificación de la cobertura universitaria educativa y de una dinámica económica global que aumenta el uso intensivo de recursos humanos altamente capacitados. Tales 
realidades a su vez plantean cambios en los escenarios tradicionales de los mercados laborales profesionales, en tanto afectan en forma destacada los niveles de empleo, salarios, desempleo y migración así como en las lógicas tradicionales institucionales y curriculares de formación de capital humano. En este nuevo escenario, aún a pesar de que la región políticamente no lleva adelante una fuerte política de internacionalización en el ámbito regional, sin embargo, los mercados profesionales se tornan tanto directa como indirectamente in7ternacionales, mientras los desequilibrios locales se expresan en un aumento de la diversidad de opciones de trabajo y educación, entre las cuales destaca un aumento de la presión hacia una migración estructural de los recursos humanos especializados a medida que los países aumentan su tasa de cobertura terciaria en el actual escenario de la división internacional del trabajo y que cambian los perfiles de las capacidades requeridas en los empleos en los países centrales.

Tal proceso sin embargo tiene limitaciones derivadas de las regulaciones del ejercicio profesional en los países receptores, de políticas selectivas a la migración profesional en esos mercados y de la existencia de requisitos de estándares superiores de la calidad de las certificaciones, como requisitos para viabilizar la movilidad profesional así como del grado de diferenciación y masificación de los sistemas educativos, lo cual impulsa la búsqueda de nuevas articulaciones universitarias con el mundo del trabajo que incentivan las reformas de la calidad y la internacionalización universitaria.

\section{EXPANSIÓN DE LA MATRÍCULA}

Y DEL EGRESO DE PROFESIONALES

EN AMÉRICA LATINA

La matrícula universitaria en América Latina muestra tasas quinquenales de crecimiento continuo desde los años sesenta. El motor del impulso a esta masificación de la educación superior esta dado por el diferencial de salarios de los distintos niveles de formación 
y especialmente el universitario, de la tasa de desempleo entre la población con y sin estudios así como de las expectativas futuras de las personas y de las sociedades [Rama, 2009]. El diferencial de salarios se constituye en el mayor impulsor de la escolarización terciaria: en dólares constantes, el ingreso de la población ocupada que tiene la educación primaria terminada era de 434 dólares, en tanto que aquella que tiene secundaria completa era de 686 dólares o sea, mientras que para los que tienen universidad completa su ingreso promedio es de 1964 dólares, o sea 4.52 veces superior. Con una media de ingresos salariales de 666 dólares, los profesionales tenían un ingreso monetario tres veces superior [CEPAL, 2007]. Estas estructuras salariales de los profesionales históricamente descansan tanto en su productividad más elevada, en los acuerdos salariales sobre todo en el sector público, en los bajos niveles de desempleo de los profesionales así como en el modelo de crecimiento económico con mayor demanda de competencias laborales. ${ }^{1}$ Tal realidad salarial ha aumentado en los años noventa asociada con un cambio en las demandas de competencias con la apertura externa generalizada. Sin embargo, esto no es nuevo, ya que en la mayoría de los países tradicionalmente la tasa de desempleo de las personas con educación superior es la mitad de quienes no la tienen, además sus tiempos de desempleo son menores.

Múltiples estudios han mostrado históricamente las altas tasas de retorno de la educación y sobre todo de la pública dada su gratuidad generalizada en la región. En este sentido, más allá de la problemática de la limitación de cupos y de los ingresos familiares, son los niveles de las tasas de retorno uno de los factores determinantes de la demanda educativa sobre el sector privado en tanto el sacrificio del pago de la matrícula está asociado con los retornos esperados superiores. En este contexto de primas

\footnotetext{
${ }^{1}$ La situación y la dispersión salarial varía ampliamente y se constituye en uno de los factores determinantes del crecimiento de la matrícula terciaria. Según un informe del Banco Mundial en Panamá para 2008 mientras que el ingreso con educación primaria era de 293 los profesionales (educación universitaria y más) tenían un ingreso de 1150 dólares por mes, 3.92 veces más, mostrando la diversidad de la región y de sus mercados laborales.
} 
salariales por capacitación asociado al perfil de las nuevas demandas, se ha producido en forma continua un aumento de la oferta profesional, que facilita la transformación de las estructuras productivas. La vigorosa modernización en curso en la región deriva de un ciclo virtuoso de trabajo por el cual el aumento de profesionales facilita a su vez cambios en la composición orgánica y por ende nuevamente un aumento de las demandas de mayores capacidades asociado a esas inversiones y transformaciones en el trabajo.

Sin embargo, es este un ciclo virtuoso en tensión permanente ya que requiere la existencia de una sobreoferta de profesionales como condición para las modernizaciones en los procesos de trabajo y permitir impulsar la mayor utilización de la mano de obra profesional. En este contexto, la oferta y la sobreoferta profesional local facilitan tanto la modernización productiva y la creación de puestos de trabajo profesionales, como también la sustitución de trabajo no calificado por el profesional en puestos que no siempre requerirían tales perfiles de formación. Ello promueve una puerta circulatoria del mercado de trabajo al sustituir trabajadores de menos calificación así como también los niveles de emigración de algunos de estos sectores. Así, los desequilibrios educativos con respecto del trabajo se constituyen en una variable de primera importancia en la dinámica del empleo, la migración y los salarios.

En la década pasada en la región el crecimiento de la matrícula terciaria ha continuado tanto en el sector público como en el sector privado lo que ha facilitado mayores niveles de egreso [Rama, 2011b]. Tal expansión se asocia con la mayor modernización productiva, al aumento de los recursos fiscales y de los ingresos de las familias. La expansión pública fue mayor que en los noventa como resultado del aumento de los recursos y de las plazas y cupos públicos, del aumento de la cantidad de instituciones públicas, especialmente en Brasil, México y Venezuela, del aumento de la gratuidad en general y específicamente en Ecuador y Venezuela, y del aumento generalizado de los precios de las matrículas privadas ante las exigencias de los recién creados sistemas de aseguramiento de la calidad. Por su parte, en el sector privado el 
aumento de la matrícula fue menor que en los años noventa y estuvo asociada con el aumento de las escalas de las instituciones, con una menor creación de instituciones y con una gestión más empresarial con aumento de las escalas y de eficiencia, así como con un aumento de los recursos de las personas. El crecimiento se asoció con una mayor calidad de las instituciones privadas derivado de mayores exigencias de la política pública que también implicaron aumentos de los costos educativos y que sólo pudieron ser cubiertos gracias al incremento de los ingresos económicos de las familias durante la década. Todo ello ha permitido acompañar la expansión de la demanda asociada con la generalizada expansión económica en casi toda la región que está requiriendo mayor dotación de recursos humanos de alta calificación y que, además, favoreció la creación de sistemas de aseguramiento de la calidad. En esa década, el sector privado aumentó en términos absolutos aunque con tasas mucho menores que en la década anterior.

El aumento combinado de la matrícula de ambos sectores, público y privado, tuvo también una contribución derivada de la expansión de ofertas de educación a distancia. En Brasil y México el peso de la educación a distancia comenzó a ser muy significativo y alcanzó entre 10 y 16\%, respectivamente, de los nuevos estudiantes como resultado de una política pública, decididamente proclive a esta modalidad. Algunos países con muy rápidos cambios en los mercados laborales fueron los que más privilegiaron la expansión de modelos flexibles y a distancia como Brasil, México, República Dominicana, Perú y Costa Rica.

La elevada tasa de expansión de nuevas instituciones que alcanzó a 1.3 instituciones por día entre 1994 y el 2005 [CINDA, 2008], se mantuvo aunque a tasas menores derivado de mayores exigencias de licenciamiento y menos disposición de la demanda a nuevas ofertas. Además, en casi todos los países el establecimiento de sistemas de aseguramiento de la calidad condujo a limitaciones del ingreso de nuevas instituciones universitarias. En varios países se produjo una sobreoferta de instituciones que ha comenzado a favorecer la concentración institucional por compra de universidades y lógicas de mercado, donde las instituciones con 
mayores escalas pueden alcanzar precios relativamente más competitivos. El crecimiento de la oferta de programas se mantuvo en todas las instituciones y, sobre todo, en el sector privado, lo cual a su vez coadyuvó al aumento de la concentración referida que se consolidó como nueva modalidad de crecimiento en el sector privado a diferencia de las décadas anteriores donde la diferenciación institucional era el mecanismo dominante de expansión privado [Rama, 2012].

Se mantuvo el proceso de feminización de la matrícula, pero su dinámica tiende a desacelerarse. La expansión de la cobertura al ingresar en sectores sociales de menos capital humano muestra lentitud de la tendencia a la feminización, e inclusive en Venezuela, se ha revertido al verificarse un aumento de la masculinización de la matrícula terciaria en la medida que ingresan más jóvenes de sectores de menores ingresos apoyados con amplios planes de becas públicos.

Como se observa en el cuadro 1, visto en el largo plazo desde 1970 hasta 2010, la matrícula terciaria ha tenido una verdadera explosión, con un incremento continuo de 6.6\% y más allá de la elevada tasa de deserción y abandono, se ha producido un aumento continuo de los egresados universitarios. Para el 2010 la cobertura de educación superior en América Latina rondo 41\% de cobertura con una matrícula de 21.5 millones de estudiantes y una incidencia de $55 \%$ de mujeres con cerca de más de $50 \%$ de los estudiantes localizados en instituciones privadas [UIS, 2010; OCDE/CEPAL, 2011]. Tal expansión de la matrícula terciaria en la región al calor de la demanda y de los mayores salarios tendió a ser superior al crecimiento de la población, del empleo y del producto bruto, impulsando cambios en la estructura laboral tanto en el ámbito interno como externo con una mayor propensión hacia la emigración y al desempleo.

Correlativamente con el aumento de la matrícula, el egreso también muestra un crecimiento constante y representa entre 6 y $13 \%$ de la matrícula en los distintos países dependiendo del nivel de selección de acceso, de la presencia privada y de la presión de la demanda de empleo sobre los jóvenes, y de la composición 
socio estudiantil, siendo superior al aumento del producto bruto tanto en la región como de los países. Para toda América Latina, tomando el periodo de diez años entre 1994 y el 2005, mientras que el producto interno bruto (PIB) pasó de 100 a 132.8, la matrícula terciaria saltó de 100 a 209.6, o sea 58\% más. Si tomamos el crecimiento del producto per. cápita que pasó de 100 a 111.6 frente a la matrícula, el desequilibrio fue superior, al aumentar los estudiantes en $87 \%$ frente al incremento del producto per cápita [IESALC, 2006]. Dado este crecimiento del egreso en forma superior al crecimiento de la población, se produjo un aumento sostenido de la participación de los profesionales en la población económicamente activa que va de 9 a $15 \%$ en los distintos países, pero en todos en sostenido proceso de crecimiento.

Si bien los mercados internos han incorporado a la mayoría de los egresados, en tanto el cambio de los patrones de producción requiere más recursos humanos profesionales por unidad de producto, pero al tiempo la dimensión del egreso profesional ha comenzado a ser superior a los niveles de absorción. Es necesario, sin embargo, relativizar e identificar el nivel de egreso, el cual se localiza fundamentalmente en los sectores de los quintiles superiores, tanto derivado de la deserción y conclusión estratificada del ciclo secundario, como de la propia dinámica de deserción social de la educación superior. Para la región, se calcula que entre los jóvenes de 25 a 29 años, sólo 8.7\% logra concluir al menos cinco años de educación terciaria, resultado de marcadas diferencias por quintiles de ingreso: mientras que sólo $0.6 \%$ de los egresados son del primer quintil de ingresos $22 \%$ corresponde a los del último quintil [OCDE/CEPAL, 2011].

Sin embargo, el egreso ha aumentado y también se ha producido un aumento del desempleo profesional cuya tasa en 20 años aumentó $40 \%$, con un aumento de $10 \%$ quinquenal y $2 \%$ anual, al pasar de $4.69 \%$ en 1990 a $6.63 \%$ en 2010 como se ve en el cuadro anterior. Así, mientras que el incremento quinquenal de la matrícula fue del orden de $40 \%$, el nivel de incremento quinquenal del desempleo de los profesionales aumento $10 \%$ en promedio en la región [CEPAL, 2011]. 


\begin{tabular}{|c|c|c|c|c|c|c|c|}
\hline 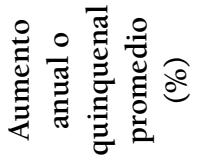 & $\begin{array}{l}\forall \\
\dot{\sigma}\end{array}$ & $\stackrel{n}{*}$ & $\stackrel{\sim}{\sim}$ & $\stackrel{\odot}{\forall}$ & \& & & $\stackrel{0}{-1}$ \\
\hline$\stackrel{\circ}{\stackrel{1}{0}}$ & $\hat{n}$ & ஏ & 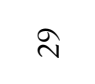 & $\stackrel{0}{n}$ & $i n$ & $\begin{array}{l}\stackrel{2}{0} \\
\text { r }\end{array}$ & $\hat{\sigma}$ \\
\hline 命 & $\frac{\sqrt{a}}{n}$ & $\stackrel{\infty}{\dot{m}}$ & $\begin{array}{l}\infty \\
i n \\
m\end{array}$ & $\stackrel{\sim}{i}$ & $\stackrel{\nabla}{\stackrel{\nabla}{+}}$ & హิ & $\begin{array}{l}\text { ڤ్ } \\
\text { in }\end{array}$ \\
\hline ஓ̊ & $\begin{array}{l}\text { ò } \\
\text { ㄱ }\end{array}$ & $\stackrel{\nabla}{\ddot{v}}$ & $\stackrel{\bullet}{\sim}$ & $\stackrel{\sim}{\sim}$ & $\stackrel{m}{\infty}$ & ర్ర & $\stackrel{i n}{\tilde{r}}$ \\
\hline ลू & $\underset{\infty}{\stackrel{\Xi}{ \pm}}$ & $\underset{\infty}{\stackrel{0}{*}}$ & $\underset{\sim}{\sim}$ & 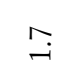 & $\stackrel{0}{\stackrel{\sim}{v}}$ & $\hat{\alpha}$ & $\stackrel{\vartheta}{\sigma}$ \\
\hline 요 & $\begin{array}{l}\hat{\theta} \\
0\end{array}$ & $\underset{\bullet}{\stackrel{\oplus}{ }}$ & $\stackrel{\eta}{r}$ & 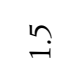 & $\stackrel{\check{\jmath}}{\check{\jmath}}$ & ¿o & $\underset{\stackrel{\sigma}{\sigma}}{\text { }}$ \\
\hline $\begin{array}{l}n \\
\infty \\
\stackrel{2}{-1}\end{array}$ & $\begin{array}{l}\infty \\
\tilde{n} \\
n\end{array}$ & $\begin{array}{l}\infty \\
1 \\
n\end{array}$ & $\stackrel{\varrho}{0}$ & $\stackrel{n}{-}$ & 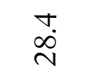 & $\vec{b}$ & \\
\hline 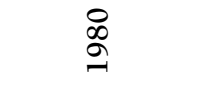 & $\begin{array}{l}\hat{\mho} \\
\forall\end{array}$ & $\stackrel{\sim}{ \pm}$ & $\stackrel{\vartheta}{10}$ & $\tilde{m}$ & $\stackrel{0}{+}$ & $\underset{\sim}{\sim}$ & \\
\hline $\begin{array}{l}n \\
\\
\end{array}$ & 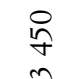 & $\stackrel{\Re}{\sim}$ & $\stackrel{n}{ \pm}$ & $\stackrel{-}{-}$ & $\stackrel{0}{\circ}$ & $\stackrel{\circ}{\stackrel{ }{\sim}}$ & \\
\hline $\begin{array}{l}0 \\
2 \\
2\end{array}$ & 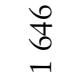 & $\underset{n}{n}$ & & $\stackrel{0}{0}$ & & $\stackrel{8}{\varrho}$ & \\
\hline & 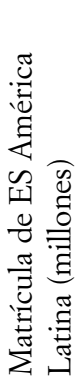 & 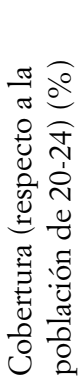 & 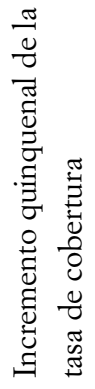 & 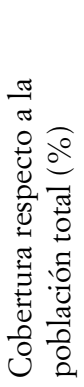 & 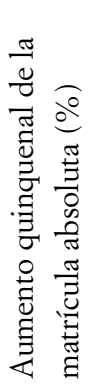 & 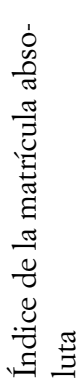 & 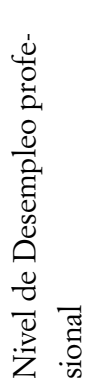 \\
\hline
\end{tabular}


En América Latina, para el año 2008 los egresados universitarios alcanzaron la cifra de 2225 mil [uIs, 2010]. Para 2010, se calcula que los egresados serán más de 2.5 millones. En el ámbito regional la eficiencia de titulación es aproximadamente $11 \%$ de los estudiantes terciarios con fuertes diferencias de eficiencia de titulación en los distintos países que van desde 6 a $20 \%$ del porcentaje de los graduados con respecto a la matrícula. El aumento de los egresados ha tenido una tendencia constante de crecimiento asociada con el aumento de la cobertura, la feminización, la privatización por su mayor eficiencia de titulación, con el aumento de la eficiencia de los sistemas y los cambios en los procesos educativos como la titulación sin tesis. Los sistemas educativos han flexibilizado sus procesos para permitir mayores niveles de egreso. Al tiempo cabe destacar que también estos procesos han sido contrarrestados por mayores exigencias de controles de calidad y un aumento de la deserción al incorporarse nuevos grupos sociales con menos capital humano y, en esta década, por un aumento del empleo y del crecimiento económico generalizado que ha llevado a una incorporación al trabajo antes de la titulación y la conclusión de los estudios. ${ }^{2}$ La deserción universitaria se asocia no sólo con la vocación o la situación económica [CINDA/IESALC, 2006], sino con condiciones de alta demanda de trabajo en los niveles de retornos que facilitan la no conclusión de los estudios.

La situación de algunos países con respecto del egreso terciario nos permite observar tendencias generales desde el lado de la oferta profesional que contribuyen a conformar y complejizar el mapa del mercado de profesionales y de sus dinámicas en el actual contexto.

${ }^{2}$ El nivel de egreso es, sin embargo, aún bajo comparado con otros en el mundo. Mientras que el promedio de titulación en Chile, el país más eficiente de la región, es de 6.32 años, el de los países de la OCDE bordea los 4.32 años. Hay aún un amplio camino para recorrer que tenderá a aumentar los niveles de egreso y, por ende, a futuro de una posible saturación en los mercados profesionales. 


\section{Cuadro 2. Análisis de casos nacionales de dinámicas de egreso}

\begin{tabular}{|c|c|}
\hline Argentina & $\begin{array}{l}\text { Sobre una población universitaria de } 1729560 \text { en el } 2009 \text { los } \\
\text { egresados fueron } 105 \text { 068, } 6.07 \% \text { una de las más bajas tasas de } \\
\text { titulación de la región. Entre } 1999 \text { y } 2009 \text { los egresados pasaron } \\
\text { de } 54957 \text { a } 98129 \text {, que significó un crecimiento constante de } \\
6 \% \text { interanual, diferenciado entre el sector público ( } 5.8 \% \text { ) y el } \\
\text { privado (6.5\%). El sector privado pasó de representar } 27.8 \% \text { de } \\
\text { los egresados en } 1999 \text { a } 29.2 \% \text { en } 2009 \text {. }\end{array}$ \\
\hline México & $\begin{array}{l}\text { Los egresos totales de la educación superior (2001-2011) fue- } \\
\text { ron } 4076084 \text { con una tasa promedio de aumento interanual de } \\
4.8 \% \text {. Esta tasa de egreso fue sensiblemente superior que el in- } \\
\text { cremento del PIB de } 1.8 \% \text { interanual. El incremento del producto } \\
\text { per cápita ( } 0.67 \% \text { en } 30 \text { años) hace más sensible los desequilibrios } \\
\text { entre oferta y demanda. }\end{array}$ \\
\hline Costa Rica & $\begin{array}{l}\text { El sector privado alcanzó } 63 \% \text { de la matrícula universitaria (2010) } \\
\text { y la emisión de títulos de educación superior alcanzó } 292 \text { mil di- } \\
\text { plomas entre } 2001 \text { y } 2010 \text {, con un incremento anual promedio de } \\
5.7 \% \text {. Según un estudio del Observatorio Laboral de Profesiones } \\
\text { del Consejo Nacional de Rectores (Conare), las personas que con- } \\
\text { cluyeron estudios universitarios han tenido mejores posibilidades } \\
\text { de empleo y de salario [Gutiérrez y Kikut, 2010]. De los profe- } \\
\text { sionales } 66 \% \text { se graduaron en universidades privadas siendo } 60 \% \\
\text { mujeres. Un estudio identificó que } 93 \% \text { de los egresados trabajaba, } \\
82 \% \text { a tiempo completo, } 11 \% \text { a menos de tiempo completo, de } \\
7 \% \text { restante, } 5 \% \text { no trabaja por diversas razones y solo } 2 \% \text { buscaba } \\
\text { trabajo. El desempleo profesional era muy bajo y diverso por profe- } \\
\text { siones y menos de la mitad del desempleo nacional. }\end{array}$ \\
\hline Uruguay & $\begin{array}{l}\text { Entre } 2005 \text { y } 2010 \text {, los egresos terciarios pasaron de } 5514 \text { a } 7223 \text {, } \\
\text { con un crecimiento anual de } 6.1 \% \text {. Para } 2011 \text {, el mercado de } \\
\text { trabajo para mayores de } 25 \text { y menos de } 65 \text { años, se distribuía } \\
\text { en } 11 \% \text { de personas con título universitario ( } 16 \text { años y más de } \\
\text { estudio), } 6.4 \% \text { con entre } 13 \text { y } 15 \text { años de estudio (educación me- } \\
\text { dia), } 22.5 \% \text { que terminó entre } 10 \text { y } 12 \text { años de estudio (media } \\
\text { incompleta); } 19.1 \% \text { de la población en edad de trabajar que sólo } \\
\text { tenía entre } 7 \text { y } 9 \text { años de estudio (sólo el primer ciclo de la media } \\
\text { incompleta) y } 33.5 \% \text { de la población que sólo tenía entre } 4 \text { y } 6 \\
\text { años de estudio (no terminaron primaria). El sesgo por género } \\
\text { mostraba una mayor propensión del egreso de las mujeres en la } \\
\text { medida que aumentan los años de estudio. Para } 2011,20.1 \% \text { de }\end{array}$ \\
\hline
\end{tabular}




\begin{tabular}{|c|c|}
\hline & $\begin{array}{l}\text { las mujeres de } 25 \text { años o más, tenían } 13 \text { o más años de educa- } \\
\text { ción, frente a } 14.3 \% \text { de los hombres, mostrado las disparidades } \\
\text { de género en favor de la mujer dentro del campo educativo, en } \\
\text { tanto } 13 \% \text { de las mujeres terminaron la universidad y solo } 8.6 \\
\text { de los hombres, más allá de una diferencia de } 10 \% \text { en los niveles } \\
\text { de remuneración en favor de los hombres [MEC, 2011; INE, 2012]. }\end{array}$ \\
\hline Perú & $\begin{array}{l}\text { En } 2010 \text { hubo } 82838 \text { graduados y } 60.750 \text { representando éste úl- } \\
\text { timo guarismo } 7.75 \% \text { de los estudiantes de grado matriculados. Si } \\
\text { el porcentaje se calcula sobre los graduados y sobre el total de estu- } \\
\text { diantes (grado y postgrado), se alcanzaría } 9.87 \text { de los estudiantes de } \\
\text { grado matriculados [ANR, 2010]. La graduación al mismo tiempo se } \\
\text { asocia con la concentración. En tanto hay } 133 \text { universidades, sólo } \\
10 \text { universidades ( } 5 \text { públicas y } 5 \text { privadas) tuvieron en ese año a } \\
33193 \text { graduados, que representaron } 40 \% \text { del total de graduados } \\
\text { por el sistema universitario, mostrando como la concentración y el } \\
\text { tamaño institucional afecta en mayores niveles de titulación. }\end{array}$ \\
\hline Colombia & $\begin{array}{l}\text { Entre } 2001 \text { y } 2007 \text { se otorgaron } 1054865 \text { títulos terciarios, de } \\
\text { los cuales } 54 \% \text { fueron de mujeres y } 62 \% \text { procedentes de institu- } \\
\text { ciones privadas, siendo } 64.8 \% \text { universitaria, } 12.5 \text { tecnológica, } 17 \\
\text { de especialización y } 1.53 \% \text { entre maestría y doctorado [MEN, } \\
2008 \text { ]. Con ese total, } 82.9 \% \text { son graduados cotizantes en los } \\
\text { diversos sistemas de seguridad social, revelándose que fueron su- } \\
\text { periores en promedio de } 10 \% \text { los salarios de aquellos graduados } \\
\text { de instituciones de educación superior acreditadas. Para } 2007 \text {, } \\
\text { un egresado de nivel técnico-profesional ganaba en promedio } \\
40 \% \text { más que aquellos que sólo terminaron el bachillerato, en } \\
\text { tanto que los que tenían doctorado alcanzaban salarios de engan- } \\
\text { che } 80 \% \text { superior al promedio de los salarios del nivel técnico. } \\
\text { En todos los niveles de formación terciarios los hombres tenían } \\
\text { promedio de salarios superiores de } 12 \% \text { frente a las mujeres. A } \\
\text { partir de una muestra de } 25 \text { mil personas, } 82 \% \text { de los encuesta- } \\
\text { dos respondió que su trabajo está directamente relacionado con } \\
\text { lo que estudió. Las áreas de conocimiento con mayor número de } \\
\text { egresados, no coinciden con las de mayor remuneración. }\end{array}$ \\
\hline
\end{tabular}

Sin embargo, las tasas de egreso en la región son bajas relativamente y ello ha sido incentivado por mayores exigencias de controles de calidad y un aumento de la deserción al incorporarse nuevos grupos sociales con menos capital humano, así como por el impacto del aumento del empleo y del crecimiento econó- 
mico que en varios países ha impulsado un ingreso anticipado en los mercados de trabajo [MEC, 2011; INE, 2012]. En algunos mercados, la alta deserción universitaria se asocia a bajos retornos profesionales.

Los casos referidos permiten verificar tasas crecientes de titulación en toda la región incentivadas por la masificación de la cobertura y de una mayor eficiencia de titulación resultado de múltiples variables, entre las cuales la mayor diferenciación de los sistemas universitarios, de sus modalidades y de la localización geográfica, así como del aumento de las ofertas y de la competencia que han derivado en una mayor flexibilización de los mecanismos de egreso. Otros factores también han contribuido con los mayores niveles de egreso, entre los cuales el crecimiento del sector privado, en tanto el sacrificio de rentas directas impulsa una mayor eficiencia de titulación, así como la propia feminización de la matrícula que implicó también una mayor eficiencia de titulación derivado del mayor nivel de deserción y abandono tradicional de los hombres por su ingreso más temprano en el mercado laboral en tanto cabeza de familia tradicional [Papadópulos, 2005; de Vries, 2011]. También en la década pasada el aumento de los recursos en los sistemas terciarios públicos ha contribuido para mejorar la eficacia de titulación.

Todo ello ha facilitado el aumento de la cobertura y del egreso, y el nacimiento de una tendencia a la sobreoferta de profesionales y comienza a plantear cambios en los mercados laborales y nuevas articulaciones educación-trabajo. Como resultado, se constata en toda la región, más allá de la diversidad de situaciones por profesiones en el nivel de empleo, un peso creciente de profesionales y de egresados del sector privado, un aumento de profesionales en la población trabajadora, una feminización de los mercados laborales profesionales derivado de una mayor incidencia en el egreso actual de profesionales y, al tiempo, un aumento en los niveles de desempleo y de la emigración universitaria. Asociado con ello se destaca también una tendencia a la baja de la tasa interna de retorno de los profesionales en casi 
todos los mercados derivada del aumento del desempleo universitario, del aumento de la oferta de profesionales en los mercados laborales y del aumento de los costos de la educación privada resultado de un aumento de la competencia en un contexto de mayores exigencias de calidad. ${ }^{3}$ Tal aumento de la competencia y la caída relativa de las remuneraciones profesionales por sobreoferta, ha limitado a su vez trasladar los aumentos de costos a los precios de las matrículas. Incluso en varios países como Argentina, Venezuela y Ecuador, los precios de las matrículas han sido regulados por los gobiernos.

La caída de la tasa de retorno ha sido diversa para las distintas profesiones y procedencias institucionales en los países de la región en los últimos años [Hernández, 2010]. Más allá de su efecto en los ingresos, ha favorecido procesos de concentración institucional con aumento de las escalas en el interior del sector privado para poder ofertar a precios de matrículas relativamente competitivos [Rama, 2012]. La caída de los retornos profesionales fundamentalmente de egresados del sector privado y el aumento de precios de sus matrículas recanalizaron una mayor demanda social sobre la educación pública dado su carácter gratuito en la región. En varios países los precios de las matrículas en las instituciones de elite están muy cerca de los salarios de enganche de los jóvenes y, aunque en el largo plazo la tasa de retorno siga elevada, en los primeros años de trabajo es muy baja.

\section{CAMBIOS EN LOS CONTEXTOS DE LOS MERCADOS LABORALES PROFESIONALES}

El aumento del egreso profesional ha sido relativamente absorbido en las últimas décadas, derivado de la modernización de la

${ }^{3}$ La tasa de retorno se calcula estableciendo el valor descontado de los costos directos e indirectos y los beneficios en el tiempo igualados a cero y resolviendo por la tasa de descuento implícita [Vila 2001]. 
estructura productiva asociada con la apertura, el cambio tecnológico y la expansión de modelos de exportación primarios con mayor valor agregado por incorporación de más tecnologías gracias al aumento de los precios internacionales. Ello se expresa en el aumento de la proporción de profesionales en la población económicamente activa (PEA) que en toda la región que oscila entre 8 y 15\%. La incorporación de tecnologías en el proceso económico y que se ha constituido en el mayor impulsor del crecimiento en contextos de apertura, se muestra en una mayor demanda de trabajadores altamente calificados y profesionales [Carnoy, 2006]. Desde los noventa, la apertura económica incrementó la competencia en los distintos mercados así como las inversiones en tecnológicas que a su vez impulsan el mayor empleo profesional. Sin embargo, ello se ha dado asociado con un aumento del componente de profesionales en la migración, un crecimiento del empleo profesional en puestos previamente ocupados por técnicos o administrativos, el aumento de la matrícula de posgrados, la caída relativa de los salarios de los profesionales y, sobre todo, de aquellos en instituciones y programas no acreditados, así como un aumento del nivel de desempleo de los profesionales y una reducción de la diferencia salarial entre hombres y mujeres.

Históricamente los salarios de los profesionales han sido superiores a los salarios de las personas sin formación en la región. ${ }^{4}$ Ello es resultado de que los retornos en educación terciaria son superiores en los países en desarrollo por la escasez permanente de capital humano especializado [Psacharópulos, 1994]. En la década de los noventa, tal brecha de desequilibrios en los mercados de trabajo y educación se incrementó y los ingresos de los

${ }^{4} \mathrm{Ha}$ habido muchos estudios en la materia. Sin embargo, a pesar de haberse comprobado exhaustivamente que la inversión en capital humano mediante una mayor educación formal es importante de los ingresos de los jefes de hogar, en un estudio de México se verificó también que los factores de carácter territorial y social, así como el tamaño del establecimiento y el tipo de actividad económica son relevantes en la determinación de los ingresos de los jefes de hogar [Varela y Urciaga, 2012]. Igualmente afectan la calidad de la institución, el género y el tipo de mercado laboral. 
trabajadores profesionales con título aumentaron sobre los salarios de las personas sin formación especializada [Weller, 2004; Amarante, 2011] como resultado de una apertura, del cambio tecnológico y del inicio de una transformación en el padrón de acumulación de capital que incrementó la demanda de trabajo con mayor capacitación. Sin embargo, a medida que aumenta el egreso universitario, las dinámicas de los mercados laborales muestran en la década de 2000 que los diferenciales salariales en algunos países de la región no parecen ensancharse en igual dimensión antes. Ello respondería además, a cambios en las políticas públicas con un persistente aumento del salario mínimo que ha reducido comparativamente la tasa de retorno profesional. Asociado con esto hay un diferenciado aumento del desempleo profesional. Es claro que las diferencias salariales son estructurales y se asocian con el efecto del aumento de la formación universitaria en el incremento de la productividad que deriva (aunque en diversa proporción en función de los niveles de desempleo y competencia, así como de la calidad de las instituciones) en un aumento de los salarios y menores niveles de desempleo.

Así (salarios y empleo) son los componentes que han retroalimentado el ciclo de aumento continuo de la matrícula universitaria y la propensión a la inversión en educación superior por parte de las familias, que se soporta en la teoría del capital humano que plantea que la educación es una inversión que genera beneficios salariales asociados con la productividad de las competencias profesionales adquiridas. Sin embargo, este marco conceptual se concibe como un modelo simple de causa efecto, en el cual el nivel de remuneración de los mercados y los costos directos e indirectos educativos establecen la tasa interna de retorno de la inversión en formación. En este escenario la determinación de los salarios es afectada directamente por el aumento de la cobertura y los egresos por aumento de la eficiencia y diferenciación de las instituciones, la mayor articulación educación mercado, expansión privada, feminización, flexibilización de las formas de titulación y reducción de los tiempos de estudios del grado. 
Sin embargo, el cambio no se produce sólo en los mercados educativos mediante esas reformas universitarias, sino que también se produce en los mercados laborales. Entre esos cambios destaca una dinámica de internacionalización de ambos mercados y una mayor movilidad profesional así como la aparición de la educación transfronteriza, el teletrabajo y el traslado de la producción. Ambos mercados y dinámicas se internacionalizan. En este contexto de cambios en los niveles de oferta y de demanda, los salarios no están asociados directamente con los niveles de la productividad marginal del trabajo profesional, sino que están acotados por los niveles de oferta y demanda de profesionales, así como a las formas que asume el trabajo y el empleo internacional. Sin duda, los incrementos de capacitación tienen el techo dado en tanto el beneficio marginal sea igual a cero, pero de manera inversa descendente, los salarios pueden caer en función con la dotación de recursos del mercado de oferta de profesionales, sin limitaciones en el corto plazo a la caída de la tasa de retorno y de salarios. Al tiempo, si los salarios mínimos o de baja capacitación suben, la caída de los salarios profesionales deriva en una relativa proletarización de las capas medias universitarias que se sostiene sobra la base de la gratuidad de la educación superior y un aumento de la propensión a emigrar.

Con esta lógica de cambios una de las transformaciones en los mercados laborales en la región se asocia con la reducción del empleo industrial y agrícola, y la expansión del empleo en los servicios con un incremento constante del empleo de personas con mayor capacitación, disminuyendo el empleo formal de personas de baja capacitación. La productividad en el sector formal local está asociada con la educación superior y se registra que, por cada año de estudios en el promedio de escolarización de la fuerza de trabajo, la productividad se incrementa entre 5 y 15\% [CEPAL, 2007], más allá del sector productivo de inserción del trabajo.

En este contexto, el crecimiento de la matrícula y del egreso en la escala regional tiende a ser superior que el producto y que la demanda local de empleo, derivando en una tendencia hacia la 
sobreoferta de educación superior, a su vez facilitada por las propias características de los desequilibrios estructurales en los mercados de oferta y demanda, como por la existencia de mercados internacionales de colocación de excedentes de personal profesional asociado con las tendencias demográficas de envejecimiento y de desarrollo desigual del avance hacia las sociedades del conocimiento. ${ }^{5}$ La tendencia a la sobreoferta profesional, favorecida por la gratuidad, el aumento de la demanda y la mayor eficiencia de titulación, muestra que facilita el aumento de la emigración profesional como un creciente componente estructural de los mercados profesionales con sus limitaciones asociadas con la calidad de los aprendizajes, la baja cobertura relativa por estratificación social y las limitaciones de los colegios al ejercicio profesional de los no egresados locales. Los niveles de desempleo profesional y las tasas de retornos se constituyen en los mayores impulsores de la emigración profesional junto con la demanda externa y las posibilidades de trabajo.

La sobreoferta y la sobre calificación se constituyen en formas de funcionamiento de esos mercados laborales que al tiempo actúan como mecanismos para acotar los aumentos salariales. Siguiendo a Thurow, la sobre educación es el mecanismo de competencia en los mercados profesionales y de mejoramiento de los salarios en tanto estrategia de sobrevivencia y mejoramiento de los profesionales. También, estas dinámicas de sobreoferta y sobre capacitación facilitan la transformación de las estructuras productivas, permiten el aumento de la composición orgánica y, por ende, del nivel de capital humano requerido, incentivando nuevos ingresos al mercado educativo en el ciclo postobligatorio terciario.

La tendencia a la sobreoferta de profesionales se constituye en un componente estructural del mercado de trabajo profesional en el contexto de un modelo de acumulación estructurado

${ }^{5}$ El punto de vista demográfico se constituye en uno de los marcos de estudio de la problemática de la cobertura de los sistemas universitarios en los países de la OCDE y que pautan la emigración profesional [OCDE, 2012]. 
jerárquicamente en función de creación de valor permitiendo valorar con más intensidad el capital humano en tanto requisito o fuente de mayor productividad con el cambio tecnológico. $\mathrm{Al}$ tiempo, la sobreoferta y sobre calificación alimentan los desequilibrios estructurales en los mercados de oferta y demanda, y facilitan la movilidad ante mercados internacionales que demandan personal altamente capacitado y la filtración de los egresados a la hora del ingreso en los mercados de trabajo. Así, al tiempo, la sobreoferta es también el mecanismo para acotar los aumentos salariales y reconstruir los niveles de oferta y demanda, acotando que el incremento del costo marginal afecte la productividad marginal facilitando la sustitución de trabajadores y el aumento de la inversión en modernización productiva.

Desde el lado del mercado educativo se producen reformas con miras a reducir los desequilibrios fundamentalmente mediante la articulación entre los estudios y el trabajo dado que programas e instituciones articuladas con éste último permiten una mejor inserción laboral. En esta dinámica, el desempleo, la emigración y los empleos profesionales de menor perfil se producen entre los egresados de los programas de menor calidad, pertinencia y articulación en el marco de una mayor diferenciación y estratificación de los sistemas universitarios. Ello impulsa la competencia institucional con base en la acreditación, la realización de pasantías y la renovación curricular para facilitar una articulación más eficaz entre educación y trabajo. La pertinencia estrecha con los mercados laborales se produce tanto local como de manera mundial y se expresa en la internacionalización de la educación superior como se observa en los programas con doble titulación y certificación, la movilidad interna entre programas, la acreditación internacional, currículos altamente internacionalizados o directamente procesos de enseñanza asociados con demandas externas con participación de empresas o colegios profesionales en los países de destino para facilitar los reconocimientos y el ejercicio laboral.

A continuación analizaremos algunos de los impactos de las dinámicas producidas por el egreso con su tendencia hacia la 
sobreoferta y la sobre capacitación sobre los mercados laborales y educativos.

\section{a. Incorporación en el mercado formal en puestos de perfil profesional}

Los cambios productivos con la modernización tecnológica impulsan el crecimiento del sector formal de las economías e implican un mayor componente del trabajo profesional. El ejercicio profesional se basa en diagnóstico y respuesta, para ello se requiere más información por lo que hay una directa relación de su empleo y trabajo con la digitalización productiva. Ello impone que el crecimiento del empleo profesional se asocia con la inversión en informática. También hay una estrecha correlación con la expansión del sector servicios en su vertiente formal, del empleo en los aparatos del Estado y de las grandes empresas productivas centradas en la exportación. Los niveles de oferta y de empleo de profesionales son altamente diferenciados por profesiones así como sus niveles de remuneraciones salariales. Estas están asociadas con el nivel de estratificación de los mercados educativos y laborales, derivado de la diferencia de formación entre las instituciones y las características del sector y de la empresa. En este contexto de aumento de la oferta, el mercado tiende a absorber con mayor intensidad a los profesionales provenientes de instituciones con certificaciones acreditadas como forma de asignar puestos de trabajo en un escenario competitivo, los cuales regularmente reciben mayores niveles de remuneración.

En Colombia, por ejemplo, los egresados de los programas acreditados tienen $10 \%$ más sobre el salario de quienes provienen de programas no acreditados de alta calidad [MEN, 2008]. Aunque el ingreso de las mujeres es mayor en tanto se gradúan en mayor proporción que los hombres y en menos tiempo, se verifica que ambos grupos tienden a trabajar en sectores distintos, percibiendo ellas menores niveles salariales. En casi todos los casos se verifica que los factores que estructuraron las remu- 
neraciones y el ingreso en el mercado laboral son tanto el prestigio de la institución y la aceptación de la profesión, en tanto que el género no se constituye en un factor relevante en el ingreso. En otros países se constata una diferencia de niveles de empleabilidad y salarios por instituciones distinguiéndose las privadas de elites en mejor valorización, posteriormente las públicas autónomas y, finalmente, las privadas de absorción de demanda.

\section{b. Sustitución de puestos de trabajos no profesionales}

La sobreoferta de profesionales afecta su incorporación en mercados de trabajo que antes eran ocupados por personas de menor formación, siguiendo el "efecto fila" en función de las certificaciones y se tiende a producir la sustitución de empleos de baja productividad o de personas sin certificación por profesionales a los mismos salarios. El ingreso de personal altamente calificado de profesionales, o incluso, de desertantes universitarios, afecta el aumento de la productividad y sustitución de trabajadores, facilitando dicha expulsión de trabajadores de baja productividad. Esta dinámica se constituye en un elemento de reconstrucción del mercado laboral asociado con los niveles de flexibilidad de los puestos de trabajo y de circulación laboral e impacta también de manera directa e indirecta en la emigración de trabajadores de baja formación. Este modelo de sustitución de puestos técnicos o administrativos por profesionales, se asocia en muchos casos con certificaciones de baja calidad, de instituciones o programas no acreditados o a distancia, o en campos profesionales con saturación de oferta. Igualmente la sustitución de puestos está asociada con los niveles de desempleo y con el tamaño de la cobertura de los sistemas universitarios y de sus egresos, se constata que en los sistemas altamente masificados y diferenciados se desarrollan múltiples procesos de incorporación de profesionales y de personas que no concluyen sus estudios en tareas no profesionales. 
Parece ser este un segundo paso en el nivel de desarrollo de los ingresos en los mercados laborales y tiene una asociación estrecha con algunos niveles inferiores de formación universitaria, así como con la ausencia de salidas intermedias y de baja participación de los estudios no universitarios.

\section{c. Aumento del desempleo universitario}

El aumento de los egresados profesionales y técnicos tiende a ser superior a su absorción tanto en los mercados formales como informales, constatándose una tendencia de largo plazo del aumento del desempleo profesional en lo que pudiéramos definir como la lenta conformación de un ejército de reserva laboral profesional. La emigración profesional acontecida ha afectado inversamente sobre esta tasa de desempleo.

\section{Cuadro 3. Porcentaje de desempleo de profesionales en América Latina (1990-2010)}

\begin{tabular}{c|c|c|c|c|c|c|c|c|c|c}
\hline \multicolumn{1}{c|}{ Año } & 1990 & 1991 & 1993 & 1994 & 1995 & 1996 & 1997 & 1998 & 1999 & 2000 \\
\hline $\begin{array}{l}\text { \% desempleo } \\
\text { profesional }\end{array}$ & 4.69 & 11.3 & 8.45 & 5.16 & 4.9 & 4 & 7.01 & 6.25 & 7.53 & 4.35 \\
\hline \multicolumn{1}{c}{ Año } & 2001 & 2002 & 2003 & 2004 & 2005 & 2006 & 2007 & 2008 & 2009 & 2010 \\
\hline $\begin{array}{l}\text { \% desempleo } \\
\text { profesional }\end{array}$ & 6.192 & 8.88 & 9.13 & 8.11 & 7.58 & 5.65 & 5.91 & 5.85 & 6.58 & 6.63 \\
\hline
\end{tabular}

Fuente: cEPAL. Informe económico. Varios años.

Los datos muestran indicadores de desempleo de graduados superiores del orden de 9\% para Chile y $14.5 \%$ para México, con una media del $11.4 \%$ para la región [Mora, 2010]. En este escenario a medida que aumenta el desempleo profesional la tasa de retorno se reduce ya que disminuye a la vez la probabilidad de conseguir empleo [Adrogué, 2006]. El desempleo es, sin embargo, altamente diferenciado por países asociado a la distinta composición de los mercados de trabajo en función de los niveles 
de oferta y de demanda de trabajo y de los niveles de saturación de los diversos mercados profesionales. Así, los niveles de desempleo de los profesionales tienen múltiples determinantes, destacándose el área de conocimientos, la realidad económica de los mercados, el tipo de institución de donde se proviene, el género y el pasado familiar [Vries y Navarro, 2011].

La diferencia institucional también facilita una estratificación salarial profesional asociada con la calidad y reputación de las instituciones, en general expresada en los procesos de acreditación. También el aumento del desempleo universitario para algunos profesionales se asocia en la región con el aumento de la selectividad en el ingreso en los mercados profesionales que se genera en la medida que aumenta la oferta. Tradicionalmente el ingreso en el mercado laboral era exclusivamente basado en la certificación académica, pero se constata crecientemente la incorporación de procesos certificación profesional para el ingreso en los mercados de trabajo profesional, lo cual se expresa en diversas modalidades como los exámenes por los colegios profesionales en Brasil o de Estado en Colombia (Icfes) y México (Ceneval).

\section{d. Propensión a la emigración profesional}

Aunque el efecto más significativo de la masificación de la matrícula y el aumento del egreso es el aumento del empleo profesional, también se constata un aumento de la propensión a la emigración profesional y, en tal sentido, el incremento de la proporción de profesionales dentro de la masa emigrante. Tal emigración se da con más intensidad en los países en los cuales el desempleo profesional es más alto, en los cuales la tasa de retorno profesional es relativamente más baja comparativamente con el nivel internacional, en los países donde el crecimiento del producto es menor y donde el egreso profesional es mayor. En muchos casos, los emigrantes profesionales tienden a ser aquellos que no logran insertarse en los mercados laborales locales. 
Otros motivos como los políticos, tienen también su efecto en el caso de Venezuela o de seguridad en el caso de México. Así, por diversos motivos desde Brasil, México, Argentina, Venezuela, Uruguay o República Dominicana se constata un aumento de la emigración de profesionales y técnicos universitarios que se constituye en un drenaje continuo de capital humano. En Uruguay por ejemplo, mientras que en el mercado laboral los profesionales son $10 \%$ en la población emigrante, los profesionales han sido 15\% [OIM, 2010], mientras que en Colombia en 1998, $8 \%$ de sus emigrantes hacia Estados Unidos tenían educación superior, para 2006 esa tasa había aumentado a 30\% [Hernández, 2010]. La emigración profesional es un flujo selectivo y ordenado, articulado a partir del otorgamiento de las visas de los países receptores. Los datos de las visas para Estados Unidos muestran su correlación con los aumentos de los egresos en la región.

Los desequilibrios de los mercados educativos locales se ajustan en el marco de un nuevo contexto económico mundial que valoriza intensamente los recursos altamente capacitados y presiona un aumento de la emigración profesional. En los años noventa los países de la OCDE tenían 12.9 millones de inmigrantes altamente calificados y una prospectiva para 2030 mostraba la tensión entre la baja natalidad y que la demanda de personal calificado se incrementará presionando un mayor ingreso de emigrantes profesionales [OCDE, 2012]. Es un patrón migratorio global que se está profundizando y desde la crisis de 2009 se expresa en la expulsión de antiguos emigrantes de baja calificación y el aumento de la migración selectiva capacitada [Aragonés, 2011]. En Estados Unidos las visas de residencia H1A y O1 para personas de América Latina con alta formación aumentaron de 30487 en 1996 a 103278 en 2008, aumentaron 239\% y acumularon 1007880 personas. En este nuevo escenario global, una política universitaria de masificación gratuita de la cobertura con bajos salarios profesionales y pocos mecanismos de retención en América Latina, tiene el riesgo en constituirse un mecanismo estructural de pérdida continua de capital humano, incluso con 
la probabilidad de que a medida que aumente la calidad universitaria se produzca un mayor drenaje de recursos.

Muchas de las actuales limitaciones a esta dinámica refieren a las diferencias de capital humano y de los requisitos para el reconocimiento de sus certificaciones con miras al ejercicio profesional, limitan el ingreso a los mercados profesionales formales por parte de estos migrantes. Ello favorece que se produzca un fenómeno de ingreso al mercado laboral en puestos técnicos y administrativos de asistencia a los profesionales. La emigración profesional se constituye en un nuevo momento del llamado drenaje tradicional de cerebros, referido entre los años sesenta y ochenta, ahora asociado con la creciente oferta de profesionales en el ámbito internacional y que se acompasa con mecanismos selectivos de inmigración y limitaciones al ejercicio profesional por medio del reconocimiento de las certificaciones. Se constata en este sentido la dificultad de ellos de acceder a puestos de trabajo de profesionales en los países de destino, por lo cual muchos de estos migrantes profesionales tienden a ingresar (y muchas veces no sólo durante un durante un tiempo inicial sino de modo permanente) en puestos técnicos o administrativos.

Emigran como profesionales, pero su incorporación en los mercados laborales centrales tiende a ser en los niveles técnicos o en trabajos profesionales inferiores dentro de las empresas, muchas veces por la incapacidad de firmar y ejercer libremente en el marco de una amplia complejización y diferenciación de los mercados laborales de profesionales. En muchos casos ello no refiere exclusivamente a problemas de legalización y de certificación, sino de los niveles de aprendizajes inferiores que tienen estos emigrantes asociadas con la debilidad de los sistemas universitarios en la periferia y semiperiferia o a su desempleo en los mercados profesionales en los países de origen. Sin embargo, la emigración recompone los mercados laborales locales al reducir la oferta, pero no afecta los niveles salariales locales [Pellegrino, 2005]. 


\section{f. Ingreso tardío al mercado de trabajo y continuación de los estudios}

El aumento de la formación de capital mediante estudios de posgrado se constituye en una de las expresiones de los desequilibrios entre la educación y el trabajo expresados en la sobreoferta de profesionales de grado, la mayor especialización de las demandas laborales y la tendencia hacia la internacionalización educativa para adquirir dichas competencias. Los posgrados son una educación internacional en tanto en el ámbito nacional no se pueden ofrecer todas las especializaciones disciplinarias y expresan los conocimientos de la creciente sociedad de la información [Rama, 2007]. Más allá del aumento de los estudios de posgrado en escala local, asistimos a un aumento significativo de los estudios de posgrado internacionales y, de manera fundamental, en los países centrales.

Algunos estudios de seguimiento de egresados muestran una mayor propensión a continuar estudiando asociado con los niveles competitivos de las profesiones, con la duración de los estudios de grado, con las tasas de retorno diferenciadas de ambos mercados (grado, posgrado y al interior de estos) [Forero y Ramírez, 2008] y a las dificultades de inserción laboral. Para el caso de México, un estudio de seguimiento de egresados de la BUAP mostró que $36.4 \%$ de esa población optó por realizar estudios posteriores al grado, cuyos indicadores tan elevados permiten suponer dificultades de ingreso al mercado a nivel de grado [Witse, 2003]. México se localiza entre los países con mayores tasas de estudios de posgrado y al tiempo de desempleo profesionales. En la década pasada, aunque continuó la expansión de los posgrados, se produjo a tasas menores que en la década anterior derivado a su vez de un aumento de la matrícula de grado que fue muy elevada en varios países (Colombia, Venezuela, Brasil y Ecuador) con lo que se redujo la incidencia del posgrado en el total de la matrícula. En el sector público aumentó el carácter mercantil de los posgrados que tuvieron lógicas de oferta, precios y demandas monetarizadas, en la mayoría de los países de la 
región contribuyendo al desestímulo. Los países con oferta gratuita pública como Brasil o Uruguay, tienen baja oferta o altos mecanismos selectivos. En Ecuador, Bolivia y Guatemala además es obligatorio el autofinanciamiento. El incremento de los posgrados es diferenciado en sus diversos niveles, verificándose un mayor incremento en aquellos que tienen mayores tasas de retorno. Algunos estudios muestran que la prima por los doctorados no es muy superior a los estudios de maestría, lo cual se correlaciona con su baja matrícula [Hernández, 2010].

En los últimos años se reafirma el aporte y el propio papel de los posgrados en los ingresos económicos de las universidades públicas y su desarrollo en base a lógicas de mercado, lo cual ha facilitado su selectividad vía precios. La caída de la tasa de retorno de los profesionales en un contexto de ausencia de gratuidad pudiera afectar además en la desaceleración del crecimiento de los posgrados y en su elitización social. La región tiene una baja cobertura de posgrado que, vista de manera global, está cerca de $5 \%$ de los estudiantes terciarios y que se constituye en un indicador muy inferior al de los países desarrollados, que indicaría aún que es dominante la baja sobreoferta de universitarios con el nivel del grado, demandas profesionales de poca complejidad en el mercado laboral, bajos niveles de desempleo profesional y una tasa de rendimiento elevada para los estudios de grado. En varios países como México, Colombia o Brasil, se verifican primas por educación altamente diferenciadas para los estudios de posgrado. Parecería que el elevado nivel de absorción de los egresados profesionales en muchos países ha desestimulado el ingreso en el posgrado. La región está transitando hacia la reducción de 5 a 4 años de tiempo de estudio en las licenciaturas pero ello no se asocia con un impulso a los estudios de posgrado como en Europa, probablemente asociado con la baja oferta de profesionales que impulse la sobre capacitación y la relación de precios de los posgrados y costos de oportunidad que no compensen las primas educativas y, por ende, faciliten el sacrificio de rentas. 
El posgrado también se constituye como un mecanismo asociado con la emigración, en tanto es un mecanismo de selección de ingreso en los mercados laborales externos y una estrategia personal de sobrevivencia mediante la emigración profesional. Ello se expresa en la alta participación de los estudios en el extranjero en el total de posgrados de la región y en el dato de que hasta $20 \%$ de quienes terminan los estudios en el extranjero no regresan a sus países de origen. El carácter gratuito de los estudios públicos facilita esta dinámica, más allá de la participación de egresados de instituciones privadas, que permite mostrar que hay una prima positiva salarial para ambos tipos de egresados.

El acceso al mercado profesional ha sido, con la excepción de medicina, a nivel del grado en toda la región. La expansión de posgrados se asocia también con el dominio de la oferta privada que se había iniciado en los años noventa por bajos cupos y poca diferenciación pública. Hacia fines de la década, la incidencia del sector privado en el posgrado es mayor que en el grado y superior al sector público, salvo en el caso de los doctorados y posdoctorados. En general se ha ampliado la perspectiva profesional altamente articulada con las demandas de los mercados laborales con posgrados de tiempo parcial y pagantes. Su baja dimensión muestra una cobertura y una demanda de elites. La mayor tasa de cobertura alcanza 7.5\% en México y Cuba, donde se verifica lentamente el pasaje de un acceso de elites a uno de minorías en este nivel y se asocia claramente con los recursos públicos y no sacrificio de renta. Priva un punto de vista academicista, una modalidad presencial y un aprendizaje teórico que ha sido favorecido por la regulación aunque se constata el crecimiento continuo de ofertas semipresenciales y flexibles.

\section{Tendencia a la constitución de sistemas educativos y laborales globales}

En una economía global, los desequilibrios entre el mercado educativo (articulación y anticipación oferta y demanda) y el mer- 
cado laboral (perfiles y competencias de oferta y demanda de empleo) se ajustan en diversidad de dinámicas, entre las cuales la emigración e inmigración profesional asociadas con una elasticidad de salarios asociados con empleo y desempleo. Si bien privan las teorías que asumen las limitaciones estructurales a la movilidad laboral profesional y que plantean el dominio de los mercados laborales locales, la dinámica en curso permite lentamente observar la constitución de sistemas laborales profesionales crecientemente mundiales. Si bien en la literatura han emergido trabajos como Katz y Varela [1999] en los cuales se incorpora el efecto relativo de los factores de oferta y demanda en la determinación de los salarios profesionales, ello asume mayor relevancia con el aumento del egreso profesional, la mayor facilidad de movilidad, el aumento de la información sobre los mercados laborales y la mayor articulación entre los sistemas educativos. Ello al tiempo, se correlaciona con los cambios más acelerados en las estructuras productivas de los países desarrollados y la expansión de políticas selectivas de inmigración. La literatura además comienza a revelar que la migración en los niveles de oferta profesional no afecta significativamente en los salarios profesionales ni en el lugar de destino, no en el lugar de origen, pero sí en los niveles globales de productividad y los salarios personales. Tampoco lo hace de modo significativo en remesas, siendo los beneficios fundamentalmente privados.

En el largo plazo, el desempleo profesional deriva en una mayor movilidad profesional internacional, tanto de aquellos egresados de programas acreditados, de instituciones de calidad o articuladas con las demandas globales o de los campos profesionales más demandados en puestos profesionales, como de aquellos de menores competencias pero en puestos no profesionales formalizados. Ello en tanto impone múltiples limitaciones de reconocimiento académico y profesional para el ejercicio laboral de tipo normativo. Las dificultades de reconocimiento de las certificaciones afectan en las formas de la emigración profesional, de sus tipos de empleo y niveles de salario. Se crea así una fuga de los profesionales del perfil superior de competencias al 
tiempo que se imponen limitaciones para aquellos de menores competencias que no acceden a los mercados profesionales sino a una amplia variedad de trabajos asociados de inferior valoración. Aunque los desequilibrios son estructurales y la emigración y movilidad profesional también, las estructuras de remuneraciones siguen otros parámetros más asociados con ofertas y demandas, en niveles de reconocimiento de las certificaciones y en un mercado de trabajo de emigrantes profesionales de bajo nivel.

Estos escenarios introducen cambios en modelo de capital humano que se estructuró como un modelo cerrado al complejizarse las dinámicas de la relación educación-trabajo-salario y al comenzar a articularse los sistemas educativos. En este sentido la dinámica educativa heterogénea y desigual impacta diferenciadamente en la emigración de los perfiles de mayor calidad y un aumento del desempleo profesional que afecta los niveles de salarios profesionales y que se constituye como base necesaria para generar y mantener el creciente ejército profesional de reserva.

El mercado de trabajo profesional internacional se estructura hacia una mayor propensión de movilidad en el marco de un mercado laboral y educativo fragmentado pero integrado, en el cual el "efecto fila" de competencia profesional [Arrow, 1972] se organiza en valor de certificaciones y capacidades verificadas crecientemente internacionales en mercados cada vez más competitivos y globalizados. En tanto los mercados profesionales tienden hacia una mayor oferta de empleo en relación a la demanda, ello se expresará en nuevas formas de formación especializada para mejorar la probabilidad de encontrar o mejorar su empleo y reposicionarlo en la "fila de empleo", pero en un contexto de emigración [Gómez, 2003]. En el contexto de mayores exigencias de competencias en los mercados globales y de aumento de la oferta de profesionales, la puerta giratoria tiende a aumentar su velocidad, e incorpora crecientemente también el ingreso en los mercados internacionales, implicando una mayor rotación de profesionales con un aumento del ingreso y egreso de trabajadores y, por ende, de una mayor sustitución y/o de emigración de profesionales. 
Si bien la combinación de crecimiento económico y modernización de la estructura productiva y de servicios derivan en una elevación de la ocupacional hacia un perfil más a la altura de los parámetros del avance tecnológico, tal derivación del efecto fila en un contexto de migración favorece un aumento de la sobre educación con menores tasas de retorno profesional en todos los mercados. Esta es, sin embargo, la puerta inicial de procesos más amplios a medida que aumenten los niveles de egreso y la masificación de la matrícula en los países en desarrollo, y que las resistencias normativas al ejercicio laboral y la obtención de visas condicionan la fluidez y articulación de los mercados profesionales.

El modelo sostenido por la teoría del capital humano de ajuste de las inversiones educativas en función de las modificaciones en las distintas tasas de retornos por profesiones no se manifiesta en el corto o mediano plazo, como se verificó en la crisis de Argentina en la década de dosmil, donde la caída de los salarios de los profesionales y el aumento del desempleo se asoció con un aumento en la demanda educativa, al tiempo que se produjo una mayor caída de los salarios de los profesionales que de los no profesionales. Este ciclo, la crisis económica, la caída de salarios profesionales y el aumento de la propensión a estudiar y al tiempo aumento del empleo, aumento de los salarios y reducción a la propensión a estudiar, muestra las limitaciones del modelo de capital humano en el contexto de la educación, tanto gratuita como de pago. Así, las determinaciones de la demanda de estudio no están determinadas por la tasa de retorno de la inversión, sino por la existencia de desequilibrios estructurales entre la demanda de estudios y la demanda de profesionales [Mungaray, 2001].

La evaluación de las diferentes tasas de retorno entre las profesiones universitarias y el continuo nivel de cobertura de las profesiones saturadas en el contexto de la conformación de un lento sistema educativo global, plantea la complejización explicativa del marco tradicional conceptual de la teoría del capital humano. Ello deriva de una imperfección del mercado reducible a costos de acceso a la información, o al desfazaje estructural 
de dichos mercados dados por los tiempos de maduración de los estudios y la incertidumbre sobre los resultados a futuro de las inversiones educativas, sino de nuevas dinámicas en los mercados laborales y educativos que propenden a una sobreoferta profesional, alta diferenciación de las competencias y mayores articulaciones internacionales entre educación y trabajo. Más allá de que los mercados laborales actúan en tiempo presente, en tanto que los educativos actúan en tiempo futuro, los desequilibrios educación-trabajo tienden a ser estructurales y afectan la coherencia del modelo de demanda de la teoría del capital humano ya que las personas carecen de completa información sobre los niveles de rentabilidad de las diversas profesiones en tiempo presente, no puedan proyectar los salarios esperados, ni los costos de oportunidad futuros, ni las diferencias salariales por lugar de trabajo o campo profesional. Sus decisiones además no están basadas en una racionalidad como inversores, y las determinaciones del salario tienen otros componentes como los niveles de oferta y demanda así como los componentes culturales y sociales. ${ }^{6}$

Si bien tradicionalmente los mercados universitarios son imperfectos como todos los mercados, el aumento de los egresos, la elevada renovación de los conocimientos, la alta diferenciación institucional, pedagógica, de niveles y de modalidades, así como las formas de emigración profesional y de articulación internacional, amplían los desequilibrios entre educación y trabajo.

La teoría del capital humano se formuló sobre la base de mercados laborales nacionales con escasa movilidad, existencia de información perfecta de los niveles de remuneración y poca diversidad de éstas, estratos iguales de calidad para cada nivel de formación, así como iguales capacidades de aprendizaje por las personas y decisiones racionales basadas en expectativas salariales y partía de una perspectiva marginalista por la cual todas las unidades adicionales de estudio producían iguales resultados en

${ }^{6}$ Uno de los elementos claros que marca límites al modelo de capital humano es la diferencia de salarios para hombres y mujeres, para diversas razas o grupos étnicos para los mismos niveles de escolarización. 
cada campo profesional más allá de la localización espacial, el tipo de empresa o el género, además no reconociendo la diversidad de los niveles de enseñanza o de las capacidades de aprendizaje de las personas. Un estudio pionero del Banco Mundial mostró en los años ochenta las especificidades de los sistemas educativos de los países en desarrollo con alta heterogeneidad de niveles de capital humano, de las instituciones y de los aprendizajes [Psacharopoulos, 1980] que en el actual contexto de la masificación y la complejización de los mercados educativos y laborales con la inclusión de componentes internacionales entre ambos mercados, se torna más compleja en sus singularidades, entre las nuevas dimensiones del trabajo profesional en contextos internacionales.

\section{BiBLIOGRAFÍA}

Adrogué, Cecilia [2006], Desempleo y retornos a la educación superior en la Argentina (1974-2002). Argentina, IAE - UCEMA. Asamblea Nacional de Rectores (ANR) [2010], Datos estadísticos universitarios. Dirección de Estadísticas, Lima, 2010.

Aragonés, Ana María y Uberto Salgado [2011], "Mercados del trabajo en la economía del conocimiento y el fenómeno migratorio. El caso de Estados Unidos (1990-2006)", en Aragonés, Ana Maria (ed.), Mercados de trabajo y migración internacional, México, IIEc- UNAM, 79-138 pp.

Azevedo, Joaquín [2007], Sistema educativo mundial. Esaio sobre a regulação transnacional da educação. Lisboa, Fundação Manuel Leão.

Carnoy, Martín [2006], La economía de la educación. Barcelona, UOC.

CEPAL [2007], "Calidad de la educación: las desigualdades más allá del acceso y la progresión educativa”, Panorama social de América Latina 2007, Santiago, CEPAL, 430 pp.

Forero, Nohora y Manuel Ramírez [2008], "Determinantes de los ingresos laborales de los graduados universitarios durante el periodo 2001-2004", Serie Documentos de trabajo, Bogotá, Universidad de Rosario (31). 
Gómez, Marcelo [2003], "El mercado de trabajo para los egresados universitarios recientes", Buenos Aires, UNTREF.

Gutiérrez, Ilse y Lorena Kikut [2010], "Seguimiento de la condición laboral de personas graduadas 2000-2007 de las universidades costarricenses”, San José, CONARE.

Hernández, Gustavo [2010], "Cuan rentable es la educación superior en Colombia?”, Lecturas de Economía, Medellín, 73 (181), Universidad de Antioquia, 214 pp.

Hüfner, K, J. Meyer y J. Naumann [1992], "Investigación sobre política educativa comparada: perspectiva de la sociedad mundial", Revista de Educación (297): 347-402 pp.

Iesalc [2006], La metamorfosis de la educación superior en América Latina. Informe sobre la educación superior 2000-2005, Caracas, UNESCO-Iesalc.

Instituto Nacional de Estadísticas (INE) [2012], Encuesta de bogares, Montevideo, INE.

Ministerio de Educación Nacional [2008], Observatorio laboral para la educación (OLE) Resultados de las condiciones laborales de los graduados de la educación superior entre 2001 y 2007. Bogotá, MEN, consultado en <www.men.gov.co>.

Ministerio de Educación y Cultura (MEC) [2011], Informe Estadístico 2010. Montevideo, MEC.

Mora, José-Ginés, José Miguel Carot y A. Conchada [2010], Informe resumen del Proyecto PROFLEX en América Latina. Comparativa con el proyecto REFLEX en Europa. Valencia, Universidad Politécnica de Valencia (CEGES).

Mungaray Lagarda, Alejandro [2001], "La educación superior y el mercado de trabajo profesional”, Revista electrónica de investigación educativa, 3 (1), consultado en <http://redie.uabc. $\mathrm{mx} /$ vol3no1/contenido-mungaray.html>, 29 de enero de 2013. OCDE [2012], “La población. Demografía”, La educación superior bacia el 2030. Volumen I. México, Instituto Internacional de Investigación en Tecnología Educativa.

OCDE/CEPAL [2011], Perspectivas económicas para América Latina 2012: transformación del Estado para el desarrollo, OCDE Publishing, consultado en <http://dx.doi.org/10.1787/leo-2012-es>. 
Pérez, Carlota [2005], Revoluciones tecnológicas y capital financiero. México, Siglo XXI Editores.

Psacharópulos, George [1980], Higher Education in Developing Countries: A cost-Benefit Analysis (Staff Paper No. 440), Washington DC, World Bank.

Psacharópulos, George [1994], The Economic Impact of Education. Washington DC, World Bank.

Rama, Claudio [2012], La nueva fase de la educación privada en América Latina. Montevideo, Universidad de la Empresa/ Magro Editores.

Rama, Claudio [2011a], Paradigmas emergentes, competencias profesionales y nuevos modelos universitarios en América Latina. México, Puebla. BuAP.

Rama, Claudio [2011b], "La educación superior en América Latina en el periodo 2000-2010: ocho ejes centrales en discusión”, Revista de Innovación Educativa, México, Instituto Politécnico Nacional, 11(57): 15-20 pp.

Rama, Claudio [2009], "La tendencia a la masificación de la cobertura de la educación superior en América Latina", Revista Iberoamericana de Educación. Madrid: Organización de Educación Iberoamericana (OEI) (50), julio de 2009, 173-195 pp., de $<$ http://www.rieoei.org/rie50a09.pdf $>$.

Rama, Claudio [2007], Los posgrados de América Latina y el Caribe en la sociedad del conocimiento. UDUAL (Unión de Universidades de América Latina). México, 2da. edición corregida, septiembre 2007, $280 \mathrm{pp}$.

unESCO-IUs [2010], Compendio mundial de la educación. Montreal, Quebec. UNESCO-UIS.

Varela, Rogelio y José Urciaga [2012], "Diferencias salariales en México: una perspectiva de educación y actividad económica”, Revista de Educación Superior. XLI, 2 (162): 25-43 pp.

Vila Arcila, Leonardo [2001], Economia de la educación. Bogotá, Universidad de los Andes.

Vries de Witse et al. [2008], Egresados universitarios y el mercado de trabajo. Puebla, BUAP. 
Vries de Witse y Yadira Navarro [2011], “¿Profesionistas del futuro o futuro taxistas? Los egresados universitarios y el mercado laboral en México", RIES, México: IsSUE. Territorios, 2 (4): 2-27 pp.

Weller, Jürgen [2004], "El empleo terciario en América Latina: entre la modernidad y la sobrevivencia", Revista de la CEPAL (84). 


\title{
Capítulo 9 \\ NuEVO PATRÓN MIGRATORIO BAJO EL CONTEXTO DE LA CRISIS
}

\author{
Ana María Aragonés* \\ Uberto Salgado**
}

\section{INTRODUCCIÓN}

¿Es posible hablar de un nuevo patrón migratorio a partir de la profunda crisis mundial que aconteció entre los años 2007-2009? Algunos autores han señalado que la crisis ha dado lugar a una importante transformación del comportamiento migratorio, basados en la disminución de los flujos de mexicanos hacia Estados Unidos. De hecho, se ha afirmado que finalmente México, principal exportador de fuerza de trabajo en el mundo, había logrado detener esos flujos. Si bien podríamos aceptar que se produjo un importante descenso de trabajadores migrantes, no estamos de acuerdo con las razones esgrimidas para tal situación y planteamos que se trata de un fenómeno temporal. Se señala que México se

* Profesora Titular C de Tiempo Completo Definitivo en el IIEC, unAm; del Posgrado Estudios México-Estados Unidos FEs-Acatlán y de Historia Económica y Social. Es miembro del SNI Nivel II. Doctora en Derecho por la Universidad de Montpellier, Francia. Correo electrónico: <amaragones@gmail.com>.

** Becario del Instituto de Investigaciones Económicas, es profesor adjunto de la materia Econometría I en la Facultad de Ciencias de la UnAM, realizó estudios de maestría en la Facultad de Economía de la UnAm, ha participado en congresos nacionales e internacionales relacionados con el tema de la migración. Correo electrónico: <ubesk8@ gmail.com>. 
encuentra en mejores condiciones económicas, que ha disminuido la tasa de natalidad y que las mejoras tecnológicas en materia de la telefonía celular y en la infraestructura, facilitarían el acceso a plazas de trabajo disponibles en nuevos lugares del país. Esto habría dado lugar a que ahora los migrantes mexicanos no se dirijan hacia Estados Unidos, sino hacia pequeñas ciudades que brindan mejores niveles de seguridad como Mérida, Oaxaca y Querétaro dentro del territorio. Lo mismo sucede con la migración guatemalteca que, según se señala, se queda a residir en México en lugar de continuar su camino hacia Estados Unidos [Cave, 2011]. La explicación que ofrecen sobre la mejora en las condiciones económicas de México no se sostiene ya que, incluso los datos oficiales proporcionados por el INEGI señalan que entre 2008-2010 todos los hogares sufrieron una disminución en sus ingresos, que cayó $12.3 \%$ afectando en mayor medida a los hogares más pobres que no cuentan con mecanismos para compensar la pérdida de ingresos [Rodríguez, 2011a]. Por otro lado, durante el periodo 2006-2011 la tasa oficial de desempleo se incrementó cerca de $60 \%$ y 17.4 millones de mexicanos se encuentran en situación de alta vulnerabilidad laboral. El empleo formal aumentó a un ritmo de 221 mil puestos por año, cifra muy por debajo del crecimiento poblacional estimado en más de 800 mil personas en edad de trabajar [Fernández-Vega, 2011]. Según datos del INEGI, durante 2011 la economía informal generó cuatro veces más puestos de trabajo que el sector formal, dando empleo a cerca de 14 millones de personas, número que supera a los 13.2 millones de trabajadores que cotizaban en el IMSs [González, 2012] En tanto que el narcotráfico ha creado unos $600 \mathrm{mil} \mathrm{em-}$ pleos, convirtiéndose en el mayor generador de puestos de trabajo [Rodríguez, 2011b].

Por otro lado, investigadores como Durand [2011] sugieren que la disminución del flujo migratorio indocumentado se debe a factores tales como el endurecimiento de las políticas antinmigrantes, las cuales han incrementado los costos de la migración, pero al mismo tiempo se ha elevado la migración legal, lo que indicaría un cambio en la actitud de la política migratoria que no 
responde a razones económicas sino a cuestiones políticas. Dos son los factores estructurales que señala el autor. El primero tiene que ver con el cambio demográfico al reducirse el número de hijos de siete en el año 1970 a dos en el año 2010 y, en segundo lugar, el crecimiento económico que si bien este es lento, ha permitido mejorar las condiciones generales de la población.

Aún cuando estos autores reconocen de forma un tanto indirecta que la crisis económica en Estados Unidos tiene efecto en la disminución de la emigración de mexicanos, el peso mayor se lo otorgan a las mejoras económicas, políticas y sociales en México, que pueden llegar a provocar un cambio permanente en la migración laboral, e incluso, se puede estar en presencia del fin de la migración mexicana, al menos en las cantidades y características que se presentó desde los años setenta [García, 2012]. En este sentido Cave [2011] y Durand [2011] sostienen que este escenario representa un nuevo patrón migratorio.

Creemos que vale la pena tratar de profundizar en los conceptos de patrón y flujos migratorios. Se trata de conceptos que nos parece se han discutido poco, pues en general se ha dado por hecho que se trata de los mismos fenómenos cuando en realidad, desde nuestro punto de vista, el "patrón migratorio" se explica por las vinculaciones con el patrón de acumulación. Es decir, se trata de articulaciones económicas entre el polo receptor y el polo expulsor, por lo tanto hablamos de condiciones estructurales y no simplemente coyunturales como puede ser la disminución de los flujos migratorios. Como señala el investigador Brito [2000] la literatura sobre migración internacional no es "lo suficientemente clara sobre los tipos de migración y sobre el patrón migratorio y en general suelen referirse más a los flujos”. Por eso nos parece importante presentar una propuesta que intentará abordar estos conceptos buscando comprender las transformaciones que se presentan en el nuevo patrón migratorio.

En este sentido y retomando los planteamientos de Valenzuela [1990] un patrón de acumulación se encuentra determinado históricamente "es decir no se trata de acumulación capitalista a secas, sino de la forma que ésta toma en un periodo histórico 
dado, por lo tanto cambian sus especificidades". Y, desde nuestro punto de vista, los patrones migratorios por medio de los flujos de trabajadores migrantes, modifican también sus características pues responden a las necesidades de reproducción del capital en el centro. Por otro lado y de acuerdo con Valenzuela, en el mundo capitalista hay una relación contradictoria entre centro-periferia, de tal suerte que a la periferia se le van asignando distintas formas de "succión y traslado de excedentes a favor del centro". Y, desde nuestro punto de vista, la migración de trabajadores es una de las formas en las que se concreta el traslado de excedentes a favor del centro.

Los distintos patrones de acumulación a lo largo de la historia sufren su agotamiento y surge la crisis, cuya causa central es la tendencia decreciente de la tasa de ganancia lo que dará paso a un nuevo patrón de acumulación y a nuevas formas de articulación entre centro-periferia. Es posible identificar distintos patrones, de acuerdo con Valenzuela. El "modelo primario-exportador" o de "desarrollo hacia afuera" que se produjo desde mediados del siglo XIX hasta la década de los años treinta del siglo pasado. La Primera Guerra Mundial, la gran crisis y luego la Segunda Guerra Mundial marcarían la transición hacia un nuevo periodo, el de la "industrialización sustitutiva de importaciones" que la CEPAL ha llamado "desarrollo hacia adentro". Una vez que este modelo se agotó, más o menos a finales de los años sesenta, se inició el patrón "secundario-exportador" y con ello el surgimiento en los años ochenta de la llamada globalización y su política económica el neoliberalismo [Valenzuela, 1990].

Bajo esa misma perspectiva, podemos decir que a diversos patrones de acumulación correspondieron patrones migratorios que satisfacían los requerimientos de la acumulación capitalista y las exigencias de sus mercados laborales. De esta forma podríamos hablar de tres grandes patrones migratorios: $a$ ) las migraciones clásicas (siglo XIX-principios del siglo XX), b) migraciones en el fordismo y la sustitución de importaciones (1945-1970) y las migraciones en la globalización y c) el neoliberalismo (1980-2009). 
En estos momentos estamos ante una crisis estructural que conformaría un nuevo patrón de acumulación que, si bien por su actualidad aún es difícil caracterizar en toda su complejidad, creemos que es posible empezar a identificar algunas tendencias del nuevo patrón migratorio ligado con estas nuevas condiciones económicas. Vamos a encontrar rasgos del patrón migratorio anterior pues, como señala Valenzuela [1990]: "la crisis de lo viejo no abre un abanico de posibilidades infinitas, muy por el contrario pues está determinado por las contradicciones que paralizaron al patrón antiguo [...] hay que identificar las contradicciones y se estará identificando los rasgos más decisivos del nuevo patrón de acumulación”.

A continuación hacemos una breve revisión teórica de algunos autores que, desde nuestro punto de vista, son importantes en la conceptualización del patrón migratorio.

\section{Comportamiento bistórico del patrón migratorio}

Algunos investigadores han realizado estudios muy importantes caracterizando el patrón migratorio. Este es el caso del extraordinario historiador económico Hobsbawn [1998] quien analiza la migración durante los periodos de 1848-1875, tanto internacional como nacional para explicar su funcionalidad, que es la de conformar ciudades y crear nuevas naciones y sociedades y empieza las famosas migraciones transoceánicas o migraciones clásicas.

Por otro lado se encuentra el trabajo de Ravenstein [1885], otro destacadísimo autor, quien señala un conjunto de regularidades empíricas entre 1871-1881 en Reino Unido y analiza un conjunto de variedades o tipos de migración, tales como las cortas, de larga distancia, las rurales-urbanas, urbanas-urbanas, la corriente de retorno y de contra-corriente, así como las medidas selectivas de migración. Ravenstein pone en evidencia que todas estas formas de desplazamiento se asocian con el desarrollo del capitalismo. Lo cual es sumamente interesante pues destaca que hay una diferencia entre las migraciones que se producen antes y 
después del capitalismo. Lo que señala el hecho de que las migraciones son un fenómeno histórico con diferentes características y funcionalidades.

En el trabajo de Martínez y Villa [2005] se analizan las tendencias y patrones de migración internacional en América Latina y el Caribe; estos autores encontraron la existencia de tres patrones migratorios en la región, el primero de ellos, la inmigración de ultramar hacia América Latina durante la segunda mitad del siglo XIX y la primer mitad del siglo XX, cuya intensidad declinó durante los últimos decenios; el segundo patrón corresponde a la migración intrarregional, alimentada por factores estructurales como la desigualdad en el desarrollo económico y las alteraciones sociopolíticas que ocurrieron durante la década de los setenta, lo que provocó que el stock de este tipo de migrantes se duplicara; el tercer patrón es el de la emigración de latinoamericanos y caribeños hacia Estados Unidos, país cuyo stock se duplicó entre 1980 y 1990.

En el trabajo de Zelinsky [1971], se busca asociar un patrón migratorio con los diferentes tipos de sociedades; en este sentido señala que la migración rural-rural es predominante en la sociedad preindustrial, la población rural-urbana, hace referencia a una sociedad que está en proceso de industrialización, la población urbana-urbana refleja la madurez industrial de una economía y la migración de la ciudad a los suburbios cercanos o pueblos pequeños, que se refiere a una sociedad postindustrial; a diferencia de los otros trabajos, Zelinsky define al patrón de migración como un tipo o modalidad de la migración que parece ser predominante en distintas circunstancias históricas y no se circunscriben al sistema capitalista, como los precedentes autores que mencionamos.

Brito [2000] señala que no basta con la existencia de trayectorias migratorias dominantes o secundarias para definir un patrón migratorio. Es indispensable precisar el contexto en el que los flujos migratorios se desenvuelven y se estructuran para cumplir sus funciones fundamentales en la dinámica económica y social. Por lo tanto, un patrón migratorio sería la forma de vinculación entre los flujos migratorios y la dinámica tanto social como económica. 
Nuestra propuesta, como ya hemos esbozado, es que el patrón migratorio está articulado con el patrón de acumulación y en la medida en que este último se va modificando a lo largo del capitalismo como consecuencia de las crisis cíclicas que enfrenta ese modo de producción, las condiciones y características del patrón migratorio lo hace en la misma medida. Esto se debe a que los recientes procesos productivos presentan nuevas exigencias en sus mercados laborales y los migrantes están articulados con ellas. A partir de ello, podremos observar las características que presentan los flujos migratorios. En este sentido, la crisis estructural de los años 2007-2009, no sólo afectó a la potencia dominante sino que se extendió al conjunto de los países capitalistas y si bien algunas de sus estructuras se eliminarán otras se mantendrán en el nuevo patrón de acumulación.

\section{La economía del conocimiento y la crisis}

Parece haber cierto acuerdo en el sentido de que uno de los elementos que contribuiría a la superación de la crisis estructural 2007-2009 es la profundización de la economía del conocimiento, para lo cual la potencia dominante, es decir, Estados Unidos, tendría que recuperar su papel como líder de la economía del conocimiento [Dabat y Ordóñez, 2009 y Ordóñez, 2008]. De acuerdo con Valenzuela [2012] este país debe llevar a cabo un reordenamiento estructural, mejorar la distribución del ingreso en favor de sus asalariados, dinamizar la inversión productiva en contra del capital financiero-especulativo, y de manera central, requiere dinamizar la oferta tecnológica mediante un conjunto de innovaciones que presenten una gran capacidad de arrastre, como son las tecnologías limpias, un importante gasto a favor de la educación, la ciencia y la tecnología (ID) y un cambio en el bloque de poder, que debe pasar de la oligarquía financiero-especulativa al gran capital industrial.

Si analizamos las propuestas del presidente Barak Obama, no es extraño que presente un conjunto de proyectos vinculados 
con la profundización de la economía del conocimiento. En este sentido, al analizar las propuestas de Robert Pollin, se puede observar la atención que otorga a aquellos proyectos basados en la energía limpia y los edificios inteligentes, no sólo porque favorecen la ecología, sino porque se trata de proyectos altamente generadores de empleo y son los que van a favorecer la superación de la crisis en el país. Pollin [2011] realizó un estimado de la influencia del gasto público en la generación de empleos basándose en encuestas industriales, y por medio del análisis de matrices insumo-producto, encuentra que el gasto público debe estar encaminado a la canalización de mayores montos de inversión pública y privada en aquellas industrias que generan incrementos en los empleos, de las cuales se destaca la inversión en energía limpia, como las fuentes más eficientes para lograrlo y como punto central se deberá invertir más en educación. Pollin compara los empleos que generan la industria militar y el sector de combustibles fósiles y no tienen los mismos efectos sobre los empleos. Es importante señalar esto, ya que en el presupuesto federal de Estados Unidos, las industrias militar y de combustibles fósiles son sectores que reciben los mayores montos de inversión pública. Dado lo anterior, Pollin [2011] plantea que si la participación de la educación y la energía limpia aumentan en el gasto, se obtendrían mayores beneficios en materia de empleos; si se redireccionaran 330 billones de dólares anuales tanto de la industria militar y de los combustibles fósiles y se destinaran hacia los rubros de educación y energías limpias, se crearían alrededor de 4.8 millones de empleos, además de que dicha expansión tendría efectos en todos los sectores y actividades, es decir, se daría un efecto directo, indirecto e inducido sobre la generación del empleo, otorgando más oportunidades laborales a toda la población en general.

El propio Paul Krugman [2012] señala la importancia de que el gobierno invierta más dinero en educación y en infraestructura, como una forma de ayudar al crecimiento de la economía; así se estimularía el factor innovación y ayudaría al crecimiento de la economía. Estas innovaciones son un estímulo muy importante para sacar a la economía de la depresión y este autor pone el 
ejemplo de cómo el iPhone5 es un valioso estímulo para la economía de Estados Unidos porque contribuye al crecimiento económico. Señala Krugman que las empresas deben encontrar razones para invertir, y esto se produce cuando se estimula la obsolescencia que los lleva a sustituir sus bienes de equipo, ya sea porque se han deteriorado o porque han aparecido algunos mucho mejores. Esto lo hacen algunas empresas como Apple, al incentivar la obsolescencia en sus productos como resultado de las innovaciones. Sin embargo, para innovar se requieren trabajadores altamente calificados y de esta forma se crea un círculo virtuoso, al generar todo tipo de empleos en distintos estratos.

Por otro lado, un estudio que presenta la Universidad de Washington plantea que hay una doble tasa de desempleo en Estados Unidos, de $4.5 \%$ para las personas con grados universitarios o más, y de $4 \%$ para aquellas profesiones que requieren una alta capacitación tecnológica [Pope, 2012]. Lo que indica que en la actualidad la oferta de empleos con elevados niveles de conocimiento tecnológico, no se presentan excedentes de trabajadores altamente calificados y en alguna forma explicaría la urgencia para incorporar a los trabajadores extranjeros; además de que limitar el acceso al talento del resto del mundo es contraproducente, pues las compañías pierden competitividad, se reducen sus exportaciones y por lo tanto el Tesoro perdería billones de dólares en impuestos que podrían recaudar de dichas compañías. En otro estudio de la University of Washington's Economic Policy Research Center se concluye que los empleos de alta calificación generan al mismo tiempo otros que requieren menor calificación, como pudieron constatar con la empresa Microsoft, industria que por cada empleo genera 5.8 trabajos para el resto de la economía [Pope, 2012].

Sin embargo, para lograr recuperar su papel de líder en la economía del conocimiento y con ello favorecer la superación de la crisis, Estados Unidos presenta problemas importantes, tanto en lo demográfico como en lo educativo que son de difícil solución en el corto plazo, lo que nos permite comprender los cambios que Estados Unidos pretende instrumentar en relación con los flujos 
migratorios altamente calificados. No es extraño que diversos sectores políticos aludan a la necesidad de incorporar trabajadores migrantes altamente calificados y a los estudiantes talentosos que se encuentran en el país, pues permitirían satisfacer las necesidades y exigencias de los mercados laborales en el nuevo patrón migratorio siendo esto una posible herramienta que favorecería el dinamismo económico.

\section{Dificultades estructurales de algunos sectores de la economía de Estados Unidos para enfrentar la crisis}

\section{Dificultades DEMOGRÁficAS EN Estados Unidos}

La población de Estados Unidos está enfrentando el envejecimiento de su población, problema de muy difícil solución en la medida en que, como la historia ha demostrado, una vez que los países entran en la modernidad demográfica, esta tendencia al envejecimiento es prácticamente irreversible (véase la gráfica 1). Sin embargo, una forma de revertir en alguna medida esta tendencia es mediante la migración femenina, que como vemos en la gráfica 2, ha favorecido el incremento de la tasa de natalidad, que es superior a la de las nativas, lo que representa un enorme beneficio para el país y una estrategia interesante, aunque es un crecimiento demográfico insuficiente y no se logra revertir por completo la tendencia negativa. Es importante subrayar que esta condición demográfica afecta la reproducción de la población económicamente activa (véase la gráfica 3), a lo que habría que añadir el hecho de que la generación baby boom, surgida después de la Segunda Guerra Mundial, está próxima a jubilarse. En este sentido, no se puede desdeñar además la ventaja que tiene la migración sobre el sistema de pensiones y jubilaciones en Estados Unidos, ya que se trata de una población que llega al país siendo jóvenes adultos y por lo tanto productivos, lo que permite que todos esos impuestos directos o indirectos se conviertan en pensiones o jubilaciones y beneficia a la población en edad de retiro. 
Gráfi ca 1. Tasa de fertilidad en Estados Unidos (nacimientos por mujer)

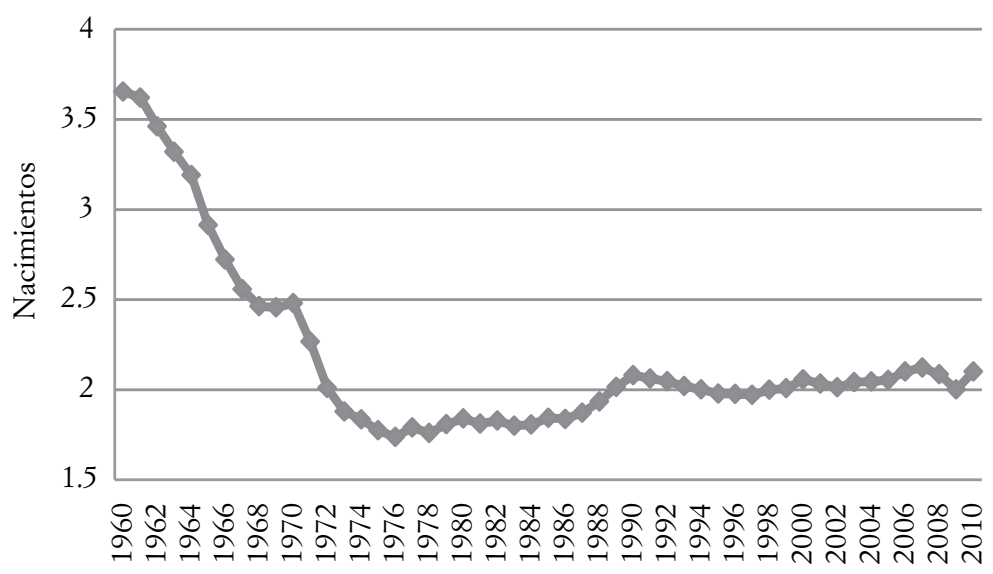

Fuente: Elaboración propia con base en datos del Banco Mundial.

Gráfi ca 2. Tasa de fertilidad en los Estados Unidos 1994-2010

(nacimientos por cada mil mujeres)

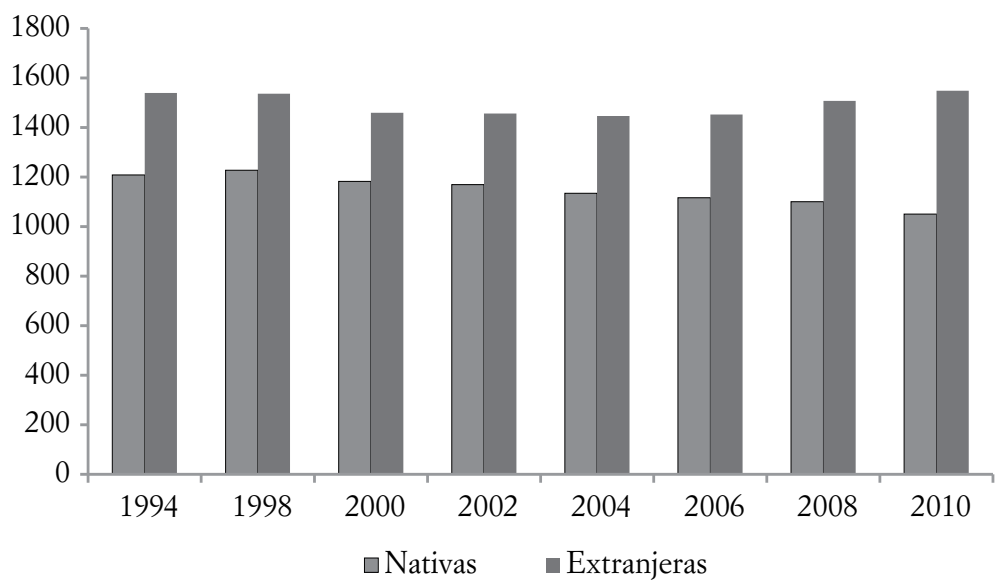

Fuente: Elaboración propia con datos del U.S. Census Bureau. 
Gráfica 3. Proporción de PEA con respecto del total de la población en Estados Unidos (2000-2010)

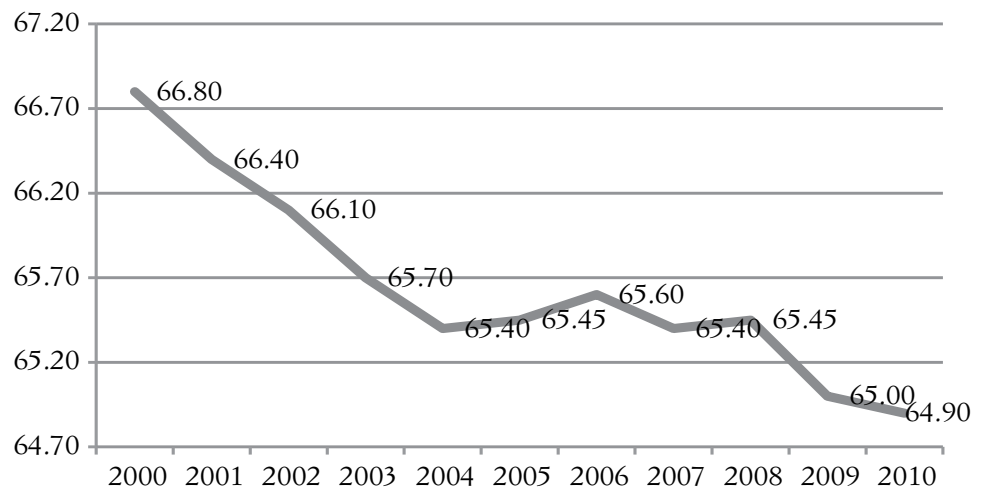

Fuente: Elaboración propia con base a ILO-Labour force survey (Laborsta).

Esta situación demográfica da lugar a que la población blanca no hispana, que es la más numerosa en Estados Unidos, muestre una disminución, al tiempo que las otras minorías se están incrementando (véase la gráfica 4).

La población blanca está viviendo un mayor envejecimiento con respecto de las otras poblaciones. En el caso opuesto se encuentran los hispanos con una población mayormente joven, lo que puede constatarse en las pirámides de población que se presentan en la gráfica 5. Se observa cómo la pirámide poblacional de los blancos se ha invertido entre 1990 y 2010, mientras que las poblaciones hispanas muestran una base más joven en su pirámide para el 2010, otras poblaciones como la negra, asiática y los indios americanos muestran una población más estable, es decir, hay una importante cantidad de población mayor aunque también presentan una base joven que se mantiene casi en los mismos niveles que la población más longeva. 


\section{Gráfi ca 4. Población total y su distribución porcentual en Estados Unidos (1980, 1990, 2000 y 2010)}

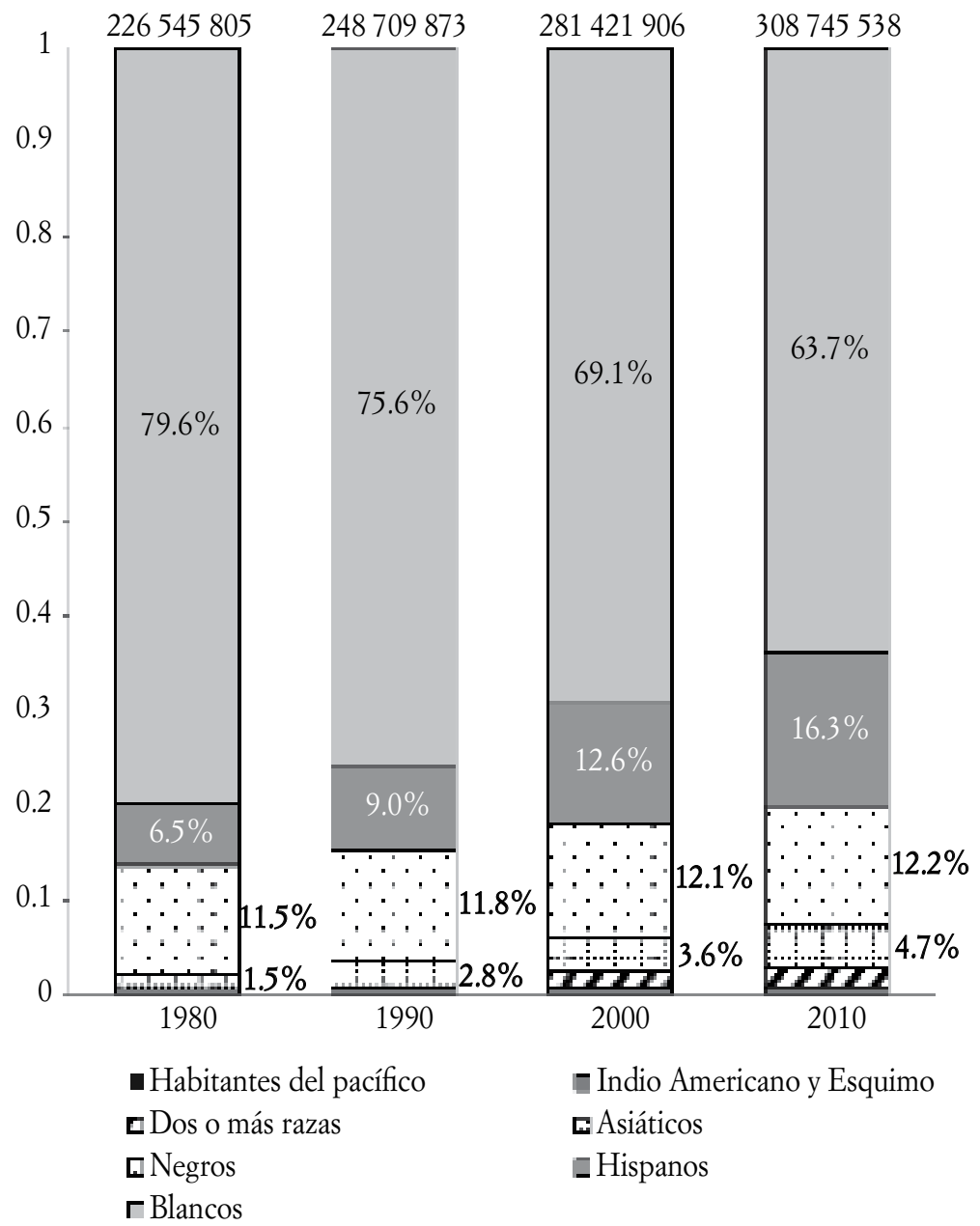

Fuente: Elaboración propia con datos del U.S. Census Bureau. 


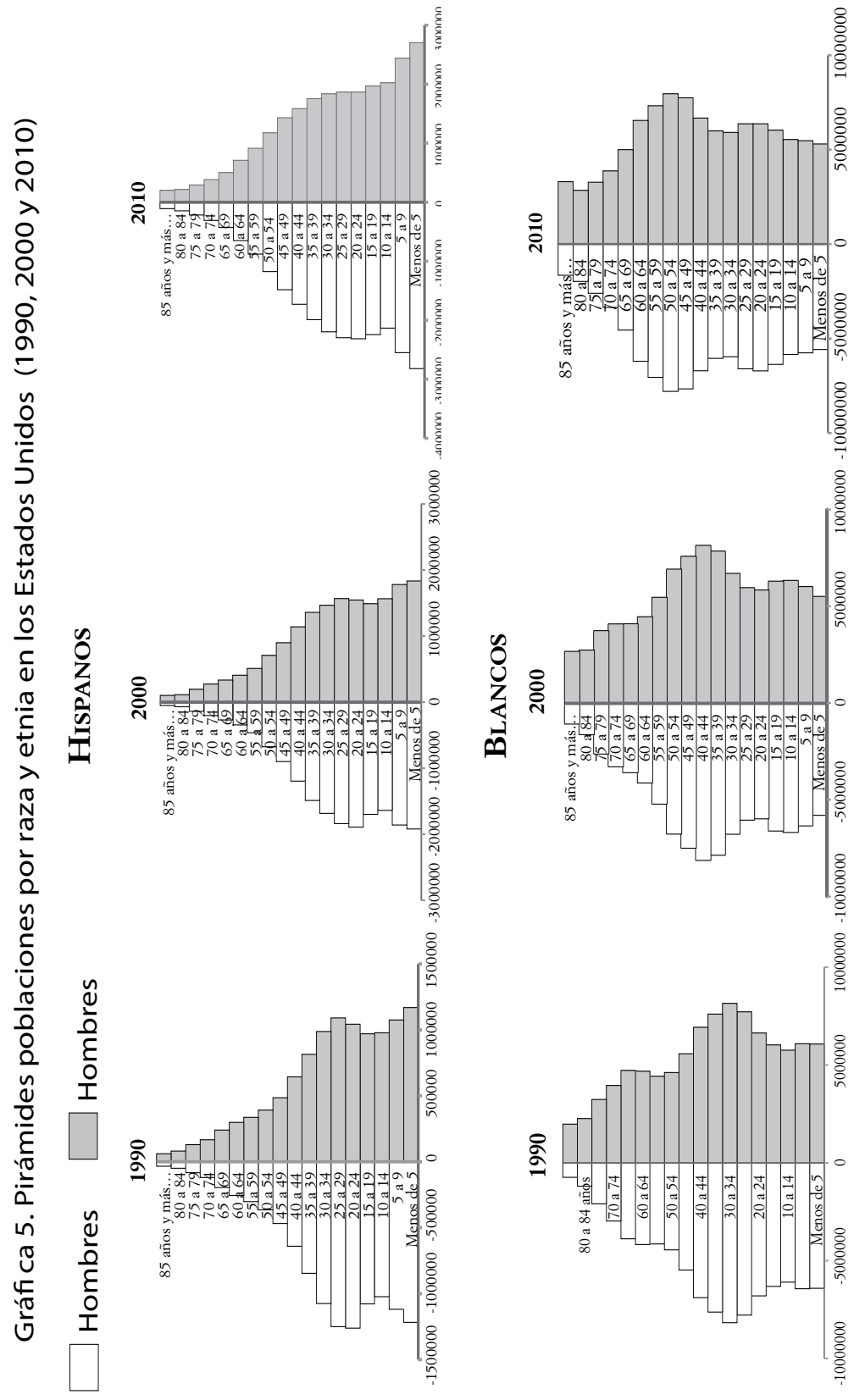




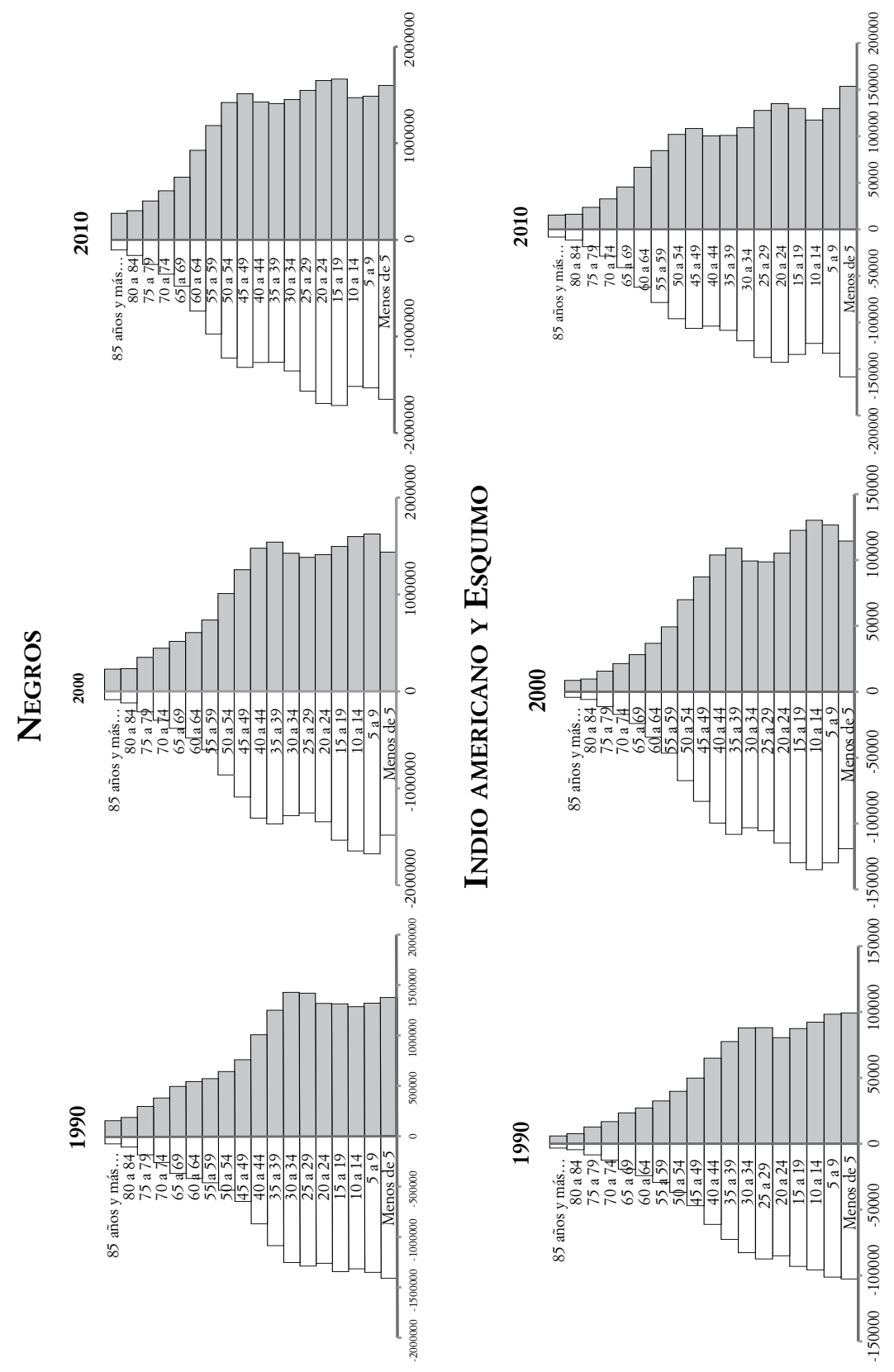




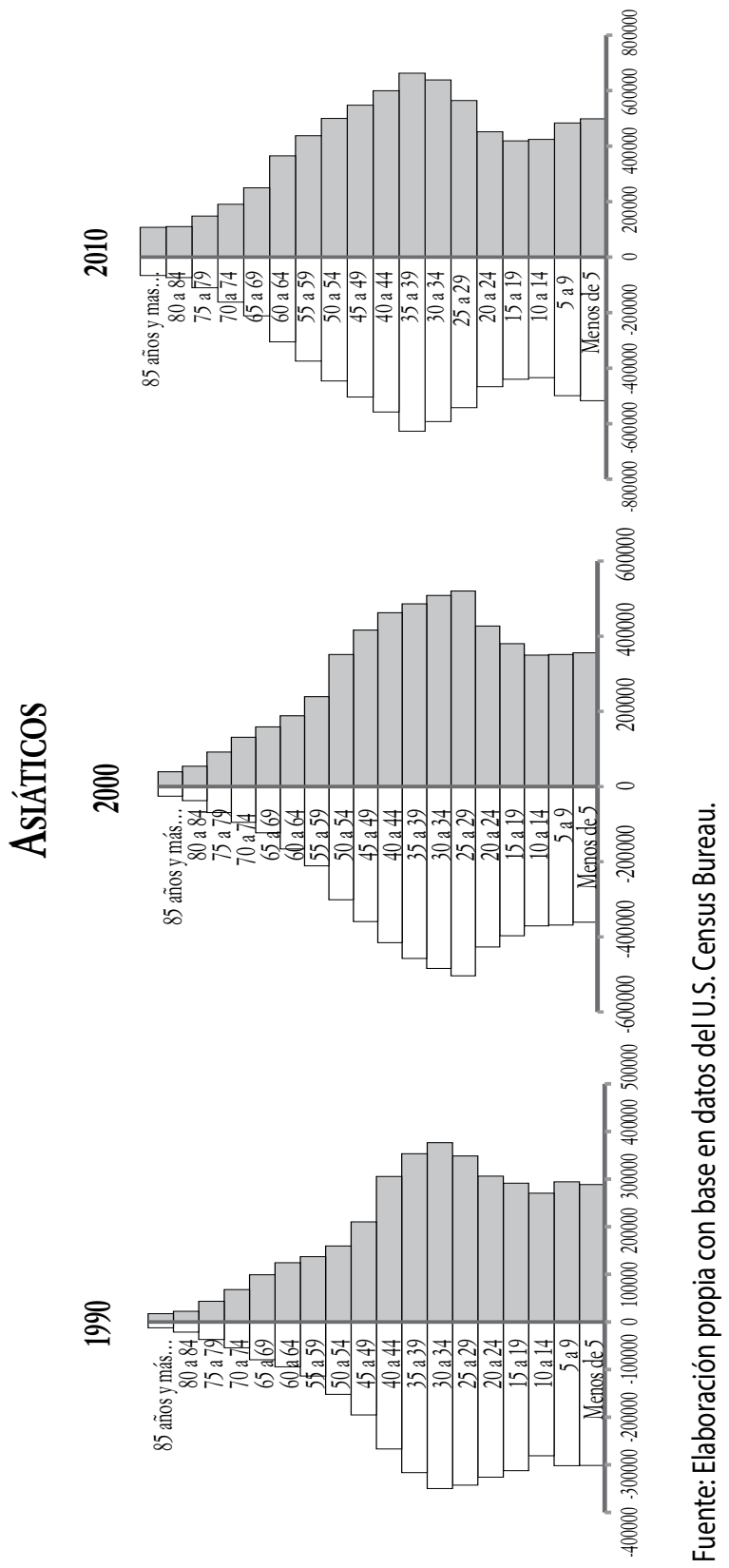




\section{LA EDUCACIÓN EN EsTAdOS UNIDOS}

Decíamos que autores como Krugman [2012] y Pollin [2011] destacan la importancia que tiene invertir de forma sustancial en la educación. Por un lado puede observarse en la gráfica 6 que el gasto del gobierno es menor en la educación terciaria que en la básica y secundaria. Es más, la brecha entre ambas se ha incrementado entre 1997 y 2009. Pero además, la educación en Estados Unidos está muy rezagada en relación con otros países y los avances en aprovechamiento no han crecido significativamente. De acuerdo con el Departamento de Educación de Estados Unidos, los puntajes en las evaluaciones de comprensión de lectura en los alumnos con 17 años fueron de 285 en 1971 y se incrementaron a 286 puntos para el 2008, mientras que, los puntajes en las pruebas de habilidades matemáticas presentaban un puntaje promedio de 300 en 1971 y para el 2008 fue de 306; es decir, se observa una muy ligera mejora de un punto en comprensión de lectura y de seis puntos en habilidad matemática en los últimos 37 años.

\section{Gráfi ca 6. Estados Unidos. Gasto público en educación, 1997 - 2009 (millones de dólares)}

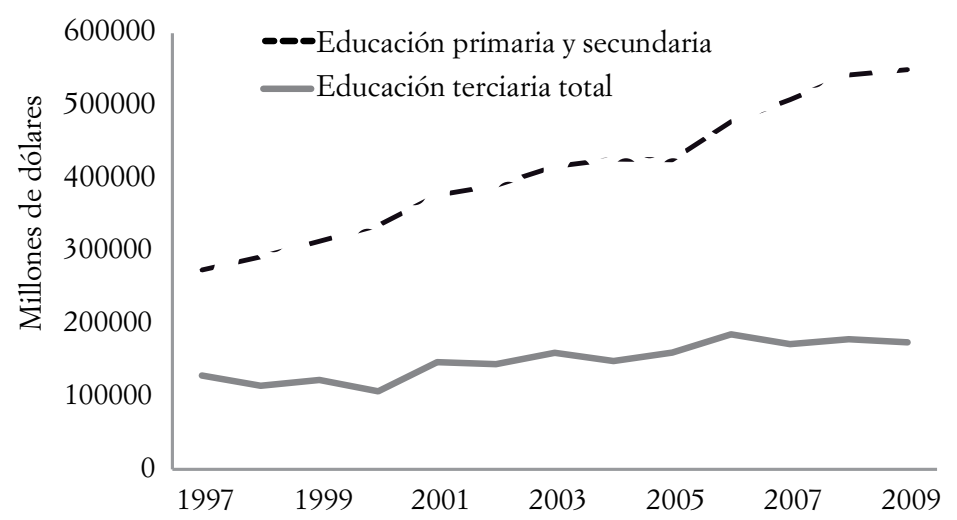

Fuente: Elaboración propia con base en dato de OCDE. Status.

El estancamiento del aprovechamiento académico en Estados Unidos se ve reflejado en los resultados de la prueba PISA 
(Programme for International Student Assessment). Para el año 2009 se observa un rezago en los niveles de aprovechamiento si se compara con otros países desarrollados. Por ejemplo en la comprensión de lectura ocupan el lugar 17, en matemáticas ocupan la posición 31. En ciencias ocupan la posición 23 con un puntaje de 502, ubicándolos ligeramente por arriba del promedio de acuerdo con datos proporcionados por la Organización para la Cooperación y el Desarrollo Económicos (OCDE).

Por otro lado, cuando se analizan las tasas de graduación de licenciatura en Estados Unidos, son muy bajas, sobre todo las que se presentan en las universidades públicas, la cual es de $31.3 \%$ en los programas escolares de cuatro años y de $20.4 \%$ en los programas de dos años, mientras que en las universidades privadas, la tasa de graduación se incrementa ligeramente a $52.5 \%$ (véase el cuadro 1).

Llama la atención el desempeño de la población asiática, muy por encima de la población blanca: 38.0 y $25.6 \%$ en programas de cuatro y dos años respectivamente en colegios públicos. Aunque hay una importante diferencia cuando se analizan los colegios privados con programas educativos de cuatro años que entre los asiáticos tienen una eficiencia terminal de 62.8 y para los blancos es de 55.4 por ciento.

\section{Cuadro 1. Tasas de Graduación de licenciatura en Estados Unidos durante 2010 (\%)}

\begin{tabular}{l|c|c|c}
\hline \multicolumn{1}{c|}{ Tipo de institución } & \multicolumn{2}{c|}{ Colegios públicos } & Colegios privados \\
\hline Duración del Programa & 4 años & 2 años & 4 años \\
\hline Total & 31.3 & 20.4 & 52.5 \\
\hline Blancos & 34.2 & 23.0 & 55.4 \\
\hline Afroamericanos & 16.4 & 11.9 & 30.6 \\
\hline Asiáticos & 38.0 & 25.6 & 62.8 \\
\hline Hispanos & 21.5 & 16.0 & 46.1 \\
\hline Indios americanos & 17.2 & 17.4 & 39.2 \\
\hline
\end{tabular}

Fuente: The Chronicle of Higher Education. College Completion. 
Habría que buscar alguna razón para comprender las discrepancias en las tasas de graduación entre los diferentes grupos sociales pues es seguro que no se deben a diferencias en las capacidades intelectuales entre los grupos. Nos parece que hay problemas estructurales más profundos y uno de ellos tiene que ver con las condiciones de pobreza que presenta cada población. Si observamos la gráfica 7, los afroamericanos e hispanos son los que presentan los más altos niveles de pobreza, a diferencia tanto de los blancos como de los asiáticos. Nos parece que éstas son condiciones que se convierten en verdaderos obstáculos para que los jóvenes puedan completar sus estudios universitarios. Aún cuando las universidades sean públicas, son muy costosas, con pocas diferencias con las privadas y, si bien los estudiantes pueden tener acceso a créditos y becas, la realidad es que en muchas ocasiones sus limitaciones socioeconómicas los obligan a trabajar para completar el costo de sus estudios. Todo esto puede afectar su rendimiento escolar y, en ocasiones, más que las deseadas, tienen que renunciar a seguir estudiando. Sin embargo, hay otros problemas de fondo como es el hecho de que los niños en las escuelas en regiones de alta pobreza funcionan peor que los que se encuentran en regiones más favorecidas económicamente. De acuerdo con autores como Jencks y Phillips [1998] y Neal [2005] esto no sólo se debe a que tienen más recursos, por ejemplo en relación con libros de textos, maestros, servicios de apoyo, es decir, toda la infraestructura que se requiere para educar a los estudiantes que se encuentran en desventaja. Además, como señalan los autores, no sólo la pobre inversión en recursos, sino la falta de mejor capacitación de los profesores y administradores en los distritos escolares más desfavorecidos impide mejorar la calidad de la enseñanza.

Sin duda que si el país quiere superar esos problemas que son un obstáculo para recuperar el liderazgo en la economía del conocimiento [Dabat y Ordóñez, 2009 y Ordóñez, 2008], tendrá que hacer no sólo enormes inversiones en el sector educativo sino además transformar lo que parecen ser factores estructurales muy arraigados en la sociedad estadunidense y que de alguna 
forma mantiene cierta discriminación sobre algunos grupos sociales.

Gráfica 7. Personas en pobreza por raza y origen hispano, 2002-2011 (\%)

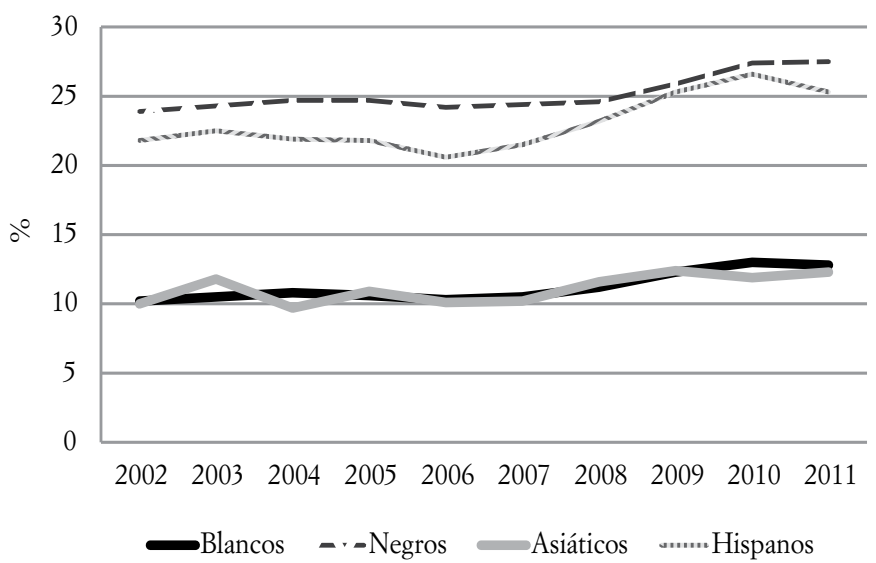

Fuente: Elaboración propia con base a datos de U.S. Bureau of the Census, Current Population Survey, Annual Social and Economic Supplements.

Importancia de los estudiantes extranjeros en Estados Unidos

Parecería paradójico que Estados Unidos cuente con 17 de las 20 universidades más prestigiosas del mundo y, sin embargo, presente tan importantes problemas para que el conjunto de su población nativa alcance a incorporarse en forma amplia dentro de las universidades. Estas universidades son un verdadero imán para una muy importante cantidad de estudiantes que llegan a Estados Unidos de todos los países del mundo. Si se observa la gráfica 8, la proporción de títulos de nivel licenciatura obtenidos entre 1981-2009 en todas las áreas del conocimiento por composición étnica en Estados Unidos se destaca que son los blancos los que presentan una mayor participación, aunque con una tendencia a la baja. Los extranjeros tienen una menor participación 
en licenciatura pues sus países no financian este tipo de estudios en la medida en que pueden realizarlo dentro de sus países de origen.
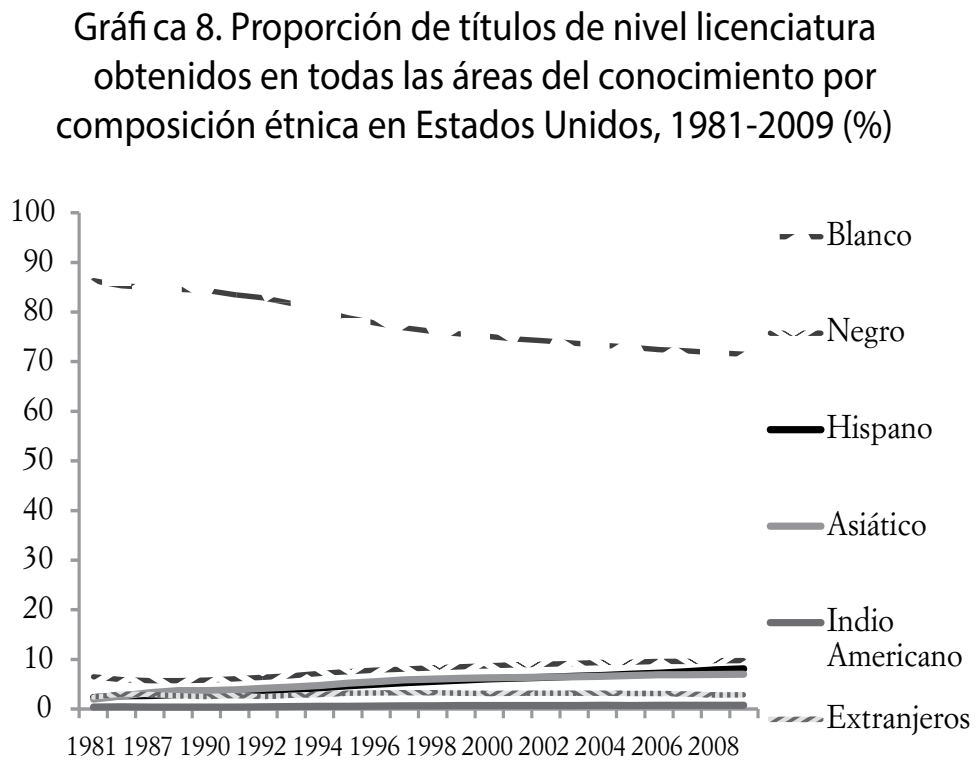

Fuente: Elaboración propia con base en datos del U.S. Census Bureau.

Respecto a los estudiantes que lograron conseguir el grado de maestro, se observa también que la población blanca es la que registra el mayor número de personas con título de maestría; sin embargo, se advierte la misma tendencia a la baja desde 1981 (82\% aproximadamente) a $70 \%$ para el año 2008 . Es interesante subrayar que los extranjeros empiezan a registrar una participación mayor en el nivel de maestría con respecto de la licenciatura, tal como se muestra en la gráfica 9.

Cuando se analiza lo que sucede con los títulos de doctorado, vuelve a aparecer la población blanca con una mayor participación con la misma tendencia decreciente. Sin embargo, llama la atención el comportamiento de la población extranjera con títulos doctorales con un incremento significativo, aproximadamente el doble respecto a los grados obtenidos de nivel maestría (véase la gráfica 10); en tanto que el comportamiento de los sectores restantes 
Gráfi ca 9. Proporción de títulos de nivel maestría obtenidos en todas las áreas del conocimiento por composición étnica en Estados Unidos, 1981-2009 (\%)

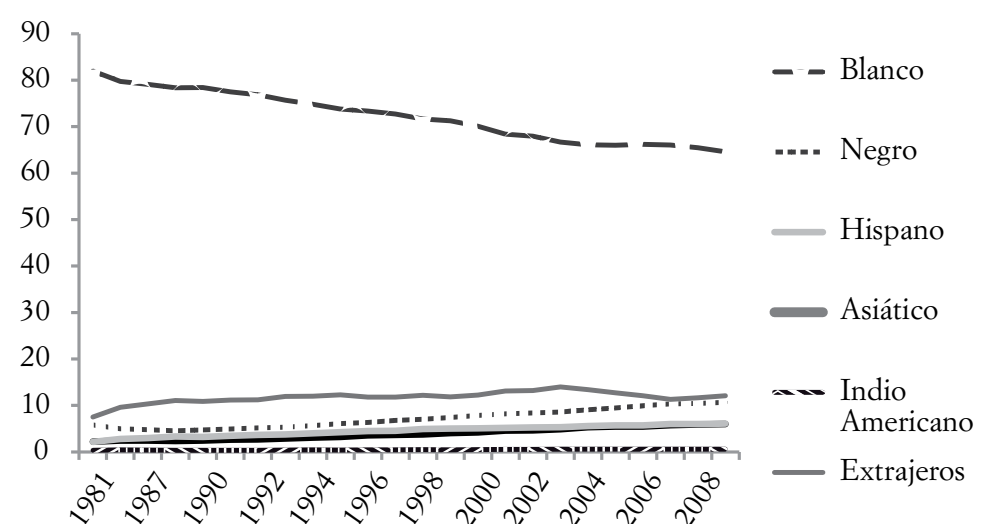

Fuente: Elaboración propia con base en datos del U.S. Census Bureau.

Gráfi ca 10. Doctorado obtenido por raza/grupo étnico, 1981-2009 (para el año escolar finalizado, tasa de actividad)

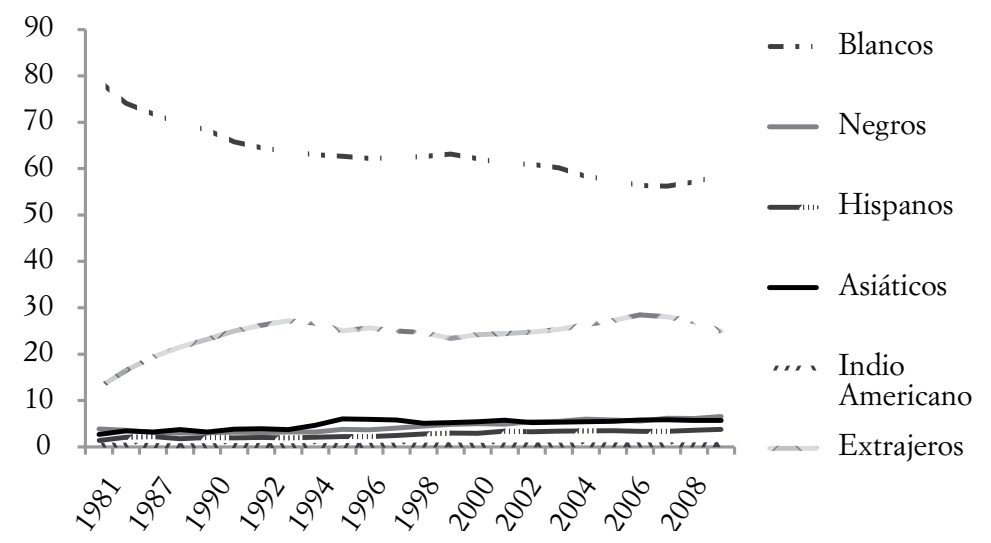

Fuente: Elaboración propia con base en datos del U.S. Census Bureau.

de población prácticamente se estanca en los mismos niveles de licenciatura. Lo que evidencia la importancia que tienen los 
extranjeros en los grados de estudios superiores (maestría y doctorado).

En las tres gráficas anteriores se observa una gran participación de la población blanca con grados de licenciatura, maestría y doctorado obtenidos, lo cual se explica debido a que este grupo poblacional es el más numeroso de la nación estadounidense; sin embargo, su población ha comenzado a descender tal como se observó en la gráfica 4, pero con una tendencia a la baja sobre el total de los grados obtenidos.

La importancia de los estudiantes extranjeros radica en que representan a un conjunto de población joven, con una importante participación no sólo en los estudios superiores de maestría y doctorado sino en aquellas disciplinas relacionadas con la economía del conocimiento, es decir, en las áreas de ingeniería y las ciencias de la computación, donde incluso han superado al número de estudiantes nativos desde 1997 (véase la gráfica 11). Lo mismo sucede en relación con los estudios de posdoctorado en áreas de ciencia y tecnología (véase la gráfica 12). Profesiones que resultan fundamentales para Estados Unidos si quiere recuperar el liderazgo en la economía del conocimiento. Aquí podemos observar otra diferencia importante entre nativos y extranjeros, los primeros tienen una marcada preferencia por profesiones tales como finanzas, negocios, educación, como se observa en la gráfica 13, entre 1971-2009, que si bien son también importantes para el desarrollo de una sociedad, no están tan directamente relacionadas con las necesidades del mercado laboral que está exigiendo profesiones que favorezcan las innovaciones, el desarrollo de la ciencia, de la tecnología, es decir, disciplinas importantes que se relacionan con la economía del conocimiento.

Por lo tanto, no es extraño que ante las exigencias de la economía del conocimiento, distintos grupos políticos y académicos estén haciendo propuestas para facilitar tanto la llegada de migrantes altamente calificados, como de estudiantes extranjeros talentosos para que puedan quedarse en el país sin tener que enfrentar el "laberinto" burocrático y otorgarles en forma rápida la green card de residencia permanente. 
Gráfi ca 11. Matrícula en estudios de posgrado. Los estudiantes extranjeros superan a los nativos en las áreas de las ciencias de la computación y las ingenierías, 1980-2009 (alumnos de tiempo completo, miles)

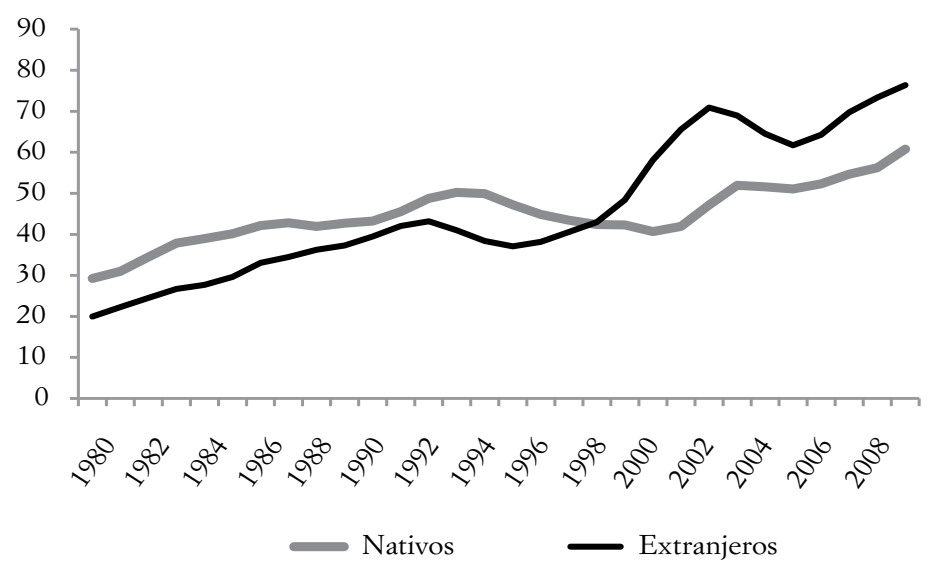

Fuente: National Science Foundation.

Gráfi ca 12. Estados Unidos. Estudiantes nombrados con posdoctorado en ciencia y tecnología (alumnos de tiempo completo, miles)

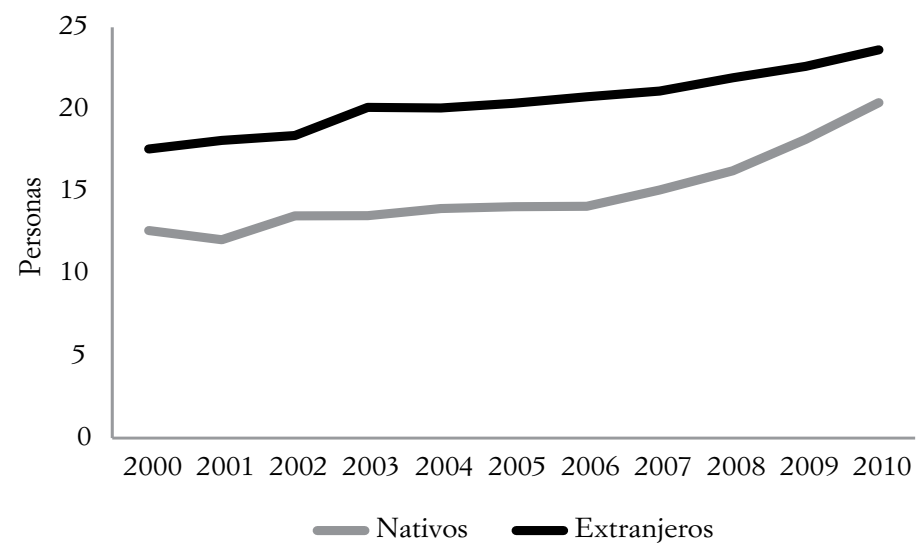

Fuente: National Science Foundation. 
Gráfi ca 13. Graduados de licenciatura por campo, Estados Unidos, 1971-2009 (cinco principales)

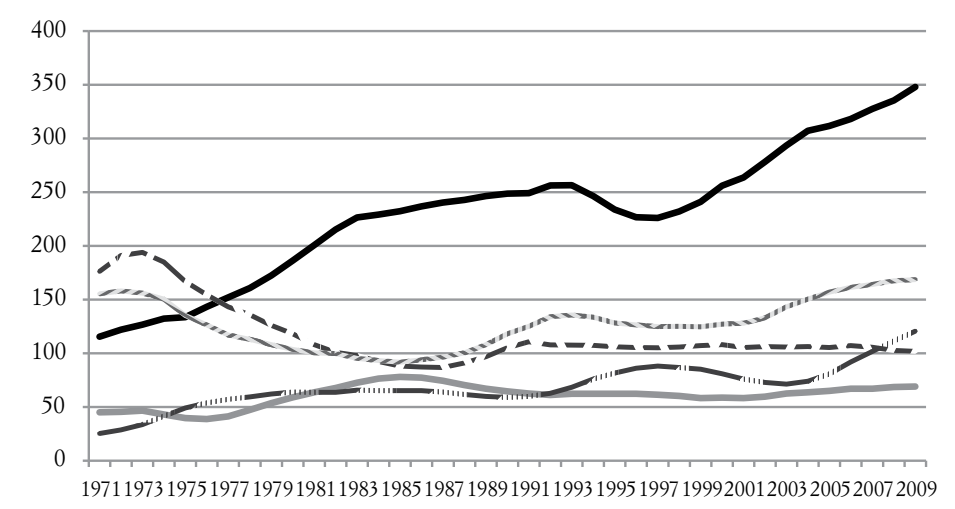

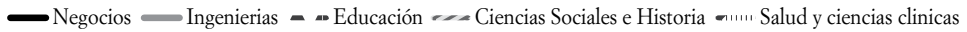

Fuente: Elaboración propia con base en datos de U.S. National Center for Education.

Los propios republicanos estaban proponiendo una ley para incrementar la green card en 50 mil para aquellos graduados extranjeros de altas calificaciones, sobre todo, para los de ciencias y tecnología. Los demócratas están haciendo lo propio, hablando de 55 mil visas, sin dejar de lado la lotería para otros migrantes, cosa que los republicanos quieren quitar por las otras visas [Preston, 2012].

Por otro lado, 165 líderes de universidades estadunidenses, enviaron una carta al Congreso y al presidente Obama alertándolos por la falta de visas para graduados de ciencias, lo que se convierte en una amenaza para la preeminencia de Estados Unidos como un centro global de innovación y prosperidad. Entre estos se encontraban los presidentes de la Universidad de Stanford, Harvard, Cornell y el MIT. De acuerdo con los líderes de las universidades en el año 2009 los estudiantes extranjeros que se encontraban graduados en ingeniería, computación y ciencias, $52 \%$ habían obtenido el doctorado en estos campos. Finalmente, el propio alcalde de Nueva York, Michael Bloomberg, importante abogado de la causa de los migrantes, urgió a los políticos para 
no perder este momento en el que parecería que ambos partidos estaban de acuerdo en el tratamiento para los migrantes. Por otro lado, parecería que después de la reelección de Barak Obama, para lo cual el voto latino fue decisivo, hay una mayor tendencia por parte de los republicanos para apoyar una reforma migratoria [Pope, 2012].

Una vez analizados los problemas que enfrenta Estados Unidos, no nos llama la atención que requiera la aportación de los estudiantes talentosos extranjeros, en la medida en que los puede captar en tiempo y cantidad a diferencia de los que puede formar de modo interno.

Parecería claro que Estados Unidos está impulsando una política migratoria cuya finalidad es resolver sus dificultades estructurales y así recuperar su papel como líder de la economía del conocimiento. Es necesario que el mundo le envíe a sus mejores cuadros para seguir innovando y creando investigaciones en todos los campos del saber, pero básicamente entre los dedicados a la ingeniería, ciencias físicas, computación, informática, justamente profesiones en las que ese país tiene grave déficit. Por lo tanto, si se esperaba desde el año 2000 un flujo migratorio altamente calificado hacia Estados Unidos, parece que el nuevo patrón migratorio estará conformado por una mucha mayor participación del talento mundial, como no se había observado en patrones anteriores.

\section{Nuevo patrón migratorio bajo el contexto de la crisis}

Llama la atención que a pesar de la profunda crisis vivida por Estados Unidos en 2007-2009 y que afectó a los flujos migratorios debido al desempleo que se disparó a grados sólo vistos en la crisis de 1929, sin embargo, aquellos flujos de trabajadores altamente calificados tuvieron una corta tendencia a la baja en los años de la crisis y han vuelto a recuperar su importancia. Algunos autores están conscientes de que es necesario reformular 
el sistema de migración de alta calificación como una forma para estimular la innovación y la competitividad. No es extraño observar un incremento considerable en la emisión de visas para migrantes con altos niveles de calificación, como son las $\mathrm{H}-1 \mathrm{~B}$, L1 y O1 que superan una tasa de $10 \%, 10.8,12.3$ y $17.9 \%$, respectivamente. Las variaciones porcentuales absolutas entre 1996 y 2011 nos muestran que la emisión de visas O1 para trabajadores con habilidades extraordinarias fueron las que presentaron el mayor incremento en términos absolutos (véase el cuadro 2).

\section{Cuadro 2. Total de visados emitidos por Estados Unidos, 1996, 2008, 2011 (nominales, \%)}

\begin{tabular}{l|c|c|c|c|c}
\hline $\begin{array}{c}\text { Tipo } \\
\text { de visa }\end{array}$ & 1996 & 2008 & 2011 & $\begin{array}{c}\text { Tasa de } \\
\text { crecimiento } \\
\text { Promedio } \\
\text { anual } \\
\text { 1996-2011 }\end{array}$ & $\begin{array}{c}\text { Variación } \\
\text { porcentual } \\
\text { 1996-2011 }\end{array}$ \\
\hline $\mathrm{H}-1 \mathrm{~B}$ & 144458 & 409619 & 494565 & 10.8 & 242.4 \\
\hline $\mathrm{L} 1$ & 140457 & 382776 & 562776 & 12.3 & 300.7 \\
\hline $\mathrm{O} 1$ & 7177 & 53735 & 51775 & 17.9 & 621.4 \\
\hline $\mathrm{H} 3$ & 2986 & 6156 & 3279 & 0.8 & 9.8 \\
\hline $\mathrm{J} 1$ & 215475 & 459126 & 469993 & 6.7 & 118.1 \\
\hline
\end{tabular}

Fuente: Elaboración propia con base en U. S. DHS, Office of Immigration Statistic, 1996, 2012 Yearbooks of Immigration Statistics.

Es interesante observar la distribución geográfica de las visas otorgadas por Estados Unidos. Poco más de $50 \%$ de las visas H1-B se otorga a solicitantes europeos y asiáticos. En relación con las visas tipo H-2B la participación más importante, y además al alza, es para América del Norte pasado de 66\% en 1996 a 91\% en 2011. Para el caso de las visas L1, el mayor peso porcentual lo retoman Europa y Asia, sin embargo, en 2011 se ven superados por América del Norte. En cuanto a las visas O1 están concentradas en mayor medida para la región de Europa (véase el cuadro 3). 
Cuadro 3. Visados por tipo en Estados Unidos, 1996 y 2011 (\%)

\begin{tabular}{l|c|c|c|c|c|c|c|c|c}
\hline \multirow{2}{*}{$\begin{array}{c}\text { Región/Tipo } \\
\text { y periodo }\end{array}$} & \multicolumn{3}{|c|}{ H-1B } & \multicolumn{3}{c|}{ L1 } & \multicolumn{3}{c}{ O1 } \\
\cline { 2 - 12 } & $\mathbf{1 9 9 6}$ & $\mathbf{2 0 0 8}$ & $\mathbf{2 0 1 1}$ & $\mathbf{1 9 9 6}$ & $\mathbf{2 0 0 8}$ & $\mathbf{2 0 1 1}$ & $\mathbf{1 9 9 6}$ & $\mathbf{2 0 0 8}$ & $\mathbf{2 0 1 1}$ \\
\hline Europa & 36 & 20 & 16 & 47 & 40 & 26 & 64 & 55 & 52 \\
\hline Asia & 39 & 55 & 47 & 30 & 34 & 28 & 9 & 12 & 10 \\
\hline África & 2 & 2 & 1 & 1 & 1 & 1 & 1 & 1 & 1 \\
\hline Oceanía & 3 & 1 & 1 & 3 & 3 & 2 & 5 & 5 & 5 \\
\hline América del Norte & 9 & 12 & 27 & 9 & 12 & 37 & 12 & 17 & 23 \\
\hline América del Sur & 9 & 10 & 7 & 7 & 9 & 5 & 6 & 9 & 7 \\
\hline Desconocidos & 1 & 0 & 1 & 2 & 0 & 1 & 2 & 0 & 1 \\
\hline Total & 100 & 100 & 100 & 100 & 100 & 100 & 100 & 100 & 100 \\
\hline
\end{tabular}

Fuente: Elaboración propia con base en U. S. DHS, Office of Immigration Statistic, 1996, 2012 Yearbooks of Immigration Statistics.

Es muy interesante observar que las visas $\mathrm{O} 1$ otorgadas para migrantes de alta calificación, con habilidades y logros extraordinarios, se mantuvieron incluso en el momento más profundo de la reciente crisis mundial, es más, se puede decir que se han mantenido en continuo crecimiento (véase la gráfica 14).

\section{Gráfi co 14. Total visas emitidas por Estados Unidos para los trabajadores con habilidades o logros extraordinarios (O1), 1985-2011}

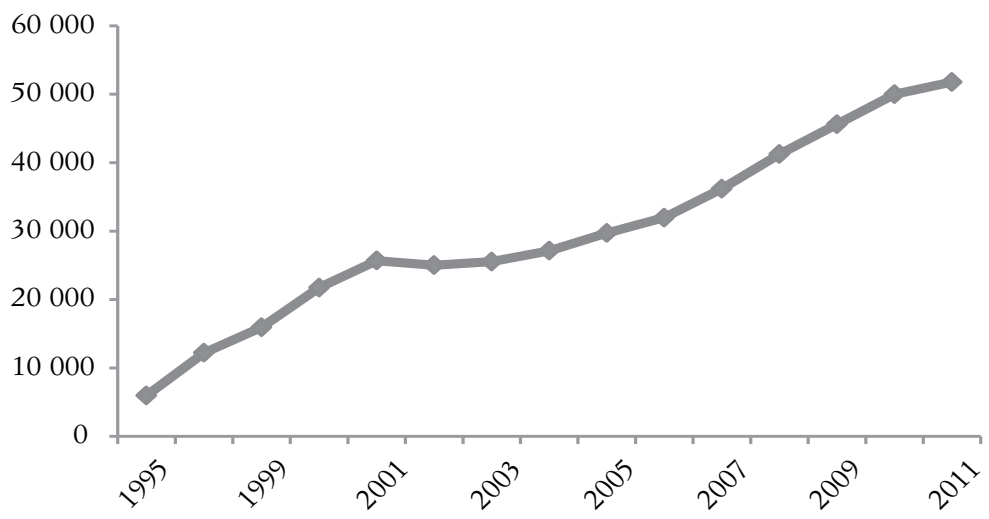

Fuente: Elaboración propia con base en datos de Homeland Security, U.S. 
De acuerdo con el Pew Research, Social and Demographic Trends [2012], son los asiáticos quienes obtienen el mayor número de visas de ingreso como residentes y tienen el mayor número de visas patrocinadas por empleadores para llegar a trabajar y no mediante la reunificación familiar como sucede con la mayoría de los hispanos. Estos migrantes provienen principalmente de Japón, China, Corea, Filipinas, Vietnam e India. Los asiáticos tienen niveles educativos por encima de la media nacional estadounidense. De los migrantes asiáticos $39 \%$ poseen título universitario en contraste de $28 \%$ de los estadounidenses. Son la minoría con menos problemas de asimilación y las principales áreas en las que trabajan son ciencias, ingeniería, medicina y finanzas.

De acuerdo con los datos que presentan Docquier et al. [2009], 15 países de la Unión Europea para el año 2000 mostraron una pérdida neta de trabajadores de alta calificación que se trasladaron hacia el resto del mundo, básicamente hacia Estados Unidos, Australia, Canadá y Nueva Zelanda, países que presentan un enorme déficit. Tritah [2008] estimó que la fuga de talentos es un síntoma de la falta de demanda de trabajo altamente calificado en Europa, lo que se traduce en bajos salarios para los científicos, trabajos inestables y no atractivos pues tienen una carga excesiva de trabajo administrativo. Por lo tanto, hay pocos incentivos para enrolar a los profesionistas en estudios relacionados con la ciencia y la tecnología, sin embargo, Europa forma más doctores en estos campos que Estados Unidos. De hecho, en el año 2010 había 1.09 millón de ofertas y sólo 582 mil trabajadores estaban disponibles.

Esta situación pone de manifiesto que otros países están subsidiando a la principal potencia del mundo y están contribuyendo con sus recursos a una posible atenuación de los efectos adversos de la reciente crisis global en el marco del nuevo patrón de acumulación. En este sentido, México incrementará el envío de trabajadores altamente calificados, lo que lo sumergirá aún más en la subordinación y el subdesarrollo ya que, ha comenzado un importante proceso de diversificación en la emisión de visas para los trabajadores mexicanos, a pesar de que el 
número de emisiones para trabajadores agrícolas es muy elevado se ha observado un incremento importante en las visas para trabajadores con ocupaciones especializadas (H1-B) y que en 2011 representan seis veces a la cantidad de visas emitidas para 1996. Las visas para trabajadores con habilidades extraordinarias $(\mathrm{O} 1)$ son casi 13 veces mayores, mientras que las de transferencia dentro de una misma empresa (L1) son 15 veces más altas que en 1996 (véase el cuadro 4). De esta forma, parecerían redefinirse los términos de la dominación y la dependencia que tipifican a la economía mundial, mediante la innovación y la tecnología como base de esa dominación, para lo cual la migración será un elemento central.

\section{CONCLUSIONES}

En el presente trabajo planteamos que la crisis estructural 20072009 , está conformando un nuevo patrón migratorio cuyas características son el enorme peso que están teniendo los trabajadores migrantes altamente calificados, los que, si bien empezaron a fluir desde finales del siglo pasado, ahora han incrementado sus flujos en forma extraordinaria pues son considerados como un elemento importante para favorecer la superación de la crisis en los países receptores y en forma muy especial para Estados Unidos. Esto se debe, en parte, a que este país enfrenta problemas estructurales en el sector educativo lo que dificulta recuperar su liderazgo en la economía del conocimiento y, por lo tanto, enfrentar la crisis. En este sentido, no es extraño que el propio presidente Barak Obama se muestre sumamente preocupado con la educación de su país y, por ello, señaló en su campaña la importancia de cambiar la situación que vivía el sector, destacando la importancia de disciplinas tales como las matemáticas y otros rubros en los que los estadounidenses están muy rezagados en comparación con otros países. 


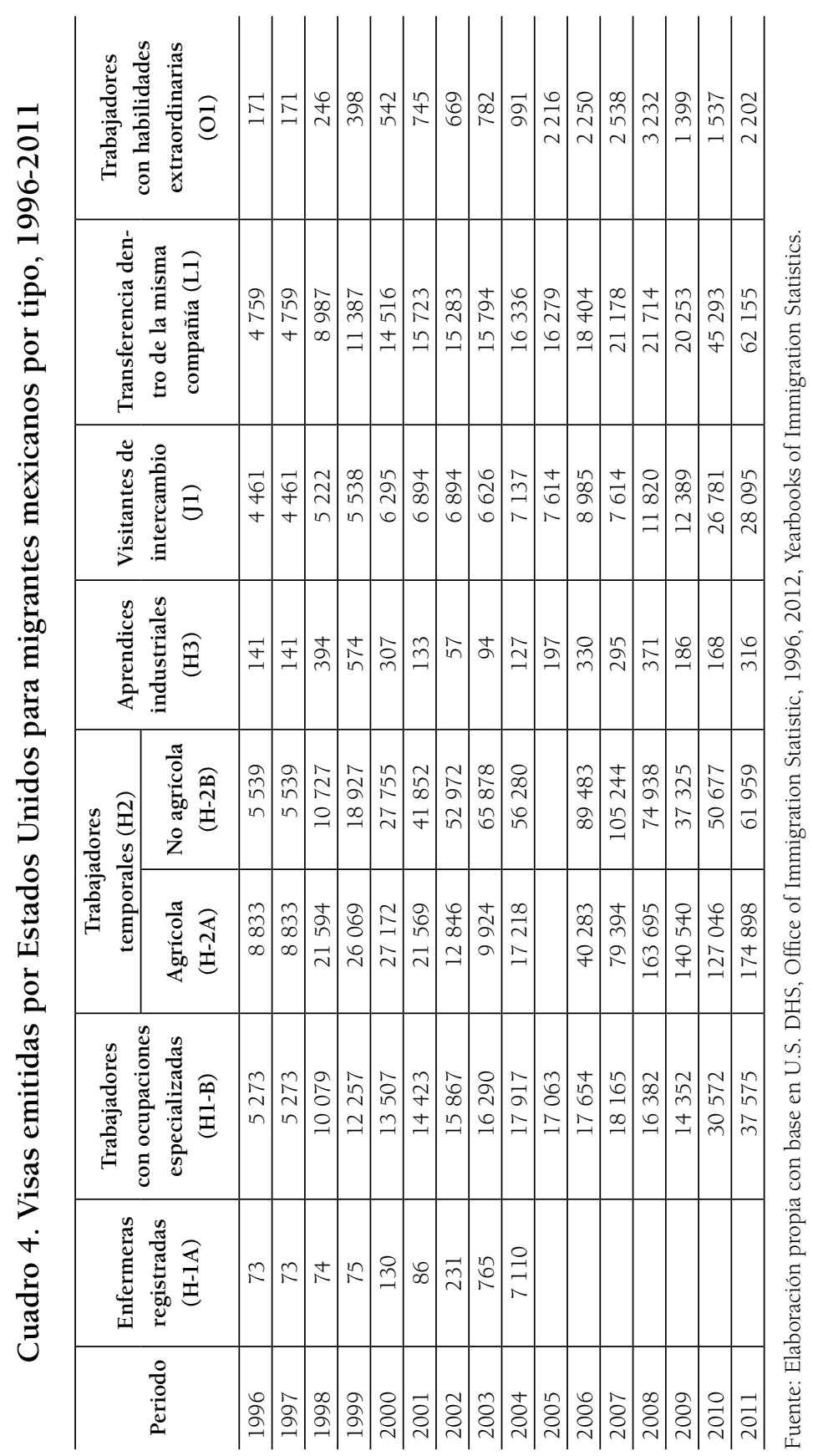


Lo grave de esta situación es que los estudiantes extranjeros que tienen un peso importante en estudios tanto de maestría y doctorado en Estados Unidos son financiados, en muchas ocasiones, por los presupuestos limitados de los países expulsores; por lo tanto, la política migratoria que impulsa Estados Unidos con la finalidad de resolver sus dificultades estructurales dará lugar a que esos países auxilien a la potencia estadounidense en relación con la economía del conocimiento, lo cual mantendrá la subordinación de los países periféricos en la reconfiguración del nuevo patrón de acumulación.

\section{BiBLIOGRAFÍA}

Brito, F. [2000], "Brasil, final de século: a transição para um novo padrão migratório?”, Encuentro Nacional de Estudios Poblacionales; Anales de Cedeplar, Caxambu.

Cave, D. [2011], "Better lives for mexican cut allure of going north", The New York Times, en sección "Nation/World", 6 de julio.

Dabat, A y Sergio Ordóñez [2009], Revolución informática, nuevo ciclo industrial e industria electrónica en México, IIEc-UNAM, México.

Docquier, F., L. Lowell y A. Marfouk [2009], "A gendered assessment of highly skilled emigration", Population and Development Review, 35 (2), 297- 322.

Durand, J. [2011], "Migración a la baja", La Jornada, en sección "Opinión", 17 de julio.

Fernández-Vega, C. [2011], "México SA"; La Jornada, sección opinión 15 de septiembre, disponible en: <http://www.jornada.unam.mx/2011/09/15/opinion/030o1eco>.

García, R. [2012], "Cero migración: declive de la migración internacional y el reto del empleo nacional", Migraciones internacionales, vol. 6, núm. 4, julio-diciembre, págs. 273-283.

González, R. [2012], "Histórico: 14 millones de mexicanos en la economía informal, revela INEGI”, La Jornada, en sección 
"Economía", México, sábado 11 de febrero, disponible en: $<$ http://www.jornada.unam.mx/2012/02/11/economia/ 026n1eco>.

Hobsbawn, E. [1998], La era del capital, 1848-1875. Barcelona, España, Crítica.

Jencks, C. y M. Phillips [1998], The black-white test score gap, Washington, DC, Brookings Institution.

Krugman, P. [2012], "El estímulo del iPhone”, El País, sección de "Opinión", 16 de septiembre, consultado el 16 de enero de 2013, disponible en: <http://economia.elpais.com/econo$\mathrm{mia} / 2012 / 09 / 14 /$ actualidad/1347641376_523817.html>.

Martínez, J. y M. Villa [2005], "International migration in Latin America and the Caribbean: a summary view of trends and patterns", artículo presentado en la United Nations Expert Group Meeting on International Migration and Development, Nueva York, 6-8 de julio.

Neal, D. [2005], Why has black-white skill convergence stopped?, Cambridge, MA: NBER Working Paper 11090.

Ordoñez, Sergio [2008], "La industria de servicios de telecomunicaciones en la crisis actual: Estados Unidos y México", ponencia en el Seminario de Economía Méxicana, IIEc, UNAM, México.

Pew Research, Social \& Demographic Trends [2012], "The rise of Asian americans", 19 de junio, consultado el 14 de enero de 2013, disponible en: <http://www.pewsocialtrends. org/2012/06/19/the-rise-of-asian-americans/ $>$.

Pollin, R. [2011], "Back to full employment", New Democracy Forum, págs. 13-31.

Pope, J. [2012], "College costs: new research weighs the true value of a college education", Huff Post Money, consultado en 26 de enero de 2013, disponible en: <http://www.huffingtonpost.com/2012/08/20/college-costs-new-research-weighsvalue-of-college-education_n_1813337.html>.

Preston, J. [2012], "Republicans push bill to help foreign science graduates stay", The New York Times, septiembre. 
Ravenstein, E. [1885], "The laws of migration", Journal of the Statitical Society 48, págs. 167-235.

Rodríguez, I. [2011a], "Nadie se salvó de la caída en su ingreso, entre 2008 y 2010: INEGI", La Jornada, en sección "Economía”, México, sábado 16 de julio.

Rodríguez, I. [2011b], "El narcotráfico, el que genera más empleos: 600 mil, afirma experto", La Jornada, en sección "Economía", México, domingo 17 de julio, disponible en: <http:// www.jornada.unam.mx/2011/07/17/economia/024n1eco >.

Tritah, A. [2008], "The brain drain between knowledgebased economies: the european human capital outflow to the US", Économie internationale, núm. 115, diciembre, págs. 65-108.

Valenzuela, J. [1990], ¿Qué es un patrón de acumulación?, Facultad de Economía, Universidad Nacional Autónoma de México, pág. 189.

Valenzuela, J. [2012], "América Latina: alternativas frente a la crisis", La jornada de oriente, sección "Opinión", 24 de enero.

Zelinsky, W. [1971], "The hypothesis of the mobility transition", Geographical Review, núm. 61. 


\section{SOBRE LOS AUTORES}

\section{JoHn SAXE-FERNÁNDEZ}

Doctor en Estudios Latinoamericanos por la Facultad de Filosofía y Letras de la UNAM e Investigador Adlai Stevenson en el United Nations Institute for Training and Research (Unitar). Autor, coautor y coordinador de 23 libros, entre los más recientes La compraventa de México (Plaza y Janés, 2002); Tercera vía y neoliberalismo (Siglo XXI, 2004); Terror e Imperio (Random House, 2006); y La energía en México. Situación y Alternativas (CEIICH, UnAm 2009). Recibió el Premio Anual de Investigación Económica Maestro Jesús Silva Herzog 1993, otorgado por el Instituto de Investigaciones Económicas al mejor ensayo publicado en la revista Problemas del Desarrollo y el Premio Universidad Nacional 2000 en Docencia en Ciencias Sociales. En 2008 obtuvo el Primer Premio Nacional de Periodismo en la categoría Análisis Internacional. Sus artículos han aparecido en revistas de México, América Latina, Europa, Canadá y Estados Unidos. Es miembro del Sistema Nacional de Investigadores nivel III. Correo electrónico: <jsaxef@gmail.com>.

\section{ARMANDO BARTRA}

Tiene estudios en Filosofía en la Facultad de Filosofía y Letras de la unAm. Fue profesor en la Facultad de Economía, impartiendo 
las materias Seminario de El capital y Seminario de La cuestión agraria, de 1973 a 1980, también en la Escuela Nacional de Antropología e Historia, en la licenciatura y la maestría de Antropología Social. Fue director del Instituto de Estudios para el Desarrollo Rural Maya, A.C. Actualmente es Profesor-investigador titular C, en la Universidad Autónoma Metropolitana, campus Xochimilco, imparte cátedras en la licenciatura en Sociología y el posgrado en Desarrollo Rural. Correo electrónico: <abartra@ correo.unm.mx>.

\section{Arturo Huerta González}

Realizó estudios de maestría en Economía en la Universidad de Chile y de doctorado en la Facultad de Economía de la UNAM. Es Jefe de la División de Estudios de Posgrado de la Facultad de Economía. Ha realizado estadías de investigación en las universidades de Berkeley y Kansas City Missouri, en Estados Unidos, Campinas en Brasil y Cambridge Inglaterra. Asimismo, ha sido merecedor del Premio Anual de Investigación Económica Maestro Jesús Silva Herzog 1985, otorgado por el Instituto de Investigaciones Económicas de la unAm y el Premio Universidad Nacional 1994 en el área de Investigación en Ciencias Económico-Administrativas. Es autor de 16 libros con el tema de economía mexicana, más de 190 artículos teóricos y analíticos publicados en revistas especializadas, así como en libros colectivos en México y el extranjero. También es miembro del Sistema Nacional de Investigadores nivel III del Conacyt. Correo electrónico:<ahuerta@unam.mx> .

\section{Alejandro Valle BaEZa}

Maestro y doctor de Economía por la UnAm. Es profesor de tiempo completo del Área de Economía Política y del Posgrado de la Facultad de Economía de la UNAm. Entre sus publicaciones más recientes se encuentran los artículos "Profit and trade déficit in 
the U.S. economy: a marxist perspective" y "What is the relationship between the rates of the interest and profit? An empirical note for the U.S. economy, 1869-2009”, publicados en 2012 junto con Iván Mendieta Muñoz. Correo electrónico: <valle@ servidor.unam.mx>.

\section{EDUARDO LORÍA}

Doctor y maestro en Economía, es miembro del Sistema Nacional de Investigadores desde 1988 y de la Academia Mexicana de Ciencias. Es profesor titular $\mathrm{C}$ de tiempo completo, fundador y coordinador del Centro de Modelística y Pronósticos Económicos (CEMPE) de la Facultad de Economía de la UnAM. Fundador y coordinador de la Especialidad en Econometría Aplicada, División de Estudios de Posgrado, Facultad de Economía, unam. Es autor de múltiples artículos de investigación y libros especializados, también es árbitro y miembro del comité editorial de varias prestigiosas revistas. Para una reseña más completa consultar: $<\mathrm{http} / /$ www.economia.unam.mx/profesores/eloria/>.

\section{EMmanUel SALAS}

Técnico académico titular $\mathrm{B}$ adscrito al CEMPE, doctorante en el área de econometría aplicada bajo asesoría del doctor Eduardo Loría. Es profesor de la especialidad en Econometría aplicada, árbitro de la revista Economía teoría y práctica de la UAM y miembro del comité editorial de Journal of Economics \& Finance.

\section{AlejandRo García}

Es pasante en la Facultad de Economía de la UnAm y becario del proyecto PAPIIT "Recesión y mercados laborales en México. Un análisis estructural, 1985-2020”. Es asistente de investigación en el CEMPE. 


\section{ALEJANDRO GÓMEZ}

Es pasante en la Facultad de Economía de la UNAM y becario del proyecto PAPIIT "Recesión y mercados laborales en México. Un análisis estructural, 1985-2020”. Es asistente de investigación en el CEMPE.

\section{JOAQUín ARANGO}

Es catedrático de Sociología en la Universidad Complutense de Madrid y director del Centro de Estudios sobre Migraciones y Ciudadanía en el Instituto Universitario de Investigación Ortega y Gasset. Hasta hace pocos meses fue presidente del Foro para la Integración Social de los Inmigrantes. También es co-director del Anuario sobre Inmigración y Políticas de Inmigración en España y miembro de los consejos asesores o científicos de varias instituciones internacionales y nacionales. Es miembro de los Consejos de Redacción del Journal of Ethnic and Migration Studies (Jems), Migration Studies, Studi di Sociologia, Migraciones y Desarrollo (México), Mondi Migranti (Italia), Demográfia (Budapest), Revista de Occidente y Pensamiento Iberoamericano. Correo electrónico: <arango@cps.ucm.es>.

\section{Claudio Rama}

Es decano de la Facultad de Ciencias Empresariales de la Universidad de la Empresa de Uruguay (UDE). Economista (UCV), master en Gerencia de la Educación (UjMv), doctor en Educación (UNESR), doctor en Derecho (UBA), además de tres posdoctorados (Universidad Estatal de Campinas, Unicamp; Universidad Nacional Experimental Simón Rodríguez, UNESR; Universidad Federal Fluminense, UFF). Fue Director del Instituto Internacional de la UNESCO para la Educación Superior en América Latina y el Caribe (IESALC). Dictó cursos y conferencias en más de 170 
instituciones y eventos académicas en 30 países. Tiene 21 libros propios, 10 libros como coeditor, 78 artículos publicados en libros y revistas arbitradas, además de cientos de artículos en diversos diarios. Recibió en dos ocasiones el Premio Nacional de Literatura del Uruguay por sus escritos académicos y tres doctorados honoris causa (Universidad Nacional Mayor de San Carlos, unmsm; Universidad Católica de los Ángeles de Chimbote, Uladech; Universidad Inca Garcilaso de la Vega, UIGV). Correo electrónico: <claudiorama@gmail.com>.

\section{JuAn Luis Ordaz Díaz}

Maestro en Economía por El Colegio de México y licenciado en Economía por la UnAm. Desde 2008 es Economista Senior del BBVA, en los temas sobre migración y desarrollo. También es profesor de la Facultad de Economía de la UnAm. Fue economista y consultor de la Comisión Económica para América Latina y el Caribe (CEPAL). También fue consultor del Programa de Desarrollo Humano Oportunidades. Ha sido evaluador de diferentes programas sociales en México, entre los que se encuentran: Programa de Desarrollo Humano Oportunidades, Programa Estratégico para la Seguridad Alimentaria-Guerrero sin Hambre, Diconsa y Liconsa. Cuenta con diferentes publicaciones sobre los siguientes temas: Migración y desarrollo, cambio climático, educación y pobreza en México, y segmentación laboral en México. Correo electrónico: <juan.ordaz@bbva.com>.

\section{JuAN JosÉ Li NG}

Es licenciado en Economía por la UNAM y maestro en Economía por El Colegio de México. Desde 2011 se desempeña como Economista Senior del BBVA en los temas sobre migración y evaluación. Ha laborado en la Secretaría de Salud, en el Museo Interactivo de Economía, ha sido profesor de la UNAM en temas de 
microeconomía y economía mexicana, se ha desempeñado como consultor y analista para la UNAM y el Programa de las Naciones Unidas para el Desarrollo México (PNUD) en diversos programas públicos de dependencias federales como el Instituto Nacional de las Mujeres, Nacional Financiera, Secretaría de Economía, Secretaría del Trabajo y Previsión Social, Sedesol, Oportunidades, Sagarpa, Pemex, Conafe, IFE, Diconsa, Liconsa, entre otros. Correo electrónico: <ljuan99@hotmail.com>.

\section{Ana María Aragonés}

Profesora titular C de tiempo completo definitivo en el IIEc, unAm. También es profesora del Posgrado Estudios México-Estados Unidos en la FES-Acatlán y de Historia económica y social. Forma parte del Sistema Nacional de Investigadores nivel II. Es doctora en Derecho por la Universidad de Montpellier, Francia. Entre 1998-1999 fue profesora invitada en la Universidad de Lanus, Argentina; de 2000-2001 fue profesora invitada Fulbright, en la Universidad de Salisbury, MD, Estados Unidos. Cátedra Nabor Carrillo, 2006. Es profesora de las cátedras: Historia económica general, de América Latina y México. Su obra escrita incluye libros, capítulos y artículos de revistas sobre el tema migratorio. Ha participado en congresos y coloquios nacionales e internacionales relacionados con el tema de la migración. Correo electrónico:<amaragones@gmail.com>.

\section{UBERTO SALGADO}

Becario del Instituto de Investigaciones Económicas, es profesor adjunto de la materia Econometría I en la Facultad de Ciencias de la UNAM, realizó estudios de maestría en la Facultad de Economía de la UNAM, ha participado en congresos nacionales e internacionales relacionados con el tema de la migración. Correo electrónico:<ubesk8@gmail.com>. 
Crisis económica y migración ¿Impactos temporales o estructurales? es una obra del Instituto de Investigaciones Económicas de la Universidad Nacional Autónoma de México. Se terminó de imprimir el 27 de marzo de 2014. Se tiraron 500 ejemplares en impresión offset en los talleres de Fuentes Impesores, Centeno 109, col. Granjas Esmeralda, C. P. 09810, México, D. F. La formación tipográfica estuvo a cargo de José Dolores López Sánchez; se utilizaron fuentes Simoncini Garamond Std, ITC Berkeley Oldstyle Std, Verdana de 11:13, 12:14.3, 13:14.3, 10:12, 9:11 y 8:10 puntos sobre papel cultural de $75 \mathrm{~g}$. y los forros en cartulina couché de $250 \mathrm{~g}$. El cuidado de la edición estuvo a cargo de Hélida De Sales Y. 